\title{
Diversity and Habitat Selection of Papilionidae in a Protected Forest Reserve in Assam, Northeast India
}

\author{
Dissertation \\ zur Erlangung des Doktorgrades \\ der Mathematisch-Naturwissenschaftlichen Fakultäten \\ der Georg-August-Universität zu Göttingen
}

\author{
vorgelegt von \\ Kamini Kusum Barua \\ aus Assam, Nord-Ost Indien
}

Göttingen 2007 
D7

Referent:

Prof. Dr. Michael Mühlenberg

Korreferent:

Prof. Dr. Rainer Willmann

Tag der mündlichen Prüfung: 23.01.2008 


\section{SUMMARY}

ZUSAMMENFASSUNG 


\section{EXTENDED SUMMARY}

The Eastern Himalayas covering entire Northeast India is located at the confluence of the Oriental and Palaearctic realms and exhibits a high level of endemism in the flora and fauna. The region has a high diversity of butterflies as reported from the first documentation on the butterfly fauna of this region. However there has hardly been any focus on research studies for butterflies in this biodiversity rich zone. The butterfly family Papilionidae is associated with pristine forests and their abundance is directly associated with loss of forest cover due to logging and human disturbance. A review of the past records of Papilionidae from this region and comparison with recent checklists have brought into the limelight, some important questions pertaining to the probable extinction of many species and the need for further monitoring of some of the still existing species. There are also several Eastern Himalaya endemic Papilionidae at sub-species level and we need to investigate their status and distribution at both regional and local levels.

The habitat association by forest type and distribution pattern, seasonal abundance, correlation between mean abundance and geographic range and the feeding guild and indicator properties of swallowtail butterflies (Lepidoptera: Papilionidae) were studied in a disturbed secondary protected forest reserve in Assam, Northeast India. The method of multivariate analysis by constrained canonical correspondence ordination (Ter Braak, 1986) was used for examining the effects of some independent, continuous environmental variables like altitude, rainfall, year, geographical position (latitude and longitude) on the swallowtail butterfly group and species assemblages during the two-year study period. The separating effects of season and forest type as categorical variables were examined for observing their effects on the abundance and distribution of the Papilionidae within the study area. We used the indicator (IndVal) method of Dufrene \& Legendre (1997) to detect some characteristic indicator taxa within the study area by defining the indicator values of the group and species assemblages for the transects by forest types and mean seasonal abundances. The analyses were done separately for the three study sites of Garbhanga range and two study sites of Rani range based on the pooled abundance data. All the five study sites were moderately to heavily disturbed as observed from the land-use satellite imageries and actual field observations. Line transect method (Pollard, 1977, 1984; Thomas, 1983; 
Pollard \& Yates, 1993) was followed for sampling the butterflies within a 50 ha study area. Permanent line transects were laid within the study sites on the basis of habitat type scattered forest and closed forest, which were selected on the basis of canopy openness and observed levels of disturbance. A total sample effort of 131 days across the five study sites during dry and wet seasons of the two-year study period resulted in 18,371 individuals identified from 28 species of Papilionidae. Our sampling effort was not equal across the study sites of both the ranges within the Reserve. For the three study sites in Garbhanga range, we walked $24 \mathrm{kms}$ amounting to two transect counts in nine hours of sampling per day in the 12 transects. For the two study sites of Rani range we walked $16 \mathrm{kms}$ amounting to two transect counts in six hours of sampling per day in the eight transects.

As the study area experiences a tropical monsoon type of climate, therefore the different diversity parameters including species richness, evenness and rarefaction estimates were examined by forest type and season. As the host-plant specificity of the swallowtail butterflies is confined to a few tropical plant families, we therefore tried to document the availability of some of the important larval food-plants of the swallowtail butterflies within the study area.

We identified 28 species of Papilionidae within the protected reserve during the 2year study period. In the study sites of Garbhanga and Rani ranges, 28 and 26 species were recorded respectively. Vegetation study relating to estimation of the species diversity and richness conducted in each of the two study sites of Garbhanga and Rani ranges showed a near similarity in the floral composition and could be considered to represent the overall vegetation profile of the study area. The total plant family representation in the study area was 65 which included a total of 197 species out of which 99 species were represented by trees, 63 species were herbs/shrubs and 35 species were represented by climbers. Seven plant families represented the larval host-plant resources and 29 plant families represented the potential adult nectar sources of the swallowtail butterflies. The monophagous feeding guild recorded the highest number of species (12) and the correlation between the mean abundance and feeding guild of the Papilionidae was significant, showing a marked increase in the mean abundance of the Papilionidae from 'specialist' to generalist' feeders and monophagy to polyphagy.

The correlation between the mean abundance and the pre-defined geographic range of the species assemblages in the three study sites of Garbhanga range was weak but significant and positive indicating a marked increase in the mean abundance of the 
Papilionidae with the widest geographic range. For the two study sites of Rani range, the correlation was not significant but still positive. Species with the widest range did not show a large variation in their mean abundance as observed in the correlation results for the study sites of Garbhanga range.

Canonical Correspondence Analysis (CCA) showed that the swallowtail butterfly species assemblage could be divided into two groups with respect to habitat association and abundance by forest types was highly significant for all the five study sites. In Garbhanga range, 16 species were closed forest restricted and nine species were open/scattered forest dependent while another three species could be classified as intermediate as they were encountered in both gaps and closed forests. In Rani range, only 14 species were found to be confined to the closed forest while the number of species associated with gaps and the intermediate species was the same as in Garbhanga range. In Garbhanga range, higher abundances of butterflies from the genera Graphium (Jays and Bluebottles), Papilio (Common Mormon and Great Mormon) and Pathysa (Swordtails and Zebras) were encountered in the open forest transects while the abundances of the butterflies from the closed forests and particularly from the genera Atrophaneura (Windmills and Batwings), Troides (Birdwings) and Papilio castor (Common Raven) were lower. Peacocks and Helens (Papilio sp.) from the closed forests and the gap species like Pachliopta aristolochiae (Common Rose) and Lamproptera sp. (Dragontails) recorded moderate abundances. However in Rani range, the abundance trend for the group (genus-wise) assemblages were found to be different - closed forest confined groups like the Birdwings (Troides sp.), Peacocks and Helens (Papilio sp.) and open forest dependant groups like the Jays and Bluebottles (Graphium sp.), Swordtails (Pathysa sp.) as well as the Dragontails (Lamproptera sp.) were recorded in higher abundances.

The site scores in the ordination plots for both Garbhanga and Rani ranges simply showed the changing abundances of swallowtail butterflies across the open and closed forest transects throughout the study period. However they could not be considered as strong predictors of butterfly seasonality. Therefore in our study we only tried to observe the changing patterns of species abundances through dry and wet seasons of the study period between the two forest types.

The effects of independent variables were studied separately for Garbhanga and Rani ranges and the results of the CCA ordination showed the significant effects of some of these variables on the species assemblages. The significant effect of the amount of rainfall as an 
independent variable on the abundances of different species assemblages within Garbhanga and Rani ranges clearly indicated the influence of the monsoon climate on plant phenology and the resultant high wet season abundances. However the effect of rain on butterfly abundances indicated a larger variation between the dry and wet season abundances in Rani range and this could be attributed to favourable microclimatic conditions within this range. In the constrained ordinations for both Rani and Garbhanga ranges, the influence of the monsoon rain on the seasonality of some species like particularly the Limes (Papilio demoleus), Jays (Graphium sp.) and Common Rose (Pachliopta aristolochiae) was strongly predicted. Again some of the closed forest restricted species like the Crimson Rose (Pachliopta hector) and Common Raven (Papilio castor) were found to be highly seasonal in their association with the monsoon period.

To examine the continuum of seasonal abundance of the swallowtail butterflies, the effect of year as an independent variable on the butterfly abundances was tested separately for Garbhanga and Rani ranges. In Garbhanga range, year as a variable did not show a significant effect on the butterfly abundances whereas in Rani range, the effect of year was significant and higher abundances of some of the species assemblages were recorded during the wet season of the second year of study.

Altitude as an independent variable showed a significant effect on the total variance of the species assemblages within the study area and species characteristic of closed forest were recorded in greater abundances at higher elevations and open forest species were recorded in higher abundances at lower elevations. The effect of altitude on species abundance and distribution was observed to be more pronounced in Garbhanga than Rani range. On an overall such findings could be correlated to the sampling design where the locations of the open forest transects at lower elevations and closed forest transects at higher elevations were influencing the ordination results.

The ordination results did not show a significant correlation between the geographical position and species abundances although at least statistically a significant correlation was seen in the genus (group-wise) and species ordination for Garbhanga range. One of the limitation being the small size of the sampling area and the close location of the transects, the results could not be meaningfully interpreted.

The homogenous species assemblage within the protected reserve showed varying diversity patterns by forest type and season. The diversity parameters were analysed separately for Garbhanga and Rani ranges. In the study sites of Garbhanga range, there were 
no differences in species diversity, evenness and rarefaction estimates between dry and wet seasons throughout the study period but by forest type, the closed forests were more diverse than the open/scattered forests. A similar trend was also detected for the evenness and rarefaction estimates of the species assemblages. There were no significant differences in species richness between forest types and season as probably all the species were encountered in almost all the transects in varying levels of abundance and secondly could also be related to the pooled data. In Rani range, the conditions were different where only Shannon's diversity (H') was higher during the wet season of both years but there were no significant differences by forest type. The scattered/open forests were more diverse than the closed forests as shown by Simpson's and Inverse Simpson's indices but $\alpha$-diversity was again higher in the closed forests The evenness and rarefaction estimates were also higher in the open forest habitats although there were no significant differences between seasons. Observed differences in the landscape features with higher levels of disturbance in the study sites of Rani range and probable microclimatic conditions could have influenced the results.

Characteristic indicator taxa defined by their Indicator Values (\% IndVal) were determined separately for the study sites of Garbhanga and Rani ranges by their transect and seasonal abundances. In the scattered/open forest transects of Garbhanga range identification of the group assemblages (genus-wise) showed that the Graphium species (Jays and Bluebottles) scored IndVals $>60 \%(\mathrm{p}<0.05)$ while in the closed forest transects, none of the group assemblages were statistically significant except Papilio castor castor (Common Raven) which did not score a high IndVal but was statistically significant at $\mathrm{p} \leq$ 0.05. Amongst the species assemblages, only two species from the open forests or gaps scored significantly high IndVals $>60 \%(\mathrm{p}<0.05)$ and therefore could be selected as indicators for open or scattered forests within Garbhanga range. In Rani range, when the group assemblages for the indicator taxa were defined by values of the pooled transects from the 2 study sites, Pathysa sp. (Zebras), Graphium sarpedon sarpedon (Bluebottles) and Papilio demoleus (Limes) were identified as the indicator groups for the open/scattered forests although they did not score high IndVals $(\mathrm{p}<0.05)$. When species assemblages were defined by values of the pooled transects, two gap species were statitistically significant $(p<0.05)$ although they did not score high IndVals $(>45 \%)$ in the open forest transects. However no indicator species could be detected statistically for the closed forest habitats.

When the indicator values of the species assemblages were defined by values of seasonal abundances within Garbhanga and Rani ranges separately, a total of seven closed 
forest-restricted species and one gap species scored statistically significant IndVals $(>70 \%$, $\mathrm{p}<0.05$ ) for all the five study sites. In Garbhanga range, four closed forest restricted species from the red-bodied group- Windmills (Atrophaneura sp., 3) and Birdwings (Troides sp., 1) scored significantly high IndVals $(>80 \%, \mathrm{p}<0.05)$ while one black-bodied species (Papilio helenus (Red Helen) scored an IndVal $<65 \%$ but was significant at $\mathrm{p}<0.05$. In Rani range, four species from the closed forest and one gap species scored high IndVals $(>65 \%$, $\mathrm{p}<0.05)$. The result of the identification of indicator species by both transect and seasonal abundances was that seven species were finally selected as indicators for the two forest types and the findings would be helpful for the proposed butterfly monitoring program in this protected forest reserve. The five indicator species for the open forests were mostly opportunistic species with wide geographic distribution and also known to be good colonists of extreme early succesional habitats (Leps \& Spitzer, 1990) while the two indicator species for the closed forests had restricted distribution and such endemics with high conservation priority can play a crucial role in determining the habitat quality and control of disturbances.

This present study has reflected the changing patterns of Papilionidae diversity, abundance and distribution in a protected tropical landscape which is disturbed but effective forest management practices are being taken up to protect the remaining fragmented habitat of the elephants and the Hoolock gibbons. The identification of the swallowtail butterflies along with some of their important larval food-plants and potential nectar resources has been an important part of the study. Further research into their ecology by examining the effects of some independent environmental variables on their abundances and habitat association with respect to preference of forest types thereby determining their distribution pattern within the forest reserve has helped in the identification of some of the threats facing their survival. An analysis of the diversity and species richness patterns of the species assemblages by season and forest type has helped in evaluating their status within the landscape and determining the indicator values of both group and species assemblages by their transect and seasonal abundances will be a useful tool for monitoring or evaluating their role in forest management. 


\section{Ausführliche Zusammenfassung}

Im östlichen Himalaya, der sich über das gesamte Gebiet Nordost-Indiens erstreckt, treffen die biogeographischen Regionen der Paläarktik und des Orients zusammen und zeigen dabei eine beträchtliche Flora und Fauna Biodiversität mit einem außergewöhnlich hohen Anteil an Endemiten. Die Region verfügt auch über eine hohe Diversität an Schmetterlingsarten, die bereits in dem ersten Bericht über die Schmetterlingsfauna dieses Gebietes dokumentiert wurde. Dennoch gibt es für diese biodiversitätsreiche Zone praktisch keine weiteren Untersuchungen, die sich mit Schmetterlingen befassen. Die Familie der Papilionidae wird assoziiert mit dem Waldökosystem und ihre Abundanz steht in direktem Zusammenhang mit dem Verlust an Waldfläche durch Abholzung und anthropogene Störungen. Ein Vergleich von Bestandsaufnahmen der Papilionidae der Vergangenheit mit aktuellen Artenlisten der Region, verdeutlichen die Problematik des lokalen Aussterbens vieler Arten und die Notwendigkeit für ein Monitoring der noch verbliebenen Arten. Weiterhin gibt es mehrere im Ost-Himalaya endemische Papilionidae-Unterarten, die, sowohl auf regionaler wie auf lokaler Ebene, weiterer Untersuchungen zu aktuellem Bestand und Verbreitung bedürfen. Die Schwalbenschwanzgesellschaften (Lepidoptera:Papilionidae) wurden nach Waldtyp, Verteilungsmuster, saisonaler Abundanz, Indikatoreigenschaften, Korrelation zwischen der geographischen Verbreitung und der mittleren Abundanz und der Nahrungsgilde in einem gestörtem Sekundärwaldreservat in Assam (Nordost-Indien) untersucht. Die Methode der multivariaten Analyse mit kanonischer Korrespondenzordination (Ter Braak, 1986) wurde benutzt um die Einflüsse einiger unabhängiger, kontinuierlicher Umweltvariablen wie Höhe üNN, Niederschlag, Jahr, geographische Lage (geografische Breite und Höhe) auf die Schwalbenschwanzgesellschaften während eines zweijährigen Zeitraums zu untersuchen. Die trennenden Effekte von Jahreszeit und Waldtyp als kategorischen Variablen wurden hinsichtlich eines Einflusses auf Abundanz und Verbreitung der Papilionidae des Untersuchungsgebiets analysiert. Wir benutzten die Indikatiormethode (IndVal) von Dufrene \& Legendre (1997) um charakteristische Indikatortaxa im Untersuchungsgebiet zu ermitteln, indem die Indikatorwerte für Gruppen und Gesellschaften in den Transekten nach Waldtyp und mittlerer saisonaler Abundanz definiert wurden. Die Untersuchungen wurden, basierend auf gepoolte Abundanzdaten, getrennt für die drei Gebiete des GarbhangaGebirges und die zwei Gebiete des Rani-Gebirges durchgeführt. Alle fünf 
Untersuchungsgebiete waren gemäß Landnutzungs-Satellitenbildern und eigenen Feldbeobachtungen, mäßig bis stark gestört. Die Linentransektmethode (Pollard, 1977, 1984; Thomas, 1983; Pollard \& Yates, 1993) wurde angewandt, um Stichproben in einem 50 ha Gebiet $\mathrm{zu}$ sammeln. Permanente Linientransekte wurden innerhalb der Untersuchungsflächen gemäß den Waldtypen (offener bis geschlossener Wald) eingerichtet. Die Waldtypen wurden nach Lichtdurchlässigkeit der Baumkrone und Störungsgrad eingeteilt. Der gesamte Untersuchungsaufwand von 131 Tagen für alle fünf Untersuchungsgebiete in Trocken- wie in Regenzeiten, ergab über den Untersuchungszeitraum von zwei Jahren, eine Anzahl von 18.371 Individuen von 28 Arten. Der Untersuchungsaufwand war unterschiedlich in den Untersuchungsflächen der beiden Gebirgszüge des Reservats: In den drei Flächen des Garbhanga-Gebirges wurden insgesamt $24 \mathrm{~km}$ begangen, zusammengesetzt aus 12 Transekten von je $1 \mathrm{~km}$ Länge, die je zwei Mal in ca. Neun Stunden untersucht wurden. In den zwei Untersuchungsgebieten des RaniGebirges wurden $16 \mathrm{~km}$ begangen, resultierend aus acht Transekten mit je zwei mal sechs Stunden Untersuchungsaufwand.

Da die Untersuchungsgebiete einem tropischen Monsunklima ausgesetzt sind, wurden die Diversitätsparameter einschließlich Artenreichtum, Äquitabilität und rarefaction, nach Waldtyp und Saison analysiert. Da die Wirtspflanzenspezifität von SchwalbenschwanzSchmetterlingen auf einige wenige tropische Pflanzenfamilien beschränkt ist, haben wir versucht die Verfügbarkeit einiger wichtiger Larven-Futterpflanzen im Untersuchungsgebiet zu dokumentieren.

Während der zwei-jähringen Untersuchungszeit fanden wir 28 Papilionidae-Arten. Im Garbhanga- und im Rani-Gebirge wurden 28 beziehungsweise 26 Arten gefunden. Vegetationskundliche Untersuchungen zur Abschätzung der Artenvielfalt, die in beiden Gebirgen durchgeführt wurden, ergaben eine große Ähnlichkeit in der floristischen Zusammensetzung und können als repräsentativ für die Vegetation der gesamten Untersuchungsfläche angesehen werden. Insgesamt 65 Pflanzenfamilien waren repräsentiert durch 197 Arten, von denen 99 Bäume, 63 Krautpflanzen und Sträucher und 35 Arten Kletterpflanzen waren. Sieben Pflanzenfamilien stellten Larven-Wirtspflanzen dar, und 29 Familien sind potentielle Nektarressourcen für adulte Schwalbenschwanz-Schmetterlinge. Für die Nahrungsgilde der Monophagen wurden die meisten Arten (12) beobachtet und es konnte eine Korrelation zwischen der mittleren Abundanz und der Nahrungsgilde der Papilionindae aufgezeigt werden, die sich in einem deutlichen Anstieg der mittleren 
Abundanz von den Spezialisten zu den Generallisten und von monophagem zu polyphagem Nahrungsverhalten ausdrückt.

Die Korrelation zwischen der mittleren Abundanz und der vordefinierten geographischen Ausbreitung von Artengemeinschaften in den drei Untersuchungsgebieten des GarbhangaGebirges war schwach, aber signifikant und positiv, und zeigte sich in einem Anstieg in der mittleren Abundanz der Papilionidae mit der größten geographischen Ausbreitung. Für die zwei Untersuchungsgebiete im Rani-Gebirge gab es keine signifikante Korrelation. Diejenigen Arten mit den größten Ausbreitungen zeigten keine großen Veränderungen in ihrer mittleren Abundanz, wie sie im Garbhanga-Gebirge beobachtet wurde.

Eine kanonische Korrespondenzanalyse zeigte, dass sich die Zusammensetzung von Schwalbenschwanz-Schmetterlingsarten in zwei Gruppen einteilen lässt: in der einen korrelierte die Habitatvergesellschaftung und in der anderen die Abundanz mit dem Waldtyp in allen fünf Versuchsflächen in signifikanter Weise. Im Garbhanga-Gebirge waren 16 Arten an geschlossenen Wald und 9 Arten an offenen/lichten Wald gebunden, während drei Arten als intermediär klassifiziert wurden, da sie sowohl im geschlossenen Wald, als auch in Waldlücken angetroffen wurden. Im Rani-Gebirge wurden nur 14 Arten gefunden, die mit geschlossenem Wald assoziiert sind, während die Zahl der Schmetterlingsarten, die auf Waldlücken beschränkt sind und die Zahle der intermediären Arten genauso hoch wie im Garbhanga-Gebirge war. Im geschlossenen Wald des Garbhanga-Gebirges gab es hohe Abundanzen der Gattungen Graphium, Papilio und Pathysa, während die Individuenzahlen im geschlossenen Waldtyp vor allem für Atrophaneura, Troides und Papilio castor geringer waren. Andere Papilio-Arten („Peacocks” und „Helens”) im geschlossenen Wald und Arten der Waldlücken, wie Pachliopta aristolochiae und Lamproptera sp. kamen in mittleren Abundanzen vor. Im Rani-Gebirge dagegen verhielten sich die Abundanz-Trends der verschiedenen Gattungen anders: an geschlossenen Wald gebunden Arten wie „Birdwings” (Troides sp.), „Peacocks” und „Helens” (Papilio sp.) und Arten der offenen Waldtypen wie „Jays” und „Bluebottles” (Graphium sp.), „Swordtails” (Pathysa sp.) und „Dragontails” (Lamproptera sp.), kamen in höheren Abundanzen vor.

Die Ordinationswerte für die einzelnen Transekte zeigten für den gesamten Versuchszeitraum sich mit dem Waldtyp verändernden Abundanzen der Schmetterlinge. Dennoch können sie nicht als Beleg für starke jahreszeitenbedingte Schwankungen herangezogen werden. In dieser Studie werden daher nur die sich mit Trocken- und Regenzeit verändernden Abundanzmuster für die zwei Waldtypen beschrieben. 
Die Effekte der unabhängigen Variablen wurden separate für die beiden Gebirge untersucht. Die Ergebnisse der Ordination zeigen signifikante Effekte einiger dieser Variablen zur Artenzusammensetzung. Der signifikante Einfluss der Niederschlagsmenge als unabhängige Variable auf die Abundanz verschiedener Artzusammensetzungen innerhalb des Garbhangabzw. des Rani-Gebirges, zeigte deutlich die Wirkung des Monsunklimas auf die Phänologie der Flora und die daraus resultierende hohe Abundanz während der Hoch-Regenzeit. Dieser Effekt des Niederschlags auf die Schmetterlingsabundanz, weist auf einen deutlichen Abundanzunterschied zwischen der Regen- und der Trockenzeit im Rani-Gebirge hin, der wiederum mit den mikroklimatisch günstigeren Bedingungen in diesem Gebirge zusammenhängen könnte. In der Ordination wurde für beide Gebirge ein Einfluss des Monsun-Regens auf die Saisonalität einiger Arten, insbesondere für Papilio demoleus, "Jays" (Graphium sp.) und Pachliopta aristolochiae festgestellt. Weiterhin zeigten sich einige Arten des geschlossenen Waldtyps, wie Pachliopta hector und Papilio castor durch die Monsunzeit bedingt, als stark saisonal.

Um die Kontinuität der jahreszeitlichen Abundanz der Schwalbenschwanz-Schmetterlinge $\mathrm{zu}$ untersuchen, wurde der Effekt des Jahres als unabhängige Variable auf die Individuenzahl für das Garbhanga- und das Rani-Gebirge einzeln analysiert. Im GarbhangaGebirge zeigt das Jahr als Variable keinen Einfluss auf die Schmetterlingsabundanz, während im Rani-Gebirge der Effekt des Jahres signifikant war und dort deutlich höhere Abundanzen einiger Artengemeinschaften in den Regenzeiten des zweijährigen Untersuchungszeitraums beobachtet wurden.

Die Höhe als unabhängige Variable, zeigte einen signifikanten Einfluss auf die totale Varianz der Artengemeinschaften des Untersuchungsgebietes: Charakteristische Arten des geschlossenen Waldtyps wurden in größeren Höhen deutlich häufiger beobachtet, während Arten der offenen Waldtypen in geringeren Höhen häufiger waren. Der Effekt der Höhe auf Abundanz und Verbreitung der Arten war im Rani-Gebirge stärker ausgeprägt. Theoretisch könnten diese Ergebnisse auf den Versuchsaufbau zurückzuführen sein, indem die Lage der Offenwald-Transekte in geringeren Höhen und der Transekte im geschlossenen Wald in größeren Höhen die Ergebnisse der Ordination beeinflussten.

Die Ergebnisse der Ordination zeigten keine signifikante Korrelation zwischen der geographischen Lage und der Artzahl, obwohl, zumindest statistisch, für das GarbhangaGebirge eine signifikante Korrelation für Gattungen (gruppenweise) und Arten beobachtet wurde. Eine der Beschränkungen, die die relativ kleine Untersuchungsfläche und die Nähe 
der Transekte zueinander mit sich bringt, ist, dass dieser Teil der Ergebnisse nicht ökologisch sinnvoll interpretiert werden kann.

Die homogene Artzusammensetzung innerhalb des geschützten Gebietes, zeigte eine mit dem Waldtyp und der Jahreszeit variierende Diversität. Die Diversitätsparameter wurden für das Garbhanga- und das Rani-Gebirge einzeln analysiert. In den Untersuchungsgebieten des Garbhanga-Gebirges gab es keine Unterschiede hinsichtlich der Artenvielfalt, Äquitabilität und der rarefaction Schätzungen zwischen der Regen- und der Trockenzeit, aber der geschlossene Waldtyp zeigte eine höhere Diversität als der offene. Eine vergleichbare Tendenz wurde auch für die Äquitabilität und die rarefaction Schätzungen der Artengemeinschaften beobachtet. Es gab keinen signifikanten Unterschied der Artenvielfalt zwischen den Waldtypen und den Jahreszeiten, da wahrscheinlich alle Arten in verschieden hohen Abundanzen in fast allen Transekten angetroffen wurden. Andererseits könnte auch das Poolen der Daten einen Einfluss gehabt haben. Im Rani-Gebirge waren die Verhältnisse anders: Dort war der Shannon-Diversitätsindex (H') in den Regenzeiten beider Jahre höher, aber es gab keinen signifikanten Unterschied zwischen den Waldtypen. Die lichten/offenen Waldtypen waren diverser, wie am Simpson- und Inversen Simpson-Index abzulesen ist, aber die $\alpha$-Diversität war wiederum höher im geschlossenen Wald. Die Äquitabilität und die rarefaction Schätzungen waren wiederum höher in den offenen Waldhabitaten, aber es gab keinen signifikanten Unterschied zwischen den Jahreszeiten. Die beobachteten Unterschiede in den Merkmalen der Landschaft, wie der höhere Grad der Störung im Rani-Gebirge, sowie die wahrscheinlichen mikroklimatischen Bedingungen könnten die Ergebnisse ebenfalls beeinflusst haben.

Charakteristische Indikatorarten, definiert durch ihren Indikatorwert (\% IndVal) wurden einzeln für die Untersuchungsgebiete in den beiden Gebirgen anhand ihres Vorkommens pro Transekt und pro Jahreszeit ausgewählt. In den Transekten des offenen/lichten Waldtypes im Garbhanga-Gebirge zeigte eine Untersuchung der gattungsmäßigen Zusammensetzung, dass Graphium-Arten einen Indikatorwert von mehr als $60 \%(p<0,05)$ erreichten, während im geschlossenen Wald keiner der Taxa statistisch relevant war, außer der Unterart Papilio castor, welche zwar keinen hohen Indikatorwert erzielte, aber dennoch signifikant war $(p \leq 0,05)$. Von den Artgemeinschaften erreichten nur zwei Arten der Waldlücken einen signifikant hohen Indikatorwert von über $60 \%(\mathrm{p} \leq 0,05)$ und konnten daher als Indikator für offenen/lichten Wald innerhalb des Garbhanga-Gebirges ausgewählt werden. Im Rani-Gebirge wurden die Indikatortaxa der Artengemeinschaften definiert durch Werte von gepoolten Transekten der zwei Untersuchungsgebiete. Pathysa sp. (Zebras), 
Graphium sarpedon und Papilio demoleus wurden als Indikatorgruppen für offene Waldhabitate ausgewählt, obwohl sie keinen hohen Indikatorwert erzielten $(p \leq 0,05)$. Als Artenzusammensetzungen durch Werte aus gepoolten Transekten definiert wurden, gab es zwei statistisch signifikante $(p \leq 0,05)$ Arten der Waldlücken, obwohl sie keinen hohen Indikatorwert in den Transekten des offenen Waldtypes erreichten. Außerdem konnte keine statistisch signifikante Indikatorart für die geschlossenen Waldtypen gefunden werden.

Als die Indikatorwerte durch Werte der jahreszeitlichen Abundanz für das Garbhanga- und das Rani-Gebirge einzeln definiert wurden, erreichten sieben Arten des geschlossenen Waldtypes und eine Waldlücken-Art statistisch signifikante Indikatorwerte $(>70 \% ; p \leq$ $0,05)$ in allen fünf Untersuchungsgebieten. Im Garbhanga-Gebirge erzielten drei rotleibige „Windmill”-Arten (Atrophaneura sp.) eine „Birdwing”-Art (Troides sp.) des geschlossenen Waldtypes, signifikante Indikatorwerte $(>80 \% ; \mathrm{p} \leq 0,05)$, während die Unterart Papilio helenus einen Wert von IndVal $<65 \%$ erreichte, aber signifikant war $(\mathrm{p} \leq 0,05)$. Im RaniGebirge erreichten vier Arten des geschlossenen Waldtypes und eine Waldlücken-Art hohe Indikatorwerte $(>65 \% ; \mathrm{p} \leq 0,05)$. Als Ergebnis der Identifikation von Indikatorarten durch Transekt- und jahreszeitliche Abundanz, wurden sieben Arten als Indikatorarten für die beiden Waldtypen ausgewählt, welche ebenfalls als hilfreich für das geplante Monitoring des Schutzgebietes angesehen werden. Die fünf Indikatorarten des offenen Waldtypes waren hauptsächlich opportunistische Arten mit großer geographischer Verbreitung und sind ebenfalls bekannt als gute Erstbesiedler von sehr frühen Sukzessionsstadien (Leps \& Spitzer, 1990), während die beiden Indikatorarten des geschlossenen Waldtypes eine nur geringe Verbreitung aufwiesen und daher als Endemiten mit hoher Schutzpriorität eine entscheidende Rolle bei der Beurteilung der Habitatqualität und der Kontrolle von Störungen spielen können.

Die vorliegende Studie gibt die Veränderungsmuster der Diversität, Abundanz und Verbreitung von Papilioniden in einem geschützten tropischen Lebensraum wieder, der Störungen aufweist, indem man aber beispielsweise auch bemüht ist, die verbliebenen Habitatfragmente des asiatischen Elefanten und einer einheimischen Gibbon-Art durch geeignete Schutz- und Entwicklungsmaßnahmen $\mathrm{zu}$ erhalten. Die Aufnahme der Schwalbenschwanz-Schmetterlingsarten einschließlich ihrer Larven-Futterpflanzen und potentieller Nektarpflanzen, kann als wichtiger Erkenntnissprung angesehen werden. Die Untersuchung der Effekte einiger unabhängiger Umweltfaktoren auf ihre Abundanz und Habitatvergesellschaftung unter Berücksichtigung der bevorzugten Habitattypen, und die Bestimmung der Verbreitungsmuster innerhalb des Waldschutzgebietes, hat dazu 
beigetragen einige wichtige Bedrohungsursachen $\mathrm{zu}$ identifizieren. Eine Analyse der Diversitätsmuster der Artengemeinschaften nach Jahreszeit und Waldtyp, trug dazu bei ihren Zustand innerhalb der Landschaft $\mathrm{zu}$ evaluieren und die Bestimmung von Indikatorwerten für Gruppen und Artgemeinschaften durch ihre Abundanz pro Jahreszeit und Transekt kann ein gebräuchliches Werkzeug für Monitoring oder Evaluierung im Forstmanagement darstellen. 


\section{ACKNOWLEDGEMENTS}

I owe my vision and accomplishment of my research studies in Germany to my 'Doktorvater' Prof. Dr. Michael Mühlenberg, whose supervision, encouragement and support throughout my study period and stay in Germany has made this thesis become a fruitful reality. His excellent academic guidance and helpful advice at every stage of my research work has helped me to develop my performance skills in the field of Conservation Biology and this will go a long way in my professional life. My exposure to an international environment and excellent infrastructure has been possible due to Prof. Mühlenberg's continued support.

I would like to express my words of gratitude to my Co-Referrent Prof. Dr Rainer Willman and Dr. Michael Kessler for kindly consenting to examine my thesis and contribute their valuable advice and inputs for my research work.

I would have the pleasure to express my heartfelt gratitude to my guide and mentor, Dr. Jolanta Slowik, who discovered me in the remote corner of India. It was her continued invaluable support and advice which has given a new dynamic frame to my professional career.

I would like to express my sincere words of appreciation for Dr Matthias Waltert, who during the final phase of my thesis writing gave valuable inputs and advice which has helped me in giving the final frame to my thesis.

I would also like to thank Dr. Eckhard Gottschalk and Dr. Hermann Hondong, scientific staff at the Centre for Nature Conservation for their helpful support during my stay here at the Centre.

I have the pleasure to express my sincere words of thanks to my colleagues Dr. Bobo Kadiri Serge who took up the painstaking task of meticulously reading and editing my thesis and Mark Hallfeldt who did a fantastic job with the translation of the summary of my thesis into the 'Deutsche' version.

My sincere words of thanks are expressed for Elisabeth Opielka who handled the informatics section and kept me updated on the computer applications and programs.

I would also like to express my words of gratitude to Monika Deseniß and Andrea Lambertz who have been so helpful in assisting me with all the official and administration related works and giving me good guidance.

I express my sincere thanks to Dr. Carsten Schröder, who gave me the opportunity to participate in the 'Summer School' program on 'Close to Nature Forestry' in 2007 which 
gave me an enlightening insight into the long and impressive history of forest development in Germany.

My words of appreciation for my colleagues Dr. Margaretha Pangau, R. Sunjidmaa, Dr. Martina Meeske, Dr. Innocent Tschigio, Lien, Christos Astaras, Anna Kemmling, Dr. Mei Ling Bai and Oyunsanaa who have cooperated with me and helped me during my tenure here at the Centre for Nature Conservation.

I would also like to express my words of appreciation for Dr. C. Dulamsuren and Dr. Markus Hauck whose invaluable advice and guidance has made my stay in Göttingen wonderful.

I would like to thank my team in Assam, India- Prof. Dr. J. Kalita from the Department of Entomology and Environmental Biology, Gauhati University and the Principal Investigator of the Ministry of Environment and Forests funded Research Projects in Dibru-Saikhowa Biosphere Reserve and Manas Biosphere Reserve and the University Grants Commission funded Research Project on assessing the Swallowtail butterfly (Papilionidae) diversity in the protected areas of the Assam Himalayas. It was under these projects that as a Junior Research Fellow, I had the opportunity to conduct my field-based research work in some of the protected areas of Assam, including my present research study area.

My sincere gratitude goes to N. K. Bhagobaty, Senior Instructor, Institute of Advanced Study in Science \& Technology, Guwahati, who has contributed to the new ideas on the statistical framework of my research work.

My words of thanks are also expressed for S.Hazarika, Director of Forest Communication, State Forest Department, Government of Assam who provided the sceitnific information on the study area, and the scientific team from 'Assam Remote Sensing Application Centre' Guwahati, and the 'Regional Meteorological Research Station' Guwahati for assisting me in the preparation of the GIS images of the study area with analysis of the land-use patterns and the meteorological data for my research work.

I finally dedicate this work to my parents who always guided me and showed me the way towards academic excellence and the good wishes of all my near and dear ones in India and Hongkong who have given me the mental strength to achieve my dream.

I finally end my words of gratitude for all with the renowned phrase from Robert Frost :

'When the woods are lovely, dark and deep,

I have promises to keep and miles to go before I sleep '. 
ACKNOWLEDGEMENTS 


\section{TABLE OF CONTENTS}

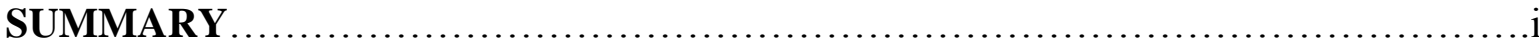

ZUSAMMENFASSUNG .................................................... vii

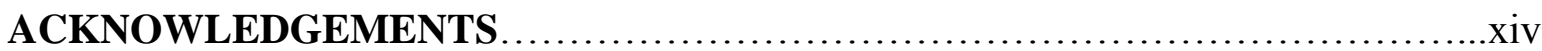

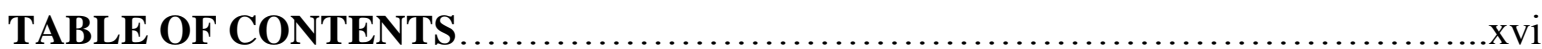

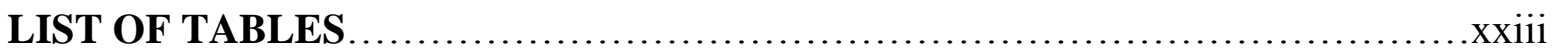

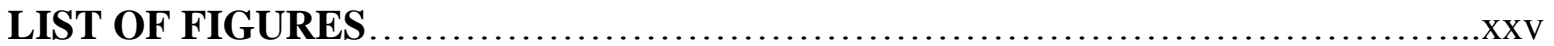

LISTOF

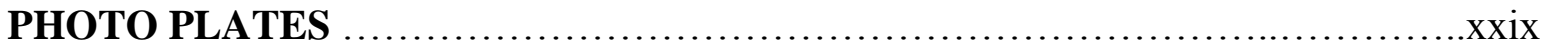

LISTOF

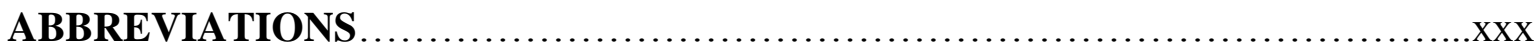

LIST OF CITATIONS ON REPORTS AND POLICIES $\ldots \ldots \ldots \ldots \ldots \ldots \ldots \ldots \ldots \ldots \ldots \ldots \ldots$

\section{PART I : GENERAL INTRODUCTION}

CHAPTER 1 :INTRODUCTION..............................................

1.1. An Overview of the Tropical forests..............................1

1.2. The Eastern Himalayas...........................................2

1.3. Study on tropical butterfly communities..........................4

1.4. The Protected Forest Management Scenario in Assam..................7

CHAPTER 2: BACKGROUND, OBJECTIVES AND HYPOTHESES..............9

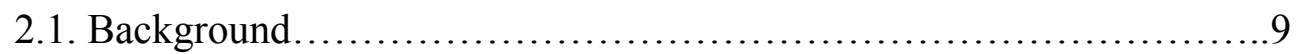

2.2.Objectives...............................................13

2.3. Research questions........................................14

2.4 Hypotheses..................................................17 
3.1. Review of Rani-Garbhanga Reserve Forest.............................20

3.2. Butterfly-Plant interaction.......................................... 30

3.3. Climate, Vegetation and Soil.......................................... 31

3.3:1. Climate conditions in the study area............................31

3.3.2. Vegetation and Soil..........................................33

3.4. Forest Management and Biomonitoring................................. 37

3.4.1. Sal Regeneration.......................................... 37

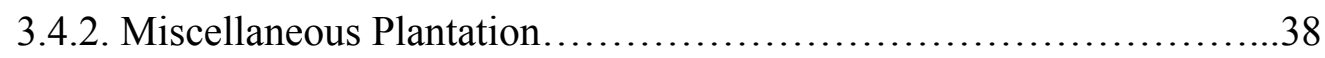

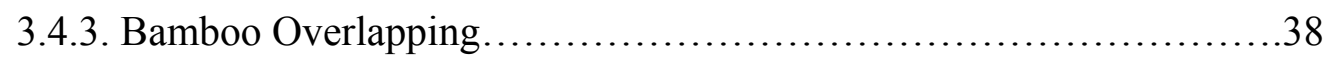

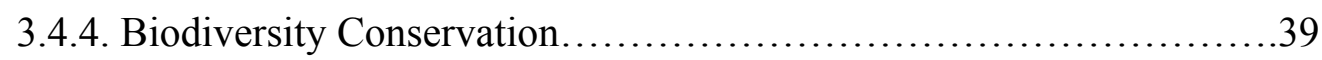

3.4.5. Watershed management and Soil Conservation....................39

3.4.6. Joint Forest Management (JFM)/ Peoples' Participatory Plantation

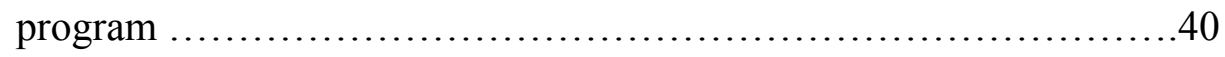

\section{PART II : METHODS AND RESULTS}

CHAPTER 4 : METHODS. . .43

4.1. Study Sites .......................................................43

4.2. Satellite Image Preparation, Interpretation and Area Estimation.............44

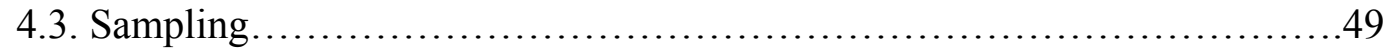

4.3.1. Sampling period.............................................49

4.3.2. Sampling design...............................................49

4.3.2.1. Permanent Line Transects...................................51

4.4. Butterfly collection, identification and geographic range classification.......55

4.5. Diet breadth classification.........................................56

4.6. Vegetation survey..............................................57 
4.8. Investigations on the climate conditions during the study period .59

4.9. Data analysis .60

4.9.1. Swallowtail butterflies- habitat relationships .62

4.9.2. Measures of Diversity Index................................63

4.9.3. Indicator Taxa.............................................66

4.9.4. Vegetation analysis....................................67

4.9.5. Basic statistical tests........................................67

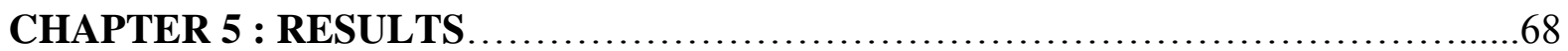

5.1. Plant Community (Trees, Herbs, Shrubs and Climbers).................68

5.1.1. Flora Overview..............................................69

5.1.1.1. Study site S1 (Garbhanga range).......................69

5.1.1.2. Study site $\mathrm{S} 4$ (Rani range)...........................70

5.1.1.3. Comparison of plant diversity parameters between $\mathrm{S} 1$

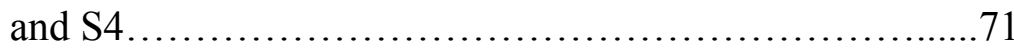

5.2. Plant community representation in the study area....................73

5.2.1 Plant families, genera and species........................73

5.2.2. Larval host-plants and adult nectaring plant families and species. .74

5.3. Papilionidae diversity in Rani-Garbhanga Reserve Forest................77

5.3.1. Genera, Species and Abundance..............................77

5.3.2. Differences in total and mean abundances between seasons and years. .79

5.3.2.1. Differences in total abundance between seasons and years. .79

5.3.2.2. Differences in mean abundance between seasons and xviii 
years.

5.3.3. Differences in abundance between genera. 83

5.3.4. Abundance and Geographic range. .85

5.3.4.1. Correlation between the mean abundance and geographic range of the swallowtail butterfly species assemblages in Garbhanga range. ...

5.3.4.2. Correlation between the mean abundance and geographic range of the swallowtail butterfly species assemblages in Rani range.

5.3.5. Abundance and Feeding guild

5.3.5.1. Papilionidae species and their feeding guild

\subsubsection{Correlation between mean abundance of Papilionidae} and their feeding guild

5.4. Ordination of the swallowtail butterfly assemblages in relation to their abundance and distribution or habitat specificity

5.4.1. Ordination of the swallowtail butterfly assemblages in relation to their abundance and distribution in Garbhanga range. 91

5.4.1.1. Ordination of the group assemblages (Genus-wise).........91

5.4.1.2. Ordination of the species assemblages .94

5.4.1.3. Effect of independent variables on species assemblages within Garbhanga range. ...

5.4.2. Ordination of the swallowtail butterfly assemblages in relation to their abundance and distribution in Rani range. .99

5.4.2.1. Ordination of the group assemblages (Genus-wise).

5.4.2.2. Ordination of the species assemblages 100

5.4.2.3. Effect of independent variables on species assemblages within Rani range. 
5.4.3. Partial conclusion of CCA on swallowtail butterfly assemblages within the study area. 106

5.5. Impact of season and forest type on species diversity.... 108

5.5.1. Study sites of Garbhanga range .108

5.5.2. Study sites of Rani range. 109

5.6. Indicator values and characteristic species.

5.6.1. Indicator values and characteristic species in the study sites of Garbhanga range.

5.6.2. Indicator values and characteristic species in the study sites of Rani range

\section{PART III : DISCUSSION AND RECOMMENDATIONS FOR}

CONSERVATION

\section{CHAPTER 6 : DISCUSSION}

6.1. Climate, Vegetation and butterfly abundance....

6.1.1. Climate and butterfly abundance 119

6.1.2. Vegetation and butterfly abundance. 120

6.2. Geographic Range and butterfly abundance. 123

6.3. Feeding guild and abundance. 124

6.4. Effects of environmental variables on swallowtail butterfly abundance and distribution pattern by using the method of multivariate analysis

6.4.1. Swallowtail butterfly species composition and habitat association by forest type

6.4.2. Seasonality of the Papilionidae. 
6.4.3. Effect of rainfall as an independent variable on the swallowtail butterfly species assemblages

6.4.4. Effect of altitude as an independent variable on the abundance and distribution pattern of the swallowtail butterfly species assemblage.

6.4.5. Effect of geographical position (latitude and longitude) on the abundance and distribution pattern of the swallowtail butterfly species assemblage.

6.5. Effect of season and forest/habitat type on species diversity, richness, evenness and rarefaction estimates.

6.5.1. Species diversity in the study sites by forest type and

season

6.5.2. Species richness, evenness and rarefaction in the study

sites by forest type and season

6.6. Butterfly assemblages and indicator taxa

6.6.1. Indicator species defined by transect abundance of butterflies in open and closed forest

6.6.2. Indicator species defined by values of mean seasonal abundance of butterflies 145

CHAPTER 7 : RECOMMENDATIONS FOR CONSERVATION 148

7.1. Study overview 148

7.2. Implications for Conservation of Butterflies .153

7.2.1. Threats to butterfly habitats. .154

7.2.1.1. Habitat exploitation and fragmentation. .154

7.2.1.2. Illegal trade in butterflies. 155

7.2.2. The role of butterflies in conservation. 155

7.2.3. Recommendations for conservation of butterflies in 
PART IV : REFERENCES, APPENDICES, PHOTO SECTION

REFERENCES........................................................ 160

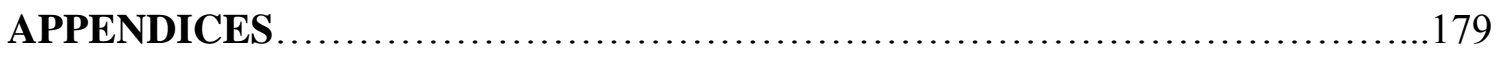

PHOTO SECTION.................................................. 216

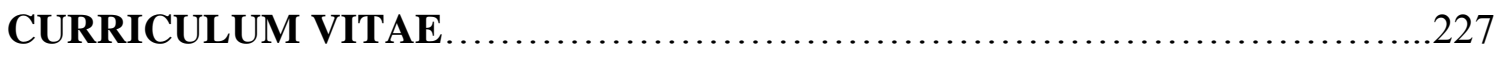




\section{LIST OF TABLES}

Table 4.1: Study sites in Rani-Garbhanga Reserve forest

Table 4.2: Land-use analysis of the study area in hectares (1998 and 2002). 46

Table 4.3: Sampling activities in the 50 ha study site of Rani-Garbhanga Reserve forest.

Table 5.1: Diversity parameters for tree species sampled as number of individuals in the study sites S1 (Partially disturbed) and S4 (Heavily disturbed) within the forest reserve using PC-ORD, 4.01

Table 5.2: Diversity parameters for herbs/shrubs sampled as number of individuals in the study sites S1 (Partially disturbed) and S4 (Heavily disturbed) within the forest reserve using PC-ORD, 4.01

Table 5.3: Diversity parameters for climbers sampled as number of individuals in the study sites S1 (Partially disturbed) and S4 (Disturbed) within the forest reserve using PC-ORD 4.01.

Table 5.4: Total and Mean abundances of Papilionidae genera sampled during dry and wet seasons of 2003-2004 in the 20 fixed transects of the study area...

Table 5.5: Diversity indices of swallowtail butterfly species assemblages in the open and closed forest habitats of Garbhanga range during dry and wet seasons of 2003-2004. 108

Table 5.6: Species-wise diversity indices of swallowtail butterflies in the open and closed forest habitats of Rani range during dry and wet seasons of 2003-2004. 
Table 5.7: Indicator values (\%IndVals) of swallowtail butterflies (Genus-wise) in the 12 sampling transects of the three study sites (S1, S2 and S3) in Garbhanga range

Table 5.8: Indicator values (\%IndVals) of swallowtail butterflies (Species-wise) in the 12 sampling transects of the 3 study sites (S1, S2, S3) under Garbhanga range

Table 5.9: Indicator values for 28 species of swallowtail butterflies sampled season -wise in the study sites of Garbhanga range during 2003-2004. ...

Table 5.10: Indicator values (\%IndVals) of swallowtail butterfly group assemblages (Genus-wise) in the 8 fixed transects of the two study sites (S4 \& S5) in Rani range

Table 5.11: Indicator values (\%IndVals) of swallowtail butterflies (Species-wise) in the fixed transects of the two study sites (S4 \& S5) in Rani range.

Table 5.12: Indicator values for 26 species of swallowtail butterflies sampled season-wise in the 8 transects of study sites S4 and S5 within Rani range during $2003-2004$. 


\section{LIST OF FIGURES}

Figure 3.1: Map showing the Eastern Himalayas Region comprising Northeast India, Bhutan and Southern, eastern and central Nepal

Figure 3.2:Location of Rani-Garbhanga Reserve Forest/ Landscape in Assam,

Northeast India .24

Figure 3.3: Map of the proposed 'Deepor Beel Wildlife Sanctuary' .25

Figure 3.4: GIS image of Rani-Garbhanga Landscape showing the different types of forest mosaic .26

Figure 3.5: Map of Rani-Garbhanga Landscape showing the drainage pattern and butterfly collection points within the study area....

Figure 3.6: Ombrothermic diagram $(\mathrm{P}=2 \mathrm{~T})$ for the study area during January to December (mean of years 1996-2000)

Figure 3.7 : Ombrothermic diagram $(\mathrm{P}=2 \mathrm{~T})$ for the study area during January to December (mean of years 2001-2005)

Figure 4.1: GIS image showing the land-use pattern in Rani-Garbhanga Reserve forest in 1998

Figure 4.2: GIS image showing the change in the land-use pattern associated with human disturbances within the forest reserve over a period of four years (1998-2002) .48

Figure 4.3: Schematic plan of the sampling design for conducting butterfly sampling within the study area of the protected forest reserve during the two-year study period. .50

Figure 4.4: Monthly total rainfall data for the study area during January to December for the period of 5 years (2001-2005). 
Figure 4.5: Monthly Mean Maximum temperature $\left({ }^{\circ} \mathrm{C}\right)$ of the study area over the period of 5 years (2001-2005) that includes the study period (2003-2004)

Figure 5.1: Rarefaction curve for the plant community of the two study sites (S1 \& S4).....68

Figure 5.2: Percentage representation of trees, herbs/shrubs and climbers in the Forest Reserve $\quad(n=$ number of species $)$. .73

Figure 5.3: Number of species of trees, herb/shrubs and climbers per family represented in the floral composition of study sites S1 and S4 .74

Figure 5.4: Number of species per family representing the larval and adult food-plant resources of the swallowtail butterflies in Rani-Garbhanga Reserve Forest .75

Figure 5.5: Number of plant families and species represented in the total floral diversity, larval and adult food-plant resources of the swallowtail butterflies in the study area. .76

Figure 5.6: Percentage representation of the total, larval and adult food-plant resources of the swallowtail butterflies in the study area. .76

Figure 5.7: Genus representation of the swallowtail butterflies sampled during the dry and wet seasons of 2003-2004 in the 50 ha study site of Rani-Garbhanga Reserve forest

Figure 5.8: Papilionidae representation in the forest reserve from the present study (2003-2004) as compared to the first documentation on the Papilionidae of the Indian Himalayan Region by Evans (1932) and Talbot (1939). .78

Figure 5.9: Total abundance of swallowtail butterflies sampled in the 20 fixed transects of the study area during the wet and dry seasons of 2003-2004. .79 
Figure 5.10: Differences in mean annual transect abundance of butterfly individuals between dry and wet seasons of the study period (2003-2004) in Garbhanga range .80

Figure 5.11: Differences in mean annual transect abundance of butterfly individuals between dry and wet seasons of study period (2003-2004) in Rani range.

Figure 5.12: Mean abundances (mean number of butterfly individuals per season/year \pm standard error) of swallowtail butterflies sampled as individuals during dry and wet seasons of 2003-2004 in the fixed transects (1-8 for dry and wet season of 2003 again resampled as 9-16 for dry and wet season of 2004) in study sites S1, S2 and S3 of Garbhanga Range.... .82

Figure 5.13: Mean abundances (mean number of butterfly individuals per season/year \pm standard error) of swallowtail butterflies sampled as individuals during dry and wet seasons of 2003-2004 in the fixed transects (1-8 for dry and wet season of 2003 again resampled as 9-16 for dry and wet season of 2004) in study sites S4 and S5 of Rani Range.... .82

Figure 5.14: Total abundance of swallowtail butterfly individuals per genera recorded during dry and wet seasons of 2003-2004 in study sites (S1-S5) of Rani-Garbhanga Reserve Forest.

Figure 5.15: Mean abundances of Papilionidae genera sampled as individuals in the 20 fixed transects of the study area during dry and wet seasons of 2003-2004 .85

Figure 5.16: The relationship between the geographic range and mean abundance of species assemblages in the study sites (S1, S2 \& S3) of Garbhanga range. .86 
Figure 5.17: The relationship between the geographic range and mean abundance of species assemblages in the study sites (S4 \& S5) of Rani range.

Figure 5.18: Larval diet breadth of the swallowtail butterflies of Rani-Garbhanga Landscape

Figure 5.19: Relationship between mean abundance and feeding guild of the species assemblages in the study area. 90

Figure 5.20: CCA ordination of swallowtail butterfly abundance in Garbhanga range $(\mathrm{S} 1, \mathrm{~S} 2 \& \mathrm{~S} 3)$

Figure 5.21: CCA ordination of locations and distribution of swallowtail butterflies of Garbhanga range (pooled data of 12 fixed transects of study sites $\mathrm{S} 1, \mathrm{~S} 2 \& \mathrm{~S} 3$ in species space (Common names). .94

Figure 5.22: CCA ordination of locations and distribution of swallowtail butterflies of Garbhanga range (pooled data of 12 fixed transects of study sites S1, S2 \& S3 in species space (Scientific names)...

Figure 5.23: CCA ordination of swallowtail butterfly abundance (Group assemblages, genus-wise) of Rani range (S4 \& S5) 100

Figure 5.24: Ordination plot of CCA of swallowtail butterfly species matrix on sampling locations (pooled data of 8 fixed transects) of Rani range (S4 \& S5) by common names during the wet and dry seasons of 2003-2004 102

Figure 5.25: Ordination plot of CCA of swallowtail butterfly species matrix on sampling locations (pooled data of 8 fixed transects) of Rani range (S4 \& S5) by scientific names during the wet and dry seasons of 2003-2004. 


\section{LIST OF PHOTO PLATES IN CHAPTERS 3 AND 4 :}

\section{CHAPTER 3 : STUDY AREA}

Photo 1 : ‘ Deepor Beel’ - the 4.14 sq. Km (core area) wetland is the only Ramsar site in Assam and is under proposal for being declared as a 'Wildlife Sanctuary'

Photo 2 : Small-wood collection by the local villagers from the fringe areas is a common problem within the forest reserve.

Photo 3 : A typical 'bamboo forest' habitat type within the forest reserve Bamboo (Dendrocalamus hamiltonii) .28

\section{CHAPTER 4 : METHODS}

Photo 4 : Study site S1 - Partially disturbed (Garbhanga ) - transect T1 in open/scattered forest (SCF).

Photo 5 : Study site S1 - Partially disturbed (Garbhanga) - transect T3 in closed forest $(\mathrm{CF})$.

Photo 6 : Study site S4 - Heavily disturbed (Rani) - transect T1 in open/ scattered forest.

Photo 7 : Study site S4 - (Rani) - transect T4 in closed forest (CF) 54 


\section{LIST OF ABBREVIATIONS :}

ASTER : Advanced Space borne Thermal Emission and Reflection Radiometer

CITES : Convention on International Trade in Endangered Species of Wild Fauna

FAO : $\quad$ Food and Agriculture Organisation

FSI : $\quad$ Forest Survey of India

GPS : $\quad$ Global Positioning System

GIS : Geographic Information System

IHR : Indian Himalayan Region

IUCN : International Union for Conservation of Nature and Natural Resources

ICIMOD : International Centre for Integrated Mountain Development

ICBP : International Council for Bird Preservation

IBA : Important Bird Area

IRS LISS : Indian Remote Sensing -Linear Imaging Self-Scanning System

JFM : Joint Forest Management

TEK : Traditional Ecological Knowledge

UNEP : $\quad$ United Nations Environment Programme

USF : Unclassed State Forest

WWF : Worldwide Fund for Nature 


\section{LIST OF CITATIONS ON REPORTS AND POLICIES :}

\section{CHAPTER 2 :}

Media Report, 2002 (The Assam Tribune, $8^{\text {th }}$ November, 2002)

Media Report, 2006 (The Hindu, $11^{\text {th }}$ April, 2006).

Journal of Himalayan Biosphere Reserves

\section{CHAPTER 3 :}

State Forest Department Communication, 2005.

Director, Forest Communication, Forest Department, Assam .

www.assamforest.co.in

Assam Forest Policy, 2002.

Department of Environment and Forests,

Government of Assam, India

Assam Forest Policy, 2004.

Department of Environment and Forests,

Government of Assam, India

National Afforestation Programme, 1990

WWF India (2002)

National Forest Policy, 1988.

Department of Environment, Forests and Wildlife,

Ministry of Environment and Forests,

Government of India

Indian Wildlife Protection Act (1972)

Ministry of Environment and Forests,

Government of India.

\section{CITES Appendix I :}

CITES Appendix I includes those species which are threatened with extinction and are, or may be, affected by international commercial trade. These species may not be traded internationally (including import from the high seas) for primarily commercial purposes. 


\section{CHAPTER 1 : INTRODUCTION}

\subsection{An Overview of the Tropical forests}

Tropical forest ecosystems are dynamic systems occupying ca. 7\% of the earth's area (Myers, 1984). These ecosystems are under threat across the world and tropical forest deforestation as well as the impact of this disturbance on the global biodiversity has become a global concern in recent years (Fimbel et al., 2001; Groombridge \& Jenkins, 2000; Lawton et al., 1998). Although the tropical forests are known to contribute significantly to the global diversity (Sutton \& Collins, 1991; World Conservation Monitoring Centre, 1992), not more than $4 \%$ of the total tropical forest cover is within the boundaries of reserves or national parks (Whitmore \& Sayer, 1992). Sometimes even the best-protected areas might not be adequate to maintain the original ecosystem either due to their small size or difficult political and social conditions (Terborgh, 1999). Ecological disturbance is a continuously operating process in tropical environments (Blau 1980). Most estimates of species loss have focused on tropical forests, as they are known to harbour the majority of species. However with increasing anthropogenic pressures, tropical forests are undergoing fragmentation, leading to a loss of habitat and subsequently erosion of biodiversity (Pimm 1998; Laurance 1999). In developing countries, degradation of tropical forests through selective logging, hunting, change in land-use practices, shifting agriculture and urbanization is both widespread and continuing yet, despite several decades of research into this problem, the impacts of such disturbance on the diversity of fauna within tropical forests are poorly understood (Hill \& Hamer, 2004). Severe disturbances like clear felling and conversion of forest into grassland usually reduce diversity (Holloway, Kirk-Spriggs \& Chey, 1992) but impacts of moderate habitat disturbance such as commercial selective logging still remains unclear. Given the rapid loss of tropical forest habitats ecologists and conservationists urgently need to understand the factors contributing to this lack of consensus. In densely populated countries like India forest degradation is a serious problem. The country has about $6 \%$ of the total human population and about $15 \%$ of the world's cattle population. Indiscriminate utilisation of both forest and non-forest resources is leading to a change in the quality of the forests/habitat. Shifting cultivation, which was once said to be a 
sustainable practice, is causing a serious threat to the endemic flora and fauna (Ramakrishnan, 1993). Shifting cultivation is widely prevalent in Northeast India. It is the major land-use in this region and extends over 1.73 million ha (FSI, 1999). A meaningful solution to this problem has become critical not only from the point of biodiversity conservation, but also for the productive agriculture in the region.

The tropical moist deciduous forests occur under varied climatic conditions, but essentially with alternate wet and dry periods. The structure and composition of deciduous forests change with the length of the wet period, amount of rainfall, latitude, longitude and altitude (Shankar, 2001). Phytosociological patterns in Indian deciduous forests are not well known. In Northeast India, the moist mixed deciduous forests are classified as 'East Himalayan moist deciduous forest' (Champion \& Seth, 1968) and in Assam, the tropical deciduous forests cover is 11,358 sq. Kms, which is $14.5 \%$ of the total forest cover (FSI, 2003). Deciduous forests are not considered species rich (Gentry, 1995) but have a diversity of life forms (Medina, 1995). These forests still assume unusual significance for conservation as they are the most used and threatened ecosystems (Janzen, 1986), especially in India.

\subsection{The Eastern Himalayas}

The Indian Himalayan Region (IHR) covering about 16.2\% of the country's total geographical area occupies the entire northern boundary of the Indian sub-continent extending from the Northwest (Kashmir-Kumaon) to the Northeast (Eastern Himalayas). This region portrays India's ecological and social identity by virtue of being the center of biological and cultural diversity with the ethnic hill tribes primarily depending on the natural forest resources for their daily sustenance. The cultural and ethnic diversity in the region is remarkable, with each group of people adapting to the demands of the region in their own unique way. Great differences in altitude, latitude and longitude create vast variation in microhabitats throughout this range. The Western Himalaya is relatively dry and cold, while the Eastern Himalayan region is extremely wet. However the exceptionally rich and higher biological diversity in the Eastern Himalaya is attributed to its multiple biogeographic origins. Its location at the junction of two continental plates places it in an ecotone that is represented by flora and fauna from both. The Indo-Malayan realm of Southeast Asia has contributed to many tropical taxa and particularly represented by such primitive plants like Michelia, Magnolia, Camellia, Dipterocarpus, Shorea, Terminalia and Rhododendrons and epiphytic orchids. The monsoon forests below 1000 metres have a close 
affinity with the monsoon forests of Indo-China where Dipterocarpaceae is the dominant family while the faunal elements are mainly the representatives of the Indo-Malayan realm. The Palaearctic realm to the north contributes to the Sub-tropical Broadleaved Hill type of forests including the conifers while the temperate and sub-tropical East Asian or SinoJapanese region contributes to a primitive biota with a high level of endemism. There is also a good representation of the Palaearctic mammals like the Snow leopard (Uncia uncia), Brown Bear (Ursus arctos) and a diverse assemblage of ungulates. The high degree of climatic variability associated with the steep and complex topography has enhanced the biodiversity across the north-south axis (WWF and ICIMOD, 2001).

Conservation International has upscaled the Eastern Himalaya Hotspot to the Indo-Burma Hotspot (Myers et al., 2000) and as one of the earth's biodiversity hotspots includes several Global 200 Ecoregions (Olson \& Dinerstein, 1998), two Endemic Bird Areas (Stattersfield et al., 1998) and several centres for plant diversity (WWF/IUCN, 1995). The region's lowland and montane moist to wet tropical evergreen forests are considered to be the northernmost limit of true tropical rainforests in the world (Proctor et al., 1998). The region harbours India's largest elephant (Elephas maximus) population and the world's largest population of the one-horned rhino (Rhinoceros unicornis). This region also harbours the highest avian diversity in the Orient with about 836 of the 1200 species of birds known from the Indian subcontinent (ICBP, 1992). The political boundaries of this region now include entire Northeast India, Bhutan, Nepal, Myanmar and Southern China. Northeast India, which covers the entire Indian extent of the Eastern Himalayas, and representing this transition zone between the Indo-Malayan, Indo-Chinese and Indian biogeographical realms, is unique in providing a profusion of habitats with diverse biota and a high level of endemism. Physiogeographically the region can be categorised into the Eastern Himalayas, Northeast hills (Patkai-Naga Hills and Lushai Hills) and the Brahmaputra and Barak valley plains. Northeast India forms the main region of tropical forests in India with a rich diversity of medicinal plants and many other rare and endangered taxa. Although $64 \%$ of the total geographical area is under forest cover, there has been a decrease of about 1800 sq.kms. in the forest cover between $1991-1999$ (FSI, 2000). The region is also the abode of approximately 225 ethnic tribes out of a total of 450 in India, the culture and customs of which have an important role in understanding biodiversity conservation and management issues. This region provides a good example of the linkages that exists between cultural diversity and biological diversity (Ramakrishnan 1999). The Biodiversity Strategy and Action Plan for Northeastern Ecoregion suggests that 3,624 
species of insects are recorded from the region. Butterflies and moths are by far the beststudied invertebrate organisms in this region. Assam is a part of this mega diversity zone by virtue of its rich tropical evergreen rain forests and moist deciduous forests (Champion \& Seth, 1968).

\subsection{Study on tropical butterfly communities}

Relatively few studies have focussed on invertebrates, despite their dominance of the animal community in species richness, abundance and biomass (Wilson 1987; Stork 1988). Insects have been shown to be sensitive to changes in vegetation composition and the physical attributes of the environment (Erhardt 1985; Gardner et al., 1995; Wood \& Gillman, 1998) resulting in a decrease in insect diversity (Holloway 1987; Holloway et al., 1992). Tropical insects are highly diverse (Hamer et al., 2003). Tropical butterfly communities are highly diverse with many endemic species, most of which are to some extent dependant on closed-canopy forest (Collins \& Morris, 1985; Sutton \& Collins, 1991). Compared with other invertebrate groups, the high visibility of butterflies together with their relatively well studied taxonomy and rapid abundance changes in response to environmental variations and local weather have resulted in them being used regularly as biological indicators of ecosystem health (New 1992; Spitzer et al., 1997; Lawton et al., 1998; Scoble 1992). They have been widely used to assess patterns of tropical insect diversity in forest conservation studies (Brown 1991; De Vries et al., 1997). Inventory and monitoring of butterflies has proven useful in the evaluation of terrestrial landscapes for biological conservation (Samways, 1994). Examples include habitat assessment and classification (New, 1991; Pollard \& Yates, 1993; New et al., 1995) as well as evaluation of the effects of land use (Erhardt, 1985; Swengel 1996) and urbanization (Kremen, 1992; Blair \& Launer, 1997). As butterflies are extremely sensitive to changes in vegetation composition and structure, butterfly assemblages may be used to characterize different habitats (Erhardt, 1985). Butterflies in general and swallowtail butterflies (Family Papilionidae) in particular also represent the 'flagship' and/or 'umbrella' taxa for invertebrate conservation (Collins \& Morris, 1985; New et al., 1995). The swallowtail butterflies have become one of the model taxa for understanding the processes involved in evolutionary divergence of host preference, host-specialization and diversification in insects (Wiklund, 1975, 1981; Rausher et al., 1983; Scriber et al., 1991; Tyler et al., 1994; Thompson, 1994). They have diversified worldwide into more than 475 species and species complexes that differ in the range of plant taxa they attack (Scriber et al., 1995; Tyler et al., 
1995). Most species of the swallowtails are predominantly tropical but a few species are also found in the temperate zones (Slansky, 1972). They are most diverse in the equatorial rainforest zones and Southeast Asia has the highest number of species, while species richness in the eastern Asian region between $20^{\circ}$ and $40^{\circ} \mathrm{N}$ is also high as reflected in the analysis on critical swallowtail fauna where Indonesia, Philippines, China, Brazil and Madagascar are reported to include well over a half of the world's swallowtails (309 species and $54 \%$ of the world total) with highest swallowtail species endemism. Another five countries, India, Mexico, Taiwan, Malaysia and Papua New Guinea bring the total to 68\%, which is more than two-thirds (Collins \& Morris, 1985). Globally 573 species have been listed out of which nearly 78 species have been listed in the threatened categories. Amongst these, 14 species have been listed as 'Insufficiently known' (Scriber, 1973; Collins \& Morris, 1985). In the Indian sub-continent, the family Papilionidae is represented by two sub-families- Parnassiinae (Apollos), which includes 14 species, and Papilioninae (Swallowtails), which include 83 species and sub-species (Evans, 1932; Talbot, 1939). Swallowtail butterflies are the most spectacular and magnificent of all insects with brilliant colouration and large variations in size ranging from the minute $50 \mathrm{~mm}$ wingspan of the Dragontails of India and Malaysia (Lamproptera species) to the giant Birdwings (Troides, Trogonoptera and Ornithoptera species) of India, Indonesia and New Guinea. The female Queen Alexandra's Birdwing (Ornithoptera alexandrae) is the largest butterfly in the world, attaining a wingspan of over $250 \mathrm{~mm}$. Due to their fabulous colours and aesthetic value, the swallowtails are vulnerable to commercial collection and trading and are the sole insects included in Appendices to CITES. The Birdwings (Troides, Trogonoptera and Ornithoptera species) have been listed by CITES on Appendix II. Butterfly trading based in India and Indo-China is quite extensive and occurs at all levels from personal collectors to substantial business (Collins \& Morris, 1985). In the Eastern Himalayas, the trade in the swallowtail butterflies has been most intensive since the early part of the $19^{\text {th }}$ century and over collection of Teinopalpus imperialis (Kaiser-I-Hind) and Bhutanitis lidderdalii (Bhutan Glory) by private collectors for the international market has been a major threat to not only these specie but the illegal commercial trade in the oriental region has been the primary cause of concern for the continued survival of a number of important localised species. India occupies the $6^{\text {th }}$ rank in the list of priority countries or 'critical faunas' for swallowtail conservation (Collins \& Morris, 1985). A total of 77 species have been recorded in the Indian subcontinent out of which 6 species are known to be endemic and only 1 species is threatened (Collins \& Morris, 1985). The IUCN has identified the entire Indo-Burma hot 
spot that includes the Eastern Himalayas and other Global 200 ecoregions from this hotspot as 'Swallowtail butterfly-rich zone' and has also drawn up an action plan for their conservation ('Swallowtail Conservation Action Plan', New \& Collins, 1991). Many swallowtail butterflies are very restricted in their habitat and geographical range. Some taxa are found only in the montane regions or 'ecological islands'; others on small geographical islands while many are endemic to microhabitats in tropical forests. As the Papilionids are dependant on forest vegetation, habitat alteration associated with deforestation, agricultural conversion and intensification, alteration of pastures, urbanisation and industrialisation are posing a serious threat to their survival. (Collins \& Morris, 1985). Habitat change in densely populated and economically poor tropical regions is of increasing concern (FAO/UNEP, 1981). In tropical South-east Asia in particular, habitat alteration by way of deforestation has posed a serious threat to the survival of the Papilionidae. In the Eastern Himalayas deforestation is occurring throughout the range of an endemic species, Kaiser-IHind (Teinopalpus imperialis imperialis Hope, 1843) described as rare by Talbot (1939) and protected by law in India (Wildlife Protection Act, 1972). This species is listed by the IUCN (1996). The present IUCN status of this species is rare and much of its forest habitat is being degraded through shifting cultivation. There has also been commercial overexploitation of this species in the past and the protective legislation enacted in India and Nepal appears not to be very effective. The primary vegetation in extensive areas of Northeast India including Assam has been disturbed by human activities. The quality of the forests is also deteriorating with the dense forests (canopy closure $>60 \%$ ) becoming degraded into open forest or scrub. In Assam the percentage of 'Very Dense' forest cover is only $2.1 \%(1,684$ sq.kms), 'Moderately Dense' forest cover is $14.5 \%$ (11, 358 sq.kms.), 'Degraded/Open forests' is $18.9 \%(14,784$ sq.kms.) and 'Non-forest' area is $64.5 \%$ of the total area of forest and tree cover (FSI, 2003). This indicates a disturbing trend in the declining primary forest cover. The total estimated area under encroachment is 3,555 sq.kms. and total area under forest fringe villages is approximately 538.35 sq.kms. ( $0.69 \%$ of the Reserved forest area). A majority of the indigenous inhabitants of Assam are meat eating and almost all communities have expert hunters, trappers and fishermen. Although the traditional practices of trapping and snaring of animals are carried out in very remote areas, shooting wild animals with guns is prevalent. Moreover certain meat is valued as medicinal and such animals are hunted. It has been recommended under the National Forest Policy, 1988 that every state in India shall have atleast $5 \%$ of the geographical area under National Parks and 
Wildlife sanctuaries, which cover natural ecosystems and greater emphasis needs to be given towards anti-poaching measures in such protected areas.

\subsection{The Protected Forest Management Scenario in Assam}

Sustainable forest management is a key issue not only for biodiversity conservation but is also equally significant for the local economy (Ramakrishnan, 1999). In Assam where culturally distinct ethnic societies living close to nature and natural resources have sculptured a cultural landscape around them, this concept of cultural landscape can be seen as an effective tool for linking conservation with sustainable development of this marginalized society. With a rapid decline in the forest cover of Assam, forest rehabilitation initiatives in which local communities get involved are already being introduced. Under the National Afforestation Programme in Assam, Joint Forest Management (JFM) has been implemented which has been working on the local peoples' participation for the regeneration and protection of the forests. Rani-Garbhanga Reserve forest in Assam, Northeast India which was selected for our research study on the Papilionidae (Swallowtail butterflies), has five Joint Forest Management committees under Forest Development Agency, where the local forest village community who are the actual traditional owners of the forest are an equal stake holder, and in collaboration with the forest department have been actively involved in various community development programs like constructing village roads, school buildings, providing safe drinking water and primary health facilities, incorporation of smaller income generation schemes and growing cash crops along with the main crops. Bamboo (Dendrocalamus hamiltonii) is a very important bio-resource of Rani-Garbhanga Reserve that provides subsistence and livelihood security to the local village community and is a part of the cultural, social and economic tradition of the region in general. In the rural scene bamboo is particularly useful at the household level and the local people possess traditional skill of working with the material and knowledge of cultivation and management of bamboo. A community based development approach through active participation and involvement of communities under the JFM has been adopted for protecting the bamboo forests within the reserve. Agro-forestry and village-level social forestry initiatives have also been implemented, as unless the local people are not involved they will jeopardise the forest management. It is also critical that special emphasis should be placed on socially/culturally valued species within the forest ecosystem because such species are invariably also the keystone species and it is through this medium that the forest management authorities and other local non-governmental organisations can relate with the local communities and make 
such an interdisciplinary approach the basis for making management decisions. Formal knowledge based forestry management practices can then provide added value to and help in arriving at appropriate management decisions.

Management of 'shifting cultivation' (locally called Jhum) has been the next big problem in particularly the southern range of the reserve. The shortening fallow cycle has been managed through using appropriate tree species rather than introducing an alien technology. Scientifically analysed 'Traditional Ecological Knowledge' (TEK) available with the local communities is a powerful tool to redevelop 'Jhum' as part of a short-term strategy, and as a component of a larger and more comprehensive landscape management plan (Ramakrishnan, 1999).

In tropical regions where the management authorities are having to deal more and more with secondary forest systems rather than with primary forests, more emphasis needs to be given on the value of secondary forests in our research and management plans so that these forests are effectively able to meet the multi-purpose needs of communities (Ramakrishnan, 1999). Rani-Garbhanga Reserve Forest in Assam is also a disturbed secondary forest where such a management approach that will sustain community participatory rehabilitation or management plans can alone be sustainable in the long run as the ultimate objective is towards restoring the integrity of the cultural landscape with which the local ethnic community is closely linked. 


\section{CHAPTER 2 : BACKGROUND, OBJECTIVES AND HYPOTHESES}

\subsection{Background}

Amongst the invertebrates, butterflies are becoming sufficiently well studied for them to be used for general conservation planning in some parts of the tropics as a representative insect group (Thomas, 1991). While butterflies are considered as useful indicators of diversity, much of the extensive quantitative fieldwork on tropical lepidopteron diversity has been confined to moths (Walpole \& Sheldon, 1999). Yet the ease of sampling butterflies has made them a focal group for characterizing tropical insect diversity, community structure and disturbance effects and as tools in conservation biology (Derives \& Walla, 2001).

The state of Assam in Northeast India is home to a rich butterfly fauna and between 680-700 species and sub-species has alone been recorded while the total species count for North-east India is 962 (Evans, 1932; Talbot, 1939; Wynter-Blyth, 1957). Large-scale deforestation and habitat fragmentation have led to the decline of several butterfly populations in the region and many species, which were listed as common during the early part of the 20th century, have now declined rapidly throughout much of their range. Another serious issue has been the illegal trade in butterflies where the strong nexus between the private collectors and butterfly smugglers has been posing a serious threat to the survival of these winged creatures. The Bhutan glory (Bhutanitis lidderdalii lidderdalii Atkinson 1873) and Kaiser-I-Hind (Teinopalpus imperialis imperialis Hope 1843) are two species of swallowtails endemic to the eastern Himalayas and which were described as rare (Evans, 1932; Talbot, 1939) but the present status is not known. Both species have been listed by IUCN as 'rare' and 'not so restricted' respectively and require monitoring to ascertain their actual status (Collins \& Morris, 1985). While deforestation in India and Nepal that has been occurring throughout the range of these two species has been one of the major threats to their survival in the wild, illegal trade is the second most serious threat to these species. Hundreds of individuals are exported annually from Thailand to collectors worldwide. Trade in these two species flourished in the British Northeast India in the early part of $19^{\text {th }}$ century and now the present status of these species is unknown. It is reported that 100 
million US dollars worth butterflies are being smuggled out of the country from Assam and the Himalayan region and the target species are the Papilionids and Nymphalids. They have high market value as both dead and livestock and are mostly used for ornamental purposes. Many rare species of swallowtail butterflies fall into the 'low volume/high value' category of butterfly trade and it is extremely difficult to monitor this trade as most often the collectors pose as botanists.

The first major account on the butterflies of Assam was compiled in a series of papers by Butler (1879), Doherty (1889), Elwes (1891) and Swinhoe (1893). The biogeography of the Assam butterflies was discussed by several authors, including Bingham (1907), Evans (1932), Talbot (1939), Parsons \& Cantlie (1947), Wynter-Blyth (1957), Varshney \& Chanda (1971), Arora \& Mondal (1981), Gupta \& Shukla (1988). A historical review on the swallowtail butterfly diversity of the Indian Himalayan region (IHR) extending from Kashmir-Garhwal-Kumaon to Burma gives the earlier records of 83 species and subspecies (excluding the Parnassius sp., commonly called the Apollos) and out of these, 69 species were described from the present Eastern Himalayas covering entire Northeast India and the erstwhile political regions of Sikkim, Bhutan, Assam, Meghalaya, Manipur including Naga and Chin hills, Arunachal Pradesh, Mizoram and Tripura and 50 species were described from Southern Burma, Tavoy and Shan states (Evans, 1932; Talbot, 1939). The records of Evans (1932) described five species to be endemic to Assam while another six species were endemic to the Sikkim-Assam region, 11 species were described from Chitral and 31 species from the Western Himalayas. Another 19 species (including sub-species) of swallowtails belonged to the 'Non-Himalayan' category and were described from South or Peninsular India (Evans, 1932) and 13 species from the Andaman and Nicobar islands (see Appendix 4: 4.3). All the above species and sub-species counts did not include the Apollos (Parnassius sp.) whose range or distribution in the Indian sub-continent is again only restricted to the Himalayan region and are confined to above $2700 \mathrm{~m}$ elevation up to the maximum altitudinal level of $5500 \mathrm{~m}$ stretching from the Northeast to the Northwest Himalayas. In the Northeast Himalayas (Eastern Himalayas), the Apollos are found only in the states of Arunachal Pradesh and Sikkim. As the political divisions mentioned in the records of Evans, 1932 belonged to the period of British rule in India and Burma, therefore the biogeographical units have to be considered for the review on the documentation. Therefore it would be worth considering the species records from the Shan states also as they may be eventually found in the adjacent parts of Nagaland and Manipur in present Northeast India. Moreover the political division during British regime in 
Northeast India comprised of only one province- Assam, which is now divided into seven provinces. The records of Wynter-Blyth (1957) gave a modified version of Evans (1932) records, where he reported the total Papilionidae count for the Indian subcontinent as 94, with 62 species described from Northeast India and 66 species described from Burma (present Myanmar). The first comprehensive monograph on the swallowtail butterflies of the Sikkim region in modern literature were compiled in a series of notes by Hooker (1855), Elwes (1880), Elwes \& Moller (1888), De Niceville (1881, 1882, 1883 \& 1885), Tytler (1915) and Bailey (1911). All these publications were later incorporated into the works of Evans (1932), Talbot (1939) and Wynter-Blyth (1957). In recent literature, records on the swallowtail butterflies from the Himalayan region were compiled by Mani (1986) while Haribal (1992) reported on the diversity, status and habitat preferences of butterflies from the Sikkim Himalayas. In the Himalayan region, $80 \%$ of the butterflies have been recorded as forest species of which almost $60 \%$ of the butterflies occur in forests below the elevation of $3000 \mathrm{~m}$. The remaining species occur above the elevation of about $4000 \mathrm{~m}$ (Mani, 1986). Again in the records of Evans (1932), more than 15 species and sub-species of Papilionidae have been recorded as endemic to India (excluding the Andamans and Nicobar Islands), while the IUCN records reported only six species as endemic to India with a total species count of 77 (Collins \& Morris, 1985). There are startling lacunae in the evaluation process as for example out of 26 threatened species of butterflies listed for India by the IUCN, the threat categories of only six species (Teinopalpus imperialis, Graphium epaminondas, Euploea andamanensis, E. scherzeri, Idea malabarica, Parantica nilgiriensis) have been evaluated so far while another three species (Elymnias pealii, Charana cepheis and Mycalesis malsarida) of endemics from the family Nymphalidae do not even feature on the IUCN list. Moreover all the species listed as threatened on the IUCN list are not included under Schedule I of the Indian Wildlife Protection Act, 1972 (as amended upto1993). This clearly suggests the need for a re-evaluation of the status and a new documentation on the butterflies of particularly North-East India. In Assam, there has been less scientific focus on any kind of major butterfly fauna survey until recently and no scientific documentation of the local butterfly fauna has been done in the recent past except for a few protected areas. Academic research on butterflies is also lacking and there is no readily available recent baseline data on the butterflies of this region. Most of the wildlife parks and sanctuaries in Assam do not have butterfly lists and on an overall there is very little conservation activity directed towards butterflies because they are not considered to be flagship/umbrella species. As there are no names for butterflies in regional languages and no access to any kind of 
detailed technical information, peoples' awareness regarding butterflies and their conservation is lacking and it is also difficult for wildlife managers and policy makers to take steps for effective butterfly conservation. This is due to the fact that in India butterflies are treated as non-target species in the conservation and management of wildlife as the prime focus has always been on the vertebrate taxa. Apart from the occasional checklists, which have been more of an authoritative work, scientific work pertaining to the biological and ecological aspects of butterflies from this region is completely lacking. As large-scale deforestation and habitat fragmentation are continuing at a rapid rate, most of the butterfly species, which were described as common in the early literature, are now declining throughout much of their range. Therefore research and documentation on the butterflies with emphasis on their taxonomy needs to be undertaken as an initial step towards the conservation of this taxon. 'Horizon International and Butterfly Conservation' is one such project currently involved in the comprehensive survey and monitoring of the butterflies in the protected areas of Assam and this project is aimed towards the development of a baseline data for the butterflies of protected areas.

In the present study, Rani-Garbhanga Reserve Forest was selected as the study area with the prime objective of focussing on ecological studies as well as long-term butterfly monitoring. This protected reserve was found to harbour a good butterfly diversity based on earlier studies (Barua et al., 2004a; 2004b) and there has also been a proposal for declaring this protected reserve as a "Butterfly Sanctuary" (Media report, 2006. The Papilionidae family was however selected as the focal group for the research studies on butterflies as this group is primarily composed of forest-dwelling species and a study on the food plant data base for the swallowtail butterflies along with the impacts of some selected environmental variables on their abundances and distribution can be used as an effective research tool for conservation. As for the selection of the study area, the strategic location of this protected reserve adjacent to a wetland ecosystem, which is the only Ramsar site in Assam and sharing of common boundary with protected forest reserves from the state of Meghalaya can be, used an important tool for 'bio-monitoring studies' in the future. The first research project funded by the Ministry of Environment and Forests, Government of India started work in Rani-Garbhanga Reserve forest in 2001 to identify the butterfly community within the protected area. A total of 193 species belonging to the families Papilionidae, Nymphalidae, Pieridae, Lycaenidae and Hesperidae were documented in this study (Barua et al., 2004a). The initial stage of the research work was directed more towards taxonomic studies relating to the identification of the butterflies and particularly the Papilionidae group 
was emphasised on. The second phase of the research work was concentrated on the biology of some selected species and ecological studies pertaining to habitat assessment - vegetation survey with particular emphasis on identification of the larval food plants and adult nectar sources of the swallowtail butterflies (Papilionidae), influence of local weather conditions on butterfly abundances and anthropogenic disturbances leading to the degradation of the forest quality.

\subsection{Objectives}

Butterflies in general and Papilionidae in particular are good organisms for studying the effects of environmental change. Their activities are closely controlled by weather and many species are constrained by climate (Pollard, 1979 \& 1988; Turner et al., 1987), mostly occupying a small part of the range of their host plants (Dennis \& Shreeve, 1991). They reproduce quickly, have high dispersal ability and an annual or more frequent life cycle, so changes in abundance and distribution can be detected over a relatively short time-scale (Pollard \& Yates, 1993; Parmesan, 1996).

The main goal of our study is to evaluate the conservation status of swallowtail butterflies by documenting the effects of habitat types on the community in Rani-Garbhanga Reserve Forest, Assam, Northeast India.

Specifically, our aims were:

- To document the food or host-plants for the swallowtail butterfly community within the study area of the protected forest reserve;

- To investigate the effects of some independent environmental variables on the swallowtail butterfly abundances and distribution pattern and to detect their habitat associations relating to their preferences for a particular forest type;

- To determine the swallowtail butterfly species richness, composition, abundance and distribution pattern between different forest types and seasons;

- To detect and document the indicator properties of the group (genus-wise) and species assemblages of the Papilionidae in our study area.

- To evaluate the conservation status of swallowtail butterflies in our study area; 


\subsection{Research questions}

Keeping the above objectives in view, we therefore aimed to answer the following questions:

1) Is there any difference in the swallowtail butterfly species composition and distribution between open forest or gaps and closed forest? Which species are associated with each habitat or forest type?

Previous studies have shown that butterflies are in general very habitat specific and this habitat association could be influenced by many physical and biological factors (Ramos, 2000; Spitzer et al., 1993 \& 1997; Leps \& Spitzer, 1990; Spitzer, 1983). The swallowtail butterflies belonging to the family Papilionidae are primarily a forest dwelling species but some species are also known to be associated with open habitats (Collin \& Morris, 1985). A high proportion of swallowtails are dependant on the forest vegetation and, deforestation has been the major cause of concern for the continued survival of a number of localised species. Our first objective was therefore aimed at not only identifying all the available species within the forest reserve but to also identify the characteristic species for each forest type. Therefore by segregating the study area into two distinct forest types (gaps or open and closed forest types) and following the standard transact walk method of Pollard (1977), we investigated the distribution pattern and abundance levels of the species assemblages within the forest reserve.

Butterflies interact with plants both as larval herbivores and adult pollinators, potentially influencing plant population dynamics in both interactions (Gilbert, 1980). Although in our study we did not investigate the correlation between butterfly and plant diversity, however as part of a general vegetation survey, we tried to identify the floral resources within the forest reserve especially at the level of larval food-plants and some of the common adult nectar sources. Swallowtail butterflies are known to be strongly associated with some tropical and sub-tropical plant families (Fiedler, 1998); therefore the identification of the host-plants up to species was important as recent studies have found larval host-plant specificity and adult habitat specialization to be important determinants of extinctions across all families of butterflies in south-east Asia (Koh et al., 2004). Interactions with host plants appear to be an important means of biological diversification and these interactions are governed by nutrient content, plant phenology and geographical distribution (Slansky, 1993; Basset, 1991a \& b; Leather, 1990). The abundance and distribution 
of butterflies within a particular habitat therefore signifies the floral diversity and habitat quality, which can be used as important tools for their conservation as well as for general bio- monitoring. However high floral diversity does not always coincide with significant butterfly species diversity (Vane-Wright, 1978). Therefore our studies on vegetation were only aimed at identifying plants as trees, herbs/shrubs and climbers and then segregating the adult and larval resources with reliable references from literature and actual field observations.

2) Is there any relationship between the species abundance and their geographical range and larval diet breadth?

We tried to investigate the correlation between species geographical range and abundances as geographical range can be used as a tool for assessing conservation value. The larval diet breadth is considered to be one of the most important life-history traits of butterflies that is strongly associated with their adaptive and survival strategies and efficient uses of resources (Shapiro, 1975). The correlation between the species abundances and their feeding guild could also be considered to be an important part of the study on the biogeographical affinities of butterflies and the differences in the abundance and distribution patterns of the generalist and, specialist species can be considered to be important ecological determinants of butterflies (Kitahara \& Fujii, 1994).

3) Is the species abundance and distribution within the forest reserve influenced by such independent environmental variables like season (dry and wet seasons), forest type, year, rainfall, altitude and geographical position?

In the seasonal 'East Himalayan region', responses to the seasonal changes in local environmental factors are important (Spitzer et al., 1993). Northeast India has the tropical monsoon type of climate where the amount of rainfall, temperature and humidity are known to influence the biology and ecology of flora and fauna (Ramakrishnan et.al., 1993). Specifically in case of the butterflies, rainfall is an important factor which not only directly influences the plant phenology and especially the host-plant dynamics, but the combined effects of temperature and moisture gradients are also known to influence the biology and ecology of the butterflies, particularly the variation in adult abundance and activity (Wolda, 1989; Hill et al., 2003). Tropical butterflies have been known to be sensitive to seasonal 
changes in rainfall (Hill et al., 2003). Again in the tropical regions, there is little variation in either temperature or photoperiod and changes in rainfall are the most important factors affecting seasonality of butterflies (Hill et al., 2003). We therefore tested the effects of both season segregated as 'Dry' and 'Wet' seasons and the amount of rainfall to explain the changes in abundance of the Papilionids. Butterflyenvironment relations were inferred using Canonical Correspondence Analysis to study the effects of rainfall as an independent variable and season (combined effects of rainfall, maximum temperature and humidity to segregate into dry and wet seasons) as a categorical variable to examine the variations in abundances, distribution pattern and diversity of the assemblages of species across the two forest types.

Differences among species in the pattern of seasonal variation in abundance could have important implications for comparison of the diversity and faunal composition of species assemblages between natural and disturbed habitats in different seasons (Hamer et al., 2005). In our study we separately tested the effects of season and rainfall to examine the abundances of species across two different years. Therefore year taken as an independent variable basically defined the two distinctly separate seasons- the dry and wet seasons over a time period of two years (2003-2004) to examine the environmental effects. For butterfly sampling, the months for the dry and wet seasons were chosen on the basis of mean rainfall, mean maximum temperature and mean humidity data for the study period with information on the climate data acquired from the meteorological station in Guwahati, Assam. Therefore the differences in the sampling period in terms of the number of days between the dry and wet seasons for the study sites and pooling of the transect data did not qualitatively affect the results.

We also tried to examine the effects of altitude and geographical position (latitude and longitude) on the abundance and distribution of the Papilionidae within the protected reserve. This part of our study was an attempt on the line of a similar kind of study on the distribution patterns in butterflies and birds of the Czech Republic (Storch et al., 2003). Understanding distribution patterns must include not only an understanding of species ecological requirements, but also an understanding of geographical context, which affects structure and dynamics of species' geographical ranges (Storch et al., 2003). Although such kind of a study requires a large geographical area and wide physiogeographical and topographical gradients, 
our attempt to examine the separating effects of these variables on the butterfly assemblages is the first of its kind in this region. Therefore our future aim is to select larger gradients in the protected areas of Assam for examining the effects of geographical variables on butterfly species composition and distribution.

4) Are there any indicator group or species assemblages within the forest reserve, which can be identified or defined by values of habitat/forest type and season?

The criterion of representative diversity, which is based on the recognition of assemblages of species that are typical for specific habitats, is an interesting phenomenon (Dufrene \& Legendre, 1997). Indicator species can indicate ecological change, patterns of richness or habitat type (Fleishmann et al., 2000). Some of these species can be used as targets for conservation efforts, assuming that their protection or preservation may help to protect other species sharing the same habitat. Moreover the use of assemblages of species instead of a single species as indicators enables the enlargement of the focus of the single-species approach to wider ecological situations (Kremen, 1992). Such species assemblages with their determined species richness and taxonomic composition can characterise different habitats which can be used as an efficient conservation tool. In our study we tried to focus our efforts on the identification of indicator butterfly taxa by habitat type and season as in the "East Himalayan" region, seasonality associated with the distinctly separate dry and wet seasons has a strong influence on the butterfly abundance fluctuations.

\section{4. Hypotheses}

- Spitzer et al. $(1987,1990,1993)$ and Ramos (2000) had used the method of multivariate analysis for assessing the composition, abundance and diversity of butterfly communities in southern Vietnam and Amazonian rain forest fragment. Their results on the CCA ordination showed great variations in species composition and abundance particularly with respect to levels of disturbance and vegetation gradients. In our present study we also expect to find a heterogenous species assemblage of the Papilionidae with respect to forest type based on the canopy cover and disturbance gradient although we have not measured the disturbance levels; 
- Spitzer et al. (1993) found in their studies on the seasonality of the butterflies in a montane tropical rain forest in Vietnam that the most characteristic seasonal patterns in abundance fluctuations are closely associated with the monsoon climate. Our research study predicts a similar seasonal trend with higher swallowtail butterfly abundances, richness and diversity during the wet seasons, thereby clearly indicating the influence of monsoon rain on Papilionidae populations and ecology;

- Corresponding to the findings of Spitzer et al. (1993) and Leps \& Spitzer (1990), where the observed seasonality of the forest butterflies seems to be determined not only by plant phenology and climate but butterfly biogeography and fauna history evolution also play an important role, we can expect a similar result in our study where the swallowtail butterfly geographic range and feeding guild could be correlated with their abundances to investigate their habitat associations. We could thus expect swallowtail butterflies with wider ranges to be more closely associated with gaps and disturbance while forest restricted species exhibit endemicity. This trend is typically normal for taxa with endemic distribution in Northern Indo-China (East Himalaya);

- According to Spitzer et al. (1997), endemic specialized stenotopic closed canopy forest taxa are the most endangered groups and have higher conservation value. We expect to record a high proportion of closed forest-restricted species within the protected reserve and particularly in reference to the red-bodied Aristolochia feeding guild, a good diversity is expected. This guild which normally has restricted range and preference for closed forests can also be expected to have good conservation value;

- Environmental factors and geographical position represented the main determinants of species distribution and composition of local assemblages of birds and butterflies of the Czech Republic as found by Storch et al. (2003). We also propose to examine the separating effects of season and forest type and the effects of altitude, latitudelongitude, year and amount of rainfall as independent variables and thereby predict a significant influence of all these factors on the Papilionidae abundances, distribution patterns, species diversity, richness, evenness and rarefaction estimates;

- Forest edges and areas of intermediate to high disturbances presented higher species richness and diversity of Nymphalid butterfly communities in an Amazonian forest 
fragment (Ramos, 2000). We however expect to detect higher species diversity and richness in the closed forest fragments within our study area;

- Although rare or less common species with restricted range have higher conservation value, common species should be selected to be used as indicators (Ramos, 2000). We also expect to detect more common species with wider ranges and ability to utilise a wide range of resources for selection as indicators of habitat quality for future management plan in this protected reserve. 


\section{CHAPTER 3 : STUDY AREA}

\subsection{Review of Rani-Garbhanga Reserve Forest}

Rani-Garbhanga Reserve forest located between $26^{\circ} 55^{\prime}$ to $26^{\circ} 0.5^{\prime} \mathrm{N}$ latitude and $91^{\circ} 35^{\prime} \mathrm{E}$ to $91^{\circ} 49^{\prime} \mathrm{E}$ longitude is situated on the south bank of the river Brahmaputra and is adjacent to Guwahati, the capital city of Assam in Northeast India (see Fig. 3.1 \& 3.2). In Assam, which is a part of the Eastern Himalayas (see Fig. 3.1), one of the global biodiversity hotspots in the Indian subcontinent (IUCN, 1991) and now the recently upscaled Indo-Burma biodiversity hotspot (Myers et al., 2000), there are a total of 312 Reserved forests covering an area of 13,870 sq. Kms $(17.68 \%$ of the state's geographical area). The total recorded forest area in Assam is 26,748 sq.kms out of which the Protected Area Network (25 in number) covers 3925 sq.kms. (5\% of the state's total geographical area). The Unclassed State Forests (USF) cover an area of 5865 sq.kms. The number of proposed Reserve forests in Assam is 145 covering an area of 3103 sq.kms (State Forest Department Records, 2005). The total area of Rani-Garbhanga Reserve forest is 232 sq.kms $(23,230.58$ hectares) and is divided into two ranges- The Garbhanga range having 188.86 sq. kms area (18,860.58 hectares) and the Rani Range with 45 sq.kms (4370 hectares). The Reserve is located at an altitude of 170-200 metres above the mean sea level. The forest type in Rani-Garbhanga reserve corresponds to Champion and Seth's (1968) 'Assam valley Tropical mixed moist deciduous' forest with bamboos and are classified as 'Khasi Hill Sal' [3C/C1 a(ii)] and 'Kamrup Sal' [3C/C2 d(ii)] (Champion \& Seth, 1968).

This protected forest is primarily a high-density elephant habitat (Asiatic elephant, Elephus maximus) and home to an endemic primate species, Hylobates hoolock Harlan 1834 (Hoolock or White browed Gibbon), the only species of ape to be found in the natural habitats of Northeast India. It is protected under Schedule I (1) of the Indian Wildlife (Protection) Act, 1972, Appendix I of the CITES and 'Endangered' category of the IUCN Red Data Book. The other common species amongst the larger animals are Tiger (Panthera tigris), leopard (Panthera pardus), Barking deer (Muntiacus muntiak), Indian wild Boar (Sus cirstatus), Assamese macaque (Macca inulata), Pangolin (Manis crassicaudata). The 
Reserve has a good diversity of birds (170 species), reptiles (60 species) and a large diversity of insects including butterflies (State Forest Department Records, 2005). Although there has been no proper documentation of the butterfly fauna within this reserve recent studies have recorded 193 species from the study area (Barua et al. 2002). This Reserve is the original habitat of the Sal, Shorea robusta (IUCN, 1991). The Sal forests, which are typically categorised as 'Tropical Moist Deciduous Forest' are mainly, distributed in South and South-east Asia and in India alone the Sal forests extend over an estimated area of 13 million hectares (Champion \& Seth, 1968). Sal is one of the most important timber yielding plants while the stems of Sal trees are a good source of 'aromatic gum' and is also known to have medicinal properties. The tribal people use the leaves for preparing rice cake, small baskets and disposable plates. A special type of microclimate prevailing in the Sal forest ecosystem facilitates the huge association of undergrowth diversity. However like all other Sal forests in India that are rich in phytodiversity and have been facing a great threat, in Rani-Garbhanga as well due to over-exploitation, deforestation and encroachment, the indigenous Sal vegetation was slowly replaced by moist deciduous secondary bamboo brakes. Some little amount of Sal trees are still present in the higher elevations of the forest. However the possible decline in the wealth of medicinal plants as undergrowth as well as the fragmentation of the natural habitat for threatened animals like the Hoolock gibbon are of environmental concern. There is a very good diversity of medicinal plants in this Reserve (Kanjilal et al., 1934-40). The topography of the reserve is primarily hilly although some portion also comprises of plain-forested areas in the lower elevations. What is more significant about this protected area is on one hand its close proximity to an urban human habitation (Guwahati city) on the northern side of Garbhanga Range and on the other side (touching the northern boundary of Rani range) the protected reserve lies adjacent to an important wetland, the Deepor Beel (Beel = Lake) which is a freshwater lake and the only Ramsar site in Assam (designated November, 2002). This wetland with a core area of 4.14 sq.kms. is a representative wetland type found within the bio geographic province 'Burma Monsoon Forest' and is known for its exceptional avifaunal diversity (see Fig. 3.3 \& Photo 1). It is a favourable staging ground on the migratory flyways for several species like the Siberian crane including many endemic species. Amongst the 219 species of birds (terrestrial and aquatic) recorded in the wetland some of the threatened species are the Greater Adjugant stork (Leptoptilus dubius), Whistling teal (Dendrocygna javanica), Openbilled stork (Anastomus oscitans), Little Cormorant (Phalacrocorax carbo), Shoveler (Anas clypeata), Pintail duck (Amauvor sp.), Garganey (Anas querquedula), Pond Heron (Ardeola 
grayii), CattleEgret (Bubulcus ibis), Brahminy duck (Casarca farruginea), River Tern (Sterna aurantia), Pheasant tail jacana (Hydrophasianus chirurgus). There are 70 species of endemic waterfowls. The other indigenous species recorded include 30 species of reptiles, 6 species of turtles and tortoises, 50 species of fishes, 20 species of amphibians (State Forest Department Records, 2005). This bird paradise has earned the status of an Important Bird Area (IBA) accredited by the Birdlife International, India in 1992 (Islam \& Rahmani, 2004) and being fringed by the mixed moist deciduous to semi evergreen forests of RaniGarbhanga on its southern edge exhibits a fascinating convergence of both wetland and forest ecosystem. Fishing is carried out to unsustainable proportions and the area of the wetland is slowly shrinking due to steady encroachment on its northern part. Massive siltation that is a direct consequence of deforestation and quarrying activities in the adjacent forests has emerged as a potential threat to the 'beel'. It is an important storm-water drainage system for Guwahati city and acts as a natural reservoir by absorbing the gush of water during the rainy season from the hills of the Rani range which otherwise would have created devastation in the adjacent plains by way of flash floods. The total area of the wetland as recorded in 1996 was 41 sq.kms. So a 'shrinking Deepor beel' only means a 'worsening flood situation' in Guwahati in the future. The state Forest Department has proposed 414 ha of the wetland for protection as a wildlife (Bird) sanctuary (Assam Forest Policy, 2002).

There are mainly four small rivers, which touch some parts of the boundaries of the Reserve forest, and innumerable perennial and seasonal streams, which finally drain into the mighty river Brahmaputra (see Fig. 3.5). The direction of all the rivers and most of the streams is from south to north. Along the streams there is a high density of canebrakes. The perenniality of some of the rivulets have been lost where there are large-scale teak plantation, illegal felling of trees and encroachments. This protected forest is considered to be an ecotone - transition zone between the montane sub-tropical moist broadleaf forest of Meghalaya Plateau and the Sub-Himalayan moist mixed deciduous forest of the Assam valley (Champion \& Seth, 1968). This could be the reason attributed to a good floral and faunal diversity in the area. This Reserve having the status of a good elephant habitat (Williams \& Johnsingh, 1996) is proposed to be upgraded into an 'Elephant Reserve' (State Forest Department Communication, 2005). Although the geographical area of the Reserve is small for such kind of Reserve, what is significant is the physical location of this Reserve which is adjacent to the hills of Meghalaya on southern side and the Deepor Beel on the northern side thus serving as a natural 'Elephant corridor' by linking about $70 \mathrm{kms}$ of the 
Reserve from the hills of the Meghalaya plateau into the plains of the Brahmaputra valley (see Fig.3.4). The Reserve is adjacent to Nakhalliyang Wildlife Sanctuary and Jirang Unclassed State Forest (U.S.F) of Meghalaya and also the Jarasal Reserve Forest in Assam. The second important feature is the contiguity of this Reserve with a wetland habitat (Deepor Beel) that also forms a part of the elephant movement trail and convergence of two different ecosystems.

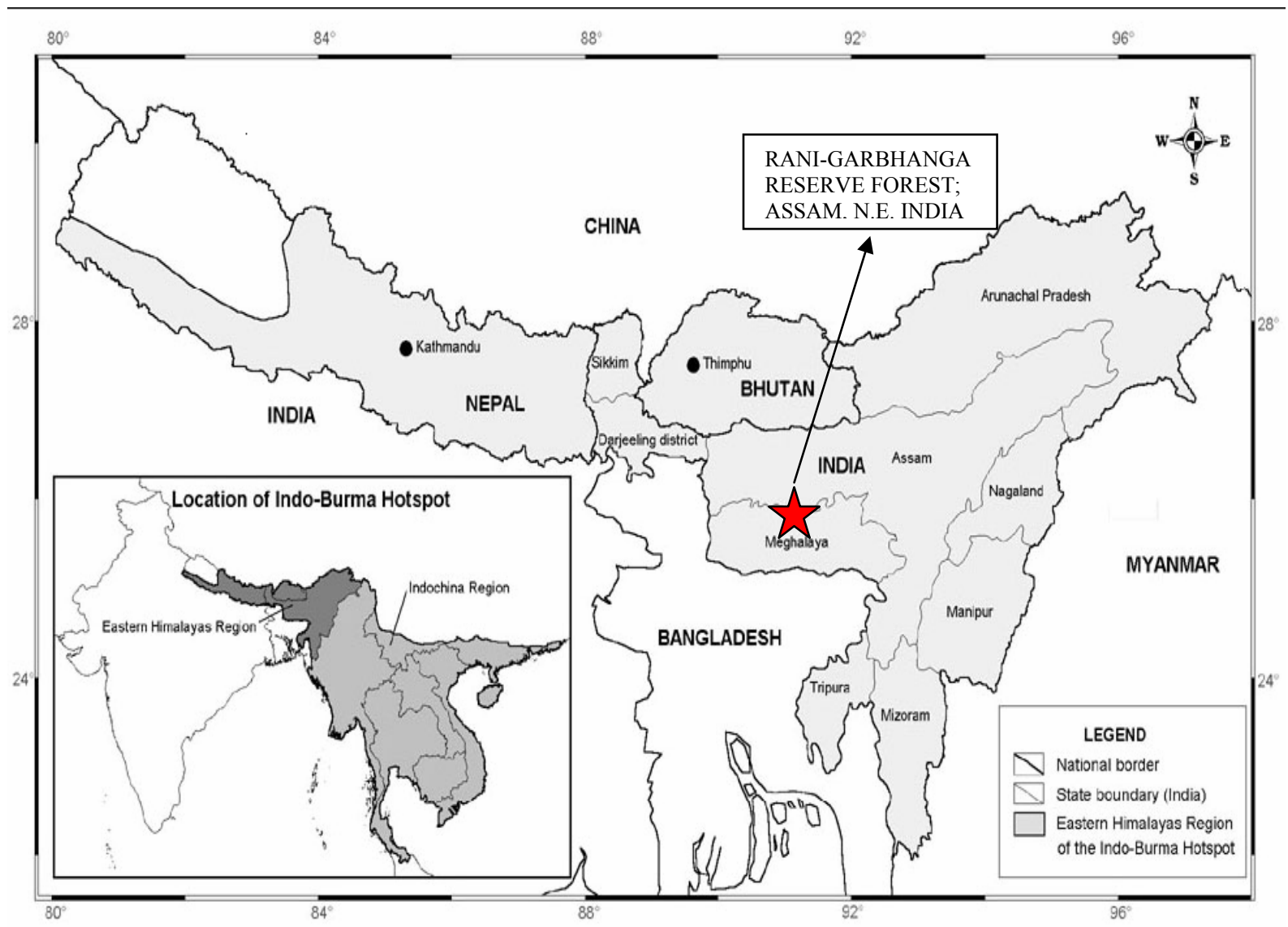

Figure 3.1: Map showing the Eastern Himalayas Region comprising Northeast India, Bhutan and Southern, eastern and central Nepal. It is a part of the Indo-Burma Hotspot as it was originally described prior to the hotspots reappraisal (2005). Rani-Garbhanga Reserve forest in Assam is indicated in the map.

Source: Ecosystem Profile, Eastern Himalayas region, WWF-US, Asia Program (2005) 


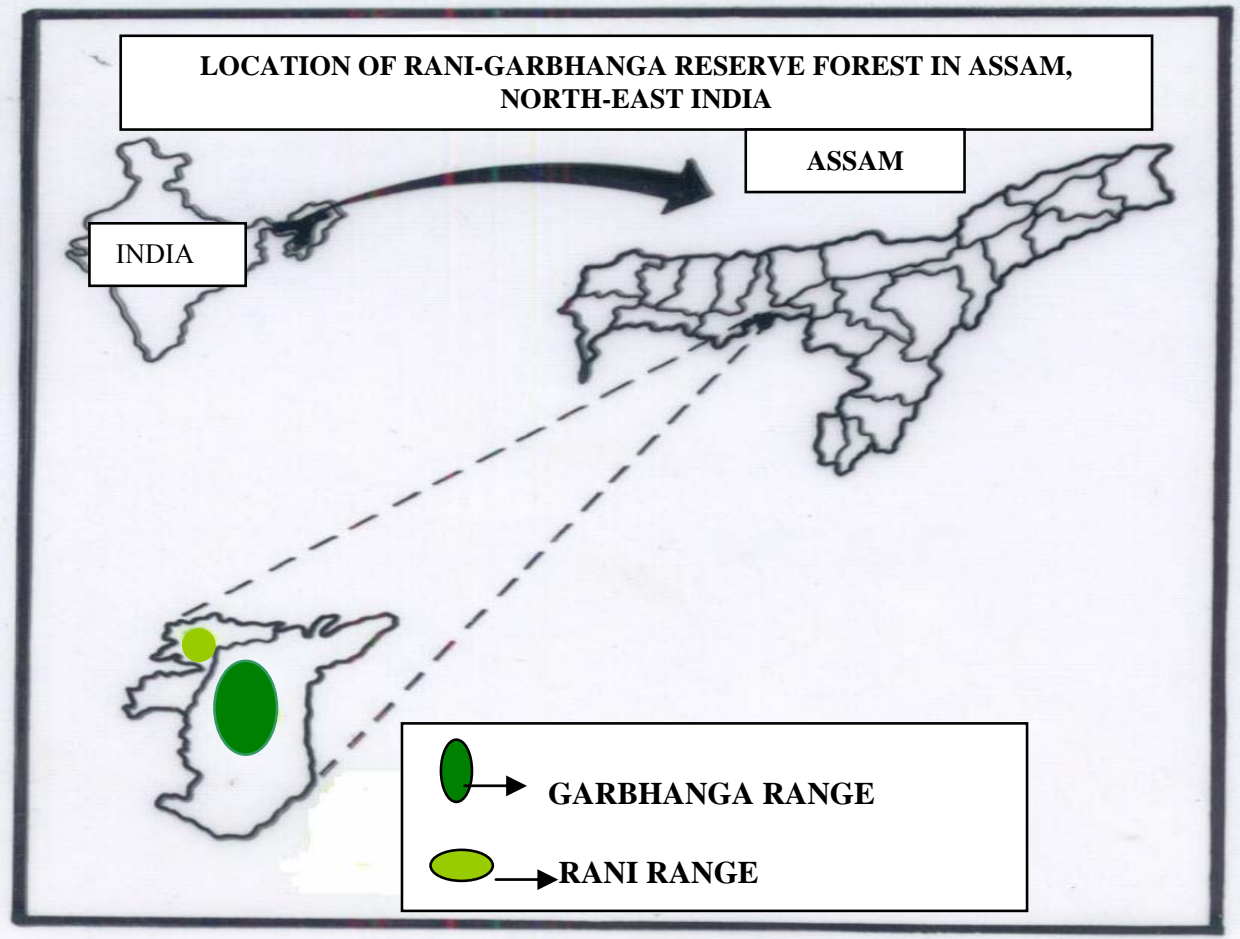

Figure 3.2: Location of Rani-Garbhanga Reserve Forest/ Landscape in Assam, Northeast India

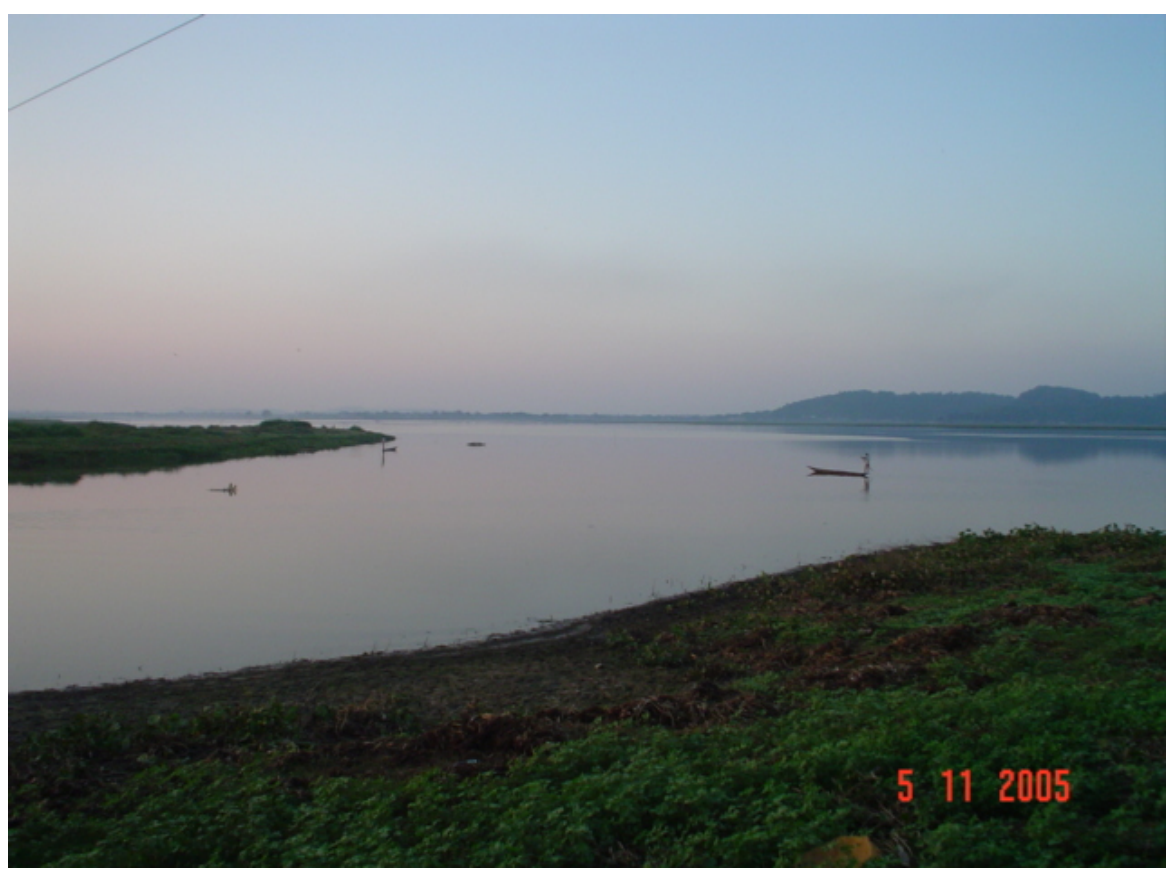

Photo 1 : ' Deepor Beel’ - the 4.14 sq. Km (core area) wetland is the only Ramsar site in Assam and is under proposal for being declared as a 'Wildlife Sanctuary' 


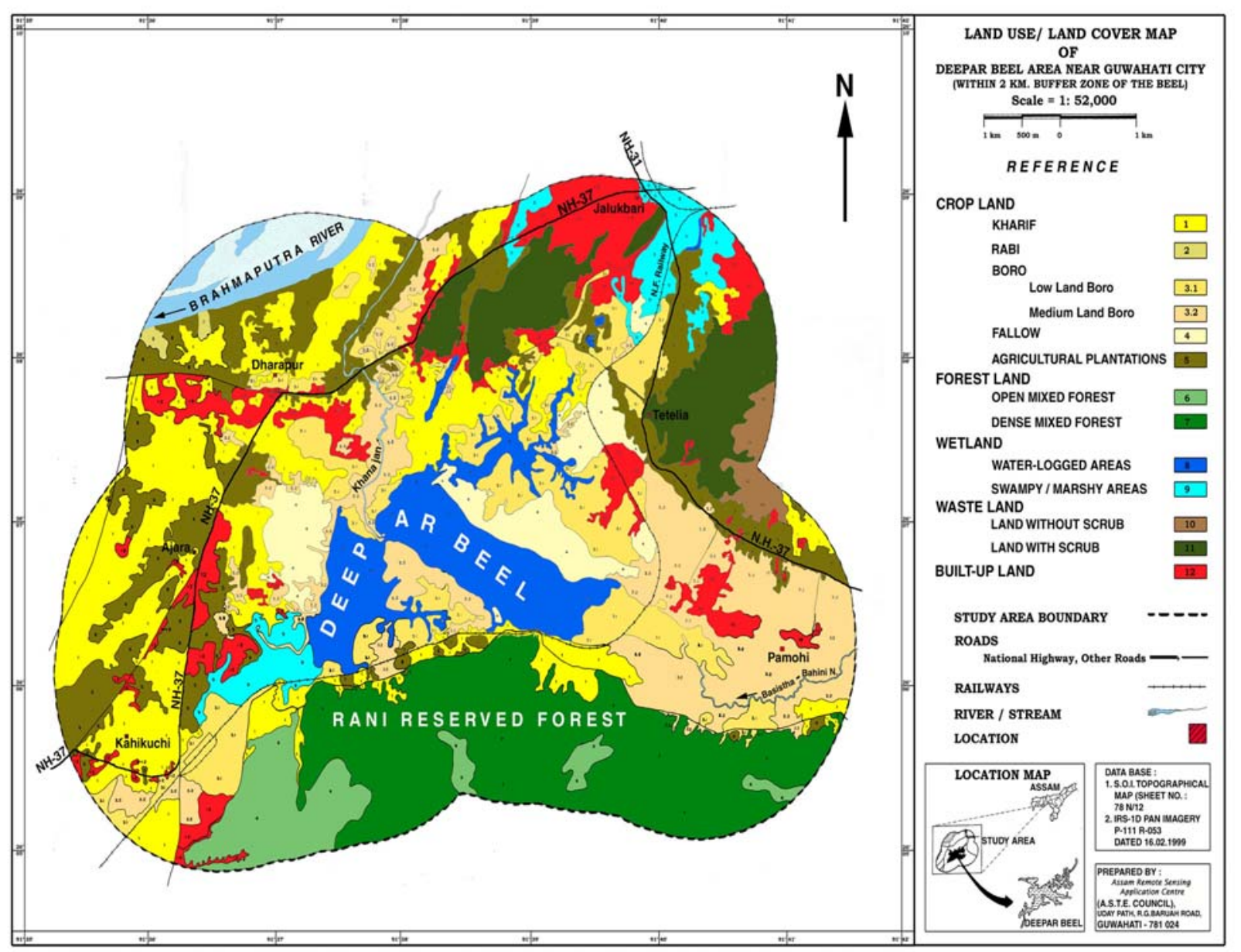

Figure 3.3: Map of the proposed 'Deepor Beel Wildlife Sanctuary'. It has been designated a Ramsar site and is located between the river Brahmaputra to its northern boundary and Rani-Garbhanga Reserve forest to its southern boundary. The wetland is about $18 \mathrm{kms}$. from Guwahati, the capital city of Assam (Map source: Director of Forest Communication, Department of Forests, Assam, India). 


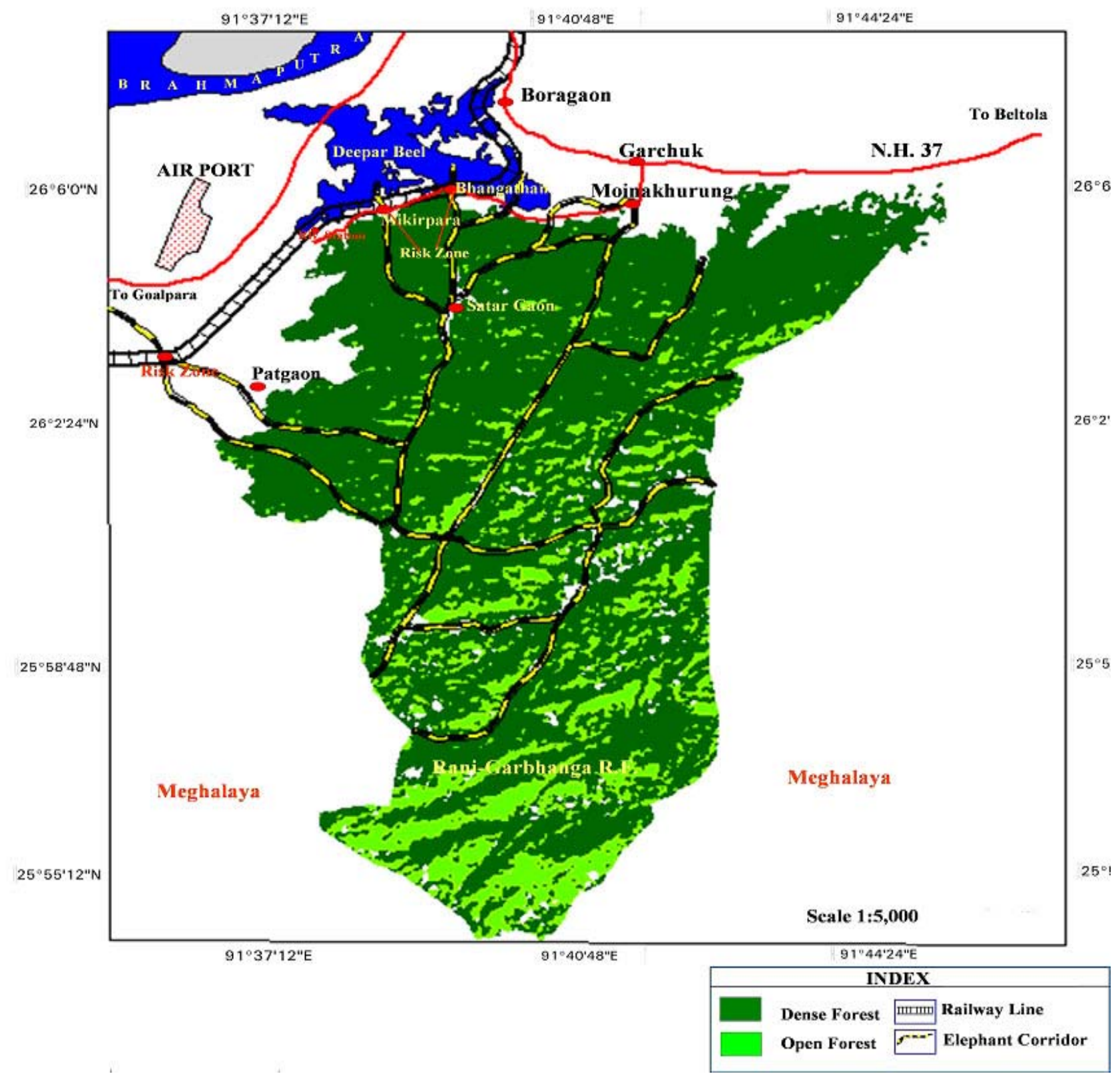

Figure 3.4: GIS image of Rani-Garbhanga Landscape showing the different types of forest mosaic. Elephant movement trails are seen within the boundary of the reserve extending from the southern part of Garbhanga range (contiguous with the Jarasal-Kwasing Reserve of Meghalaya) till the northern boundary of the forest reserve extending into Deepor Beel wetland. A railway track is seen running along the northern boundary of the reserve between the wetland and Rani range. The National Highway (NH 37) is seen along the northern boundary of the reserve. Map prepared based on ASTER data (2005).

Map source: Director of Forest Communication, Department of Forests, Assam, India. 
Rani-Garbhanga Reserve or Landscape as it is commonly known is a disturbed forest because of anthropogenic interferences like over-exploitation of the forest like illegal logging practices to cater to the rising industrial demand, encroachment, deforestation, increasing human settlements, over-grazing, forest fires, interference along the border with Meghalaya - all these factors are leading to the fragmentation of the habitat of wildlife and of particularly the larger mammals like elephants, gibbons and tigers and decline in the natural vegetation cover which is also primarily affecting the butterfly community within the reserve. Habitat shrinkage is also one of the major causes for regular elephant depredation in the adjoining fringe villages.

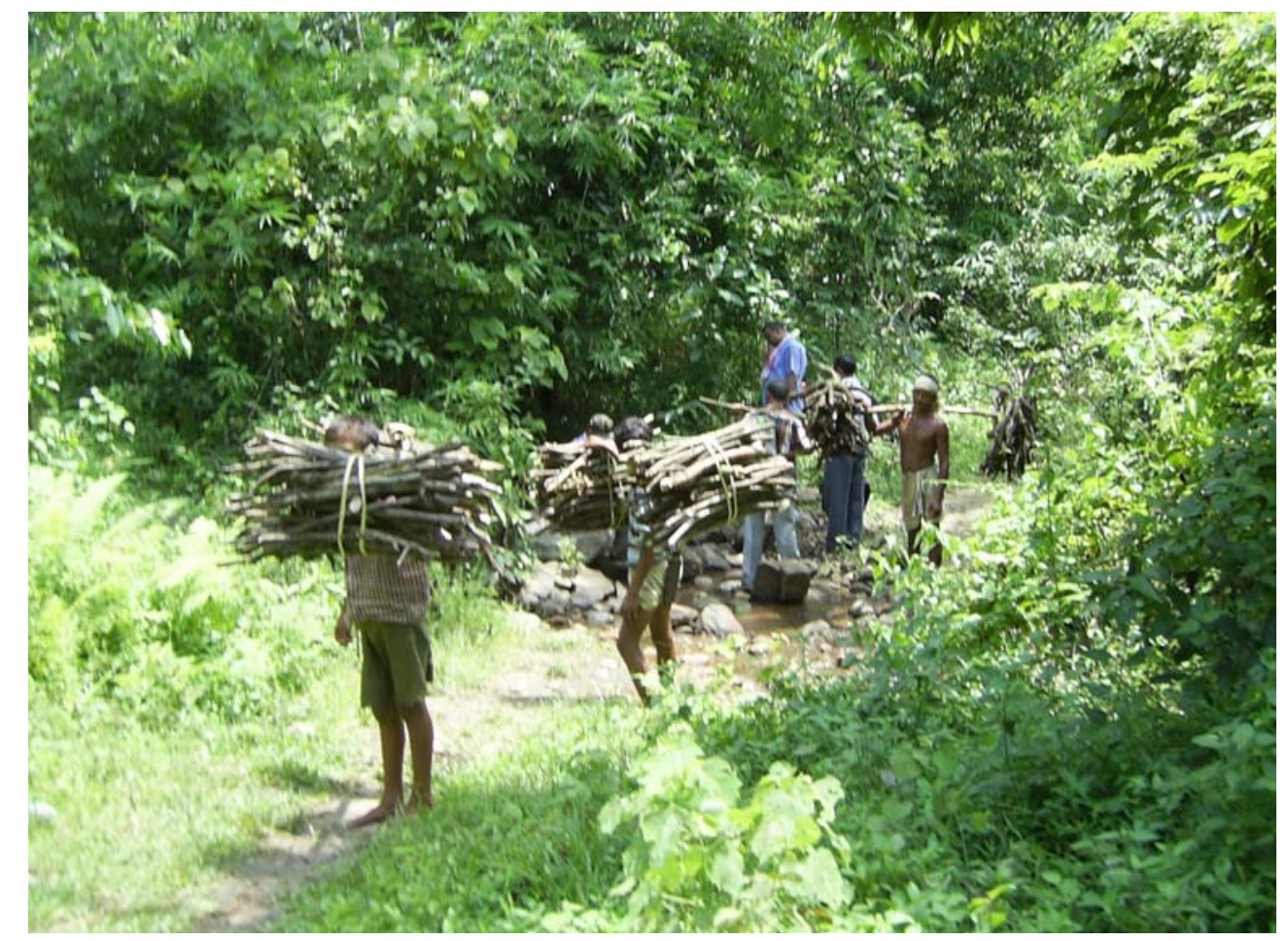

\section{Photo 2 : Small-wood collection by the local villagers from the fringe areas is a common problem within the forest reserve}

The Forest Department of Assam has recently introduced the Joint Forest Management plan (Assam Forest Policy,2004;WWF India, 2002) and Rani-Garbhanga Reserve forest also comes under this plan. The plan mainly aims at supporting the livelihoods of the forest fringe communities through improved natural resource management with community participation and simultaneuosly protecting the forests from degradation. The prime targets of this plan are Sal regeneration, raising plantations of more valuable 
indigenous species, soil and water conservation, improvement of habitat for the Asiatic elephants, leopards, barking deers and preserve the gene pool by adopting a system causing least disturbance to these forests. The other management strategies include bringing degraded areas close to habitation or encroachment under forest cover and raising plantations with people's participation, meet the household requirements of the participants and economic upliftment of the participants by way of sharing the yield with the Government. The bamboo areas of the Reserve forest have also been brought under the plan to meet the requirements of some of the nearby Paper mills of the state of Assam.

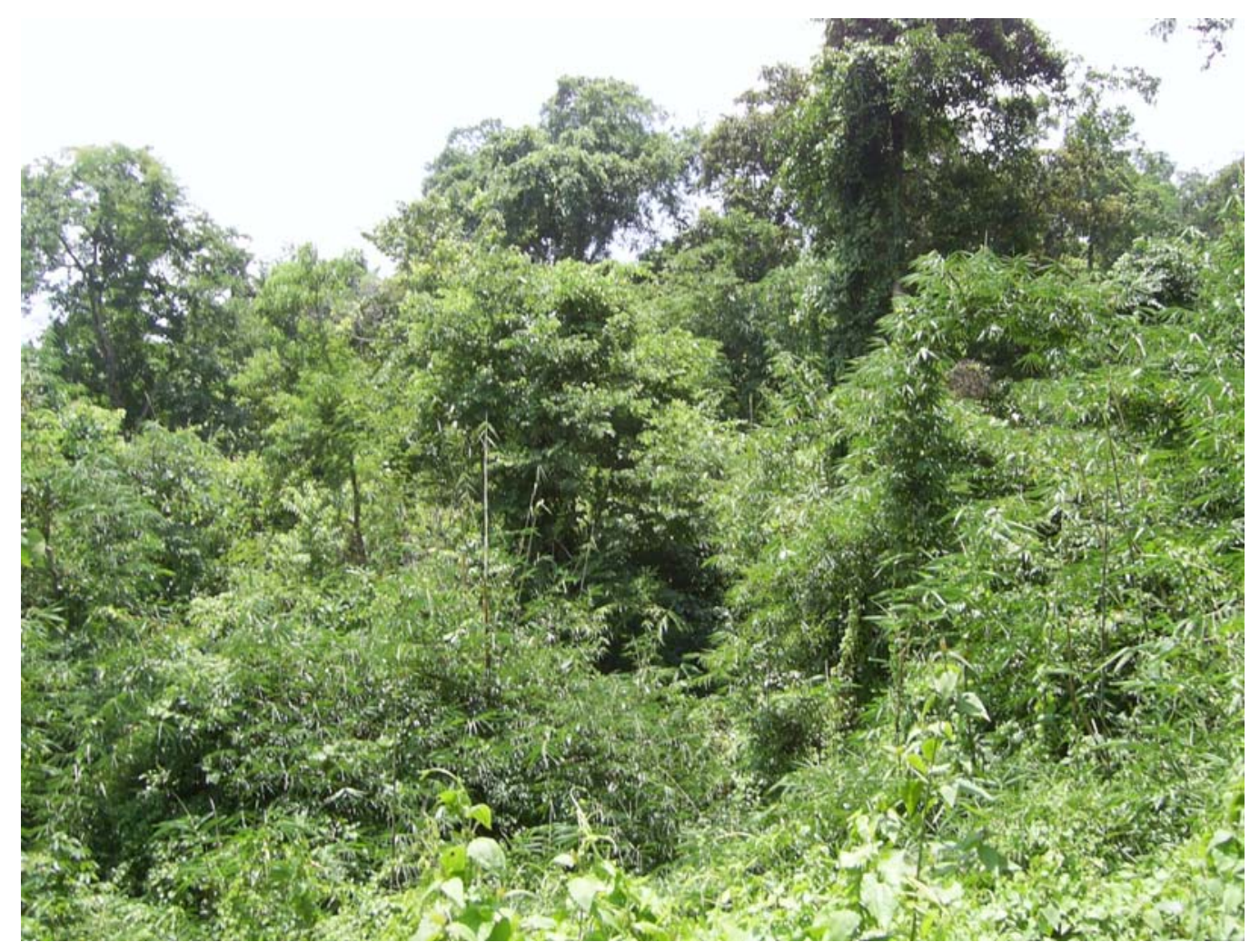

Photo 3 : A typical 'bamboo forest' habitat type within the forest reserve Bamboo (Dendrocalamus hamiltonii) 


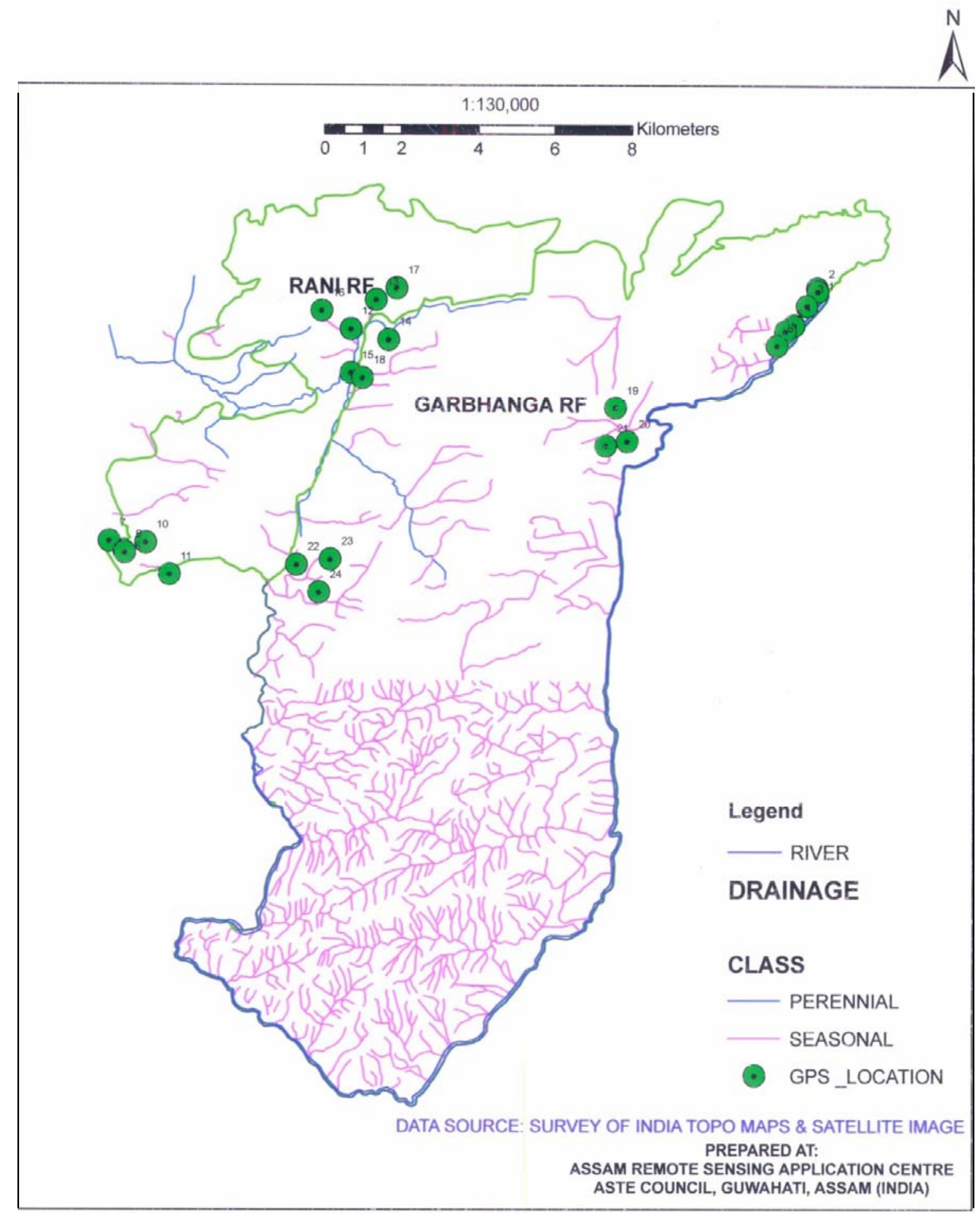

Figure 3.5: Map of Rani-Garbhanga Landscape showing the drainage pattern and butterfly collection points within the study area with superimposed GPS points indicating the geographical position of the sampling locations during the two-year study period from 2003-2004. 


\subsection{Butterfly-Plant interaction:}

There is a direct ecological relationship between butterflies and plants and this phenetic relationship may make floral diversity an important precondition for butterfly diversity (Ehrlich, 1958). Butterflies and plants are predicted to show congruent patterns in species diversity due to interactions involving herbivory and pollination (Opler \& Krizek, 1984; Scoble, 1992) and their history of close evolutionary relationships (Ehrlich \& Raven, 1964). Plants are essential resource for butterfly survival, providing nutrients for larvae and adults. Larvae are intimately associated with their host-plants (Gilbert \& Singer, 1975; Chew, 1980; Porter, 1992; Ravenscroft, 1994). Most butterflies have strong larval food preferences. Some species feed on only one plant species while others feed on a few closely related plant species and in some cases large taxonomic groups of butterflies feed almost exclusively on a single plant family. The larvae of some butterfly species feed on a broad range of plants from unrelated families. Again the populations of the same butterfly species in different locations may use different larval food-plants (Dethier \& Fuller, 1961; Singer et al., 1971; Breedlove \& Ehrlich, 1968). As the larvae remain upon the host plant throughout most of their existence, the food-plant is likely to be the key factor in the niche of most butterfly species since to a large extent it is also the shelter, substrate, or habitat upon which allelo-chemical co-evolution (Ehrlich \& Raven, 1965; Whittaker \& Feeny, 1971) of the entire 'component community' takes place (Root, 1973). Likewise, adults require some plant species as nectar sources (Murphy, 1983; Shreeve, 1992; Holl, 1995; Loertscher et al., 1995). This dependence on plants makes butterflies highly habitat specific. The vegetation can also play an important role for butterfly survival, offering particular structural elements for sun basking or mating and determining certain suitable microclimates (Dover et al., 1997). Furthermore, the vegetation responds to a large range of environmental and historical factors like altitude, temperature, precipitation, topography, land use, soil type, microclimates (Ellenberg et al., 1992). Therefore vegetation is the main physical interface between butterflies and their environment and a strong relationship between butterfly species and plant communities can be expected (Dufrene et al., 2003). Studies conducted on both wide-ranging and sedentary butterflies have shown strong associations between the distribution of butterflies and of oviposition plants and nectar sources (Gilbert, 1971; Ehrlich \& Gilbert, 1973).

Butterflies are important pollinators that help in plant propagation and therefore a positive correlation between butterfly and plant diversity can be expected (Sharp 
et al., 1974). Many species of butterflies are restricted to unique ecological conditions, very often being sensitive to thermal conditions and are known to show fast responses to climate fluctuations. This makes them valuable indicators of ecosystem quality and change. Therefore butterflies can be used as suitable 'Bioindicators' in environment monitoring. Some recent studies have shown the changes in Lepidoptera communities caused by various types of disturbance in tropical rainforests (Bowman et al., 1990; Leps \& Spitzer, 1990; Thomas, 1991; Holloway et al., 1992; Spitzer et al., 1993; Kremen, 1994; Kremen et al., 1994). Plant diversity is known to contribute to habitat complexity for butterflies and other insects by providing microclimate variation (Strong et al., 1984). The knowledge of butterfly-plant interaction is also an important tool for their conservation and management. Therefore a study on the climate, vegetation and soil profile of the study area is important in determining the suitability of the habitat for the butterflies.

\subsection{Climate, Vegetation and Soil:}

\subsubsection{Climate conditions in the study area :}

Rani-Garbhanga Reserve forest experiences a tropical monsoon type of climate. There are three seasons- the Pre-Monsoon period from February to April, Monsoon (Rainy) period from May to October and the Post-Monsoon period from November to January. The Post-Monsoon and the Pre-Monsoon periods are described as the Dry Season while the Monsoon period is described as the Wet Season. The monthly mean maximum temperature, rainfall and humidity data for the years 1996-2000 indicates the typical tropical monsoon type of climate in the study area characterised by $\geq 250 \mathrm{~mm}$ rainfall during the peak monsoon period (Wet season) from May to August with no significant variations in the mean maximum temperatures during the wet and dry periods (See Fig. 3.6 : Appendix 3: 3.1). 


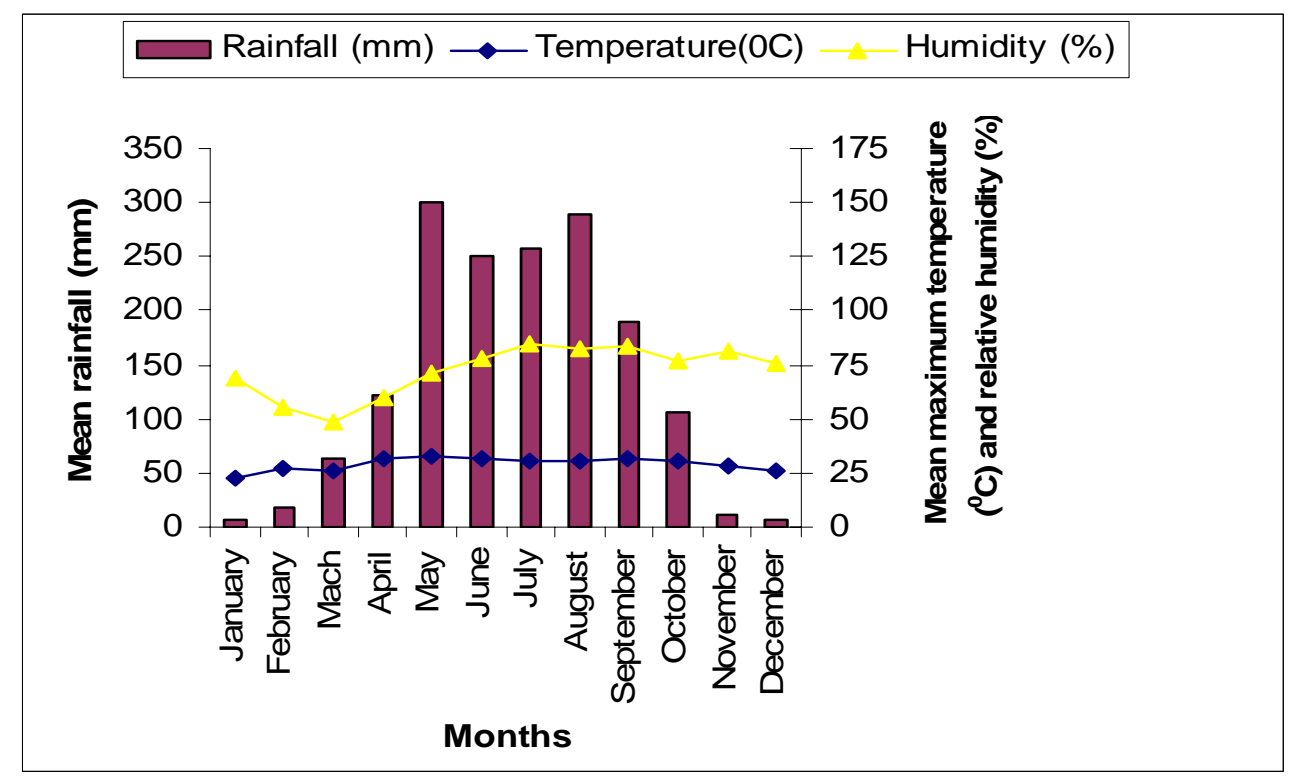

Figure 3.6: Ombrothermic diagram $(\mathrm{P}=2 \mathrm{~T})$ for the study area during January to December (mean of years 1996-2000)

The monsoon period is the longest and is characterised by frequent thunderstorms and approximately $90 \%$ of the annual precipitation occurs during this wet season. Rains are received by the Southwest as well as the Northeast monsoons, but maximum rainfall is received from the Southwest monsoon (May-October). During the Post-monsoon period (Dry season) which normally covers two ecologically dry periods in a year, rainfall is received from the Northeast monsoon and this is about $7 \%$ distributed over an average of 16 days.

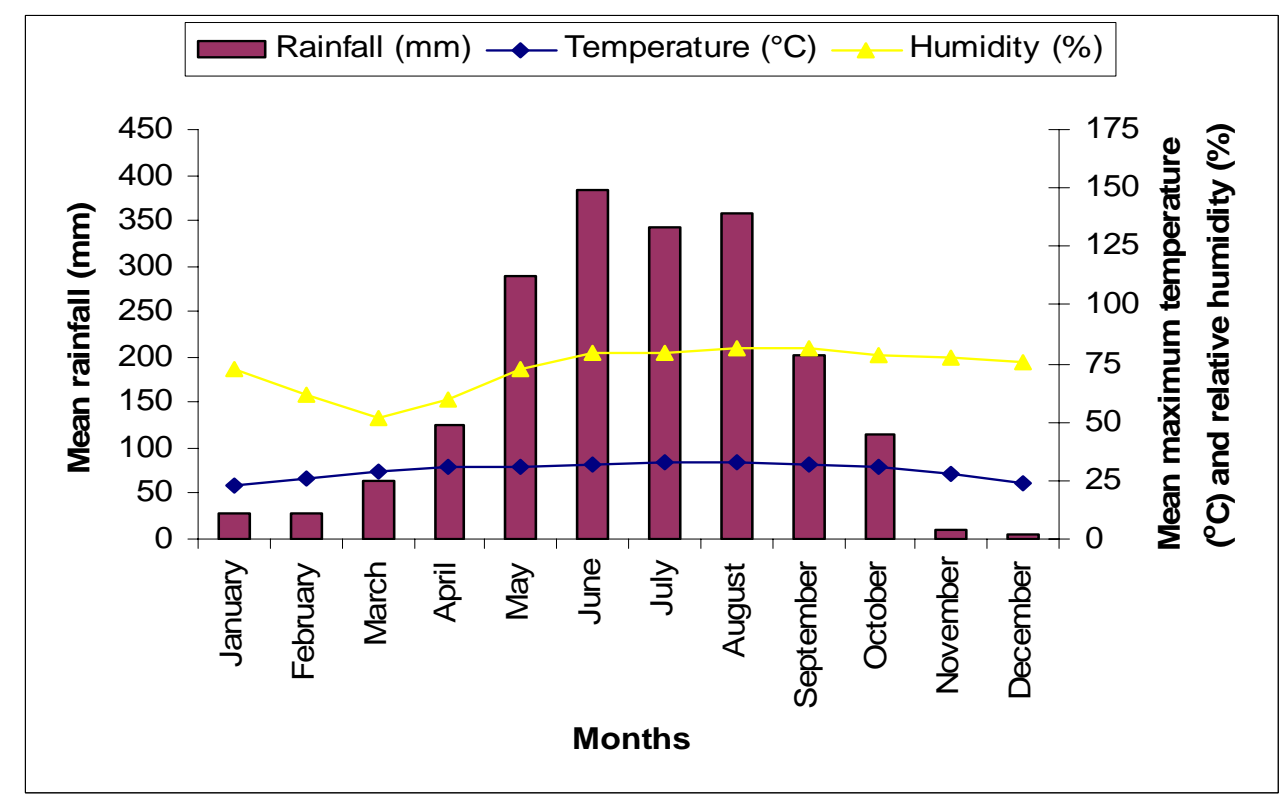

Figure 3.7 : Ombrothermic diagram $(\mathrm{P}=2 \mathrm{~T})$ for the study area during January to December (mean of years 2001-2005) 
A comparison of the monthly mean rainfall, temperature and humidity data for the period of 1996-2000 (Fig. 3.6) with that of the period 2001-2005 (Fig. 3.7) shows that the recorded mean monthly rainfall for 2001-2005 during the peak monsoon period (May to August) was $\geq 300 \mathrm{~mm}$ and this did not vary greatly from that of 1996-2000 during the same peak monsoon period. However there were no significant variations in the mean maximum temperature and humidity between the two periods (Appendix 3: $3.1 \& 3.2$ ). All data pertaining to the climate conditions in the study area were obtained from the Regional Meteorological Research Station, Guwahati, Assam, India.

\subsubsection{Vegetation and Soil}

The general vegetation of the study area is described as 'Mixed Moist Deciduous' type and there are five forest types primarily classified within the Reserve according to the 'Revised Forest Type' classification of Champion \& Seth (1968) and the description of the forest types within the Reserve are as per the records of the Department of Forests of Assam, 1990.

a) The Eastern Hill Sal forests: These forests mainly occur in the hilly areas of the Reserve. Pure patches and groups of Sal (Shorea robusta) occur in ridges and spurs but these pure patches are intersperesed by mixed deciduous forests in the middle slopes and valleys and in damp patches like the banks of the perennial streams by evergreen forets. Scima wallichii is the common associate of Sal (Shorea robusta) and the other dominant associates in the top canopy are Shorea assamica (endemic species), Lagerstoemia parviflora, Lannea corromandelica, Vitex pedicularis, Castanopsis indica, and Dipterocarpus macrocarpus.

Middle storey is composed of Holarrhena antidysenterica, Tricalysia singularis, Oroxylum indicum, Salix tertrasperma, Malletus albus, Gmelina arborea, Careya arborea, Semicarpius anacardium. Clumps of stunted bamboo (Dendrocalamus hamiltonii) occur on the ridges and slopes.

The ground cover varies considerably according to the canopy opening. In fairly open canopy and near the habitations, Imperata cylindrica is the common species. The most common shade tolerant species in locations having closed canopy is Sau grass (Microstegium ciliatum). Other species include Eupatorium odoratum, Carex stroementitia, Thysanllaena maxima. 
Some of the common climbers found in this protected reserve are Dalbergia tamarindifolia, Dalbergia remosa, Ficus scandens, Caesalpinia crista, Bauhinia anguinea, Jasminum coaractatum, Mucuna prurita, Clematis cadmia, Paederia scandens, and Stenochleana palustris.

This forest type covers an area of 3187 hectares in Garbhanga range and 1769 hectares in Rani range.

b) Moist Mixed Deciduous forests: In this forest type the principal species forming the top canopy are Scima wallichii, Vitex peduncularis, Tetrameles nudiflora, Sterospermum personatum, Lagerstoemia parviflora, Sterculia vilosa, Syzygium cumini, Gmelina arborea, Spondias mangifera, Diospyros variegata, Bridelia retusa, Machilus bombycina, Albizzia lebbeck, A.chinensis, Ficus hispida, Sapium baccatum.

In areas, which were subjected to heavy burning in the past, the middle storey is not well defined. However at lower elevations in the valleys, the middle storey is predominanatly occupied by the bamboos (Dendrocalamus hamiltonii). In the hill slopes under close canopy, Sau grass (Microstegium ciliatum) occurs as ground cover. In the lower slopes Coffea bengalensis occurs under close canopy.

Along the lower slopes of the foothills, thatch grass (Imperata cylindrica) predominates as ground cover in the open patches. Other common species forming the ground cover are Eupatorium odoratum, Holmskioldia sanguinea, Phyllanthus simplex and Lagerstoemia parviflora. Under bamboos there is practically no ground cover.

Occurrence of climbers is higher in this forest type and some of the dominant species are Butea parviflora, Millettia auriculata, Smylex macrophylla, Acacia pinnata, Dalbergia remosa, and Aristolochia indica, A.tagala.

These forests cover an area of 10,664 hectares in Garbhanga range and 1396 hectares in Rani range.

c) Evergreen patches: This type of vegetation is not very common and occurs only in patches, mainly in the hill slopes and shady moist pockets along the banks of perennial streams. Such patches are mostly situated in locations far away from habitations and not subjected to any kind of human interference like shifting cultivation, grazing, forest fire and stone quarrying activities. According to Champion \& Seth (1968) such type of vegetation is classified under Assam valley Tropical Semi-evergreen forest, 2B/C1. Only small patches of such forests now remain in Assam and are found along the Indo-Bhutan border and along 
the border of Assam and Meghalaya. They are mostly confined to protected areas as like here in Rani-Garbhanga. The typical evergreen tree species are Syzygium, Cinnamomum, Artocarpus and Magnolia sp. while the deciduous species include Terminalia myriocarpa, T.citrina, T.tomentosa, Tetrameles sp. and Stereospermum sp. These canopy trees are 20$30 \mathrm{~m}$ high. However in the study area the climax formation in such patches was mostly represented by Garcinia species, Dysoxylum sp., Castanopsis sp., Artocarpus chaplasa, Echinocarpus sp., and Ficus species. The middle storey is occupied by the bamboos (Dendrocalamus hamiltonii). The common species forming the ground cover are Alpinia speciosa, Phalogacanthus sp., Sau grass (Microstergium ciliatum), Pollinia ciliata, occasional canes and ferns. Climbers are not very abundant in this type of patches. It has an area of only 13 hectares in Rani range.

d) Secondary Moist Bamboo Brakes: Large tracts of bamboo brakes occur along with the Moist Mixed Decidous type in the higher elevations. They occur in great profusion in damp locations especially along the perennial and seasonal streams. These brakes have been found to extend into the evergreen patches in the hill slopes. The principal species of bamboo in these brakes is Dendrocalamus hamiltonii. The growth along the hilly streams is so gregarious that it almost forms a continuous belt of bamboo and it is difficult to distinguish one clump from the other. It is seen lately that the bamboos also occur in the higher elevations subjected to intensive 'jhum' (Shifting cultivation).

e) Secondary Euphorbiaceous Scrub: The extent of area under this type is very limited and occurs in the abandoned areas of 'Jhum' (Shifting cultivation) which have been left to the mercy of nature by the farmers after raising 2-3 crops continuously. This type is more common in the Garbhanga range and particularly in the southern part of the range. The pioneer species is Macaranga denticulata to be succeeded by Trema orientalis, Albizzia chinensis, and Callicarpa arborea. The undergrowth is composed of some dominant species like Solanum khasiana, Mimosa himalayana, Abroma augusta.

It covers an area of 1354 hectares in Garbhanga range while that in Rani range is 312.48 hectares.

Forest fires occur almost every year in all the accessible compartments of the Reserve. Söme of these are natural fires associated with the activities of the 'shifting cultivators' and others are associated with the dry climatic conditions particularly during the months of March and April. However the technique of 'Controlled burning' where followed meticulously by the forest authorities has been found to have a positive effect on 
propagation and advanced growth. It is also advantageous for controlling the understorey overgrowth, which could otherwise lead to disastrous wildfires (Roy, 2003).

Another remarkable feature is the climber infestation, which is heavy in the Moist Mixed Deciduous forests and moderate in the Sal areas of the Reserve. Climbers cause considerable damage in the form of producing weak and forked trees by strangling the crowns and reducing their usefulness as mother trees as also reducing the amount of foliage. During Pre-monsoon and Monsoon periods, damage in the form of high winds bringing down trees heavily infested by inter-twining climbers is very common. Sporadic instances of Ficus scandens (woody climber) strangling and killing trees are found. There are incidents of Sal trees being infested by the fungus Polyporus shorea resulting occasionally in the death of the trees. Incidences of defoliator damage are also to be found but mainly in the dry season. Grazing by domestic animals from the forest villages is very common within the plain areas of the reserve, as all other grazing fields around the Reserve have been opened up for cultivation. The heavily grazed locations have been found to be devoid of regeneration and undergrowth. Legally limited grazing is permitted in the buffer zone. There are few records of wild and domestic elephants damaging standing trees both in the forest and in settlements. Monkeys are also known to cause a certain amount of damage by breaking the inflorescences of Sal trees and pulling up young seedlings. Illegal felling of trees for meeting the domestic needs of the forest villagers is however negligible compared to the illegal logging practices by the timber traders which is posing a more serious threat to the declining forest cover. Practically there is no proper demarcation of the reserve forest boundary and as the reserve has an inter-state boundary coupled with a very hilly terrain from the Assam side, it becomes even more difficult for the forest guards to tackle unscrupulous logging activites. Due to the advantageous location of this reserve to Guwahati city there is a continuous widened demand-supply gap of timber. The $36 \mathrm{kms}$ motorable 'Fair-weather' road maintained by the Forest department is working more to the advantage of these timber traders. Moreover there is also a $45 \mathrm{~km}$ walking forest path running parallel to the perennial stream in Garbhanga range, which is extensively used by the local tribals from both Assam and Meghalaya.

The GIS data on the land-cover classes of 1998 with that of 2002 has indicated a marked increase in the area of forest villages and mixed built-up land engaged in commercial cultivation as well as the cropland inside the forest. The area under Kharif (Summer) cultivation has declined. The total area under encroachment in Garbhanga range is 410 hectares while in Rani range it is 245 hectares. However the most disturbing trend is 
the increase in the areas of shifting cultivation in particularly the southern part of the Reserve adjoining Meghalaya over a period of 5 years.

The geological formation of Rani-Garbhanga Landscape excepting the recent soil and alluvium belong to the Archean gneisses complex. The oldest formation is composed of gneissic and schist which are extensively intruded by granites. Beds of conglomerates are frequently found at the foot of the hills. The study area is geologically situated on an outlying area of the Shillong plateau. The principal rocks of this outlying portion are acid and basic gneisses which have been metamorphosed by intruded igneous rocks. The soil type is mainly alluvial although in the higher elevations it is red laterite type.

\subsection{Forest Management and Biomonitoring:}

The Government of India issued guidelines in June 1990 and adopted the 'Joint Forest Management' (JFM) under the 'National Afforestation Programme' for conservation of forests with clearly identified duties and functions for ensuring protection of forests. The Government of Assam adopted the 'Assam Forest Policy', 2004 which emphasizes the JFMs to graduate to 'Community Forest Management' aiming at sustainable forest management. The main objective is to 'support the livelihoods of the forest fringe communities through improved natural resource management with community participation'.

Under the guidelines of the National Afforestation Policy (1990), Rani and Garbhanga Reserved Forests (R.F) are managed separately under the current Working Plan (2002-2003 to 2011-2012) prescriptions for different Working Circles (W.C) instituted such as - Sal Regeneration Working Circle, Miscellaneous Plantation Working Circle, Bamboo Overlapping Working Circle, Biodiversity Working Circle, Watershed management and Soil Conservation Working Circle and JFM (Joint Forest Management) Working Circle.

3.4.1. Sal Regeneration: Sal is one of the few naturally durable timbers in India and is the principal marketable product of this Reserve forest. As this Reserve is adjacent to Guwahati city, there is a continuous widened demand supply of timber and the adverse effect is felt upon this reserve. The main objective of this management is to:

- Arrest depletion in growing stock of Sal by regulating the yield and boost natural regeneration of Sal.

- Improve the depleted growing stock of Sal under intensive system of management with the aim of attaining a normal forest in the future. 
- Conserve and improve the existing growing stock of Sal in areas other than those marked for regeneration operation.

- Reclaim all Sal areas, which had been lost to invading bamboos and other miscellaneous species due to human activities.

3.4.2. Miscellaneous Plantation: Human interferences in the form of illegal felling of trees by the adjacent forest villagers, encroachment by migrant population from the adjoining hilly regions of Meghalaya leading to springing up of pockets of habitations inside the reserve forest, 'jhum' or shifting cultivation, large scale deforestation in the neighbouring forests of Meghalaya and the raising of pure teak plantations in the past have disturbed the ecosystem and caused shrinkage in the habitats of large animals. The main management objectives under this circle are:

- Conservation and protection of existing forest cover

- Rehabilitate the depleted forest cover by raising plantations of valuable indigenous species without disturbing the forest ecosystem.

- Replacement of existing teak plantations by indigenous species in a phased manner and thus remove all the demerits of monoculture.

3.4.3. Bamboo Overlapping: This working circle comprises of the bamboo bearing areas under the other circles. There is wanton destruction of the bamboo cover by the forest villagers and encroachers to meet their basic needs like building material for their houses and fodder for cattle. A substantial supply also goes to some of the local paper-mills. However bamboos are essential to the forest ecosystem especially in hilly forests as like in the study area where they not only protect the hilly slopes from soil erosion but are the ideal habitats for many endangered species including birds and also food for elephants and Hoolock gibbons. Bamboo is an integral part of the cultural, social and economic traditions of both urban and rural Assam and particularly the poverty-stricken ethnic tribals in the forest villages who are dependant upon many forest resources for their livelihood including bamboos. The major objects of management in this circle include:

- Maintain a sustained yield and regular supply of bamboo to the paper mills of the state. Only areas where there are continuos stretches of bamboo have been considered for commercial exploitation. 
- Maintain ecological balance by prevention of unlimited cutting and removal of bamboos.

- Prevent erosion and stabilise watershed areas of the reserve covered by bamboo forests.

- Meet the demands of the local people for construction of their dwellings, agricultural implements, fencing, cottage industries etc. A sustainable use will be maintained through encouragement of 'cultivation and extraction of bamboo' by scientific management of forest based bamboo resources, systematic and block plantation of commercially significant species and improved harvesting and post harvest practices.

- Enhance employment and income generating opportunities using bamboo and cane as the prime resource

3.4.4. Biodiversity Conservation: The closed canopy as well as the open forests of this reserve is included in this plan and the main objectives are:

- Protect the forests and allow nature to take its own course in rehabilitating the forests by the re-introduction of some indigenous plant species.

- Preserve and improve the habitat of the Asiatic elephant, leopards, barking deers and Hoolock gibbon.

- Study and record the degree of success achieved in regeneration and succession of various species.

Census of animals - Census of elephants and tigers were carried out in 1993 and 1997 and the records showed the elephant figures at 403 and 116 and tigers at 5 and 3 respectively. Census of leopards in 2000 showed presence of 10 males, 11 females and 4 cubs inside the reserve forest and 1 male, 1 female and 1 cub outside the reserve forest..

3.4.5. Watershed management and Soil Conservation: This Reserve forest forms only a small part of the catchment area of the rivers and streams flowing through and around this region. The sources of most of these rivers and streams are in Meghalaya. Shifting cultivation (Jhum) which is seen to be more widely prevalent in the southern part of Garbhanga range bordering the hills of Meghalaya has its own damaging effects pertaining to soil erosion in the hilly areas of the reserve. However a positive effect is that due to favourable climatic conditions the abandoned 'Jhum' areas quickly regenerate resulting in 
less quantity of soil run-offs. A more serious threat is posed by some of the teak plantations in the hilly areas of the reserve, which have very thin undergrowth, and this has resulted in much heavier erosion as compared to the 'Jhum' areas. Following heavy rainfall during the monsoon period, high degree of siltation has occurred in the adjoining low-lying swamps and depressions as well as in the 'Deepor Beel', and the elevation of the riverbeds. This has increased the impact of flash floods in urban settlements as like in Guwahati city. Therefore the major objective of this plan is to reduce disturbance by way of restricting felling and secondly is the thinning of the congested teak plantations in order to encourage good undergrowth.

\subsubsection{Joint Forest Management (JFM) / Peoples' Participatory Plantation Program:}

This plan has been constituted under the National Afforestation Program, 1990 (Conservation with communities in the biodiversity hotspots of India, WWF India, 2002) with a view to execute and materialise the policy of the government by way of active participation and involvement of local people for regeneration, maintenance and protection of forests owned by the state but appropriated by the local communities. The working area covers both peripheral degraded as well as some of the encroached areas of the Reserve. The economic prosperity of the surrounding population is intimately associated with the proper management of this Reserve. There are almost 8 different ethnic tribes living in the fringe villages and although their agricultural customs vary to a certain extent, all of them cultivate paddy in the low-lying land adjoining the reserve. They raise only one crop in a year from June-July to December. The cattle maintained by these villagers are entirely dependant on the reserve for their grazing till paddy is harvested. The basic needs of the villagers like firewood, thatch, bamboo, and cane are met from this reserve. So to stop destruction of the forests and decrease encroachment, this plan intends to create a buffer with peoples' participation. The local people are therefore involved in converting the encroached and degraded areas into productive land so as to meet their basic needs on sustained basis. Their involvement in regeneration and other silvicultural operations is being implemented and the government in return provides a subsidiary income to the local villagers in the form of wages. However most of these locals are poverty stricken and do not have the patience to wait for a long time to get their due share of earnings from raising and protecting the plantations for which they had worked hard. Therefore such species have been chosen so that the villagers minimum rights can be met right from the 5 th year of plantation in a sustained manner. So by generating a sustainable interface between the 
Forest department and the local community it can be a possible way through which the interests of the people and long-term sustainability are harmonised in a mutually supporting manner.

As a part of the biomonitoring program to study the effects of forest management, population survey of larger herbivores like elephants and gibbons have been carried out on permanent line transects to study different habitat utilization patterns and the current elephant population is 502 (Forest records, 2005). Although the reserve has been listed as a disturbed area, it has still good conservation potential especially with respect to a good plant diversity including medicinal plants, mammals and birds. There is no previous documentation on the butterfly fauna in this area, but a comprehensive inventory showing a checklist of the available species of butterflies in the reserve also highlights the potential of this protected area as a good "butterfly reserve". However the most significant feature about the management strategy for this reserve is its potential for being managed as a good natural "elephant corridor". The Deepor beel on the northern side of the reserve is the perennial water source for the elephants. Large herds also come down from the adjoining hills of the Meghalaya forests for drinking, bathing and eating the aquatic plants in the lake. Protection of the habitat will help to reduce the man- elephant conflict and at the same time envisage elephant conservation through local community involvement (Daniel et al., 1995). Elephants influence forests at two main levels - as opportunistic frugivores, by directly effecting the dispersal and regeneration of certain plant species; and by trampling, debarking and disturbing the forest (Hoft \& Hoft, 1995; Johnstone, 1967; Laws et al., 1970, 1975; Sheil 1996; Struhsaker et al., 1996; Wing \& Buss 1970). In light to moderately logged forests, the elephants were found to use the forest gaps more than the closed canopy areas for foraging and the selective browsing of young trees by elephants affected the rates of forest regeneration, growth form and species composition (Struhsaker et al., 1996). Therefore the elephants can be taken as a keystone species for the effective conservation and management of this reserve. The WWF-India under its current elephant conservation project in Assam has also targeted Rani-Garbhanga Reserve for protection as an 'elephant reserve'. Several environmental organisations have also sent proposals to the state government for upgrading Rani-Garbhanga Landscape into an "urban wildlife sanctuary" as the proximity of this protected area to the capital city can also contribute towards the development of ecotourism. The division of International Conservation (US Fish and Wildlife Service, 2006) has also proposed for the strengthening of the conservation of Hoolock gibbon in Rani-Garbhanga Landscape, gather baseline information on the 
biodiversity of this sanctuary along with constructing one anti-poaching camp and designing a strategic conservation and management plan for the landscape. 
CHAPTER 4 : METHODS

CHAPTER 5 : RESULTS 


\section{CHAPTER 4 : METHODS}

\subsection{Study Sites}

A 50 ha study area covering five different sites or locations were selected for butterfly sampling and conducting field observations. All the five study sites were selected using satellite imagery. Sites S1, S2 and S3 were located in Garbhanga range, sites S4 and site S5 were within Rani range. The levels of disturbance in the five study sites were not quantified but were evaluated on a visual scale. The sites were partially to heavily disturbed areas with respect to human settlements, grazing, shifting cultivation, teak monoculture, earth-cutting, small wood collection by local villagers, illegal selective logging by timber smugglers and presence of stone-quarry as described in Table 4.1. However movement of people and small logging were observed to be the main disturbance parameters.

Table 4.1: Study sites in Rani-Garbhanga Reserve forest

\begin{tabular}{|c|c|c|c|c|c|}
\hline $\begin{array}{l}\text { Study site } \\
\text { in map }\end{array}$ & $\begin{array}{l}\text { Geographical } \\
\text { position }\end{array}$ & $\begin{array}{l}\text { Area in } \\
\text { hectares }\end{array}$ & $\begin{array}{l}\text { Habitat type and } \\
\text { landscape element }\end{array}$ & $\begin{array}{l}\text { Altitude } \\
\text { (metres) } \\
\text { above MSL }\end{array}$ & $\begin{array}{l}\text { Level and } \\
\text { type of } \\
\text { human } \\
\text { disturbance }\end{array}$ \\
\hline S1(Garbhanga) & $\begin{array}{l}26^{\circ} 05^{\prime} 26.71^{\prime \prime}- \\
91^{\circ} 46^{\prime} 39.01^{\prime \prime}\end{array}$ & 15 & $\begin{array}{l}\text { Mixed-moist deciduous } \\
\text { Secondary Sal } \\
\text { forest with good cover of } \\
\text { grasses }\end{array}$ & 102 & $\begin{array}{l}\text { Partially disturbed } \\
\text { Human settlement, } \\
\text { earth-cutting, small } \\
\text { wood collection }\end{array}$ \\
\hline S2 Garbhanga) & $\begin{array}{l}26^{\circ} 03^{\prime} 46.49^{\prime}- \\
91^{\circ} 43^{\prime} 41.56^{\prime \prime}\end{array}$ & 5 & $\begin{array}{l}\text { Mixed-moist deciduous } \\
\text { secondary forest with } \\
\text { intermittent tracts of } \\
\text { Bamboo brakes. Closed } \\
\text { canopy with trees }>20 \mathrm{~m} \text { in } \\
\text { height. Abundance of } \\
\text { climbers }\end{array}$ & 130 & $\begin{array}{l}\text { Partially disturbed } \\
\text { Stone-quarrying, } \\
\text { earth-cutting, } \\
\text { selective logging }\end{array}$ \\
\hline
\end{tabular}




\begin{tabular}{|c|c|c|c|c|c|}
\hline S3 (Garbhanga) & $\begin{array}{l}26^{\circ} 01^{\prime} 39.18^{\prime \prime}- \\
91^{\circ} 39^{\prime} 03.91 "\end{array}$ & 5 & $\begin{array}{l}\text { Secondary euphorbiaceous } \\
\text { scrub with grasses growing } \\
\text { upto } 10-15 \mathrm{~cm} \text { on the rocky } \\
\text { slopes and hills in the areas } \\
\text { near to the abandoned } \\
\text { patches of shifting } \\
\text { cultivation. }\end{array}$ & 170 & $\begin{array}{l}\text { Heavily disturbed } \\
\text { (Shifting } \\
\text { cultivation, illegal } \\
\text { logging }\end{array}$ \\
\hline S4 (Rani) & $\begin{array}{l}26^{\circ} 01^{\prime} 52.20^{\prime \prime}- \\
91^{\circ} 35^{\prime} 51.32 ”\end{array}$ & 10 & $\begin{array}{l}\text { Degraded secondary } \\
\text { deciduous forest edge with } \\
\text { teak plantation, Sal } \\
\text { regeneration, cropland, } \\
\text { household plantation, with } \\
\text { shrubs and grasses, } \\
\text { scrubland. }\end{array}$ & 100 & $\begin{array}{l}\text { Heavily disturbed } \\
\text { (Teak plantation, } \\
\text { selective logging, } \\
\text { grazing, road } \\
\text { construction, } \\
\text { human settlements }\end{array}$ \\
\hline S5 (Rani) & $\begin{array}{l}26^{\circ} 04^{\prime} 49.77^{\prime \prime}- \\
91^{\circ} 40^{\prime} 03.07^{\prime \prime}\end{array}$ & 15 & $\begin{array}{l}\text { Secondary mixed } \\
\text { deciduous forest near } \\
\text { human settlement }\end{array}$ & 60 & $\begin{array}{l}\text { Heavily disturbed } \\
\text { (Forest village, } \\
\text { selective logging, } \\
\text { intensive grazing) }\end{array}$ \\
\hline
\end{tabular}

Notes: The area measurement for each study site was calculated using the GPS data. The changing patterns of land-use and forest cover associated with disturbances can be observed in the GIS maps on Rani-Garbhanga Reserve Forest (see Figs. 4.1 \& 4.2, and Table 4.2).

\subsection{Satellite Image Preparation, Interpretation and Area Estimation}

Satellite remote sensing has played a key role in generating information about forest cover, vegetation type and land use changes (Houghton \& Woodwell, 1981; Botkin et al., 1984). Satellite data have also been used to quantify tropical deforestation and habitat fragmentation in the spatial context (Skole \& Tucker, 1993). Changes in shape and size of forest fragments can be assessed using satellite data and in a GIS environment. Remote sensing has also been applied in the present study. Survey of India topomaps on 1:50,000 scale was first used for preparation of the base maps.

Satellite images from IRS - 1C and 1D Linear Imaging Self-Scanner System (LISS II and III) sensor with ground resolution of $36.25 \mathrm{~m} \times 36.25 \mathrm{~m}$ were used for classification of 
vegetation cover. The image scale for the satellite images was 1:30,000 and geo-referencing of the master scene has been carried out on this scale using ancillary data and GPS locations.

Landcover classification was done within the study area using remotely sensed satellite imagery (IRS IC LISS III).

Visual interpretation technique was employed to deliniate different land-cover classes from the digital satellite data (False Colour Composite) under GIS environment (ARC GIS 9.1).

The land-cover classes were identified as per a standard classification system generated by the Department of Space, Government of India. The areas under different landcover classes were calculated from the map by the facilities with the GIS (which are presented in the Table 4.1).

Satellite images were also visually interpreted to show the details of the drainage pattern in the study area and two separate images have been prepared with one image having the GPS locations superimposed on the actual image (see Fig. 4.2).

The GPS data collected from the field in March 2003 were incorporated as "Point Information" (latitude and longitude) in a separate layer, which were superimposed onto the satellite imageries as well as land-cover maps. Based on actual field data collection on the swallowtail butterflies and vegetation, 24 points covering the 5 study sites within the study area are shown in the imagery maps. Comparative GPS data from 2 years - 1998 and 2002 was acquired to assess the change in forest cover and land-use patterns in line with the changing trends of disturbance (see Table 4.2).

Altogether three types of input maps - topomap showing the protected forest boundary and geographic location of the study area, drainage pattern map and vegetation/land-use cover map were prepared for further studies. The analysed version of the vegetation and land-use pattern of the protected reserve is presented in Table 4.2. 
Table 4.2: Land-use analysis of the study area in hectares (1998 and 2002)

\begin{tabular}{lll}
\hline Landscape type & \multicolumn{2}{l}{ Area in hectares } \\
& $\mathbf{1 9 9 8}$ & $\mathbf{2 0 0 2}$ \\
\hline Moist Deciduous forest & 21561.39 & 21230.4 (includes the river area \\
& & of 189.88) \\
Agriculture (Kharif/Summer crops) & 210.14 & 12.3 \\
Cropland (inside forest) & 30.00 & 39.12 \\
Marsh/Swampy area & 3.6 & 9.21 \\
Mixed built-up land (Residential, Planted vegetation & 54.5 & 72.5 \\
and commercial area) & & \\
Household plantation & 26.56 & 202.3 \\
Open forest & 1.36 & 33.46 \\
Scrub forest & 53.23 & 18.35 \\
Forest plantation & & 13.04 \\
*Land with scrub & & 41.82 \\
Shifting cultivation & 480.5 & 796.27 (Current) \\
Shifting (Abandoned) & & 691.71 \\
River & 189.88 & \\
Total & 22611.16 & 23160.48 \\
\hline
\end{tabular}

Notes: * Land outside the notified area as per the land-use classification norms. The interpretation for 1998 has been carried out visually from IRS LISS II data of 1998. Data source for 2002 are from IRS 1D LISS III FEBRUARY (2002). The above interpretation and preparation of the GIS images were done in the "Assam Remote Sensing Application Centre, Guwahati, Assam, India. 


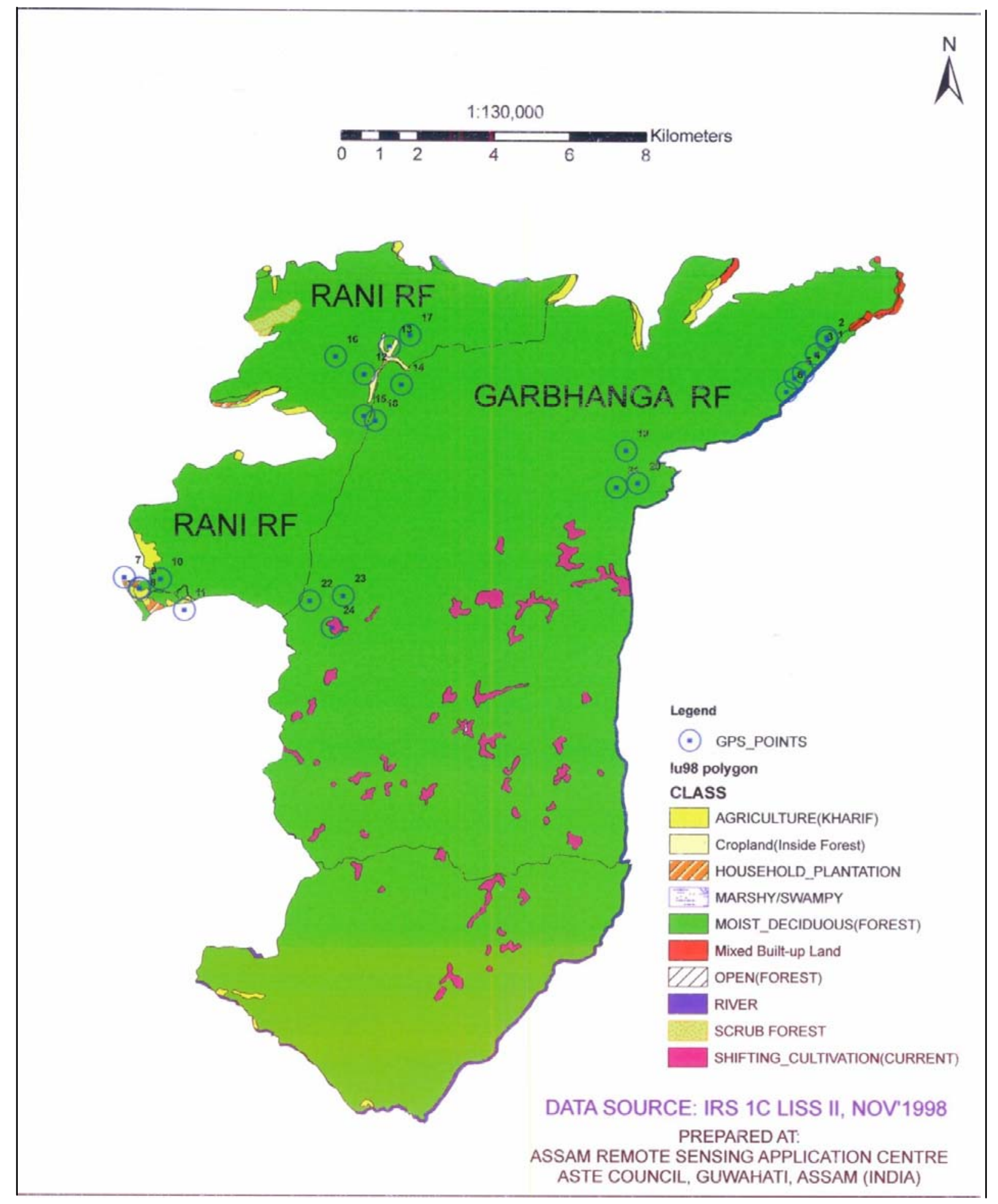

Figure 4.1: GIS image showing the land-use pattern in Rani-Garbhanga Reserve forest in 1998.. GPS points superimposed on the image show the data collection locations pertaining to butterfly identification, vegetation survey and general field observations during initial phase of research work in 2001-2002. 


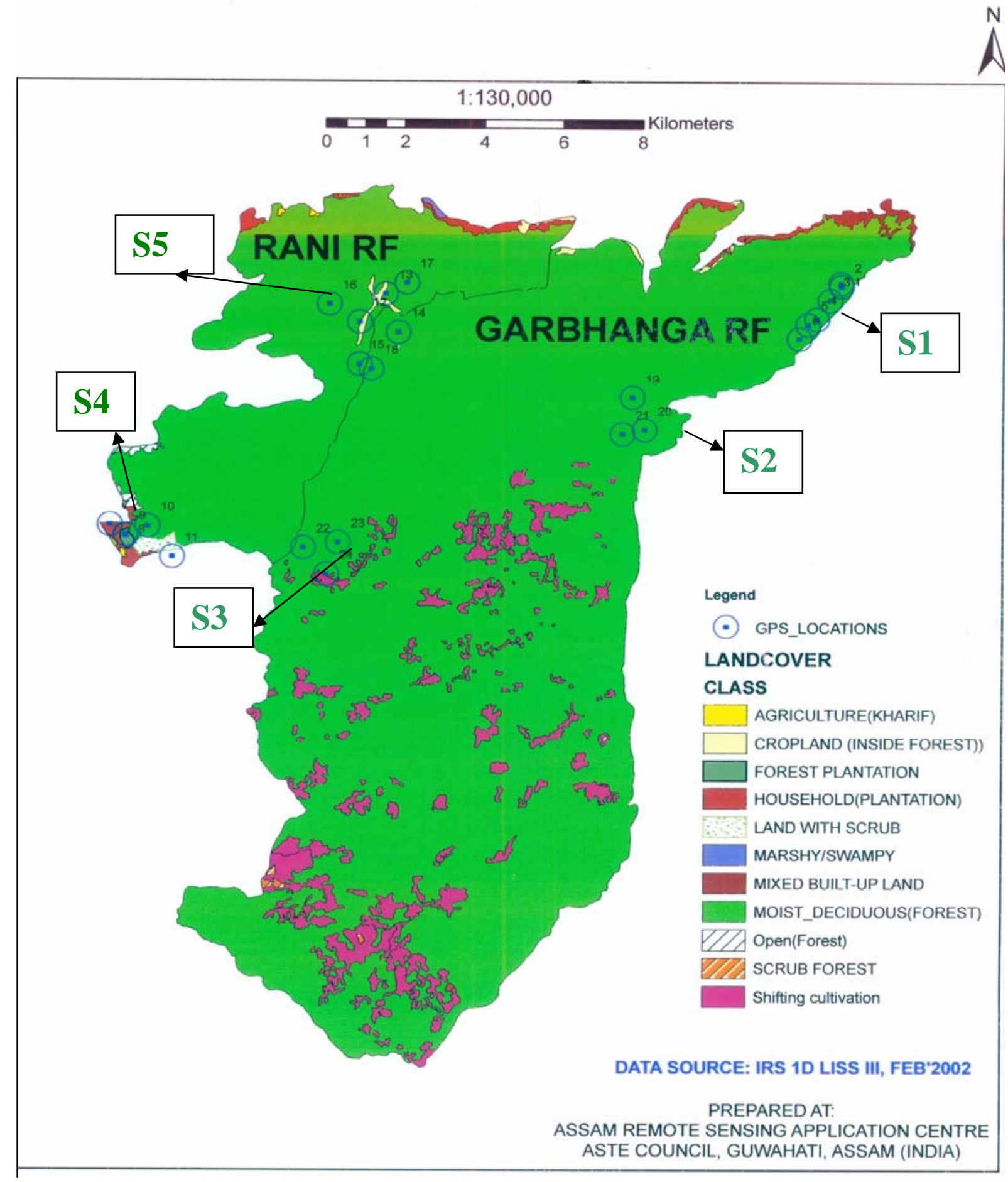

Figure 4.2: GIS image showing the change in the land-use pattern associated with human disturbances within the forest reserve over a period of four years (1998-2002). Study sites S1, S2, S3, S4 and S5 selected for initial phase of research study associated with vegetation and swallowtail butterfly (Papilionidae) identification and final phase of study for vegetation and butterfly sampling are shown in the map. GPS points superimposed on the 
image indicate the sampling points pertaining to the geographical position (latitude and longitude), altitude and general field observations.

The GIS images of the study area over a period of five years from 1998 to 2002 shows a good forest cover along with the different land-use patterns and also the changing trends of disturbance in the protected area primarily associated with deforestation due to human activities. The satellite data on 1:50,000 scale are found to some extent adequate for classification (with bare eyes) of degraded/scrub ( $<10 \%$ crown), open ( $10-40 \%$ crown) and dense/closed $(>40 \%$ crown). The satellite images indicated an increasing trend of disturbance and deforestation within the boundaries of the reserve primarily caused by illegal encroachment, shifting cultivation and other anthropogenic interferences in the form of the fringe forest villages and disturbances caused by one pocket of habitation (Garo tribal village) inside the reserve (see Figs. $4.1 \& 4.2)$ )

\subsection{Sampling}

\subsubsection{Sampling period}

The study was conducted for a period of two years from 2003 to 2004 covering 2 different seasons - Dry season (Post monsoon) from January to March and Wet season (Monsoon) from August to October. All surveys and samplings were limited to sunny days, under calm to light wind conditions when mean atmospheric temperature was about $32^{\circ} \mathrm{C}$, average humidity was about $80 \%$. The following hours of the day were selected for field survey and collection of butterflies: Early morning hours $-7.00 \mathrm{~h}$ to $13.00 \mathrm{~h}$ and late afternoon hours $-14.00 \mathrm{~h}$ to $17.00 \mathrm{~h}$.

\subsubsection{Sampling design}

In the study area, based on the observed levels of disturbance and the satellite images, we considered such factors like the degree of canopy closure, availability of sunlight on the forest floor and presence of both natural and man-made gaps, and accordingly each of the five study sites were demarcated into two zones for the sampling of butterflies - a) Scattered forest (SCF) and b) Closed forest (CF)

Line transect sampling method (Pollard 1977, 1984; Thomas 1983; Pollard \& Yates 1993) was followed in the five study sites for monitoring the swallowtail butterfly community and predicting the species diversity and distribution pattern of the Papilionids within the forest reserve. This method is now extensively used to survey and monitor butterfly populations and communities (Shreeve \& Mason, 1980; Erhardt, 1985; Warren et 
al., 1986; Yamamoto, 1988; Ishii, 1993; Pollard \& Yates, 1993) and has been applied in Vietnam in previous work (Spitzer et al., 1987; 1993; Vu \& Dang, 2002). As the protected reserve is divided into two ranges for management purposes, therefore butterfly sampling was done separately for the study sites of Rani and Garbhanga ranges (see Fig. 4.3). The records were based on visual sightings during the transect walk, active captures using nets, counts from 'mud-puddling' sites along the stream and areas of human habitation located along the transects. The sampling period covered the flying periods of most species. Some short visits were also made in other parts of the years for deriving complementary information.

Figure 4.3: Schematic plan of the sampling design for conducting butterfly sampling within the study area of the protected forest reserve during the two-year study period.

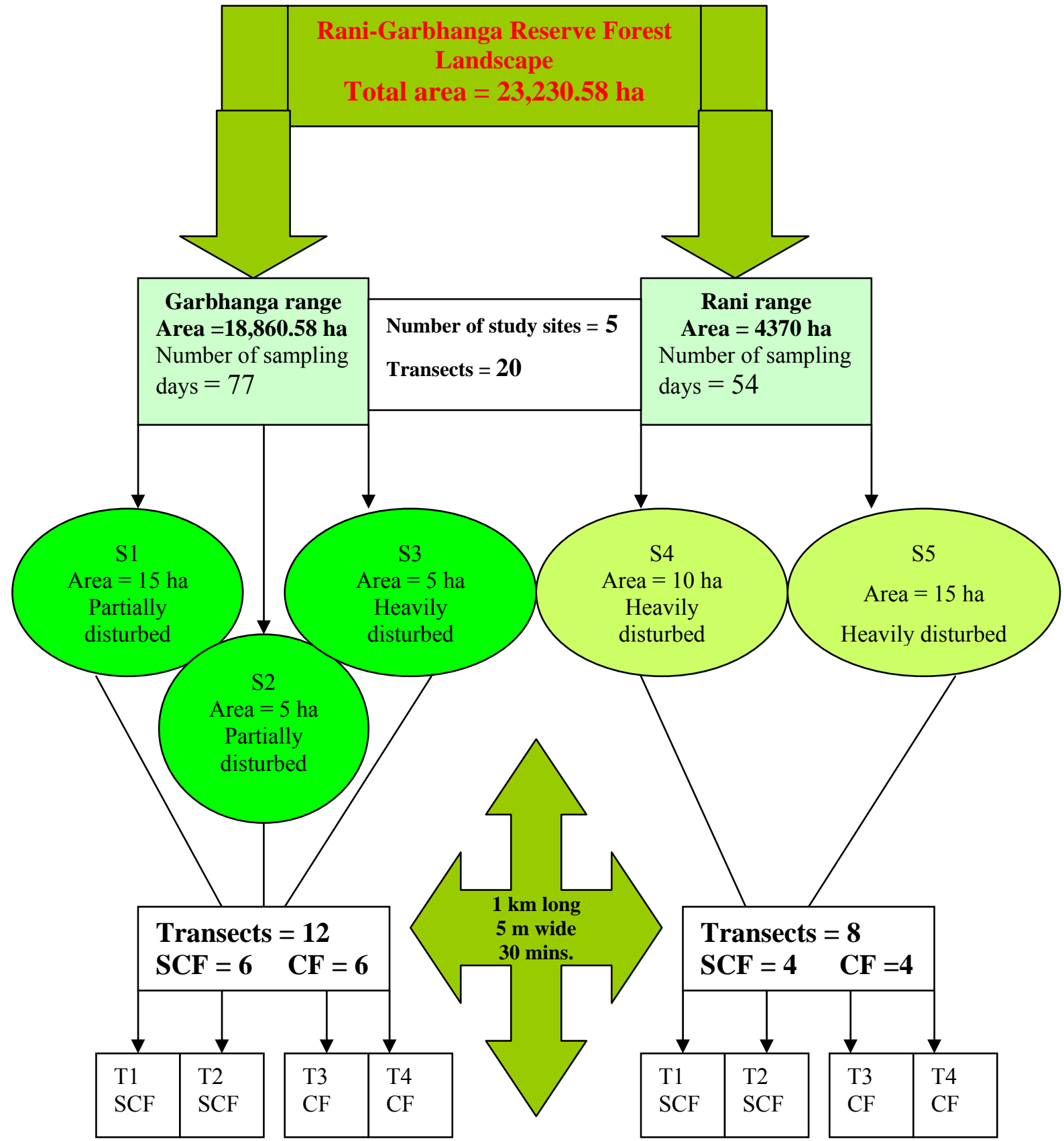




\subsubsection{Permanent Line Transects}

Prior to the actual data collection, we spent one year in the field (between July December of 2001 and 2002) constructing a reference collection (now housed at the Laboratory of Entomology and Environmental Biology, Gauhati University, Assam) and familiarising ourselves with the local swallowtail butterfly fauna. Permanent line transects were set up along existing forest paths within the study area (see Photos 4-6).

Each of the 20 permanent transects in both ranges were $1 \mathrm{~km}$ long and $5 \mathrm{~m}$ wide. Thus in each study site there were four transects where transects T1 and T2 represented scattered forest (SCF) and transects $\mathrm{T} 3$ and T4 represented closed forest (CF). The schematic plan of the sampling design for butterfly sampling within the two-year study period is shown in Fig. 4.3. Table 4.3 shows the distribution of the sampling activities in each of these study sites throughout the dry and wet seasons of the 2-year study period. In the results the study period has been marked as years 1 and 2 (2003-2004) and the multivariate analysis on Papilionidae abundance and distribution pattern and the analysis on Papilionid butterfly diversity is based on the pooled data collected from these permanent transects only.

Table 4.3: Sampling activities in the 50 ha study site of Rani-Garbhanga Reserve forest. Each day represents 12 transects from three study sites of Garbhanga range and 8 transects from two study sites of Rani range sampled for the dry and wet seasons of 2003 and 2004.

\begin{tabular}{|c|c|c|c|c|c|c|c|c|c|c|c|c|c|}
\hline Year & & 200 & & & & & & 20 & & & & & \\
\hline Season & & Dry & & & We & & & Dr & & & We & & \\
\hline Month & & $\mathbf{J}$ & $\mathbf{F}$ & $\mathbf{M}$ & $\mathbf{A}$ & $S$ & 0 & $\mathbf{J}$ & $\mathbf{F}$ & $\mathbf{M}$ & A & $\mathrm{S}$ & 0 \\
\hline Study & Days & 8 & 5 & 7 & 12 & 5 & 5 & 5 & 6 & 4 & 10 & 5 & 5 \\
\hline S2 & & 8 & 5 & 7 & 12 & 5 & 5 & 5 & 6 & 4 & 10 & 5 & 5 \\
\hline sites & & 8 & 5 & 7 & 12 & 5 & 5 & 5 & 6 & 4 & 10 & 5 & 5 \\
\hline S4 & & 5 & 3 & 5 & 7 & 4 & 4 & 4 & 6 & 4 & 5 & 3 & 4 \\
\hline S5 & & 5 & 3 & 5 & 7 & 4 & 4 & 4 & 6 & 4 & 5 & 3 & 4 \\
\hline Days/month & & 13 & 8 & 12 & 19 & 9 & 9 & 9 & 12 & 8 & 15 & 8 & 9 \\
\hline Days/season & & & 33 & & & & & & 29 & & & 32 & \\
\hline $\begin{array}{l}\text { Total } \\
\text { number of }\end{array}$ & $\begin{array}{l}\text { S1, } \\
\text { S2,S3 }\end{array}$ & & 20 & & & & & & 15 & & & 20 & \\
\hline $\begin{array}{l}\text { sampling } \\
\text { days per } \\
\text { season }\end{array}$ & S4, S5 & & 13 & & & & & & 14 & & & 12 & \\
\hline
\end{tabular}


During every transect walk of one $\mathrm{km}$ in 30 minutes, butterflies on both sides of the transect within a distance of five metres and up to two metres in front of the observer were recorded. The walking pace was slow but constant and two observers walking together along each transect identified and recorded all butterflies seen. The distance was determined to be the farthest that butterflies could be identified with certainty (using binoculars whenever necessary) at all transects. The distance is greater than most other studies on forest butterflies due to the relatively open forest structure typical of tropical deciduous forests particularly during the dry season (Ghazoul, 2002). Each transect was used twice forenoon count between 7.00 to $13.00 \mathrm{~h}$ and an afternoon count between 14.00 to $17.00 \mathrm{~h}$. Each of the forenoon transect walks were of 30 minutes duration, while each of the afternoon transect walks were of 15 minutes duration. Although sampling was done on separate days for the study sites of Garbhanga and Rani ranges, the sampling duration for each of the 8 transects from the two study sites in Rani range with respect to forenoon and afternoon counts were the same as that for the transects from the study sites of Garbhanga range. The total sampling hours for the three study sites of Garbhanga range was nine hours and for the two study sites of Rani range was 6 hours. General field observations relating to mud-puddling, foraging, egg-laying were also recorded during the morning hours when the butterflies were most active and in the afternoon for 2 hours (14.00-16.00 hours). The counts from such observations including the amount of time used for handling individuals or recording field notes were not counted towards the sampling effort. Wherever visual identification on the wing was not possible, specimens were netted. Collecting efforts were more concentrated at mud-puddling spots along the stream, sunspots, fallen fruits and in areas near to human habitation where the Papilionids along with the Pierids were found to be attracted to cow-dung and the common nectaring flowers. However it was always ensured that the counts from such spots were located within the transects. Fast-flying canopy species were underestimated as individual counts whenever identification or netting was not possible as the efficiency of the transect method is low for canopy fliers (Spitzer et al., 1993). As a measure of relative abundance of the butterfly species, we used the maximum number of observed individuals in each site. This measure allows controlling sampling intensity and weather differences (Smallidge et al., 1996). All the transect walks were taken on days with favourable weather conditions. 


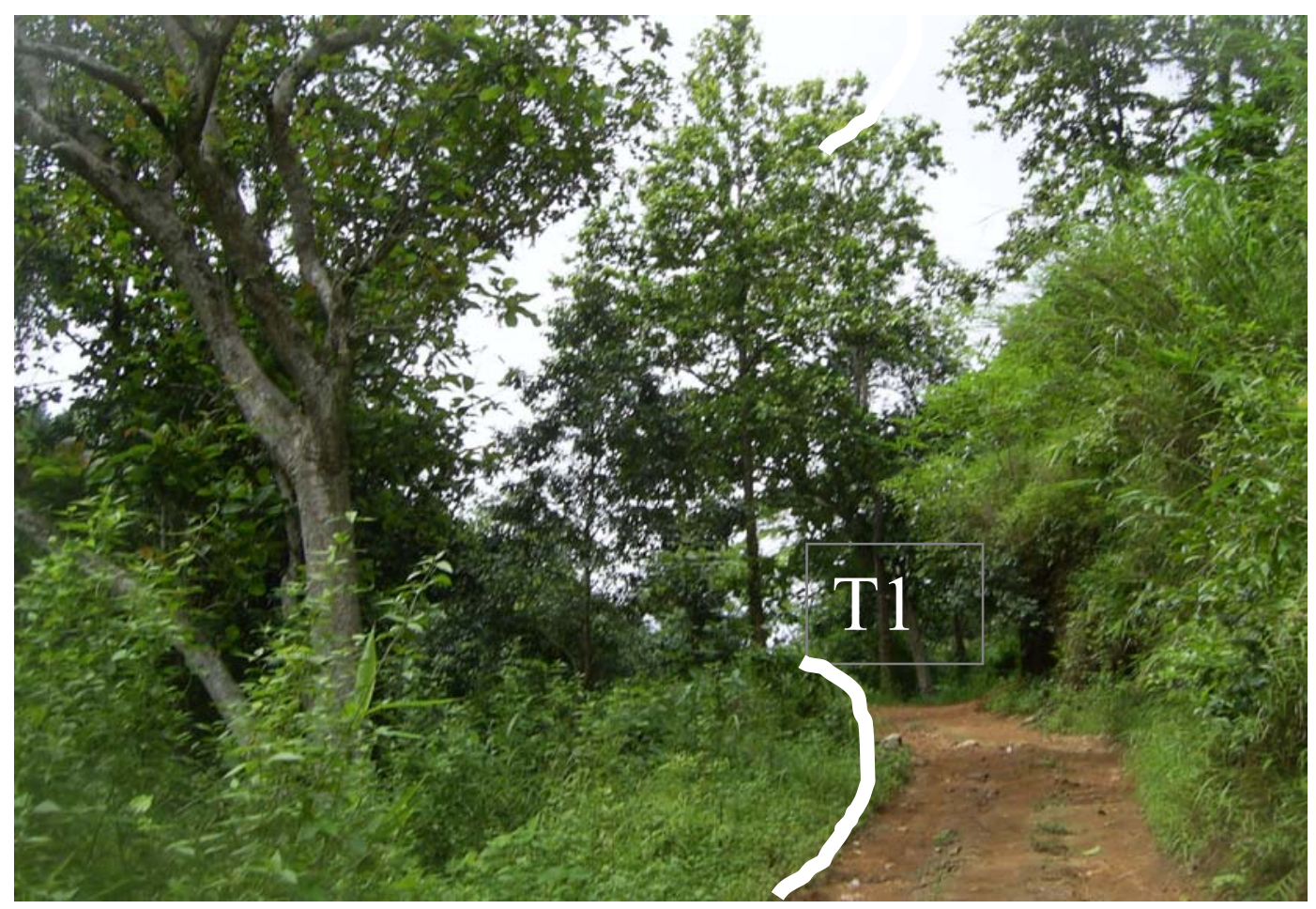

Photo 4 : Study site S1 - Partially disturbed (Garbhanga ) - transect T1 in open/scattered forest (SCF).

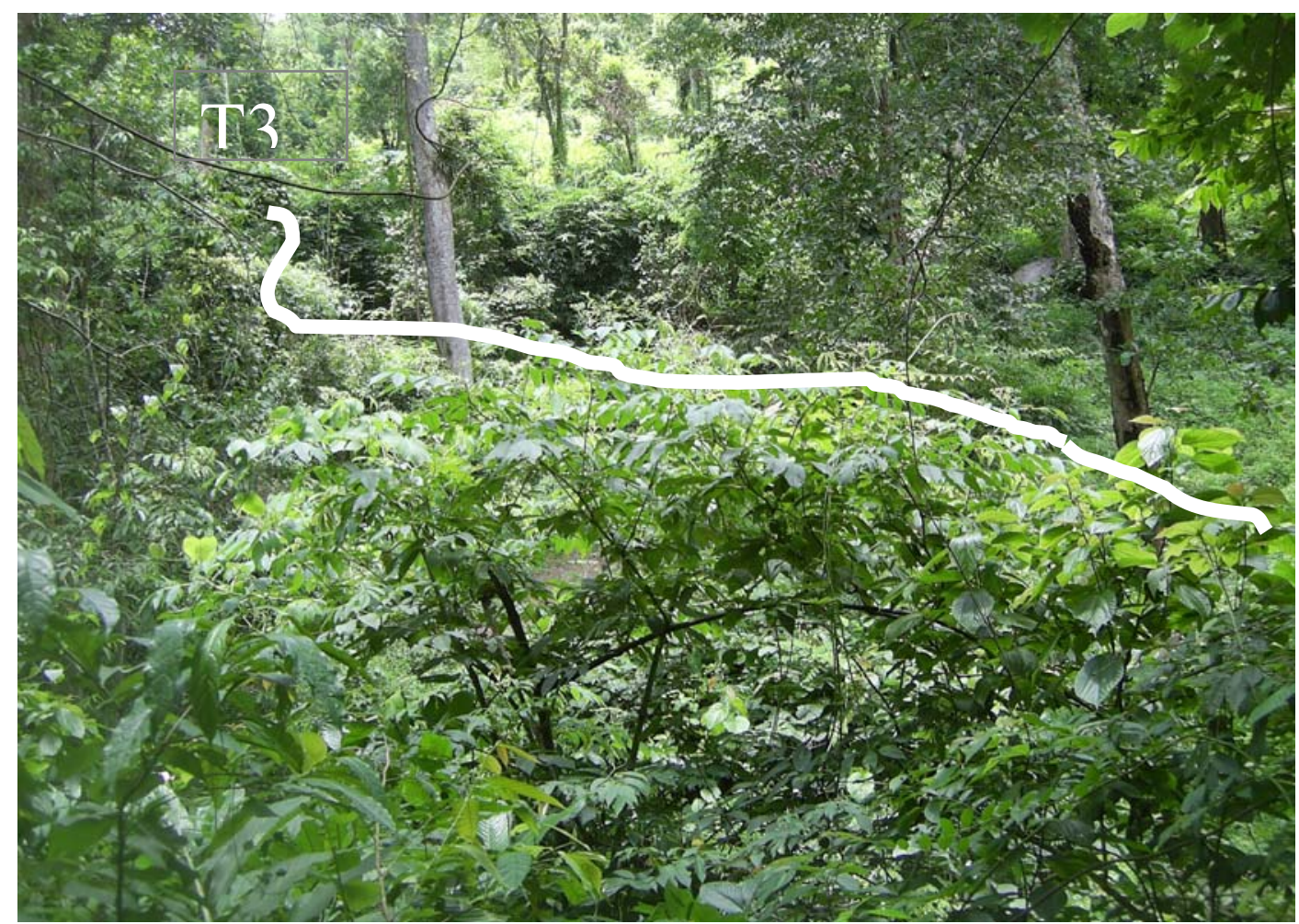

Photo 5 : Study site S1 - Partially disturbed (Garbhanga) - transect T3 in closed forest (CF). 


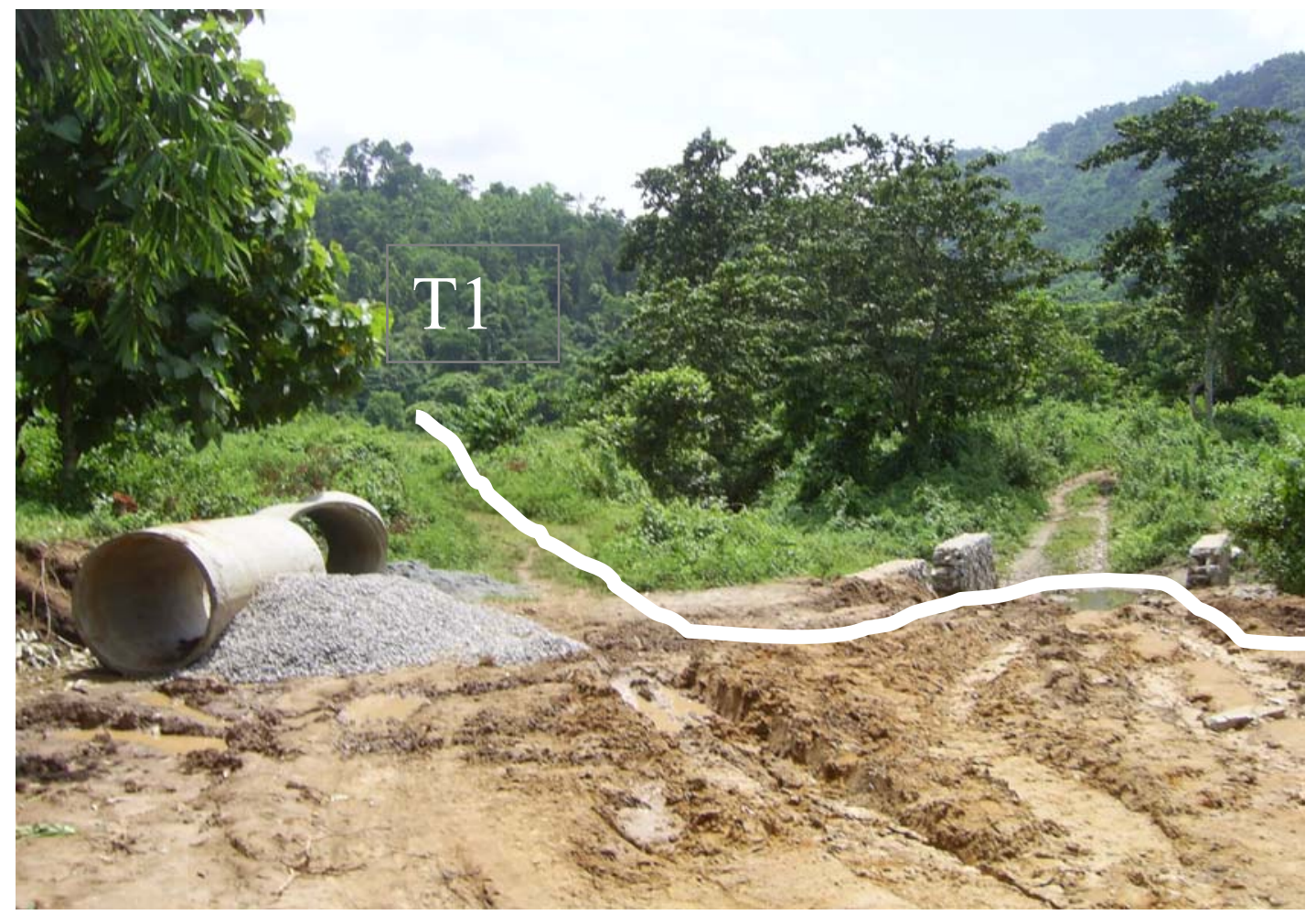

Photo 6 : Study site S4 - Heavily disturbed (Rani) - transect T1 in open/scattered forest

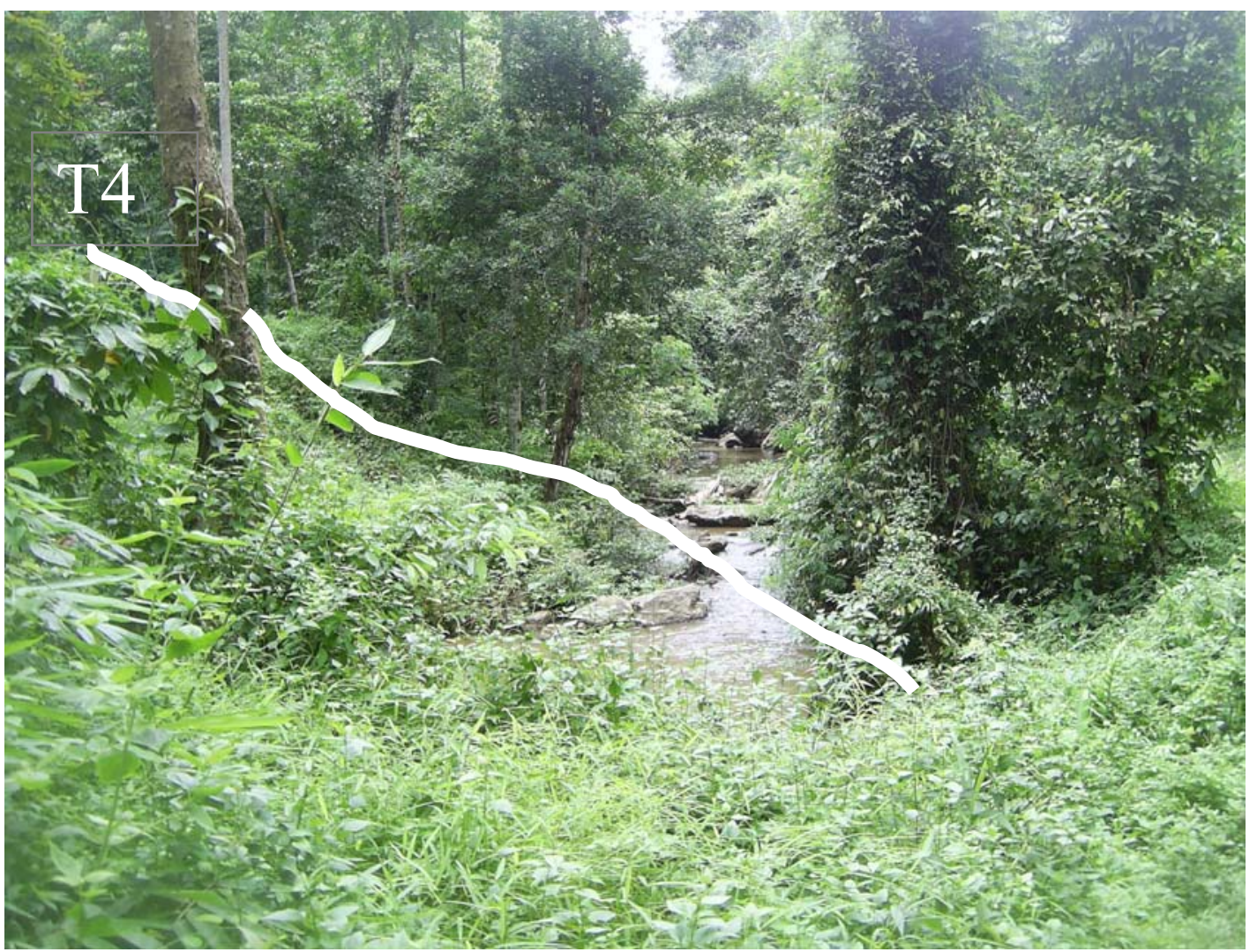

Photo 7 : Study site S4 - (Rani) - transect T4 in closed forest (CF). 


\subsection{Butterfly collection, identification and geographic range classification}

The taxonomic characteristics of the swallowtail butterflies were derived using standard keys from literature (Evans, 1932; Talbot, 1939; Parsons \& Cantlie, 1947; WynterBlyth, 1957; Mani, 1986; Haribal, 1992). The butterflies were collected using nets during the transect walks. Butterflies that could be immediately identified in the field after capture with netting were released while the unidentified specimens were collected in paper packets and taken to the laboratory for stretching and preservation. These were identified with the help of reference material at the Zoological Survey of India, Shillong, India. Type specimens of the collected butterflies were preserved in the laboratory for future reference. The collected and identified species have also been preserved for photographic references. However as part of the Conservation policy (National Forest Policy, 1988) over- collection was avoided and some rare specimens were collected only if doubts existed with respect to their specific identity. In the field wherever it was not possible to distinguish between closely related species during flight, such counts were excluded from the samples and analyses. Within the East Himalayan Papilionidae fauna, there are species with two or more different genetic forms such as in case of Common Mormon (Papilio polytes form romulus and Papilio polytes form stichius) and Common Mime (Chilasa clytia clytia and Chilasa clytia dissimilis). During sampling, the individual counts for such species were restricted to the species only without considering the respective forms. As there are several endemic subspecies in the Eastern Himalayas, therefore in case of the nominate sub-species found in Assam and adjoining regions, our sample size was restricted only to individual counts at species level. Similarly for those species, which exhibited polymorphic forms, the counts were taken wherever identification during flight or after netting was confirmed. Again for those species exhibiting mimicry, we did not include the sample counts whenever the identification was not confirmed during flight. In order to avoid sampling bias, another important factor considered was the sex of the different species. Amongst the Papilionidae, the males and females of some species are strikingly dissimilar and can be often mistaken as individuals from different species. Although we collected male and female individuals as samples for the reference collection, our sampling effort did not include individuals where identification on the wing or during flight was not confirmed. The seasonality of the tropical South-east Asian butterflies is also well marked by the distinctly different dry and wet season broods or forms (Spitzer et al., 1993) and such kind of seasonal polyphenism was also present amongst the Papilionidae in our study area. They are normally termed as DSF 
(Dry Season Form) and WSF (Wet Season Form). Therefore care was also taken during dry and wet season samplings to avoid any kind of observer bias.

Therefore to finally remove as much observer bias as possible during our sampling, approximations were averaged using values from the two transect walkers after a relevé of the four transects from each study site.

The nomenclature of the swallowtail butterflies follows Evans (1932) and D’Abrera (1986) and habitat associations were adopted from Haribal (1992). The geographic distribution ranges have been categorized on a scale of 1-6 (smallest to largest) as used by Spitzer et al. (1993):

1 - Eastern Himalayas), Yunnan and Northern Indo-China

2 - North India and all Indo-China

3 - Oriental (Indo-Malayan) region

4 - Indo-Australian region (Australasian) tropics

5 - Paleotropics

6 - Larger than Paleaoetropics - Cosmopolitan

Within the Indian Himalayan region, the Indian extent of the Eastern Himalayas is from Sikkim to the seven states of Northeast India that includes Assam. Therefore in our study, the lowest ranked species with score 1 was endemic to the Eastern Himalayas, excluding Yunnan and Northern Indo-China and the highest ranked species with a score 4 was the most widely distributed species amongst all the preceeding ranks listed above. No species with geographic range scores 5 and 6 were recorded in our study.

\subsection{Diet breadth classification}

Many species of Papilionidae are relatively specialized on certain tropical and subtropical plant families (Slansky, 1972). Feeding patterns of the Papilionidae range from strict monophagy, in which a single species of food plant is utilised to wide polyphagy in which many species, genera or families may be utilised (Brues, 1920; Dethier, 1954). The diet-breadth of swallowtail butterflies of Rani-Garbhanga forest reserve based on a measure of the number of reliably recorded host-plant families was classified as: monophagous (feeding on plant species that belong to one plant genus and family), oligophagous (feeding on several plant species within the same family) and polyphagous (feeding on a number of plant species from different families). Therefore the guild of Papilionidae with respect to the 
range of larval resource breadth was classified as monophagous specialist, monophagous generalist, oligophagous generalist and polyphagous generalist (Endo \& Nihira, 1990). The generalist and specialist species were classified on the basis of their range of host-plant species used by the larvae - Specialist feeders were confined to only one plant species within the same genus and family while the generalist feeders were classified on the basis of their range of utilisation of several species of food-plants from within the same or different families (Kitahara \& Fuji, 1994).

\subsection{Vegetation survey}

To determine the floristic diversity of the study area, we selected two study sites for sampling (Sites S1 and S4 in Garbhanga and Rani range). The selected sites could represent all habitat types within the study area. Vegetation sampling was carried out during 20032004 using the quadrate method (Kent \& Coker, 1992). The purpose of using a quadrate is to enable comparable samples to be obtained from areas of consistent size and shape. The quadrate method usually attempts to define plant community characteristics for an area much larger than the actual area sampled. Measuring tapes were used for randomly laying quadrates $\left(50 \times 50 \mathrm{~m}^{2}\right.$ for trees, $20 \times 20 \mathrm{~m}^{2}$ for herbs and shrubs and $10 \times 10 \mathrm{~m}^{2}$ for climbers within the same $50 \times 50 \mathrm{~m}^{2}$ quadrate). Eight quadrates were laid randomly in each of the two study sites near to the existing butterfly transects. All plants were counted and listed as individuals belonging to different species within the quadrates. Most of the species were identified in the field with the help of accompanying botanist and according to the keys and literature records of Kanjilal et al. (1934 - 1940), Hooker (1872-1897) and Dutta (1988). For species, which could not be identified, leaves and flowers if available were collected and prepared into herbaria and these were identified with the help of reference material in the Eastern Regional Station of the Botanical Survey of India, Shillong, Meghalaya. The sampling period covered both the dry and wet seasons of 2003-2004 although the sampling days were separate from the days of butterfly sampling. Our total sampling effort amounted to 15 days during the study period.

\subsection{Food-plants}

Butterfly larvae show strong associations with host-plants (Janz \& Nylin, 1998). The distributions and abundance of these host plants are likely to contribute to the abundance and distributions of adult butterflies in the immediate landscape as well as may influence their dispersal (Cleary \& Genner, 2004). The major objective of vegetation study was to 
examine the availability of adult nectar and larval food plant resources of the swallowtail butterflies within the study area. As the larvae feed on the leaves of angiosperms and most adults feed on nectar, there is a positive correlation between larval and nectar sources and butterfly distribution (Sharp et al., 1974). Butterflies interact with plants both as larval herbivores and as adult pollinators, potentially influencing plant population dynamics in both interactions (Rauscher et al., 1980). Moreover the host-plant specificity in butterflies plays an important role in determining the geographical range of a species (Vane Wright, 1972), noting that the host-plant use may vary over the geographical range of a species (Ehrlich et al., 1998). The Papilionid butterflies are strongly associated with a small set of secondary plant classes and compounds that might restrain their ability to use a greater taxonomic range of plants (Fiedler, 1998). Seven plant families generally dominate the host records: Aristolochiaceae, Rutaceae, Lauraceae, Annonaceae, Magnoliaceae, Piperaceae and Apiaceae (Scriber et al., 1995). Notably, the swallowtail tribes Zerynthiini (Parnassiinae), Luehdorfiini (Parnassiinae) and Troidini (Papilioninae) are limited almost exclusively to feeding on Aristolochiaceae (von Euw et al., 1968). The larval host-plants were identified in the field based on earlier studies and direct observations pertaining to the presence of larvae during field survey and interpreting recorded host plants from literature (Igarashi \& Fukuda, 1997; Ehrlich \& Ehrlich, 1961; Haribal, 1992). Field observations further supported by earlier studies showed that the adult swallowtails preferred flowers of trees, shrubs and herbaceous species for nectaring and the adults were observed through two flight seasons to identify the plants important as nectar sources. Care was used in interpreting recorded adult food plant sources (Haribal, 1994). During survey, the abundances of larval and adult food resources of the swallowtails were recorded in the study area as appropriate plant resource. Distribution may be of critical importance in determining the suitability of a habitat for butterflies (Ehrlich \& Gilbert, 1973) and for the survival of the larvae (Dethier, 1959; Singer, 1973).

To avoid perpetuating unreliable host plant records, well-researched synoptic accounts of South-East Asian faunas (Eliot, 1992; Igarashi \& Fukuda, 1997) and critical reviews of the family Papilionidae (Scriber et al., 1995) allowed collation of host plant lists for Oriental species. 


\subsection{Investigations on the climate conditions during the study period}

To investigate the seasonal abundances of tropical butterflies it is also important to examine the climate data specifically pertaining to rainfall and humidity over a long period of time prior to the actual study period. This also helps in long-term monitoring of the butterflies if climate is to be considered as an environmental variable because environmental factors, especially those related to altitude and climate (temperature, humidity and precipitation) represents the main determinants of species distribution and composition of local assemblages of butterflies (Storch et al., 2003). Moreover butterflies are particularly sensitive to thermal conditions and often show immediate dramatic responses to both macroclimatic and microclimatic fluctuations (Ehrlich et al., 1975). We have also investigated the rainfall and humidity trends in our study area over a period of 10 years (see Chapter 3: 3.3.1).

The total annual rainfall and mean monthly maximum temperature trends in the study area across a period of five years from 2001 to 2005 (see Figs. $4.4 \& 4.5$ ) shows that during the wet season, maximum precipitation occurs over a period of approximately 250 days from May to September, whereas the variations in the temperature fluctuations between the dry and wet seasons is very little.

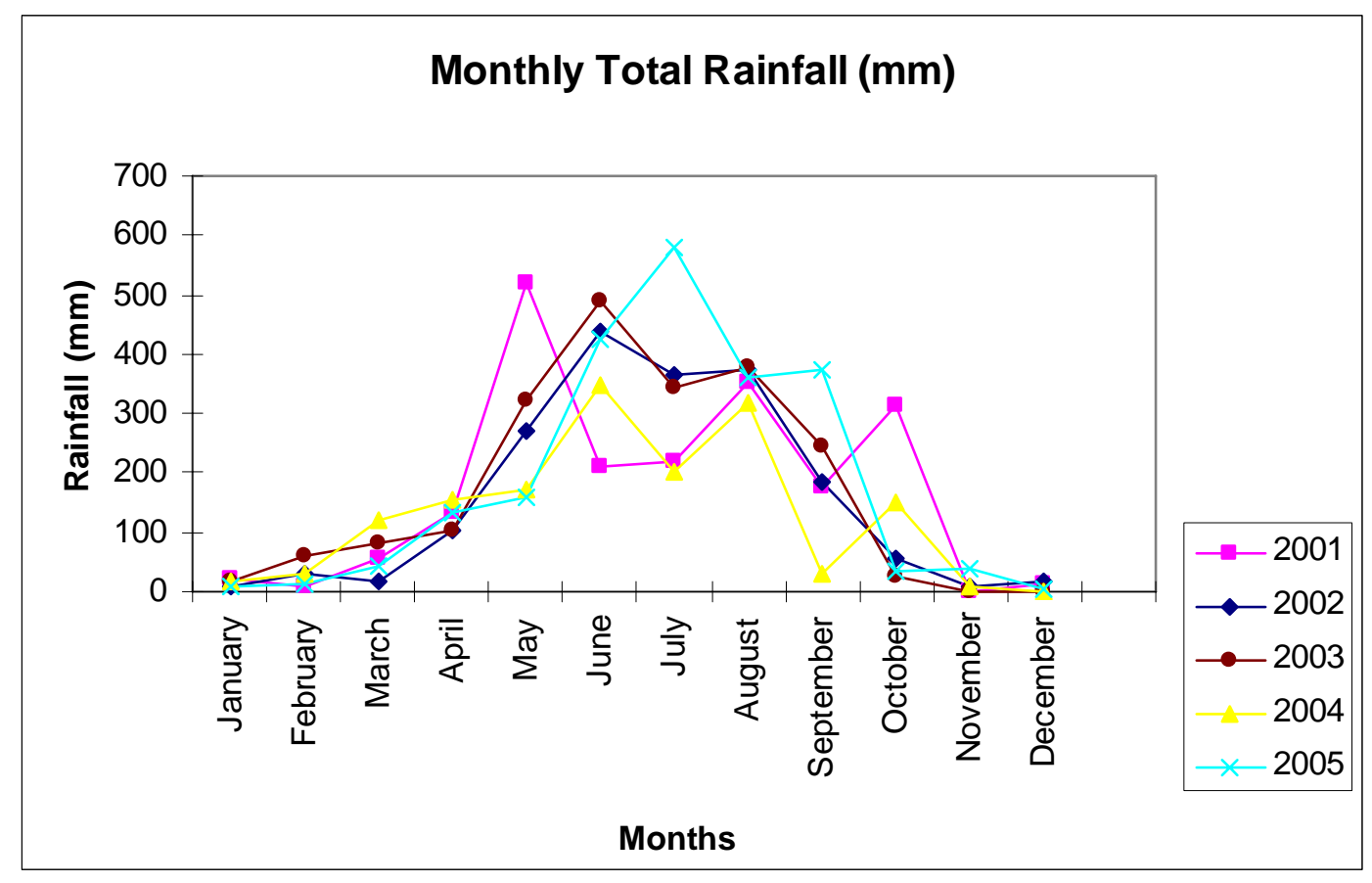

Figure 4.4: Monthly total rainfall data for the study area during January to December for the period of 5 years (2001-2005). 


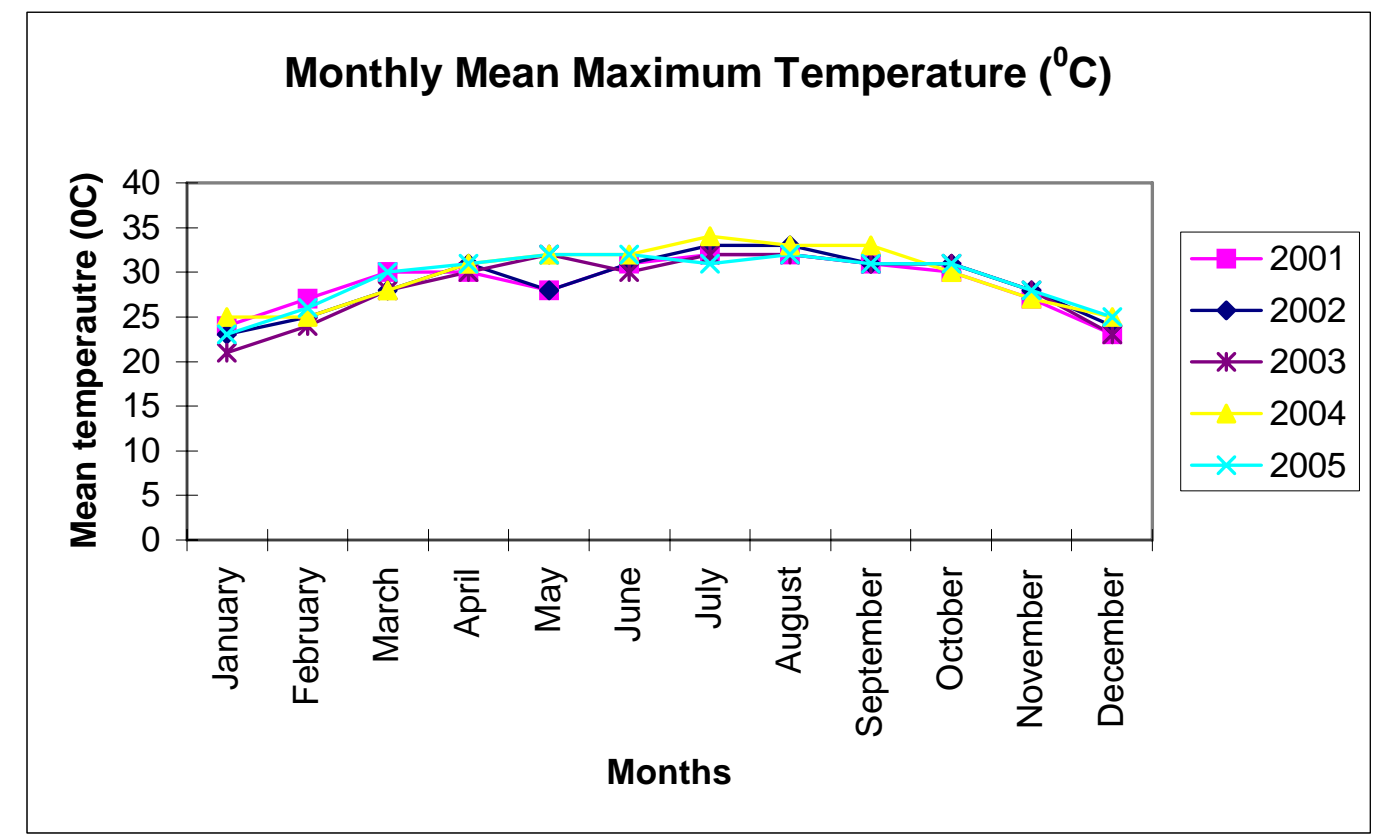

Figure 4.5: Monthly Mean Maximum temperature $\left({ }^{\circ} \mathrm{C}\right)$ of the study area over the period of 5 years (2001-2005) that includes the study period (2003-2004).

The total annual rainfall in 2004 was lower than the previous years (see Fig. 4.4). When comparing the two study years, the annual rainfall of 2004 was $1547 \mathrm{~mm}$, which was lower than the recorded annual rainfall of 2003, which was $2061 \mathrm{~mm}$ (see Appendix 4: 4.1). During the study period, maximum rainfall was recorded during June to August (see Fig. 4.4). In 2003 during the wet season, highest precipitation was recorded in June $(487.60 \mathrm{~mm})$ and the lowest in October $(24.80 \mathrm{~mm})$. In 2004 highest precipitation was recorded in June $(349.80 \mathrm{~mm})$ and the lowest in September $(28.20 \mathrm{~mm})$ during the wet season (see Appendix 4: 4.1).

\subsection{Data analysis}

Canonical Correspondence Analysis (CCA) was used for ordination of the locations, species composition and distribution on the butterfly abundance data. CCA is a 'direct' gradient analysis (ordination) method that places plots in species space relative to a matrix of habitat variables (Ter Braak, 1986). It is one of the most important eigenvector methods in community ordination and is based on Chi-square distances. In this method a set of species can be directly related to a set of environmental variables. The ordination axes are chosen in the light of known environmental variables. In this way community or species variation can be directly related to environmental variation. These variables may be quantitative or nominal. As many axes can be extracted as there are variables. Constrained 
axes are constructed to maximize the fit with linear combinations of environmental variables, and remaining (unconstrained) axes represent a residual variation in the species data after extracting the constrained axes. In the resulting ordination diagram, points represent species and sites, and arrows represent environmental variables. Such a diagram shows the main pattern of variation in species as accounted for by the environmental variables and also shows in an approximate way, the distributions of species along each environmental variable (Ter Braak, 1986). The significance of the relationships between selected external variables and data structure was assessed using permutation tests: the contrasts were permuted randomly and the model was refitted. Values of external variables were randomly assigned to the samples and eigenvalues of the CCA analysis for both constrained and unconstrained axes could be performed.

Multivariate ordination was done separately for the study sites of Garbhanga and Rani ranges. The butterfly abundance data from the 12 fixed transects of the three study sites in Garbhanga range and similarly the abundance data from the 8 fixed transects of the two study sites in Rani range were pooled by season, year and forest type for analysis. Thus transect $\mathrm{T} 1$ representing the pooled abundance data from the open/scattered forest transects of all the three study sites of Garbhanga or the two study sites of Rani range during dry season of year 1 (2003) is again resampled as transect T5 representing pooled abundance data from all the open forest transects of the study sites during wet season of same year. Again transect T3 representing the pooled abundance data from the closed forest transects of all the study sites of either Garbhanga or Rani range during dry season of year 1 is resampled in a similar way during wet season of same year (see Appendix 4: 4.2).

Three sets of ordination were done for the study sites of each of the two ranges - the first ordination matrix defined the influence of categorical and independent variables on the changing abundance and distribution patterns of the group assemblages, the second ordination matrix defined the same for the species assemblages by common English names and the third ordination matrix defined the same for the species assemblages by the scientific names. So we had in total six ordination matrices- three each for the study sites of Garbhanga and Rani ranges.

The classification of the Papilionidae fauna into such group assemblages with common names like Mormons, Helens, Peacocks, Limes and Ravens which are all included under one genus Papilio or Windmills and Batwings which are clustered under one genus Atrophaneura is mainly based on their phylogenetic history and host-plant co-evolution with sharing of a sub-set of these host plants. Such kind of grouping is also based on some 
behavioural similarities like mud-pudlling which therefore makes their identification by common group characteristics easier in the field. In the four ordination plots where we have used the common English names for both the group and species assemblages, follow Evans (1932). In the two ordination matrices for the species assemblages where we have used the scientific names also follow Evans (1932).

\subsubsection{Swallowtail butterflies - habitat relationships}

In order to explore the relationships between the butterfly fauna and the environment defined by forest type, season, rainfall, year, altitude, latitude and longitude, CCA was run on all data sets (Garbhanga and Rani) with data generated from the Line transect sampling method.

The habitat/environment matrix initially consisted of 11 habitat variables (temperature, rainfall, humidity, wind speed, altitude, soil type, vegetation, latitude and longitude, disturbance, light), but was reduced to only the six most important variables season that subsumes temperature, humidity and rainfall, forest type, altitude, latitude and longitude because there was very high correlation between these and other measured variables (See Appendix $4: 4.3 \& 4.4$ ). The CCA ordination was run using the axis scores centred and standardized to compartment variance and compartments were plotted on diagrams using linear combination scores in the statistical program ' $R$ 2.3.1.' (R: A programming Environment for Data Analysis and Graphics. http://cran.r-project.org/ 200606-01). The first two axes of CCA ordination were plotted as standard plots to compare changes as a result of the environmental variables. Season and forest type were used as major external variables to explain the community structure of the swallowtail butterflies, while altitude, geographical position (latitude and longitude), year and rainfall were taken as independent environmental variables to study their effects on the species assemblages within the study area. Separate ordination plots were constructed for the swallowtail butterfly community sampled in Garbhanga and Rani ranges within the forest reserve and these plots indicated the different taxa in genus (group assemblages) and species space. The butterfly abundance data from the 20 fixed transects in the 5 study sites were pooled by forest-type and season-wise to investigate the changing abundance and distribution pattern of the species assemblages of swallowtail butterflies within Garbhanga and Rani ranges. The significance of species-environment relationships were tested by running the permutation tests using the anova function in the vegan package of the program ' $\mathbf{R}$ '. 


\subsubsection{Measures of Diversity index}

Using the pooled abundance data on butterfly sampling by season and forest type for 2 years (2003-2004) the following estimators were computed as measures of butterfly diversity: Shannon-Weiner Index (H'), Simpson's Diversity (D), Simpson's Inverse (1/D), Fischer's alpha diversity $(\alpha)$, Rarefaction $\left(\mathrm{R}^{2}\right)$, Species richness $(\mathrm{S})$ and Pielou's evenness (J). All of these measures are widely used in ecology literature (Krebs, 1989; Magurran, 1988). The selected diversity indices are relatively easy to interpret ecologically and less sensitive to rare species and sample size (Magurran, 1988). Diversity measures vary in the relative emphasis placed on the number of species (richness) and their relative abundances (Evenness), and each has its limitations. Some information on the applied diversity indices is given below:

A frequently used diversity measure is the Shannon-Weaner Index and it is calculated as

$$
\begin{aligned}
& H^{\prime}=-\sum_{i=1}^{S} p_{i} \ln p_{i} \\
& \text { and } p i=n i / N
\end{aligned}
$$

Where $\mathrm{p}$ (i) is the proportion of the sample represented by species $i$, and $\ln$ is the natural logarithm and considers the proportion of individuals found in the ith species, pi. This value is estimated as ni/N (number of individuals in the ith species divided by the total number of individuals). Compared to other indices, the Shannon index is sensitive to changes in abundance of rare or intermediate abundant species. It appeared to have only moderate discriminate ability and since it is strongly influenced by changes in rare species, is sensitive to sample size. The index assumes that sampling is random and allows including all species present in the community.

A second group of diversity measures are referred to as dominance measures since they particularly consider the abundance of the most common species rather than providing a measure of species richness. One of the most used dominance measures is the Simpson's index, which calculates the probability that any two individuals drawn at random from infinitely large community belong to different species. It is calculated as:

$$
\begin{aligned}
\mathbf{D} & =\sum \text { pi (reciprocal) } \\
\mathbf{1} / \mathbf{D} & =\mathbf{1} / \sum \mathbf{p i} \\
\text { and } \quad & \mathbf{p i}=\mathbf{n i}(\mathbf{n i}-\mathbf{1}) / \mathbf{N}(\mathbf{N}-\mathbf{1})
\end{aligned}
$$


In the formula, $\mathbf{p i}$ is the proportion of individuals in the ith species and is estimated from the relation of the number of individuals in the ith species to the total number of individuals. Simpson's index especially takes into account the abundance of the most common species, and is less sensitive to species richness. It has a moderate discriminate ability and low sensitivity to sample size, since it does not stress on changes in abundance of rare species, but of the most common species. Since diversity decreases when D increases, mostly the reciprocal form of the index is used (1/D).

Diversity depends on the number of species (i.e. S), but also on the evenness (E); if all species are equally abundant (E max) then diversity is high, but if one species is especially abundant and the rest are rare (E min) then diversity is low. Simpson's Inverse Index of Diversity is calculated as:

$$
D=1 / \Sigma p_{i}^{2}
$$

where $\mathrm{p}_{\mathrm{i}}$ is the proportional abundance of species $i$, i.e. $\mathrm{n}_{\mathrm{i}} / \Sigma \mathrm{n}_{\mathrm{i}}$.

So, to calculate $\mathrm{D}$, we have the following parameters:

- add up the species' abundances $\left(\mathrm{n}_{\mathrm{i}}\right)$ to give the total $\left(\mathrm{N}=\Sigma \mathrm{n}_{\mathrm{i}}\right)$;

- divide each $\mathrm{n}_{\mathrm{i}}$ by $\mathrm{N}$ to give $\mathrm{p}_{\mathrm{i}}$;

- square each $p_{i}$, before we

- add them up to give a value for Dominance $\left(=\Sigma \mathrm{p}_{\mathrm{i}}{ }^{2}\right)$,

- the reciprocal of which is Simpson's Inverse Index of Diversity.

Another frequently used index is the Fisher's alpha diversity. It is calculated as:

$$
\begin{aligned}
& A=N(1-x) / x \\
& S / N=(1-x) / x-1 n(1 / x)
\end{aligned}
$$

and principally considers the total number of individuals $\mathrm{N}$ and $\mathrm{x}$ which is estimated from the iterative solution of $S / N=(1-x) / x-1 n(1 / x)$. It does not take into account the relative abundance of the species. This means, in situations where the total number of species and individuals remain constant but the evenness of the community changes, alpha will not indicate a difference. However, the index appeared to have a very good discriminate ability between different samples and is not so sensitive to sample size. This attribute of alpha is a result of its dependence on the numbers of species of intermediate abundance, it is relatively unaffected by either rare or common species abundance changes. The index is based on the log-series species abundance model developed by Fisher and is strictly speaking only appropriate when the community shows a log-series distribution. However, in practice it appeared to be a good diversity measure independent of the underlying abundance pattern. 
Pielou's evenness index, $\mathrm{j}$ (Pielou, 1966) is calculated as:

$$
\begin{aligned}
& \text { H(s) } \\
& j= \\
& H \text { (max) }
\end{aligned}
$$

where $H(s)=$ the Shannon-Wiener information function

$H(\max )=$. the theoretical maximum value for $H(s)$ if all species in the sample were equally abundant.

Rarefaction diversity is a measurement for analyzing the number of species (species richness) among collections, when all collections are scaled down to the same sample size (Hulbert, 1971; Heck et al., 1975). The number of species Sn, which can be expected from a random sample of $\boldsymbol{n}$ individuals, drawn without replacement from $\boldsymbol{N}$ individuals distributed among $\boldsymbol{S}$ species, is calculated as:

$$
E\left(S_{n}\right)=\sum_{n=1}^{s}\left[1-\left(\begin{array}{c}
N-N_{t} \\
n
\end{array}\right) /\left(\begin{array}{l}
N \\
n
\end{array}\right)\right]
$$

Where $\mathbf{S}$ is the total number of species found in the collection, and $\mathrm{Ni}$ is the number of individuals of the $\boldsymbol{i}$ th species (Hulbert, 1971).

The technique of rarefaction can be used to calculate species richness for sub samples consisting of fewer individuals. The following formula predicts the average species richness that would be obtained if $N$ individuals were randomly sampled instead of the total $N_{\text {tot }}$ individuals of the survey, when each species contains $N_{\mathrm{i}}$ individuals in the entire survey:

$$
\sum_{i=1}^{s}\left(1-\prod_{-1} \frac{N_{-}-N_{1}-a+b}{N_{\infty}-a+1}\right)-\sum_{I}^{s}\left(1-\frac{\left(\begin{array}{c}
N_{\infty}-N_{1} \\
N
\end{array}\right)}{\left(\begin{array}{c}
N_{\infty} \\
N
\end{array}\right)}\right.
$$

The species diversity, richness, evenness and rarefaction estimates were analysed separately for the study sites of Garbhanga and Rani ranges by season and forest type. The pooled butterfly abundance data from the 12 fixed transects of Garbhanga range and 8 fixed transects of Rani range were used in the analysis. The software program used for the 
computation of the diversity indices was the ' $R$ ' package 'Vegan' version 1.8-2 (2006-06$01)$.

\subsubsection{Indicator Taxa}

To determine the characteristic genera/species for each transect/forest type, we used the indicator (IndVal) method of Dufrene \& Legendre (1997). This method calculates an indicator value (IV) for each genus in predefined clusters (like the clusters identified by a cluster analysis). It is especially suited for identifying indicator taxa independently of the animal (or plant) community as a whole (Dufrene \& Legendre, 1997; McGeoch \& Chown, 1998). The method gives an integrated measure for the relative mean abundance and the relative frequency of the studied genera in each cluster and is calculated as follows:

\section{$A_{i j}{ }^{1 / 4} \mathbf{N}$ individuals; $i j=N$ individuals; $i$ \\ $B_{i j} 1 / 4$ N locations; $i j=N$ locations; $j$ \\ $I V_{i j} 1 / 4 \mathrm{Aij}_{-} \mathrm{Bij}_{-} 100 \%$}

where $A_{i j}$ (relative mean abundance) is the mean number of individuals of genus $i$ in cluster $\mathrm{j}$ divided by the mean number of individuals of genus $\mathrm{i}$ in cluster $\mathrm{j}$ plus the mean number of individuals of genus $\mathrm{i}$ outside cluster $\mathrm{j}$; $\mathrm{B}_{\mathrm{ij}}$ (relative frequency) is the number of locations in cluster $\mathrm{j}$ where genus $\mathrm{i}$ is present divided by the total number of locations in cluster $\mathrm{j}$; $\mathrm{IV}_{\mathrm{ij}}$ is the relative mean abundance of genus $i$ in cluster $j$ multiplied by the relative frequency of genus $\mathrm{i}$ in cluster $\mathrm{j}$ multiplied by $100 \%$. Genera that are weakly associated with a cluster because they are either not abundant or not present in all the locations within that cluster will score a low IV. Only genera that have both a high mean abundance and are present in the majority of locations of a cluster will score a high IV for that particular cluster. IVs can vary between $0 \%$ and $100 \%$, in which $0 \%$ indicates no association with a cluster, while $100 \%$ indicates that the genus was found in all locations of that particular cluster, and was absent in all other locations outside that cluster.

To test whether the observed IV of a genus in a cluster was significantly higher than could be expected based on a random distribution of individuals over the locations, the observed IV was compared with 999 randomly generated IVs. These random IVs were generated with a random reallocation procedure in which the number of individuals per genus per location were randomly reshuffled over the locations (Dufrene \& Legendre, 
1997). If the observed IV of a genus in a cluster fell within the top $5 \%$ of the random IVs (sorted in decreasing order) it was considered to deviate significantly from the expected random mean, i.e. the genus had a significantly higher IV than expected. Species with significant high IndVal values (>70\%) show strong habitat specificity, so they may be considered as characteristic species of the assemblages (McGeoch et al., 2002). This analysis was performed in the 'vegan' subroutine of the program ' $R$ '.

In order to identify the characteristic indicator species within the forest reserve season-wise, we performed the analysis on the same data set using the program PC-ORD 4.01 (McCune \& Mefford, 1999).

The butterfly abundance data from the 12 fixed transects of the three study sites in Garbhanga range and 8 fixed transects of the two study sites in Rani range were pooled by forest type, season and year in a similar method as followed for multivariate ordination for analysing the Indicator values of the group (genus-wise) and species assemblages.

\subsubsection{Vegetation analysis}

The vegetation profile within the protected reserve was sampled only within two study sites (S1 and S4) and plant diversity estimates of these sites with respect to the total abundance of trees, herb/shrub and climbers sampled as individuals were analyzed using the program PC-ORD 4.01 (McCune \& Mefford, 1999). The rarefaction estimates of species richness for the sampled vegetation in the study sites S1 and S4 were analysed in the program 'RAREFACT' 3.00 (Hulbert, 1971).

\subsubsection{Basic statistical tests}

Some of the basic statistical tests like One-way ANOVA for comparing the differences in the mean abundances of the sampled butterflies between the seasons and years, and Spearman's rank correlation tests for analysing the correlation between the mean species abundances and their pre-defined geographical range and diet breadth based on hostplant identification were analysed in the program STATISTICA 7.1 (Statsoft, 1995). 


\section{CHAPTER 5 : RESULTS}

\subsection{Plant Community (Trees, Herbs, Shrubs and climbers)}

The pooled data for study site S1 (Partially disturbed) in Garbhanga range included 1079 individuals of 74 species of trees, 1137 individuals of 63 species of herbs and shrubs and, 481 individuals of 32 species of climbers. In study site S4 (Heavily disturbed) in Rani range the pooled data included 1009 individuals of 72 species of trees, 1155 individuals of 62 species of herbs and shrubs and, 475 individuals of 33 species of climbers. (Appendix 5: 5.1).

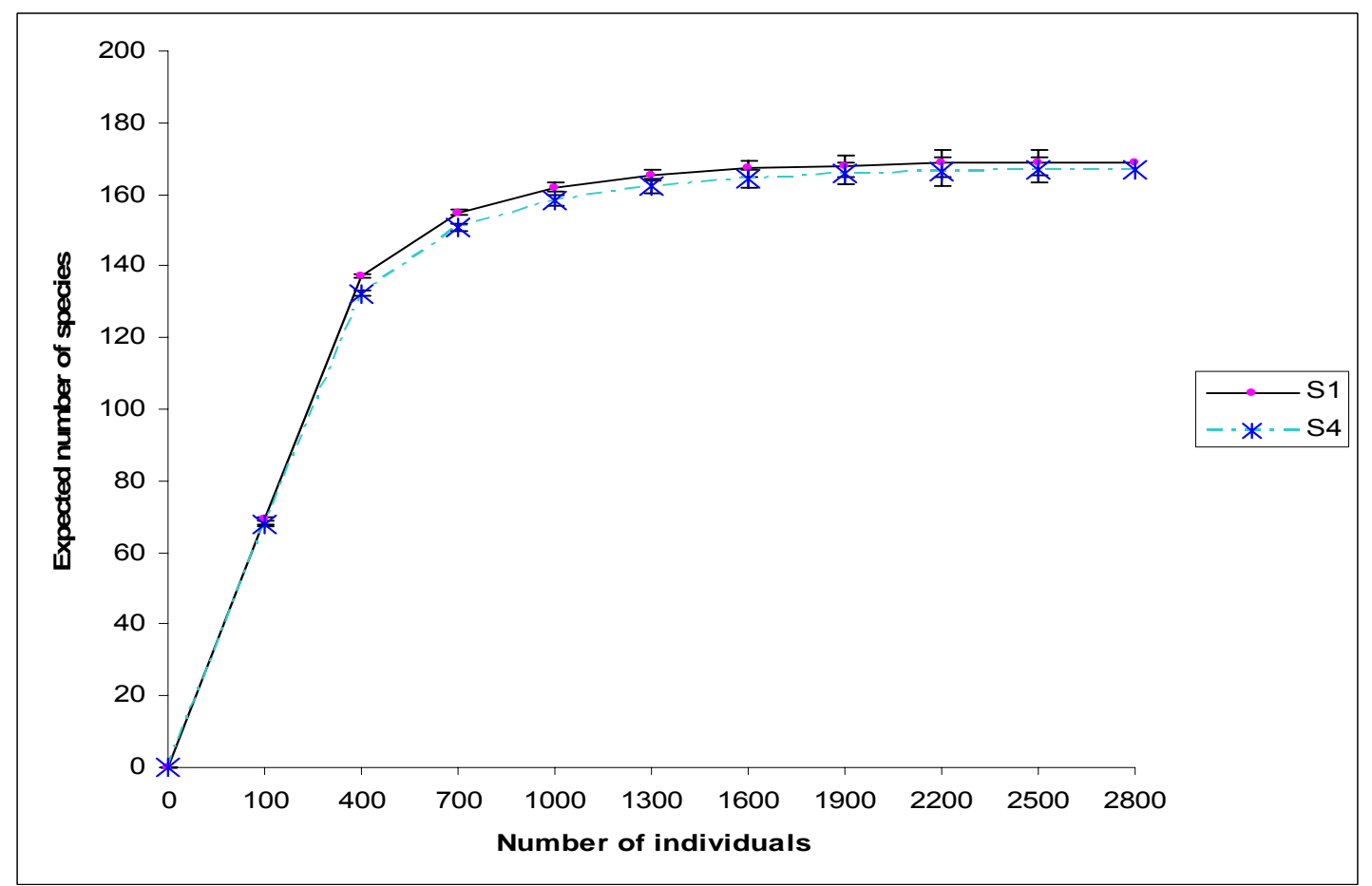

Figure 5.1: Rarefaction curve for the plant community of the two study sites (S1 \& S4). Total number of species (trees, herb/shrub, climbers) in the samples of each study site were169 and 167 respectively.

The rarefaction curves for the plant community showed a nearly close similarity in the abundance patterns of the sampled plants or the species richness between the two study 
sites (see Fig. 5.1) and the overall vegetation structure in these two sites could be considered to represent the complete floral profile of the study area (see Appendix 5: 5.2, 5.3, 5.4, 5.5 $\&$ 5.6). The forest reserve is a predominantly mixed deciduous Sal forest with teak plantation in the fringe areas of the western part of the reserve (study site S4 in Rani range as seen in GIS map) near to human settlements. Large tracts of bamboo (Dendrocalamus hamiltonii) were mostly found in the hilly slopes of the reserve at elevations ranging from 100-120 m above MSL. The specific feature of this bamboo species was that it was observed to grow gregariously in clumps forming 'pure stands' and could therefore be described as separate 'bamboo forests' under general edaphic and seral types of tropical moist deciduous forests (Champion \& Seth, 1968). Such bamboo habitats were observed to have poor undergrowth vegetation with only such species like Gardenia campanulata and Mussaenda roxburghii.

\subsubsection{Flora Overview}

\subsubsection{Study site S1 (Garbhanga range)}

We sampled 2697 individuals, belonging to 62 families, 131 genera and 169 species. The species with highest abundance was Dendrocalamus hamiltonii (86 individuals), followed by Aristolochia tagala (50 individuals), Hibiscus rosa sinensis and Lantana camara (each with 47 individuals), Glycosmis pentaphylla (44 individuals), Aristolochia indica and Homonia riparia (each with 41 individuals). Of the 169 sampled species, Diospyros variegata was represented by only one individual (see Appendix 5: 5.4. 5.5, 5.6).

Scattered patches of 'moist bamboo brakes' corresponding to Champion \& Seth's type 2/E3 (1968) were found to occur along the stream and clumps of Dendrocalamus hamiltonii was the dominant species. The ground flora in the moist habitats along the stream was composed of dominant herb species like Homonia riparia, Solanum indicum, Punica granatum, Clerodendron infortunatum, Ficus heterophylla, Bauhinia acuminata and Abutilon indicum. In areas with large gaps (scattered forest habitats) along the stream created by logging or major tree falls the herbaceous ground vegetation was dominated by species like Costus speciosus and Hemidesmus indicus. Within the closed canopy forest the dominant tree species were Ficus religiosa, Gmelina arborea, , Shorea assamica, Salix tetrasperma, Schima wallichi, Dipterocarpus macrocarpus, Aesculus assamica, Castanopsis indica, Zanthoxyllum budrunga, Semicarpius anacardium, Moringa oleifera and Tetrameles nudiflora. The height of the lower canopy was approximately $15.5 \mathrm{~m}$ while the 
upper canopy was about 35-40 $\mathrm{m}$ in height. Some of the dominant climbers observed in the closed forest were Aristolochia tagala, A indica, Mucuna prurita, Butea parviflora, Ficus scandens (woody climber), Millettia auriculata (woody climber), Smylex macrophylla. The undergrowth vegetation in these habitats was characterised by such species like Solanum nigrum, Nerium indicum, Stephania hernandifolia, Sida cordifolia, Desmodium caudatum, Litsaea salicifolia and Plumbago zeylanica.

In the scattered forests with large gaps close to human settlements some of the dominant tree species observed were Shorea robusta, Bauhinia variegata, Sharaka indica, Zanthoxylum hamiltonianum, Emblica officinalis, Annona squamosa , Mangifera indica, Citus grandis, C aurantifolia and Murrya koeningii. The ground vegetation comprised of Murrya paniculata, Glycosmis pentaphylla, Cassia sophera, Canna orientalis, Lantana camara and Eupatorium odoratum while Imperata cylindrica was the common grass species in such open habitats. Grazing and logging were absent but the forest road running along the transects was the only walking link for the villagers between the northern and southeastern part of the reserve. Mild form of disturbance by way of cutting of bamboos and collection of fodder for the cattle was observed. A comparative study on the GIS land cover images for a period of 4 years (1998-2002) showed a decrease in the cover of domestic and commercial plantation in the north-eastern part of the study site but increasing encroachment on the northern part (see Chapter 4: Figs. $4.1 \& 4.2$ ).

\subsubsection{Study site S4 (Rani range)}

We sampled 2576 individuals belonging to 62 families, 130 genera and 167 species. The species with highest abundance was Lantana camara (62 individuals) followed by Dendrocalamus hamiltonii (61 individuals), Eupatorium odoratum (50 individuals), Ixora coccinea (49 individuals), Adhatoda vasica (48 individuals), Polyalthia longifolia (46 individuals) and Mangifera indica (45 individuals).

It is a disturbed habitat characterised by the presence of shrubs, grasses, planted trees and crop plants. There is a 3 ha teak plantation and there was virtually no ground cover in this plantation site. The dominant herb and shrub species observed as household plantations in the areas of the forest settlement were Ixora coccinea, Datura stramonium, Cassia occidentalis ,Cassia tora, Aeschynomene indica, Hibiscus rosa sinensis, Vitex negundo (tree shrub) and Holmskioldia sanguinea. Cultivated plants included species like Citrus grandis, Citrus aurantifolia, Mangifera indica, Emblica officinalis, Carica papaya, Polyalthia longifolia, Litchi chinensis and Musa sanguinea. The dominant climbers in such habitat 
were species like Caesalpinia crista, Thunbergia grandiflora, Jasminum scandens, J coaractatum and Hibiscus fragrans.

The scattered forest consisted of some large natural gaps characterised by the presence of Imperata cylindrical (Cogon grass), Eupatorium odoratum, Lantana camara, Glycosmis pentaphylla, Canna orientalis and Cannabis sativa as dominant undergrowth vegetation.

In the closed forest at elevations of $120--150 \mathrm{~m}$ the dominant tree species of Rutaceae, Moraceae, Dipterocarpaceae, Lauraceae, Annonaceae, Verbenaceae, Euphorbiaceae and Caesalpiniaceae were found. The ground cover consisted of dominant species like Solanum indicum, Solanum nigrum, Punica granatum, Murrya paniculata, Cassia sophera, Clerodendrum indicum, Ficus heterophylla, Mimosa himalayana, Abroma augusta Desmodium latifolium, Litsaea salicifolia, Duranta repens, Plumbago zeylanica and Mussaenda roxburghii. Sau grass (Microstegium ciliatum) was also observed to be dominant under close canopy. At lower elevations of $60-70 \mathrm{~m}$ bamboo was dominant on the hilly slopes and ridges. Close associates of bamboo were smaller trees like Zanthoxyllum budrunga, Z hamiltonianum, Salix tetrasperma, Gmelina arborea and Holarrhena antidysentrica. The dominant climbers in the closed forest were Aristolochia indica, A tagala, Delima sarmentosa, Clematis cadmia, Butea parvifloram, Millettia auriculata, Ficus scandens, Combretum decandrum, Mussaenda glabra, Entada scandens and Naravelia zeylanica. Bamboo (Dendrocalamus hamiltonii) was found to be more abundant in site S1. The vegetation in the scrubland was dominated by grasses like Microstegium ciliatum and other species included Eupatorium odoratum and Lantana camara.

A comparison of the GIS land cover class for four years (1998-2002) showed a decrease in the agricultural activities but increasing encroachment associated with domestic plantation and grazing (see Chapter 4: Figs. $4.1 \& 4.2$ ). The closed forest was disturbed by only illegal selective logging while high levels of human disturbance were visually observed in the open/ scattered forests or gaps in the form of stone quarrying activities, earth cutting from the hilly slopes, small-wood collection and grazing.

\subsubsection{Comparison of plant diversity parameters between S1 and S4}

An estimation of the diversity parameters of the floral composition within the study sites with respect to the trees, herbs/shrubs and climbers showed the following results (see Tables 5.1, 5.2 and 5.3): 
Table 5.1: Diversity parameters for tree species sampled as number of individuals in the study sites S1 (Partially disturbed) and S4 (Heavily disturbed) within the forest reserve using PC-ORD, 4.01 .

\begin{tabular}{|c|c|c|c|c|c|c|c|c|c|}
\hline Study site & Mean & SD & Sum & Minimum & Maximum & $\mathrm{s}$ & $E$ & $\mathrm{H}$ & D' \\
\hline S1 & 10.899 & 11.633 & 1079.000 & 0.000 & 86.000 & 74 & 0.948 & 4.082 & 0.9785 \\
\hline S4 & 10.192 & 12.724 & 1009.000 & 0.000 & 61.000 & 72 & 0.916 & 3.916 & 0.9743 \\
\hline AVERAGES: & 10.545 & 12.179 & 1044.000 & $\odot .0 \odot \odot$ & 73.500 & 73.0 & 0.932 & 3.999 & 0.9764 \\
\hline
\end{tabular}

$\mathrm{S}=$ Species richness, $\mathrm{E}=$ Evenness, $\mathrm{H}=$ Shannon's index, $\mathrm{D}=$ Simpson's index, $\mathrm{SD}=\mathrm{Standard}$ Deviation

Table 5.2: Diversity parameters for herbs/shrubs sampled as number of individuals in the study sites S1 (Partially disturbed) and S4 (Heavily disturbed) within the forest reserve using PC-ORD, 4.01.

Summary of 2 study sites, $\quad \mathrm{N}=63$ herb/shrubs ( $\mathrm{N}=$ Number of species)

\begin{tabular}{cllrrrrrrr}
\hline Study site & Mean & SD & Sum & Minimum & Maximum & S & E & H & D \\
\hline S1 & 18.048 & 12.126 & 1137.000 & 2.000 & 47.000 & 63 & 0.945 & 3.915 & 0.9771 \\
S4 & 17.698 & 12.740 & 1115.000 & 0.000 & 62.000 & 62 & 0.946 & 3.904 & 0.9760 \\
\hline AVERAGES: & 17.873 & 12.433 & 1126.000 & 1.000 & 54.500 & 62.5 & 0.945 & 3.910 & 0.9766 \\
\hline
\end{tabular}

$S=$ Species richness,$E=$ Evenness,$H=$ Shannon's index,$D=$ Simpson's index, $S D=$ Standard Deviation

Table 5.3: Diversity parameters for climbers sampled as number of individuals in the study sites S1 (Partially disturbed) and S4 (Disturbed) within the forest reserve using PC-ORD, 4.01 .

Summary of 2 study sites, $\quad \mathrm{N}=35$ climbers, ( $N=$ Number of species $)$

\begin{tabular}{clllclllll}
\hline Study site & Mean & \multicolumn{1}{c}{ SD } & Sum & Minimum & Maximum & S & E & H & D \\
\hline S1 & 13.743 & 11.498 & 481.000 & 0.000 & 50.000 & 32 & 0.935 & 3.242 & 0.9520 \\
S4 & 13.571 & 8.819 & 475.000 & 0.000 & 36.000 & 33 & 0.953 & 3.332 & 0.9597 \\
\hline AVERAGES: & 13.657 & 10.159 & 478.000 & 0.000 & 43.000 & 32.5 & 0.944 & 3.287 & 0.9559 \\
\hline
\end{tabular}

$\mathrm{S}=$ Species richness, $\mathrm{E}=$ Evenness, $\mathrm{H}=$ Shannon's index $\mathrm{D}=$ Simpson's index, $\mathrm{SD}=$ Standard Deviation

Species richness for trees and herbs/shrubs was higher in S1 whereas for climbers it was higher in S4. Shannon's and Simpson's diversity showed higher values of trees and herbs/shrub composition in S1 whereas the diversity of climbers was higher in S4. Species evenness of trees was higher in S1 whereas for herbs/shrubs and climbers the evenness was 
higher in S4 (see Tables 5.1, $5.2 \&$ 5.3). However the rarefaction estimate for expected species richness showed near similarity between the two study sites S1 and S4 (see Fig. 5.1) and this could be considered to represent the overall vegetation profile of the protected reserve.

\subsection{Plant community representation in the study area}

\subsubsection{Plant families, genera and species}

The total plant family representation in the study area was 65 . A total of 197 plant species were recorded, out of which 99 species represented trees, 63 species were herbs/shrubs and 35 species were represented by climbers (see Fig. 5.2; Appendix 5: 5.7).

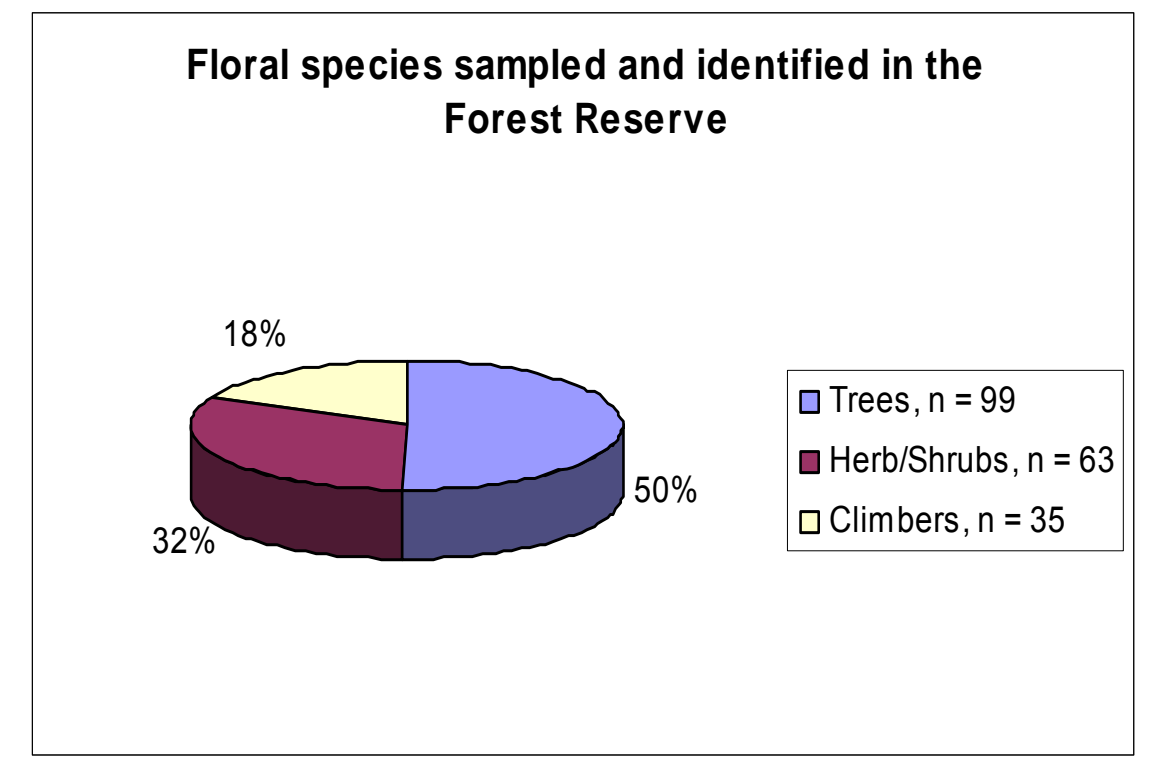

Figure 5.2: Percentage representation of trees, herbs/shrubs and climbers in the Forest Reserve ( $n=$ number of species).

The most species-rich family in the reserve was Fabaceae with 14 species, Rutaceae, Verbenaceae and Euphorbiaceae coming in close second each with 12 species. Moraceae (10) and Caesalpiniaceae (10) were also species rich. Fifty-nine families were found with less than 10 species and out of these 25 families were found to represent only 1 species (see Fig. 5.3; Appendix 5: 5.7).

Dipterocarpaceae was mainly represented by Shorea robusta (Sal) and S. assamica, which is a principal associate of Sal in entire North-east India (Singh \& Singh, 1987). A characteristic feature of the Sal forests is that the leafless period of Sal is only about 1-2 
weeks and this helps to keep the forest floor reasonably moist and cool even during the dry season. The percentage of canopy cover in an undisturbed Sal forest is about $60-80 \%$ but in the study area which is a disturbed forest, the canopy cover was about $50-60 \%$ only and the understorey in the Sal dominated patches was characterized by the presence of Microstegium ciliatum and Eupatorium odoratum.

The genera most rich in species was Ficus (Moraceae) with 7 species, followed by Bauhinia (5, Fabaceae), Zanthoxyllum ( 4, Rutaceae), Solanum ( 4, Solanaceae), Cassia ( 4, Caesalpiniacea), Cinnamomum (3, Lauraceae), Citrus (3, Rutaceae), Vitex (3, Verbenaceae) and Garcinia (3, Clusiaceae). One-hundred and twelve genera were represented by only one species.

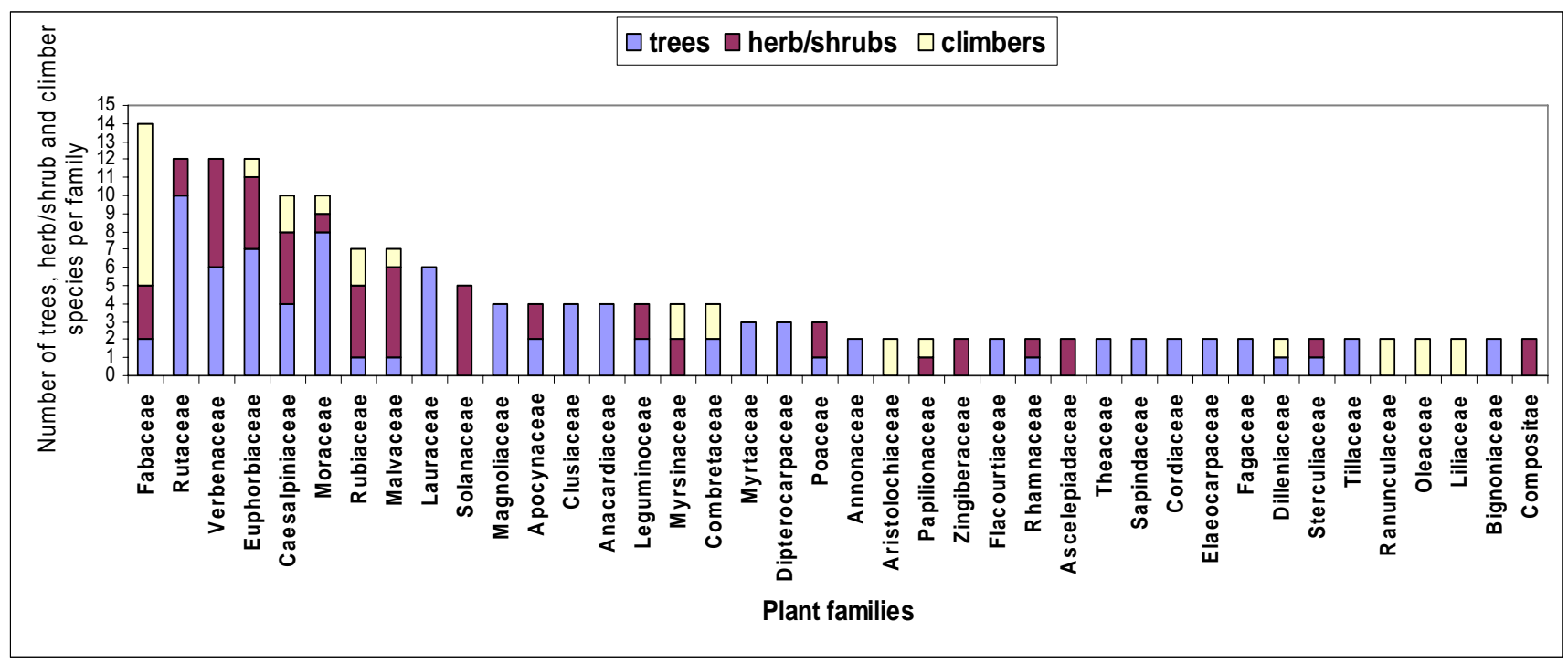

Figure 5.3: Number of species of trees, herb/shrubs and climbers per family represented in the floral composition of study sites S1 and S4. The dominant plant families with more than one species are only shown in the above figure.

\subsubsection{Larval host-plants and adult nectaring plant families and species}

Seven families in the study area represented the larval host-plants. Rutaceae represented the highest number of larval host-plants with 11 species to be followed by Lauraceae (5 species), Magnoliaceae (3 species), Annonaceae and Aristolochiaceae each with 2 species, Caesalpiniaceae and Solanaceae each with 1 species (see Figs. 5.4 \& 5.5: Appendix 5: $5.8 \&$ 5.9). The larval host-plant diversity represented only $7 \%$ of the total plant diversity in the reserve (see Fig. 5.6). 


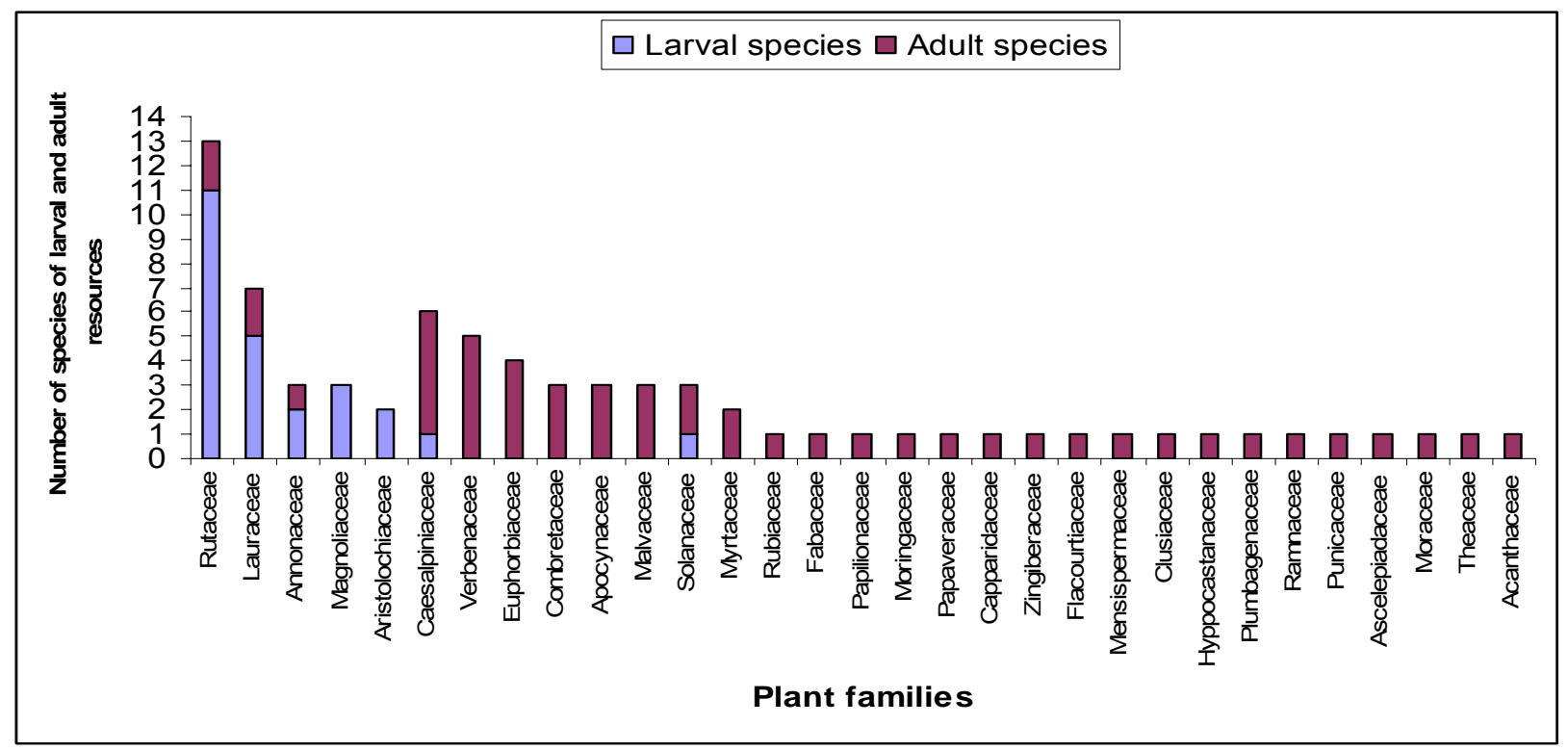

Figure 5.4: Number of species per family representing the larval and adult food-plant resources of the swallowtail butterflies in Rani-Garbhanga Reserve Forest.

Twenty-nine plant families represented the adult nectar sources of the swallowtail butterflies in the study area (see Figs. 5.4 \& 5.5: Appendix 5: 5.9). Verbenaceae and Caesalpiniaceae represented the highest number of adult food-plant sources, each with 5 species to be followed by Euphorbiaceae (4 species), Malvaceae, Combretaceae and Apocynaceae each with 3 species. The remaining 23 families were represented by 2 or only 1 species. The total number of plant species representing the adult food-plant sources of the swallowtails in the study area was 50 . This amounted to $29 \%$ of the total floral diversity in the reserve (Fig. 5.6). 


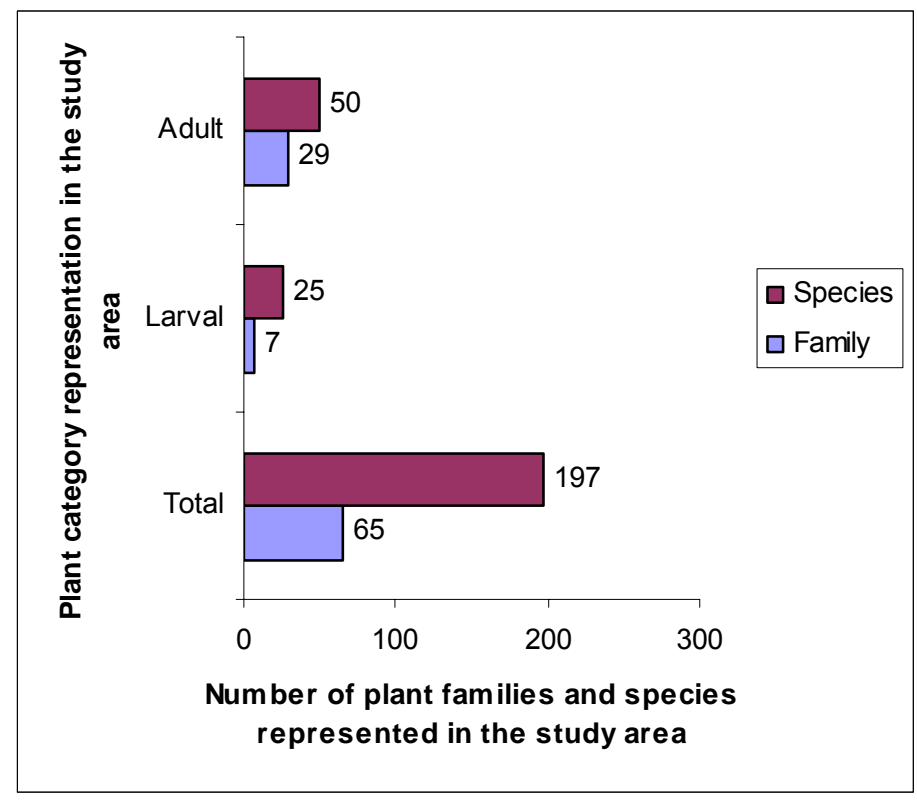

Figure 5.5: Number of plant families and species represented in the total floral diversity, larval and adult food-plant resources of the swallowtail butterflies in the study area.

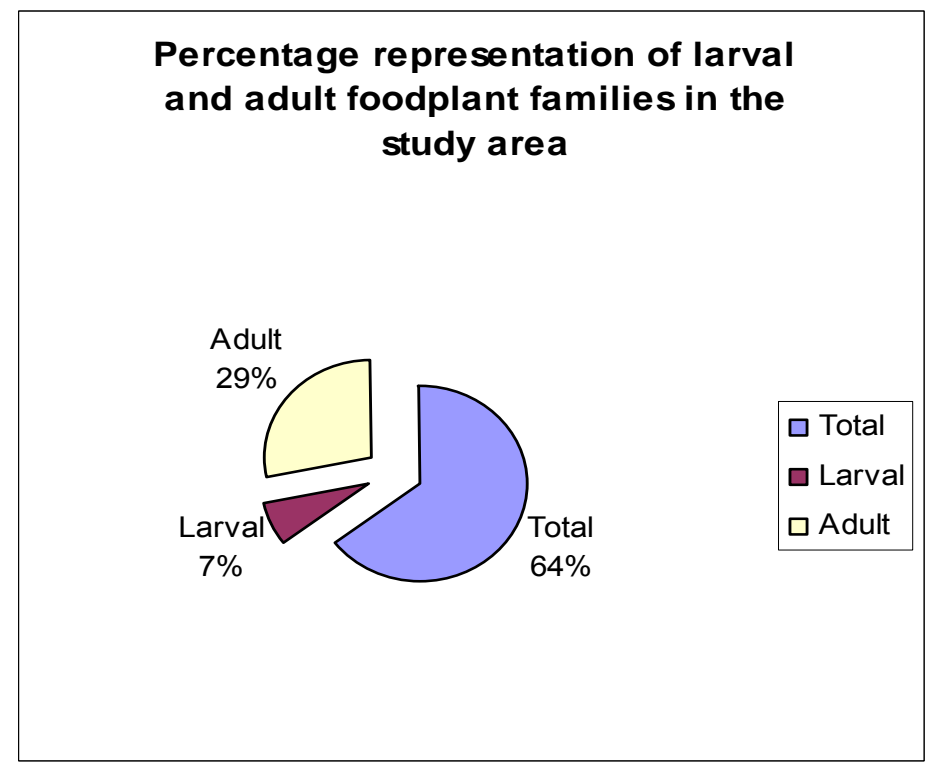

Figure 5.6: Percentage representation of the total, larval and adult food-plant resources of the swallowtail butterflies in the study area. 


\subsection{Papilionidae diversity in Rani-Garbhanga Reserve forest}

\subsubsection{Genera, Species and Abundance}

The abundance of 18,371 individuals of 28 species of swallowtail butterflies belonging to eight genera were recorded during the wet and dry seasons at the reserve by the end of 2004. A list of the recorded Papilionidae with their larval food resources and diet breadth/feeding guild, conservation status and geographic range are given in Appendix 5: 5.10. Nine of these species belonged to the 'Red-bodied' group and were included under 3 genera - Atrophaneura (5 species), Pachliopta (2 species) and Troides (2 species). The 'black-bodied' group represented by the single genus Papilio had the highest number of species (9). The genera Pathysa and Graphium were represented by 4 and 3 species respectively while the genera Lamproptera (2 species) and Chilasa (1 species) were represented by the lowest number of species (see Figure 5.7).

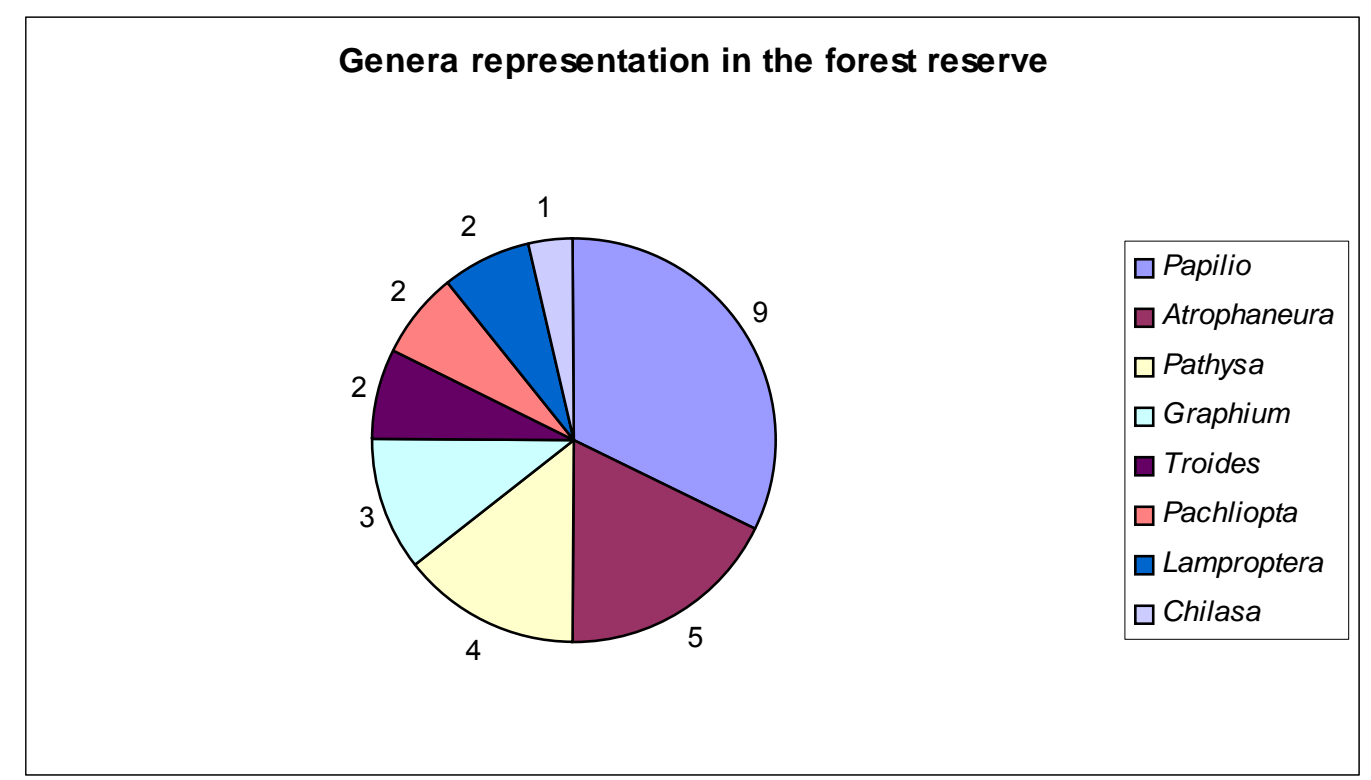

Figure 5.7: Genus representation of the swallowtail butterflies sampled during the dry and wet seasons of 2003-2004 in the 50 ha study site of Rani-Garbhanga Reserve forest. The total number of species for each genus is shown as different numbers around the pie-chart.

The total number of species recorded from our present study represented $45.9 \%$ of the total species documented from Assam by Evans (1932) and Talbot (1939). The number 
of species endemic to the Eastern Himalayas and recorded in the present study was four as compared to the five endemics of Assam described from the earlier records of Evans (1932) and Talbot (1939) (see Appendix 5: 5.11). In the three study sites of Garbhanga range 28 species of Papilionidae were recorded while in the two study sites of Rani range 26 species were recorded. The two species not recorded in the study sites of Rani range were (White Head Batwing (Atrophaneura sycorax) and Paris Peacock (Papilio paris). In the present study, there were no species records from the genera Meandrusa, Teinopalpus and Bhutanitis (see Fig. 5.8). The total species record from the Indian Himalayan Region (IHR) and Peninsular India is listed in Appendix 5: 5.11).

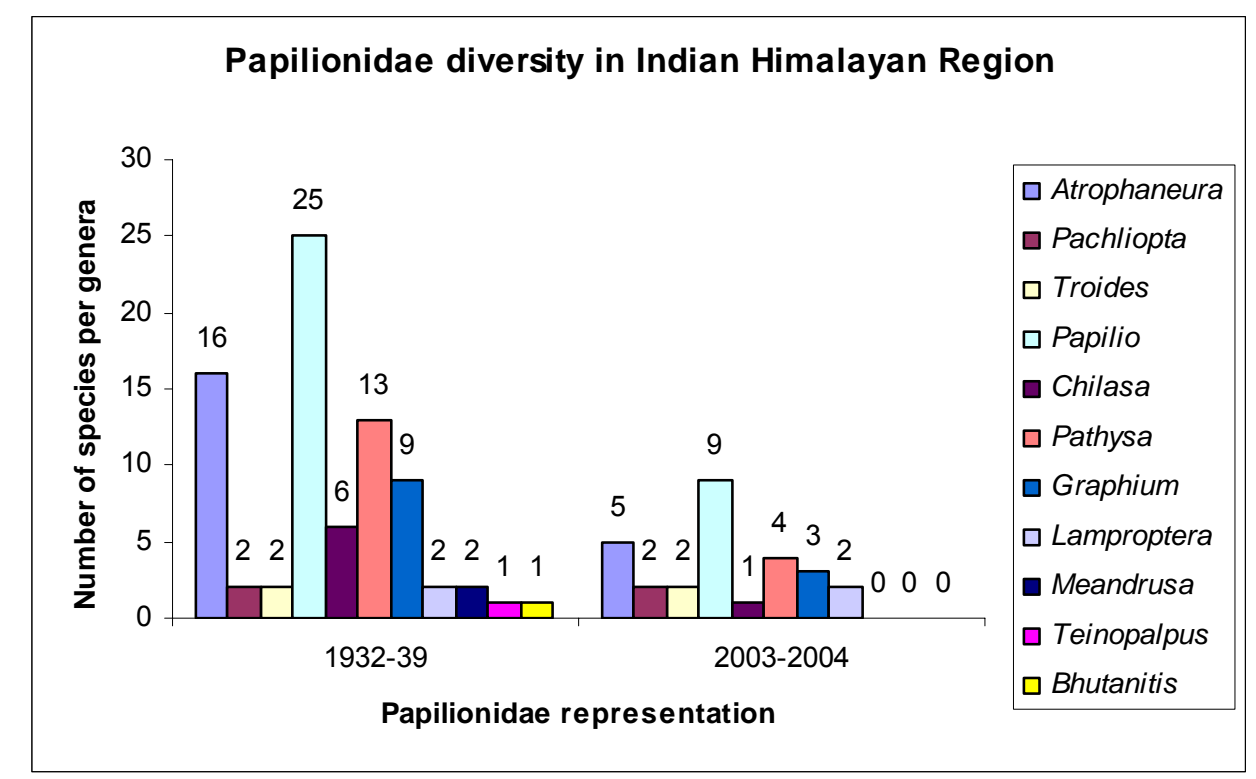

Figure 5.8: Papilionidae representation in the forest reserve from the present study (20032004) as compared to the first documentation on the Papilionidae of the Indian Himalayan Region by Evans (1932) and Talbot (1939). The number of species per genera are shown as numbers above the bars. 


\subsubsection{Differences in total and mean abundances between seasons and years}

\subsubsection{Differences in total abundance between seasons and years}

The total abundance of swallowtail butterfly individuals sampled in the five study sites of the forest reserve amounted to 2921 in the dry and 6469 in the wet season of year 1 (2003). In year 2 (2004), 3025 individuals were recorded during the dry and 6004 individuals during the wet seasons (see Fig. 5.9, Appendix 5: 5.12 \& 5.13).

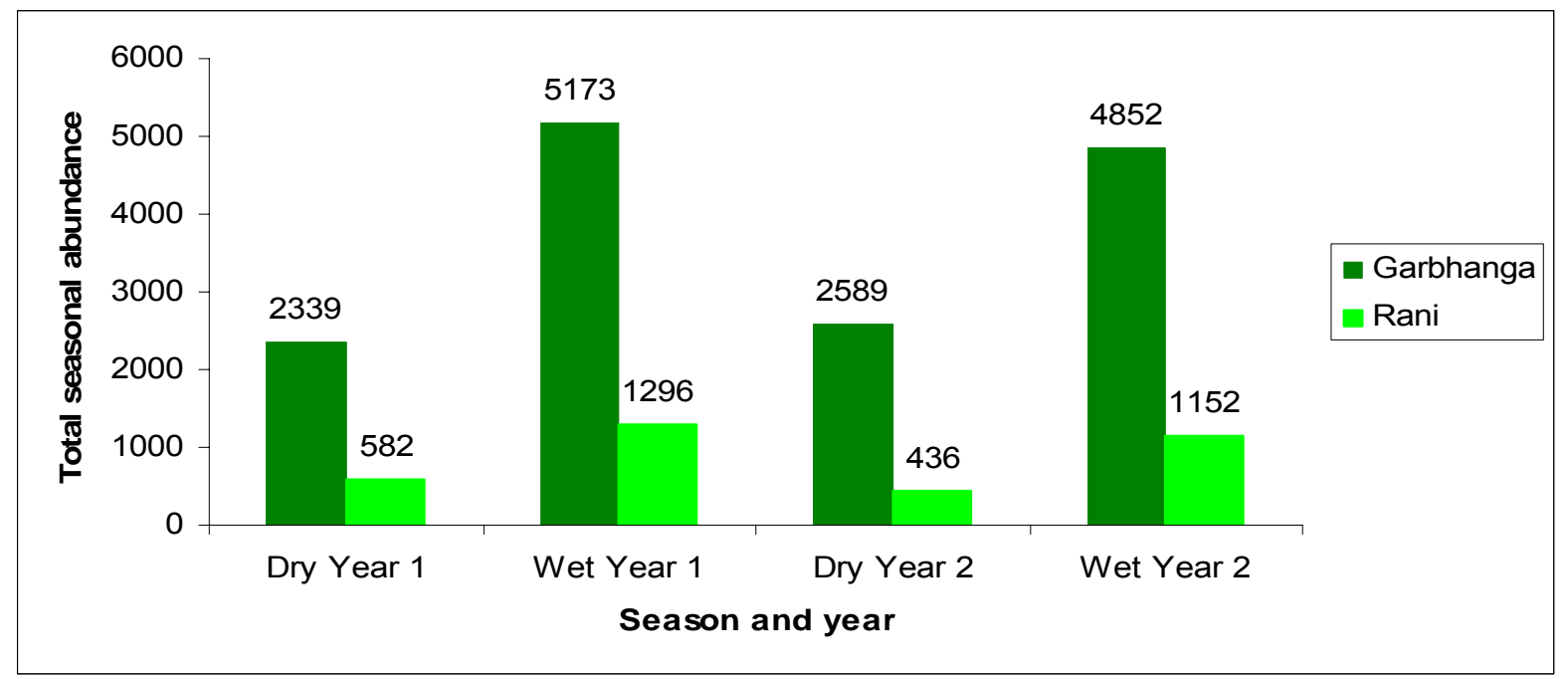

Figure 5.9: Total abundance of swallowtail butterflies sampled in the 20 fixed transects of the study area during the wet and dry seasons of 2003-2004.

In Garbhanga range the abundance of butterflies was higher during dry season of year 2 (2589 vs. 2339). The wet season of year 1 recorded higher abundances than year 2 (5173 vs. 4852) as seen in Fig. 5.9. 


\subsubsection{Differences in mean abundance between seasons and years}

The differences of the mean annual transect abundances of the Papilionidae between the dry and wet seasons of study period (2003-2004) was nearly significant (One-way ANOVA, $F_{1,14}=3.9452, p=0.0669$, see Figure 5.10).

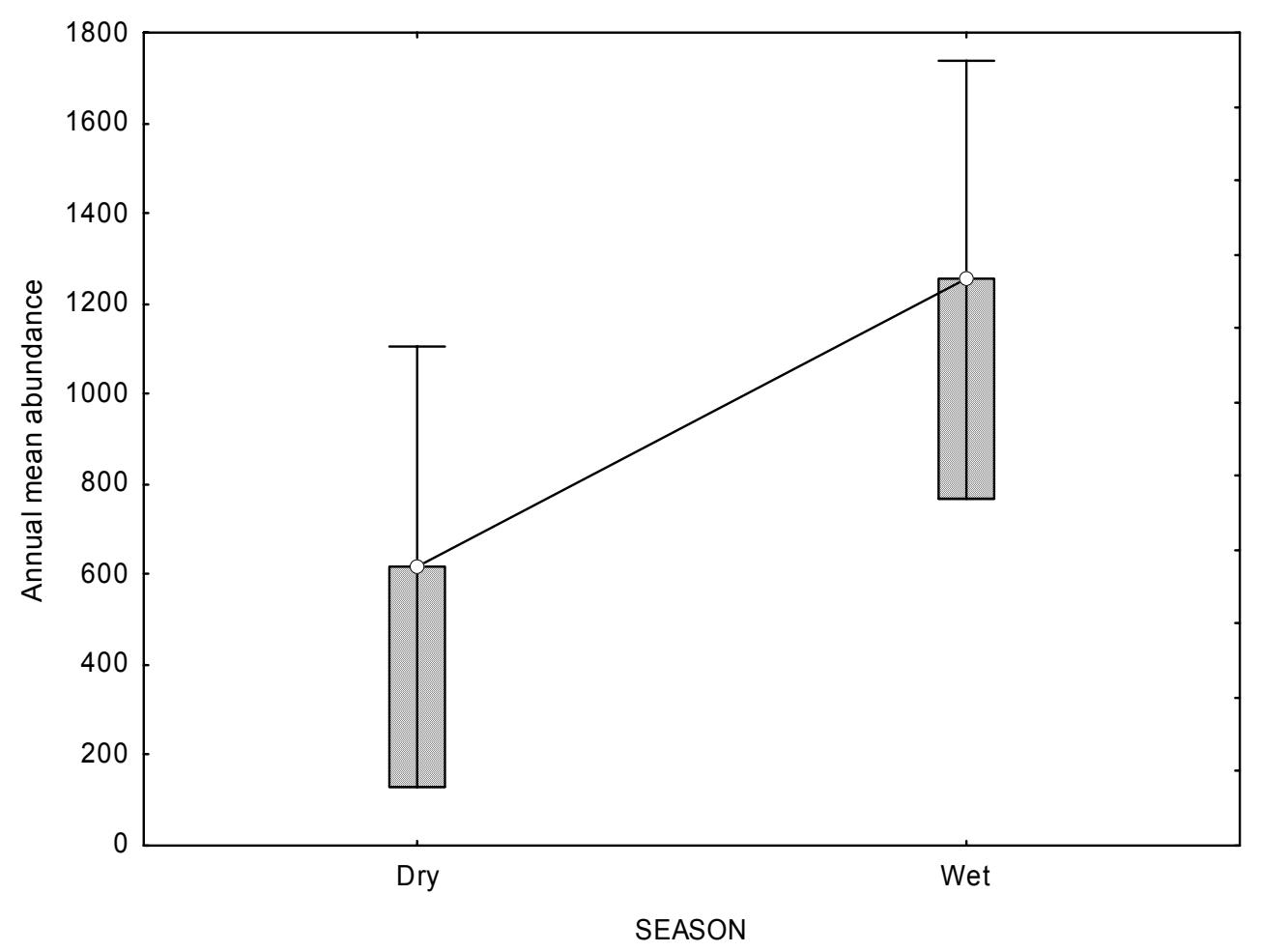

Figure 5.10: Differences in mean annual transect abundance of butterfly individuals between dry and wet seasons of the study period (2003-2004) in Garbhanga range.

In Rani range the dry season of year 1 recorded higher abundances of butterflies than year 2 (582 vs. 436). The wet season of year 1 also recorded higher abundances than year 2 (1296 vs.1152) as seen in Fig. 5.9. The differences in mean annual transect abundances of Papilionidae between the dry and wet seasons of study period (2003-2004) were significant (One-way ANOVA $F_{1,14}=38.626, p=0.00002$, see Figure 5.11). 


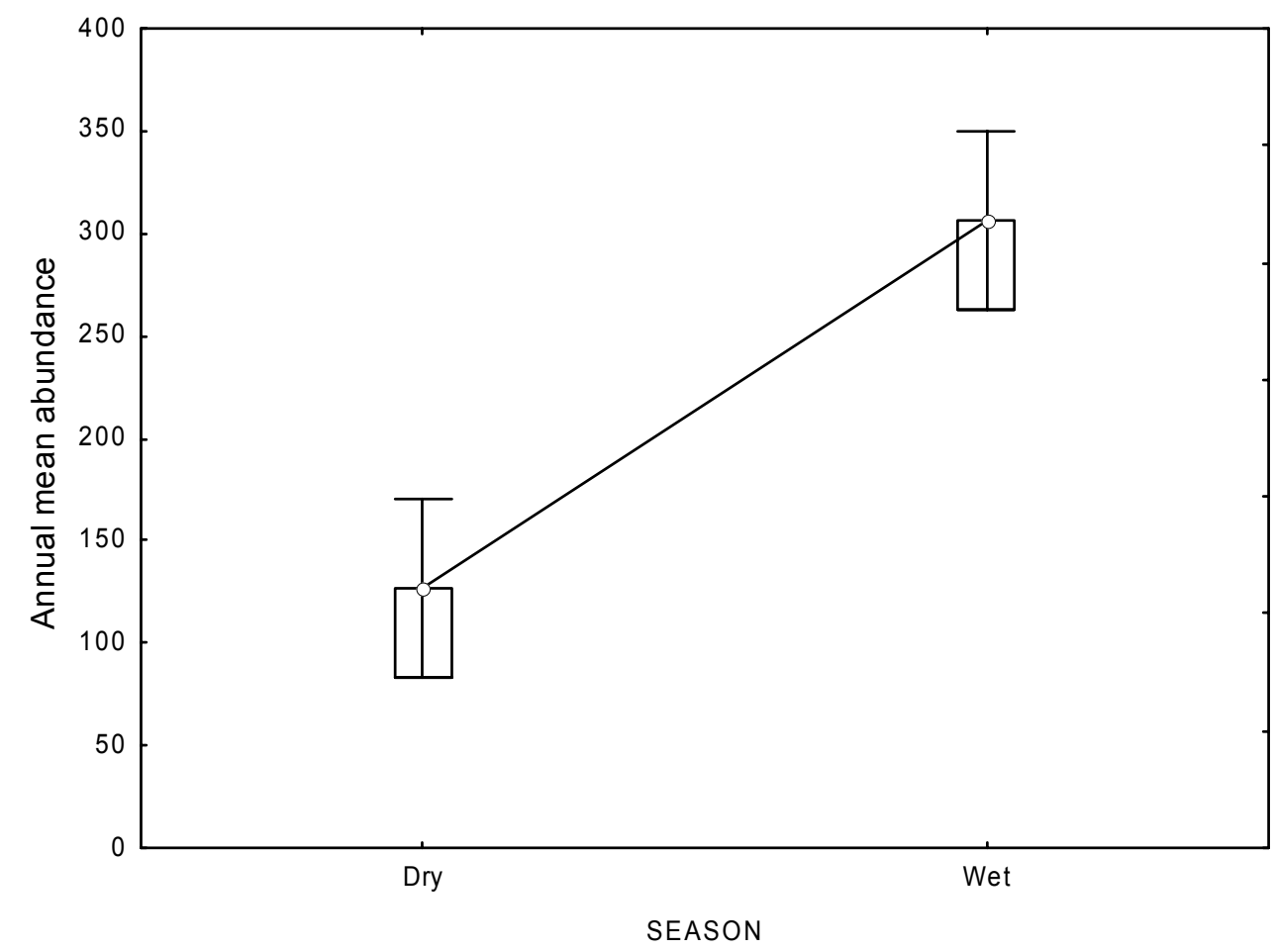

Figure 5.11: Differences in mean annual transect abundance of butterfly individuals between dry and wet seasons of study period (2003-2004) in Rani range.

The mean abundances of Papilionidae were higher during the wet season as compared to the dry season of both the years for the study sites of Garbhanga range (see Fig. 5.12). In the study sites of Rani range, the mean abundances were also higher in the wet as compared to the dry season in both years (see Fig. 5.13). 


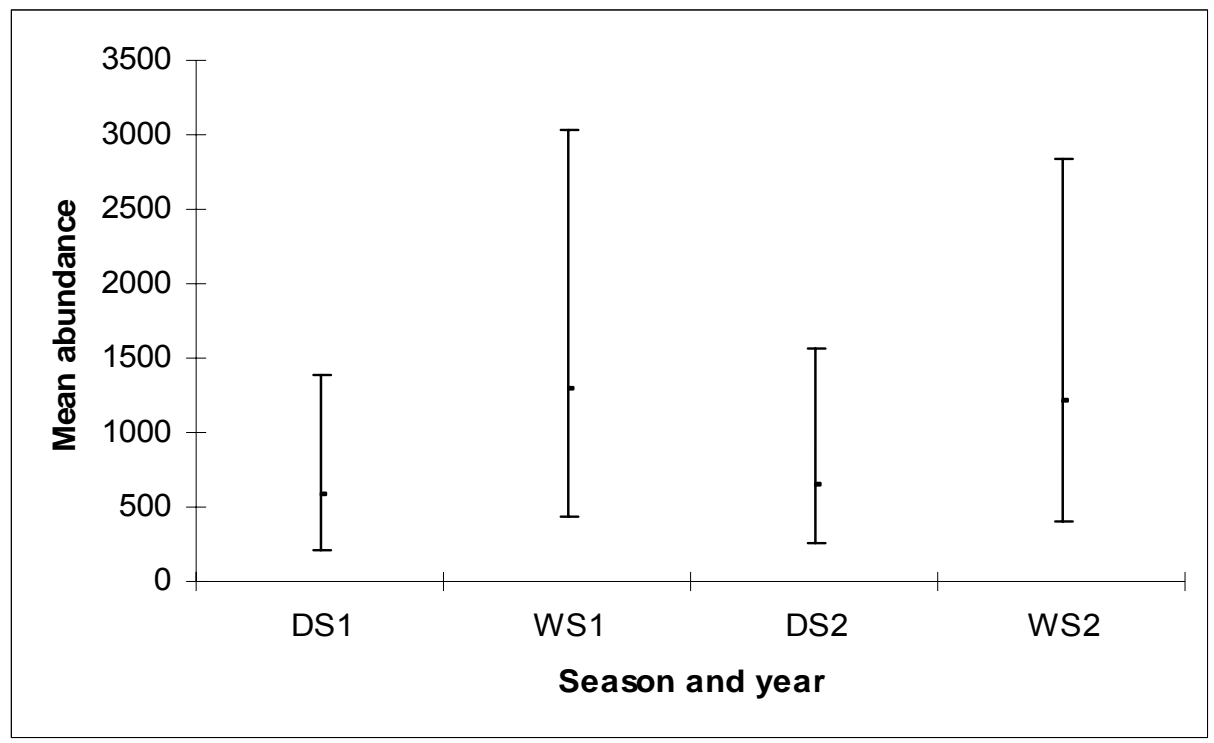

Figure 5.12: Mean abundances (mean number of butterfly individuals per season/year \pm standard error) of swallowtail butterflies sampled as individuals during dry and wet seasons of 2003-2004 in the fixed transects (1-8 for dry and wet season of 2003 again resampled as 9-16 for dry and wet season of 2004) in study sites S1, S2 and S3 of Garbhanga Range (DS1 $=$ Dry season year1, WS1 $=$ Wet season year $1, \mathrm{DS} 2=$ Dry season year $2, \mathrm{WS} 2=$ Wet season year 2).

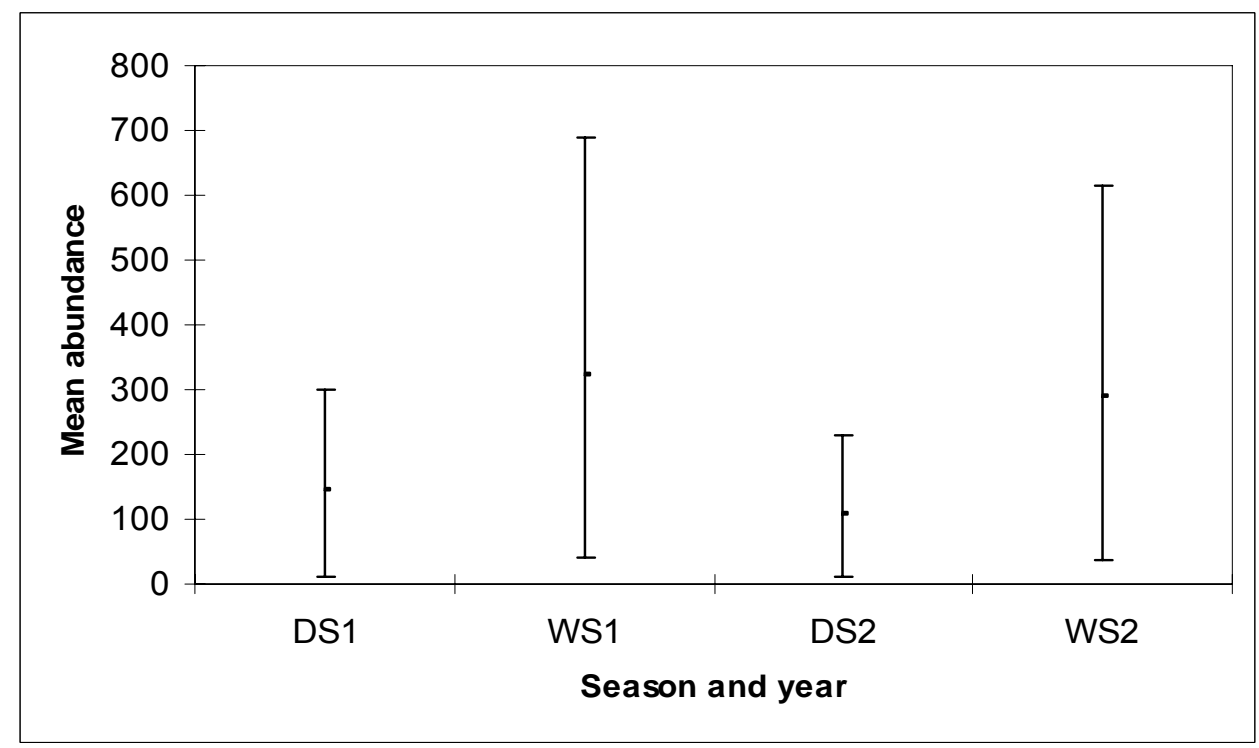

Figure 5.13: Mean abundances (mean number of butterfly individuals per season/year \pm standard error) of swallowtail butterflies sampled as individuals during dry and wet seasons of 2003-2004 in the fixed transects (1-8 for dry and wet season of 2003 again resampled as 9-16 for dry and wet season of 2004) in study sites S4 and S5 of Rani Range. (DS1 = Dry 
season year1, WS1 $=$ Wet seasons year $1, \mathrm{DS} 2=$ Dry season year 2, WS2 $=$ Wet season year 2).

\subsubsection{Differences in abundance between genera}

The genus Graphium (Jays and Bluebottles) showed the highest abundance with 8694 individuals, followed by Papilio (5450), Pathysa (1297) and Chilasa (340). In the 'red-bodied' group, the genus Atrophaneura was represented by 1295 individuals, followed by Troides (756 individuals) and Pachliopta (433). The lowest abundance was found in the genus Lamproptera with only 108 individuals (see Table 5.4 and Fig. 5.14).

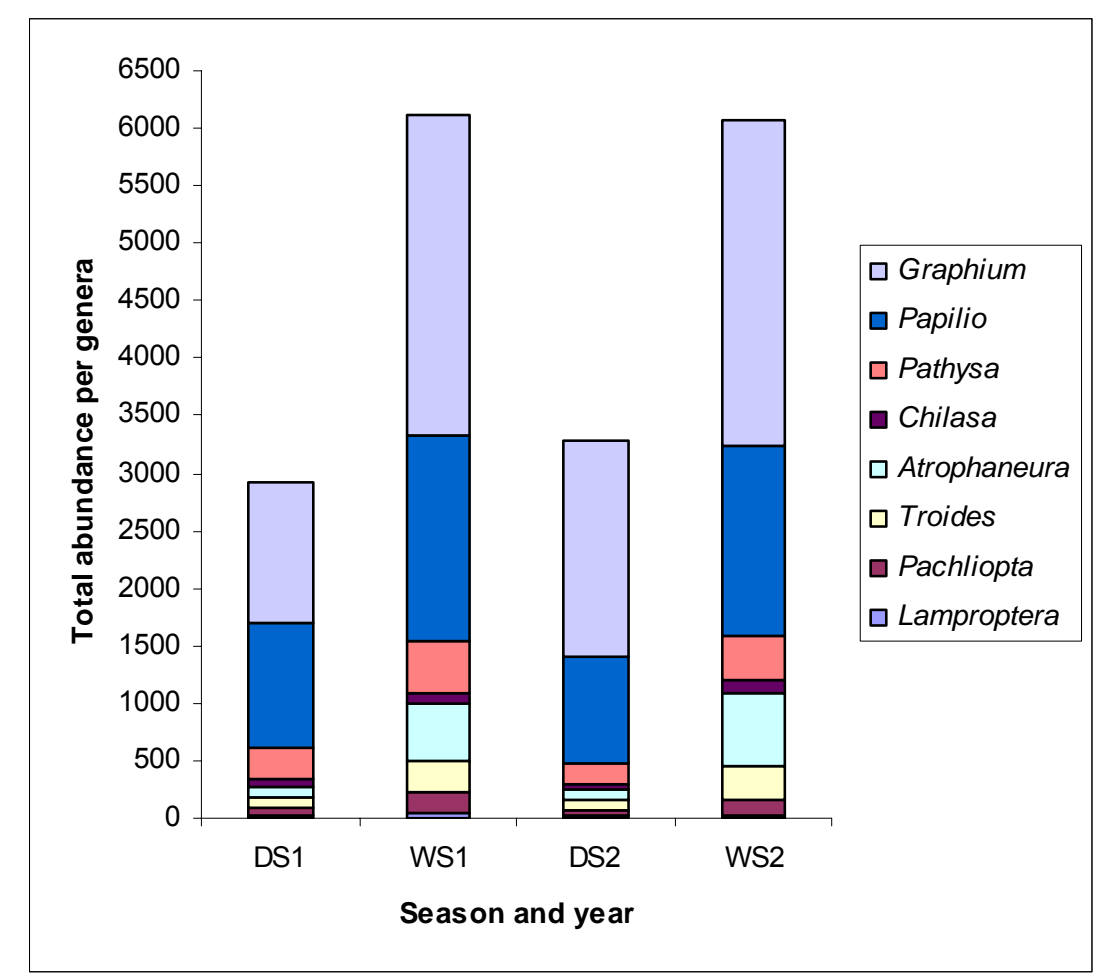

Figure 5.14: Total abundance of swallowtail butterfly individuals per genera recorded during dry and wet seasons of 2003-2004 in study sites (S1-S5) of Rani-Garbhanga Reserve Forest.. $(\mathrm{DS} 1=$ Dry season year1, WS1 = Wet season year 1, DS2 = Dry season year 2, WS2 $=$ Wet season year 2) 
Table 5.4: Total and Mean abundances of Papilionidae genera sampled during dry and wet seasons of 2003-2004 in the 20 fixed transects of the study area

\begin{tabular}{lrrrrrr}
\hline Genera & DS 1 & WS 1 & DS 2 & WS 2 & $\begin{array}{c}\text { Total } \\
\text { abundance }\end{array}$ & $\begin{array}{c}\text { Mean } \\
\text { abundance }\end{array}$ \\
\hline Graphium & 1212 & 2771 & 1886 & 2825 & 8694 & 2173.5 \\
Papilio & 1092 & 1784 & 921 & 1653 & 5450 & 1362.5 \\
Pathysa & 271 & 456 & 194 & 376 & 1297 & 324.25 \\
Chilasa & 59 & 106 & 46 & 129 & 340 & 85 \\
Atrophaneura & 90 & 491 & 87 & 627 & 1295 & 323.75 \\
Troides & 96 & 273 & 100 & 287 & 756 & 189 \\
Pachliopta & 65 & 186 & 39 & 143 & 433 & 108.25 \\
Lamproptera & 26 & 39 & 19 & 24 & 108 & 27 \\
\hline
\end{tabular}

Notes: DS 1 = Dry season year 1 , WS1 $1=$ Wet season year 1, DS $2=$ Dry season year 2, WS $2=$ Wet season year 2

The dominance in the total seasonal abundance of all the genera was pronounced during the wet season of both the years (see Fig. 5.14, Table 5.4). Graphium and Papilio species recorded the highest number of individuals during the wet seasons of both years and the dominance amongst these genera were caused by Graphium sarpedon, Graphium doson, Graphium agamemmnon, Papilio demoleus, Papilio memnon, Papilio polytes and Papilio castor. Both genera also showed relatively small differences in abundances during the dry and wet periods of both years (see Table 5.4). The abundances for the genera Pathysa, Atrophaneura and Troides were also pronounced during the wet seasons of both years. The dominance amongst these genera was caused by Pathysa aristeus, Pathysa antipathies, Pathysa xenocles, Pathysa macareus, Atrophaneura dasarada and Troides aeacus. The genus Pachliopta also recorded high abundances during the wet season of both years but this was mainly caused by Pachliopta aristolochiae. The genus Lamproptera recorded the lowest abundances during dry and wet seasons of both years. Graphium and Papilio were the only genera, which recorded high abundances during dry and wet seasons of both years and this amounted to these two genera having the highest total and mean abundances throughout the study period (see Figs. 5.14 and 5.15). 


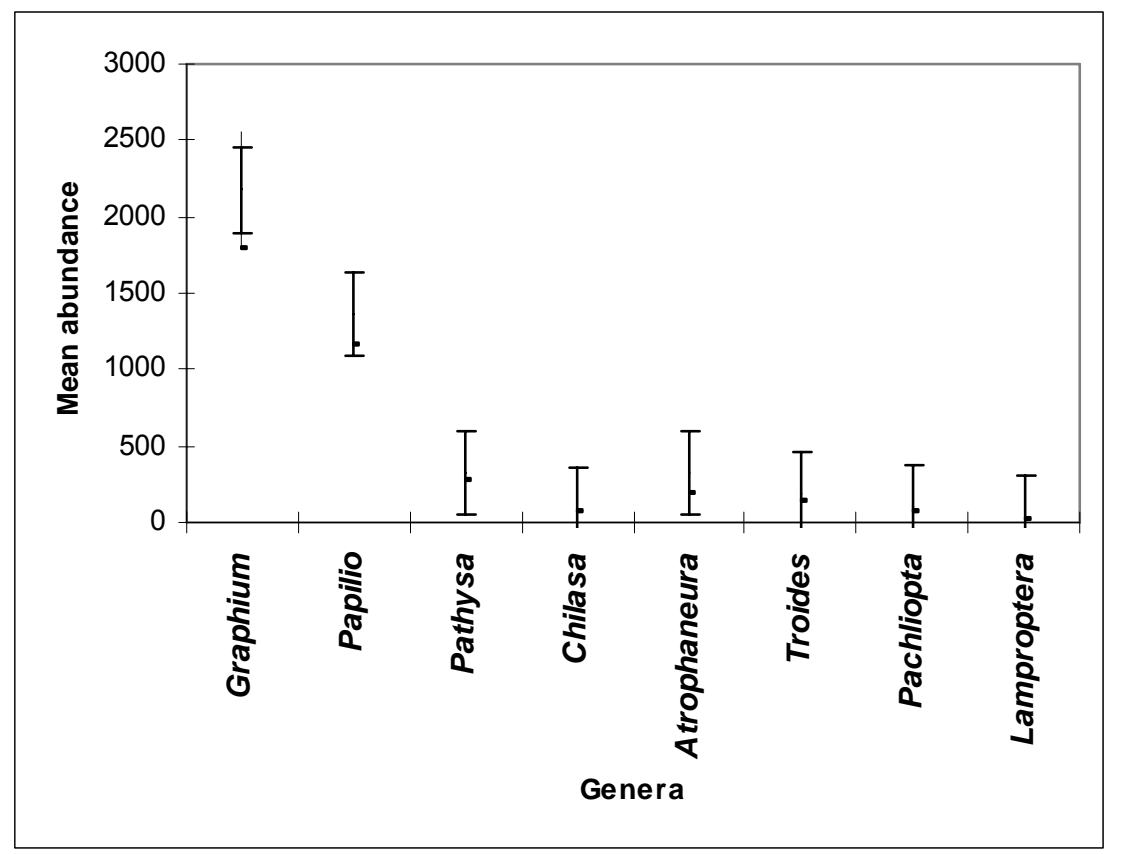

Figure 5.15: Mean abundances of Papilionidae genera sampled as individuals in the 20 fixed transects of the study area during dry and wet seasons of 2003-2004.

\subsubsection{Abundance and Geographic range}

We tried to test the correlation between the mean abundance and geographic range of the identified species within the study area. The correlation tests were done separately for the study sites of Garbhanga and Rani ranges.

5.3.4.1 Correlation between the mean abundance and geographic range of the swallowtail butterfly species assemblages in Garbhanga range

The relationship between the size of geographic range and mean abundance of Papilionidae in the three study sites (pooled data of 12 fixed transects) showed a weak, significant positive correlation (see Fig. 5.16). The Spearman rank correlation was 0.22. 


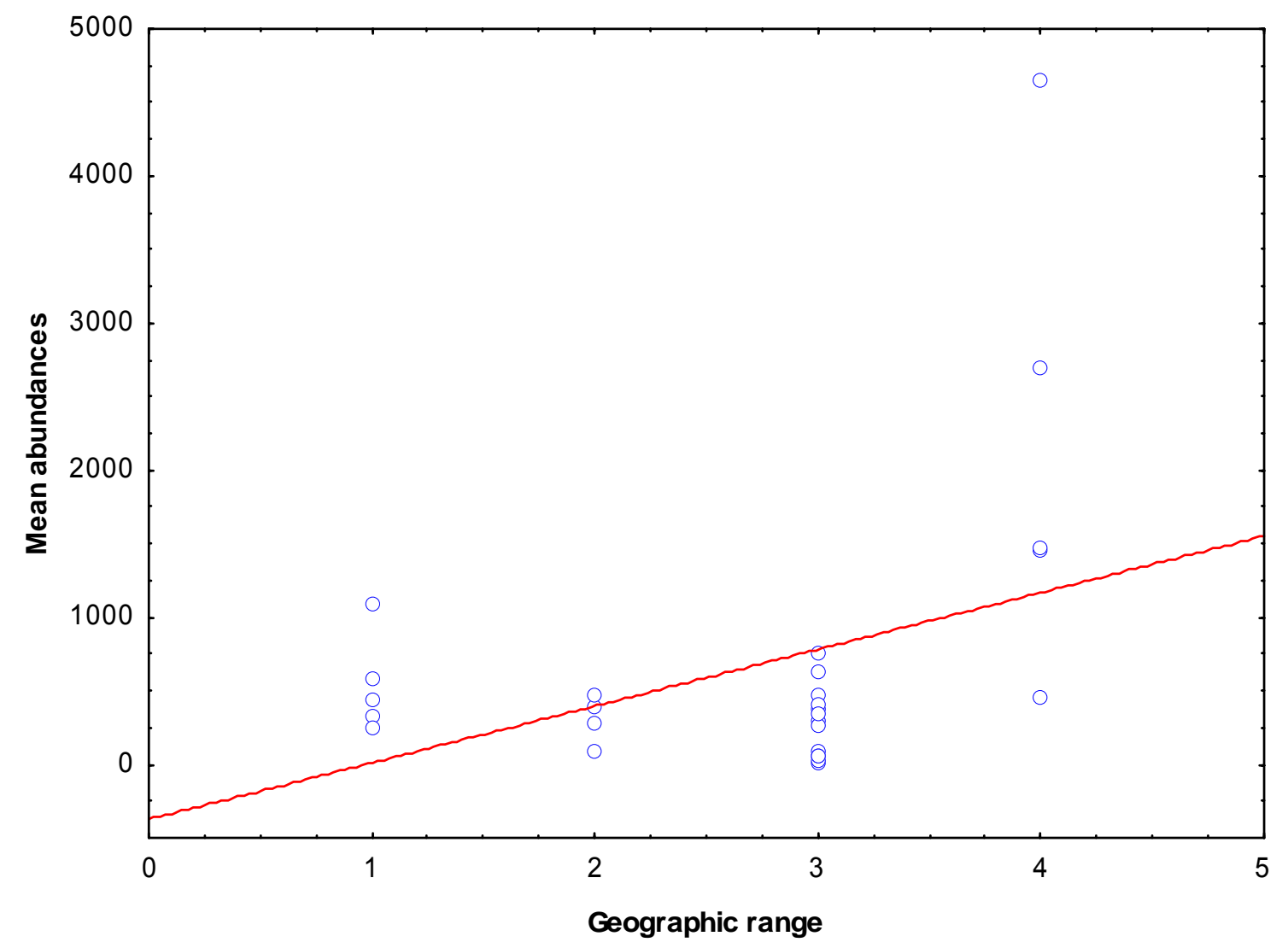

Figure 5.16: The relationship between the geographic range and mean abundance of species assemblages in the study sites (S1, S2 \& S3) of Garbhanga range. Spearman rank correlation $(\mathrm{r}=0.223)$ indicated a significant increase in the abundances of species with wide geographic range $(\mathrm{p}<0.05)$. The geographic range on a scale 1-5 $(1=$ Eastern Himalayas, 2 = Northeast-India \& Indo-China, 3 = Oriental/Indo-Malayan region, $4=$ IndoAustralian region) was assigned according to Spitzer et al. (1993). The line was estimated by means of linear regression $(y=-490.8605+382.6279 * x)$.

The species with restricted geographic range $(1=$ Eastern Himalayas, $2=$ Northeast India \& Indo-China) recorded low abundance while the number of species with geographic range score 3 (Indo-Malayan) was the highest although their mean abundance was $<1000$ individuals. Species with the smallest geographic range $(1=$ Eastern Himalayas $))$ recorded nearly same abundances as those with a range score 3 (Indo-Malayan region), while species with range score 2 (Northeast India \& Indo-China) recorded the lowest abundances. Species with the widest geographic range 4 (Indo-Australian region) also showed wide variations in 
the total abundance $(<1000->4500)$. An isolated case of one restricted range species with geographic range score 1 recording a mean abundance of $\geq 1000$ individuals was also found.

\subsubsection{Correlation between the mean abundance and geographic range of the} swallowtail butterfly species assemblages in Rani range

The relationship between the size of the geographic range and mean abundance of the Papilionidae species assemblages in the two study sites (pooled data of eight fixed transects) of Rani range showed an insignificant but still positive correlation (see Fig. 5.17).

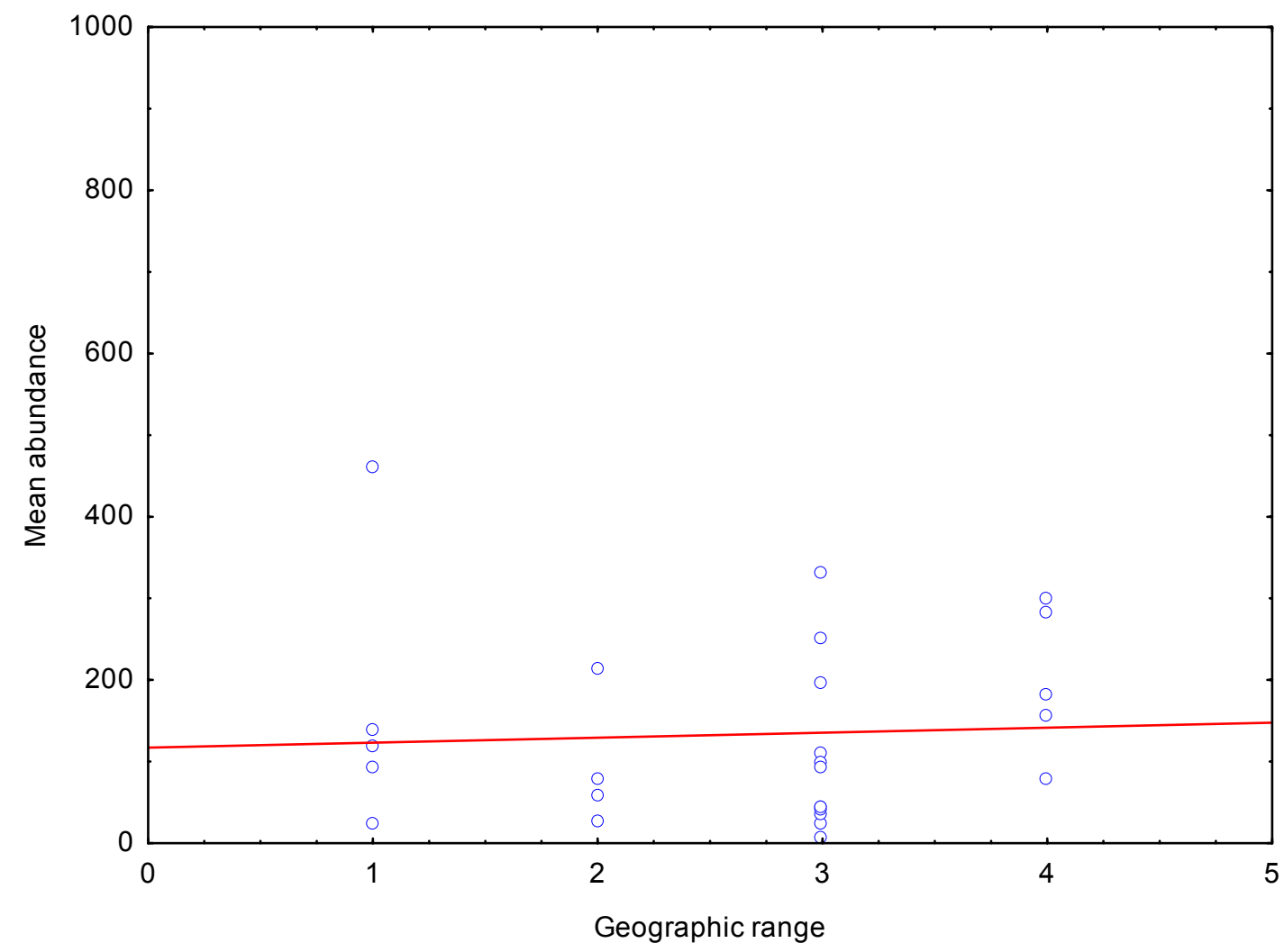

Figure 5.17: The relationship between the geographic range and mean abundance of species assemblages in the study sites (S4 \& S5) of Rani range. Spearman rank correlation ( $\mathrm{r}=$ 0.173) did not indicate a significant increase in the abundances of species with wide geographic range $(p>0.05)$. The geographic range on a scale 1-5 $(1=$ Eastern Himalayas, $2=$ Northeast-India \& Indo-China, $3=$ Oriental/Indo-Malayan region, $4=$ Indo-Australian region) was assigned according to Spitzer et al. (1993). The line was estimated by means of linear regression $\left(y=117.1322+6.0951^{*} \mathrm{x}\right)$. 
There was a significant increase in the mean abundance of species with an increasing geographic range score from 1 ( 1 = Eastern Himalayas) to 3 ( $3=$ Indo-Malayan region) as seen in Fig. 5.17. However the mean abundance of species with the widest geographic range 4 (Indo-Australian) was lower than that of species with range score 3. Moreover an isolated case of one species from the narrowest range 1 (Eastern Himalayas), which recorded higher abundance than species from all other ranges was also observed (see Fig. 5.17).

\subsubsection{Abundance and Feeding guild}

\subsubsection{Papilionidae species and their feeding guild}

The red-bodied group comprising of the genera Atrophaneura (5 species), Pachliopta (2 species) and Troides (2 species) and Chilasa clytia were 'monophagous generalist' as their range of larval diet were limited to the plant families Aristolochiaceae (2 species) and Lauraceae ( 2 species). The black-bodied group comprising of the genus Papilio (8 species) were classified as 'oligophagous generalist' as their larval resources were confined to 10 plant species from the family Rutaceae and only one 'black bodied' species (Papilio demoleus) was 'polyphagous generalist' with larval diet distributed among six plant species from the families Rutaceae and Solanaceae. Three species from the genus Graphium were classified as 'polyphagous generalist' with their larval diet breadth distributed among 10 plant species from the families Lauraceae, Magnoliaceae, Annonaceae and Fabaceae. The host-plants of the genus Pathysa (4 species) could not be identified in the study area although the host association of this genus is known with Annonaceae and Magnoliaceae (Haribal, 1992) and they could be classified as 'polyphagous generalist'. Only two species belonging to the genus Lamproptera were 'monophagous specialist' with their larval resource known to be restricted to one plant species from the family Hernandiaceae. The food-plant of the genus Lamproptera (Dragontails), Illigera cordata (Haribal, 1992) could not be located or identified in the study area (see Appendix $5: 5.10$ \& 5.14). 


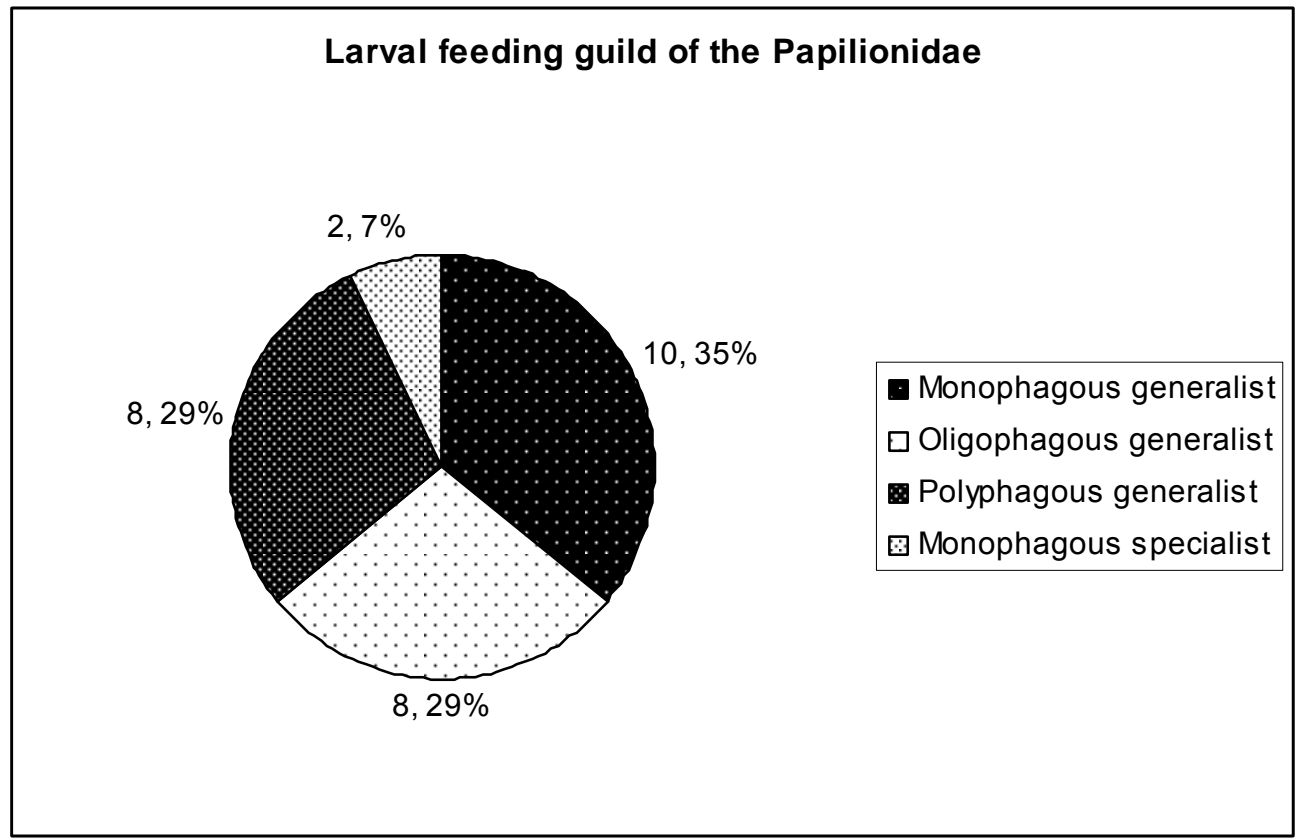

Figure 5.18: Larval diet breadth of the swallowtail butterflies of Rani-Garbhanga Landscape. The number and percentage representation of species per feeding guild are shown as numbers around the pie-diagram.

The overall percentage representation of the generalist feeders was higher than the specialist feeders (see Figure 5.18). The 'monophagous generalist' feeding guild was represented by the highest number of species and amongst these 10 species, nine species belonged to the red-bodied 'Aristolochiae' feeding group.

\subsubsection{Correlation between mean abundance of Papilionidae and their feeling guild}

The relationship between the mean abundance and the feeding guild of the Papilionidae within the study area showed a significant and positive correlation (see Fig. 5.19). The Spearman rank correlation was 0.49 . 


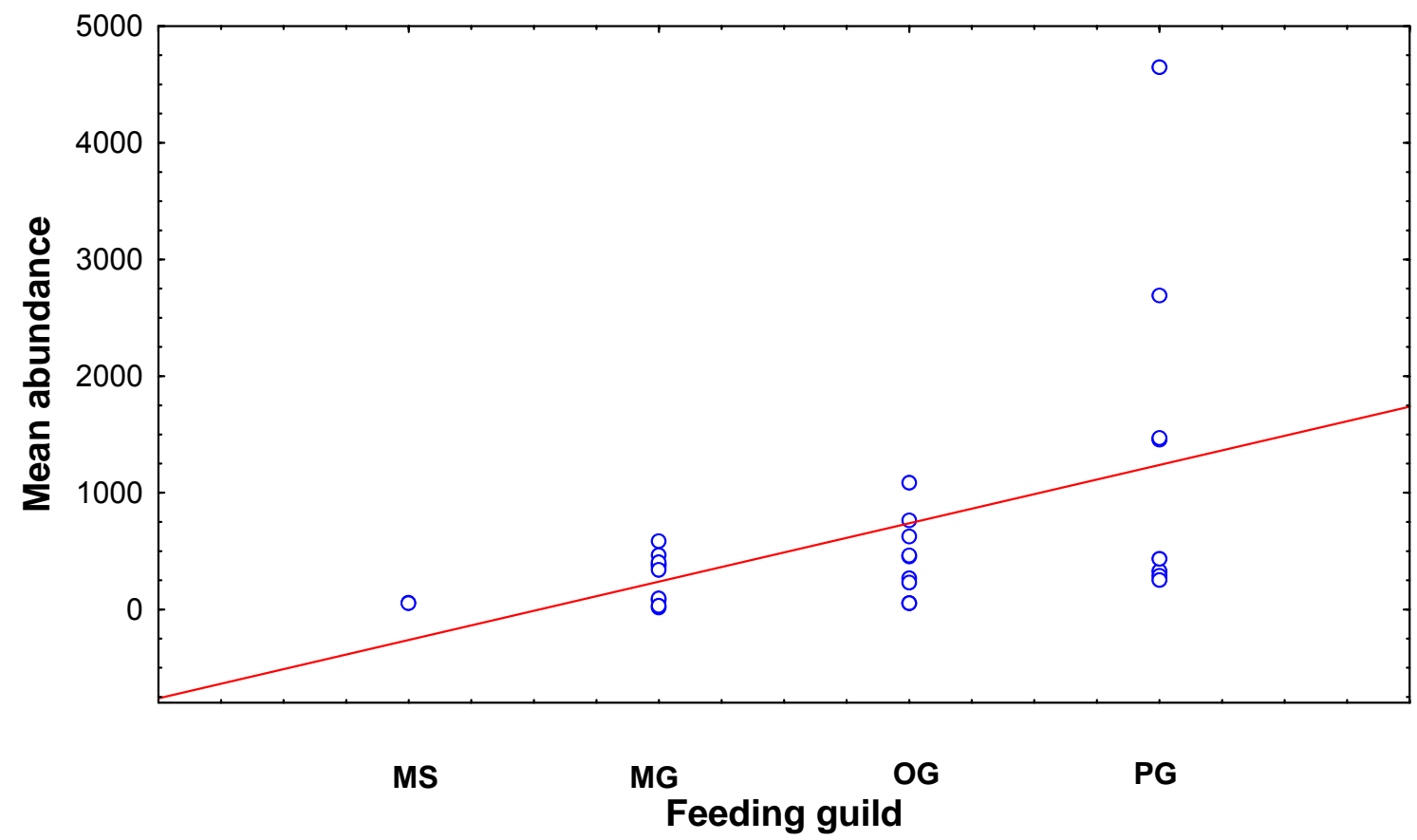

Figure 5.19: Relationship between mean abundance and feeding guild of the species assemblages in the study area. Spearman rank correlation $(r=0.49)$ indicated a marked increase in the mean abundance of generalist feeders from monophagy to polyphagy. The line was estimated by means of linear regression $\left(y=-762.2618+500.3036^{*} x\right)$. The feeding guild of the swallowtail butterflies was assigned as MS $=$ Monophagous Specialist, $M G=$ Monophagous Generalist, $\mathrm{OG}=$ Oligophagous Generalist, $\mathrm{PG}=$ Polyphagous Generalist)

Although the number of monophagous species recorded in the study area was the highest (12 species), this feeding guild recorded the lowest mean abundance $(<1000)$ while the polyphagous feeders ( 8 species) were the most abundant in the study area $(\geq$ 3000). The oligophagous feeding guild ( 8 species) also recorded lower abundances than the polyphagous guild $(\leq 1000)$. The Spearman rank correlation coefficient was weak but positive $(r=0.49)$ and significant $(p=0.0068)$ (see Fig. 5.19). There was a marked increase in the generalist feeders from monophagy to polyphagy as seen in Fig. 5.19. The list of the swallowtail butterfly species recorded in the study area along with their respective feeding guilds are given in Appendix 5: 5.10). 


\subsection{Ordination of the swallowtail butterfly assemblages in relation to their abundance and distribution or habitat specificity}

The matrix of butterfly abundance used in analyses is presented in Appendix 5: 5.15 - 5.22. Constrained Correspondence Analysis (CCA) is a method of constrained ordination and it aims to relate the species composition of a community to external (environmental) variables. To investigate the effects of environmental variables on the species space as well as season and the continuum, data were collected from the four fixed transects in each study site twice in a year for 2 successive years, e.g., transect 1 sampled in dry season of 2003 is again sampled as transects 5, 9 and 13 in wet season of 2003, dry season of 2004 and wet season of 2004 respectively. The sets of environmental variables used for the multivariate ordination are presented in Appendix 4: 4.2 - 4.4) and the summary of the analyses are presented in Appendix 5: $5.23 \&$ 5.24. The analyses were performed in ' $\mathbf{R}$ ' using the 'Vegan' subroutine.

\subsubsection{Ordination of the swallowtail butterfly assemblages in relation to their abundance and distribution in Garbhanga range}

\subsubsection{Ordination of the group assemblages (Genus-wise)}

The ordination plot shows the effect of rainfall, year, altitude, latitude and longitude (shown as vectors or arrows), and season and forest type (shown as categorical variables separated by 1 st and 2nd axes) on the Papilionid group assemblages (genus-wise) within the study sites (see Fig. 5.20). Species and group assemblages increasing in abundance during the study period are found towards the centre of origin and those decreasing are deviated from the centre of the ordination diagram. Mormons (Papilio sp.), Limes (Papilio demoleus), Zebras (Pathysa sp.), Swordtails (Pathysa sp.), Jays and Bluebottles (Graphium sp.) were recorded in high abundances and could be classified as fairly common, while Windmills and Batwings (Atrophaneura sp.), Birdwings (Troides sp.) and Ravens (Papilio castor castor) were rare. Peacocks and Helens (Papilio sp.), Roses (Pachliopta sp.) and Dragontails (Lamproptera sp.) were intermediate. The axes clearly differentiate the seasons (horizontal) and forest types (vertical) thus showing the effect of season and habitat (forest type) on the group assemblages of swallowtail butterflies within the study sites. The succession of butterfly abundance (season to season and year to year) can be seen from the 
shifting pattern of the transects shown as numbers in the ordination diagram (Transect 1 sampled in the scattered forests of the study sites during dry season of year 1 is resampled as transect 5 in wet season of year 1 and again sampled as transect 9 in dry season of year 2 and as transect 13 for wet season of year 2).

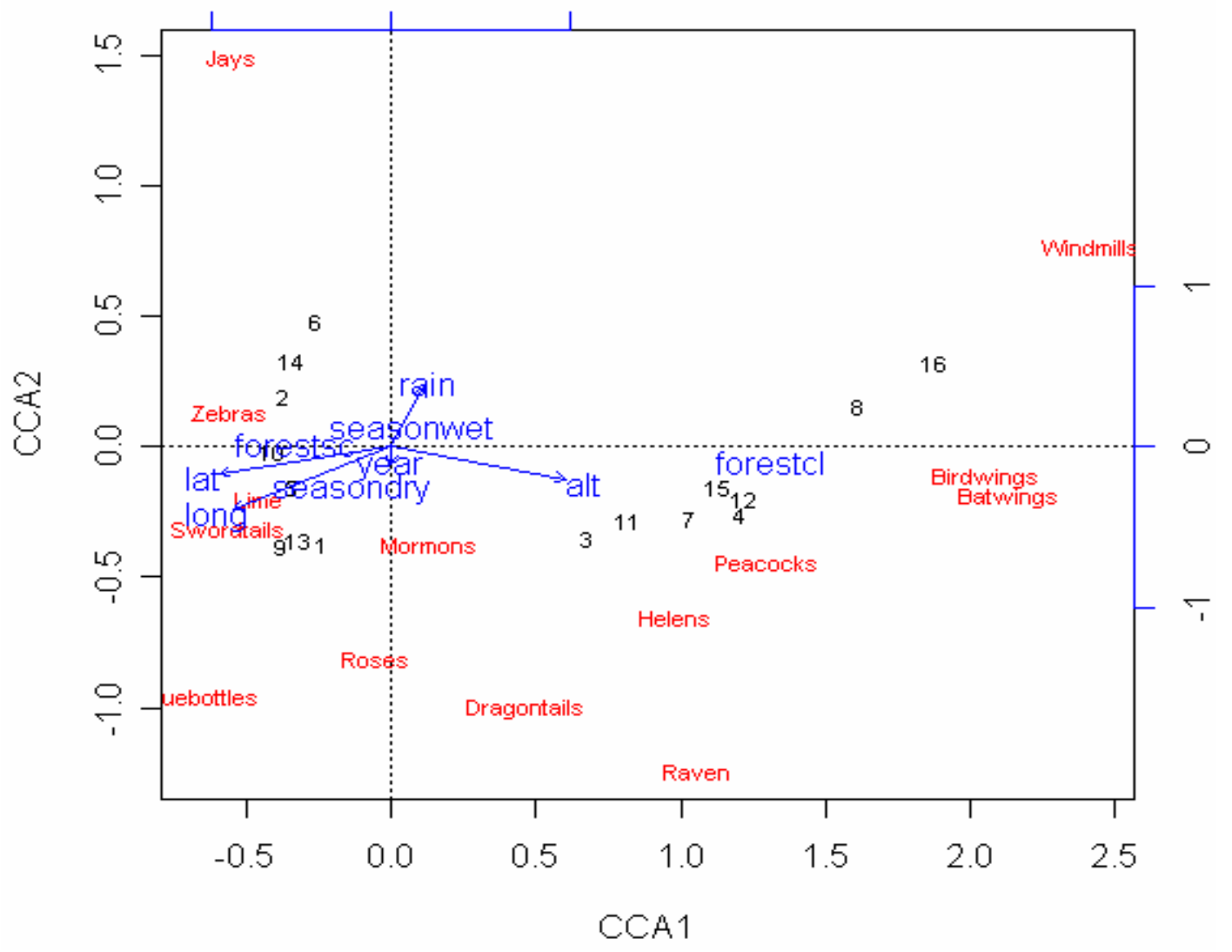

Figure 5.20: CCA ordination of swallowtail butterfly abundance in Garbhanga range (S1, S2 $\&$ S3). The first and the second CCA axes are shown. Blue arrows indicate the direction of influence of continuous variables, while season (season wet and season dry) and forest type (forest $\mathrm{CL}$ and forest SC) are the centroids of categorical variables or ordered factors. Butterflies by group assemblages (common names) are labeled in red and the site scores or transects are in numbers (black). The independent variables in arrows are abbreviated as : lat $=$ latitude, long $=$ longitude, alt $=$ altitude, rain $=$ total rainfall during sampling season, year $=2$ years of study (2003 \& 2004).

The lengths and positions of the arrows provide information about the relationship between the environmental variables and the derived axes. Arrows that are parallel to an axis indicate a correlation - there is a correlation between altitude, latitude, longitude and axis 1 and similarly a correlation between rainfall, year and axis 2 (see Fig. 5.20). The 
directions of the arrows indicate the direction of maximum change of that variable across the ordination plot. In the ordination plot (see Fig. 5.20), altitude affects the abundances of Peacocks and Helens (Papilio sp.), Birdwings (Troides sp.), Batwings (Atrophaneura sp.) increasing altitude is correlated with increasing abundances of these genera or group assemblages. Similarly lower altitude implies more abundance of Zebras and Swordtails (Pathysa sp.) and Limes (Papilio sp.). The length of the arrow indicates the strength of that correlation. Thus a long arrow for altitude indicates a large change and implies that change in altitude is strongly correlated with the butterfly community variation as shown by the ordination diagram (see Fig. 5.20).

Sampling sites that are located close to each other in the ordination are assumed to have similar species composition and environmental conditions (Storch et al., 2003). However in our ordinations, as the pooled transects are already partitioned by season and forest types, we have tried to show the effects of year and season on the butterfly abundance by each transect. Considering the 1st transect, (points or sites 1, 5, 9 and 13 as seen in Fig. 5.20), there was an increase in the butterfly abundance during the wet season of the first year, but the dry season in year 1 and both dry and wet seasons in year 2 were more or less same in terms of butterfly abundance. Again transect 4 in the closed forest is resampled as transects 8, 12 and 16 and in the ordination plot it is seen that transects 8 and 16 are deviated from the centre indicating low abundances of butterflies during wet season of both years 1 and 2 while transects 4 and 12 are nearer to the origin indicating comparatively higher abundances of butterflies during the dry season of years 1 and 2. Thus transects located closer to the origin indicated higher abundances of species during the sampling period and those located far from origin indicated decreasing abundances with respect to year, season and forest type. Therefore the sites scores in the ordination plot showed the changing abundances of butterfly communities throughout the study period while the group scores showed the overall distribution pattern of the Papilionidae group assemblages within the study area.

Although Graphium species recorded the highest proportional abundances in the study area, in the ordination on the group and species assemblages (see Figs. 5.20, 5.21\& 5.22) Jays and Bluebottles (Graphium sp.) are deviated from the centre indicating lower abundance throughout the study period; This can be explained by their high abundances in scattered forests and low abundances in closed forest in both years and in wet and dry 
seasons resulting in a shift from center in the constrained ordination map. Again if we examine the relative position of the Limes (Papilio demoleus) and Zebras and Swordtails (Pathysa sp.) in the ordination plots we can see that these group or species assemblages are more concentrated towards the centre (Figs. 5.20, $5.21 \&$ 5.22). The abundances of the Limes (Papilio demoleus) were directly related to the amount of rainfall - lower rainfall implied higher abundances of Papilio demoleus and secondly more number of individuals was encountered in transect 1. Higher abundances of Zebras and Swordtails (Pathysa sp.) recorded in transect 1 compared to the other transects could have been attributed to the abundant mud-puddling sites in transect 1 .

\subsubsection{Ordination of the species assemblages}

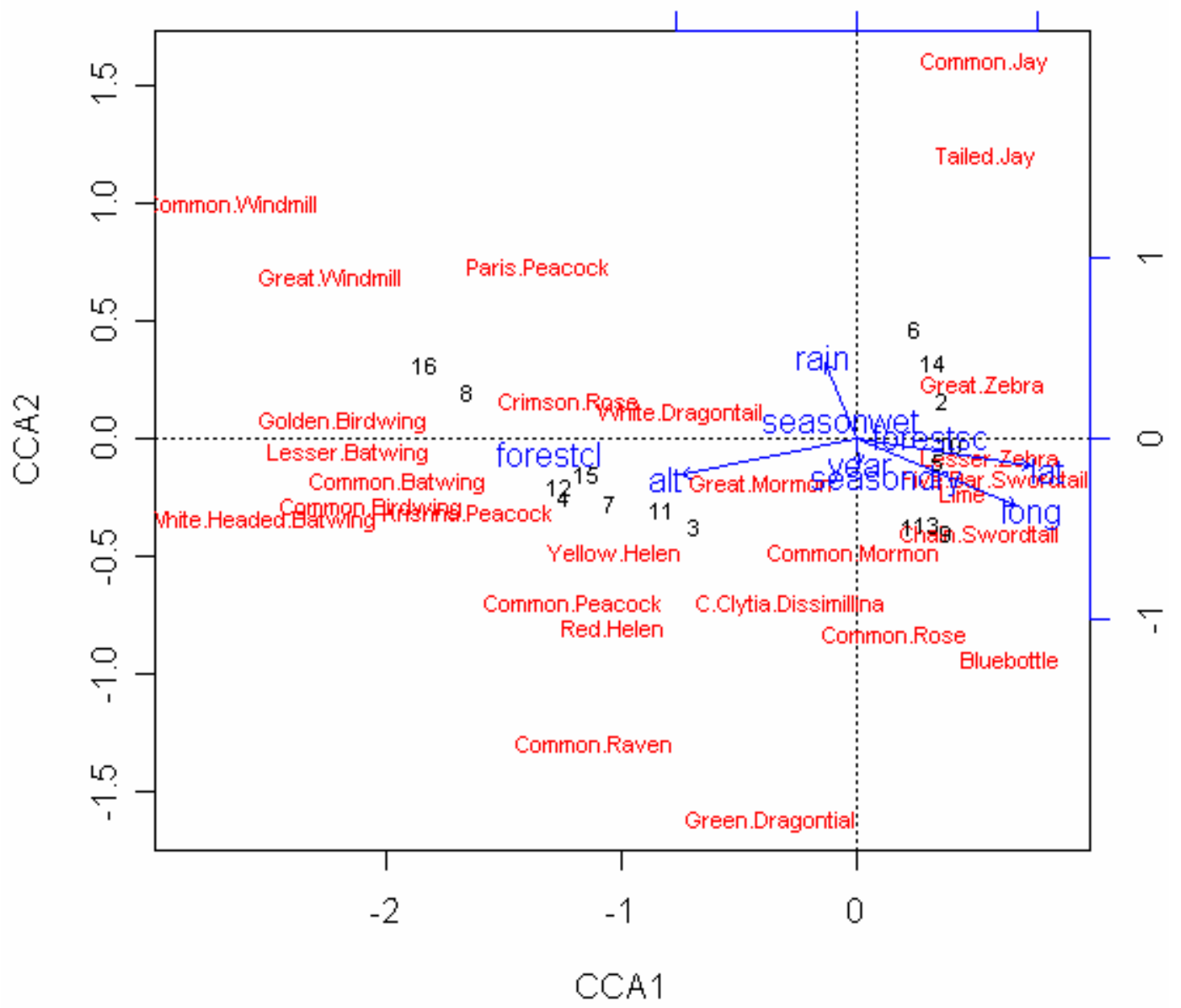

Figure 5.21: CCA ordination of locations and distribution of swallowtail butterflies of Garbhanga range (pooled data of 12 fixed transects of study sites S1, S2 \& S3) in species space. Site scores or transects are in numbers (black). Transects 1-4 (Dry season) are repeated for the wet season (5-8) for year 1 and again for year 2 (9-12 for dry season and 
13-16 for wet season). The ordination plot shows the species assemblages (Common names) in red. The independent variables in arrows are abbreviated as : lat $=$ latitude, long $=$ longitude, alt $=$ altitude, rain $=$ total rainfall during sampling season, year $=2$ years of study (2003 \& 2004).

The gradual change in the species abundance from wet to dry season and from 1st to the 2 nd year can be visualised. Transect 3 in the closed forest sampled during dry season of year 1 is deviated from the centre indicating lower abundances of butterflies. The same transect when resampled in the same forest type showed decreasing abundances of species assemblages during the sampling period with respect to season and year - transect 3 resampled as transects 7,11 and 15 are deviated from the centre indicating lower abundances of butterflies during the wet season of year 1 and dry and wet seasons of year 2 . The overall site scores in the ordination plot indicated higher abundances of butterflies encountered in the open forest transects (see Figs. $5.21 \& 5.22$ ).

Jays and Bluebottles (Graphium sp.), Zebras and Swordtails (Pathysa sp.), Limes (Papilio demoleus), were characteristic of scattered or open forests, while Birdwings (Troides sp.), Batwings and Windmills (Atrophaneura sp.) occupied the closed forest. Ravens, Mormons and Peacocks (Papilio sp.), Roses (Pachliopta sp.), Mimes (Chilasa clytia) and Dragontails (Lamproptera sp.) were intermediate (see Fig.5.20). In the ordination map on species assemblages (see Fig. 5.21) a similar pattern on the habitat specificity of the swallowtail butterflies as in the group assemblages (see Fig. 5.20) is observed. The scattered/open forest type had a significantly higher abundance as compared to the closed forest type $(p<0.001)$ although the number of closed forest species was higher than the open forest species (Fig.5.21). Endemic species from the closed forest like Great Windmill (Atrophaneura dasarada), Common Batwing (Atrophaneura varuna), Golden Birdwing (Troides aeacus), Common Raven (Papilio castor), Krishna Peacock (Papilio krishna) with restricted geographic ranges were deviated from the centre while open forest species with wider geographic ranges like the Limes (Papilio demoleus), Five-Bar Swordtail (Pathysa antipathies), Lesser Zebra (Pathysa macareus), Great Mormon (Papilio memnon) were relatively close to the origin (see Fig. 5.21). Again endemic species from the open forest like Chain Swordtail (Pathysa aristeus) and Great Zebra (Pathysa xenocles) were closer to the origin while wide-ranging species like Common Jay (Graphium doson), Tailed Jay (Graphium agammemnon), Bluebottle (Graphium sarpedon) and Green Dragontail 
(Lamproptera meges) were deviated from the origin because both endemics and wideranging species were not represented in all the transects.

\subsubsection{Effect of independent variables on species assemblages within Garbhanga range}

Continuum of seasonal abundance of swallowtail butterflies in the study sites is significant as the direction of the arrow showing year as a variable is highly correlated with axis 2 (see Figs. 5.20, 5.21\& 5.22). The abundances of species typical of closed forests such as Common Windmill (Atrophaneura polyeuctes), Great windmill (Atrophaneura dasarada), Lesser Batwing (Atrophaneura aidoneus), Golden Birdwing (Troides aeacus), Paris Peacock (Papilio paris) and species from the scattered/open forests like Common Jay (Graphium doson), Tailed Jay (G. agammemnon) and Great Zebra (Pathysa xenocles) were higher during the wet seasons of both years. The abundances of closed forest species such as Common Batwing (Atrophaneura varuna), White-headed Batwing (Atrophaneura sycorax), Common Birdwing (Troides helena), Common Peacock (Papilio polyctor), Krishna Peacock (Papilio krishna), Yellow Helen (Papilio nephelus), Red Helen (Papilio helenus) and Common Raven (Papilio castor) and of species typical of open forests such as Swordtails and Zebras (Pathysa sp.) decreased as year progressed - abundances were higher during year 1 (see Figs. 5.21\& 5.22). However the length of the arrow showing the effect of year indicated that year as an independent variable did not have a significant effect on the changing abundances of the butterfly species assemblages or that there were not significant differences in the abundances of butterflies between the two years (see Figs. 5.20, $5.21 \&$ $5.22)$.

The direction of the arrow showing the effect of the amount of rainfall on the swallowtail butterfly assemblages within the sampling period indicated that rainfall was highly correlated with axis 2 (see Figs. 5.20, 5.21\& 5.22). The abundances of Graphium doson (Common Jay) and Graphium agammemnon (Tailed Jay) from the open forests and Atrophaneura dasarada (Great Windmill), A polyeuctes (Common Windmill) and Papilio paris (Paris Peacock) from the closed forests were affected by rainfall and showed higher abundances with higher amount of rainfall during the wet season as year progressed. Species like the Golden Birdwing (Troides aeacus), Common Birdwing (Troides helena), and Red Helen (Papilio helenus) from the closed forests and Great Mormon (Papilio memnon), Common Mormon (Papilio polytes) and Common Rose (Pachliopta aristolochiae) from the intermediate areas and Papilio demoleus (Limes), Swordtails 
(Pathysa sp.) and Bluebottles (Graphium sarpedon) from the open forests showed declining abundances with decreasing rainfall (see Figs. $5.21 \& 5.22$ ). However the length of the arrow showing rainfall as an independent variable did not indicate an overall large or significant change on the butterfly abundances.

The direction of the arrow showing the effect of altitude on the abundances of butterflies indicated that species characteristic of closed forest were found to have higher abundances at higher elevations and species typical of open forests were found to have higher abundances at lower elevations (see Figs 5.20, 5.21\& 5.22). Altitude as an independent variable was found to be correlated with axis 1 and the length of the arrow for altitude also showed a strong correlation implying a large variation in the abundances of the closed forest species with increasing elevation (see Figs. 5.20, $5.21 \& 5.22$ ).

The direction of the arrows showing latitude and longitude as variables indicated that there was a significant correlation between the geographical position of the study sites (habitats or forest types) and abundances of the butterfly assemblages within the forest reserve (see Figs. 5.20, $5.21 \&$ 5.22). The arrows for latitude and longitude are correlated with axis 1 and the lengths of the arrows also indicate a large variation in the abundance of the species assemblage. However this correlation between geographical position and species abundance and distribution could not be meaningfully explained probably due to the small geographical area of the study sites and the proximity between the sampling transects.

The ordination of the species assemblages by their scientific names are presented in Fig. 5.22 and shows the same results as described above for the effects of the independent and categorical variables on the habitat association and changing abundance patterns of the swallowtail butterfly community in the three study sites of Garbhanga range across the study period. 


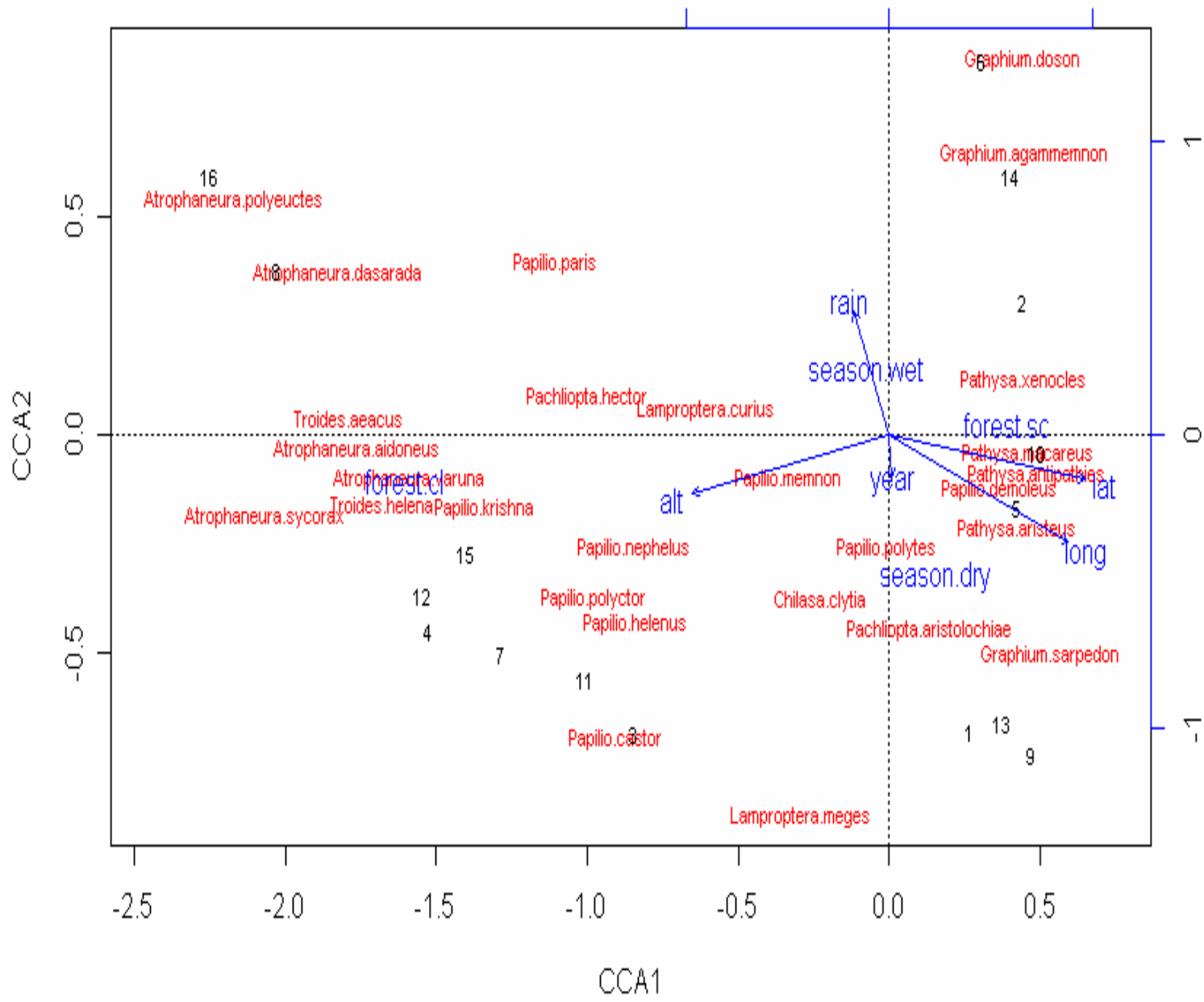

Figure 5.22 : CCA ordination of locations and distribution of swallowtail butterflies of Garbhanga range (pooled data of 12 fixed transects of study sites S1, S2 \& S3) in species space. Site scores or transects are in numbers (black). Transects 1-4 (Dry season) are repeated for the wet season (5-8) for year 1 and again for year 2 (9-12 for dry season and 13-16 for wet season). The ordination plot shows the species assemblages (Scientific names) in red. The independent variables in arrows are abbreviated as : lat $=$ latitude, long $=$ longitude, alt $=$ altitude, rain $=$ total rainfall during sampling season, year $=2$ years of study (2003 \& 2004).

In Garbhanga range ( 3 study sites and pooled data from 12 transects) it was seen that the CCA axes 1 and 2 explained around $62 \%$ variation by all the constraints in the abundance (genus wise), while a total of $69 \%$ variation in the data were explained by both axes. The permutation test for CCA under direct model (all constraints together) were 
significant $(\mathrm{p}<0.001)$. In species abundance, the CCA axes 1 and 2 explained $61 \%$ variation out of the total $71 \%$ and the full model was significant $(\mathrm{p}<0.001)$ (see Permutation test in Appendix 5: 5.23.4).

\subsubsection{Ordination of the swallowtail butterfly assemblages in relation to their abundance and distribution in Rani range}

\subsubsection{Ordination of the group assemblages (Genus-wise)}

The ordination plot for Rani range (see Fig. 5.23) shows Birdwings (Troides sp.), Peacocks and Helens (Papilio sp.), Dragontails (Lamproptera sp.), Swordtails (Pathysa sp.), Jays and Bluebottles (Graphium sp.) were having high abundances and could be classified as common while Limes and Mormons (Papilio sp.), Zebras (Pathysa sp.), Mimes (Chilasa clytia) and Windmills (Atrophaneura sp.) recorded low abundances and could be classified as rare. Ravens (Papilio sp.), Batwings (Atrophaneura sp.) and Roses (Pachliopta sp.) recorded moderate abundances. The separating effects of habitat on the group assemblages were clearly indicated in the ordination plot as the Jays and Bluebottles (Graphium sp.), Zebras and Swordtails (Pathysa sp.) and Roses (Pachliopta sp.) were characteristic of scattered forests while others occupied the closed forests. Transects overlaid on the ordination matrix showed the effect of season and year on the abundances of butterflies. Transect 1 is deviated from the centre indicating lower abundances of butterflies in the scattered or open forest during the dry season of year 1 . The same transect is resampled as 5 , 9 and 13 during the wet season of year 1 and dry and wet seasons of year 2 . The relative positions of 5, 9 and 13 on the ordination matrix indicated that these sites recorded an overall higher abundance of butterflies during the latter part of the sampling period and the wet season of year 2 (site 13 in the ordination) recorded the highest abundance. Thus the gradual change in the butterfly abundance with respect to season and year is clearly indicated by the position of the sites scores in the ordination diagram (see Fig. 5.23). Altitude is being represented by axis 1 and amount of rainfall as well as year are represented by axis 2 . However latitude and longitude was not correlated to any axis (see Fig. 5.23). 


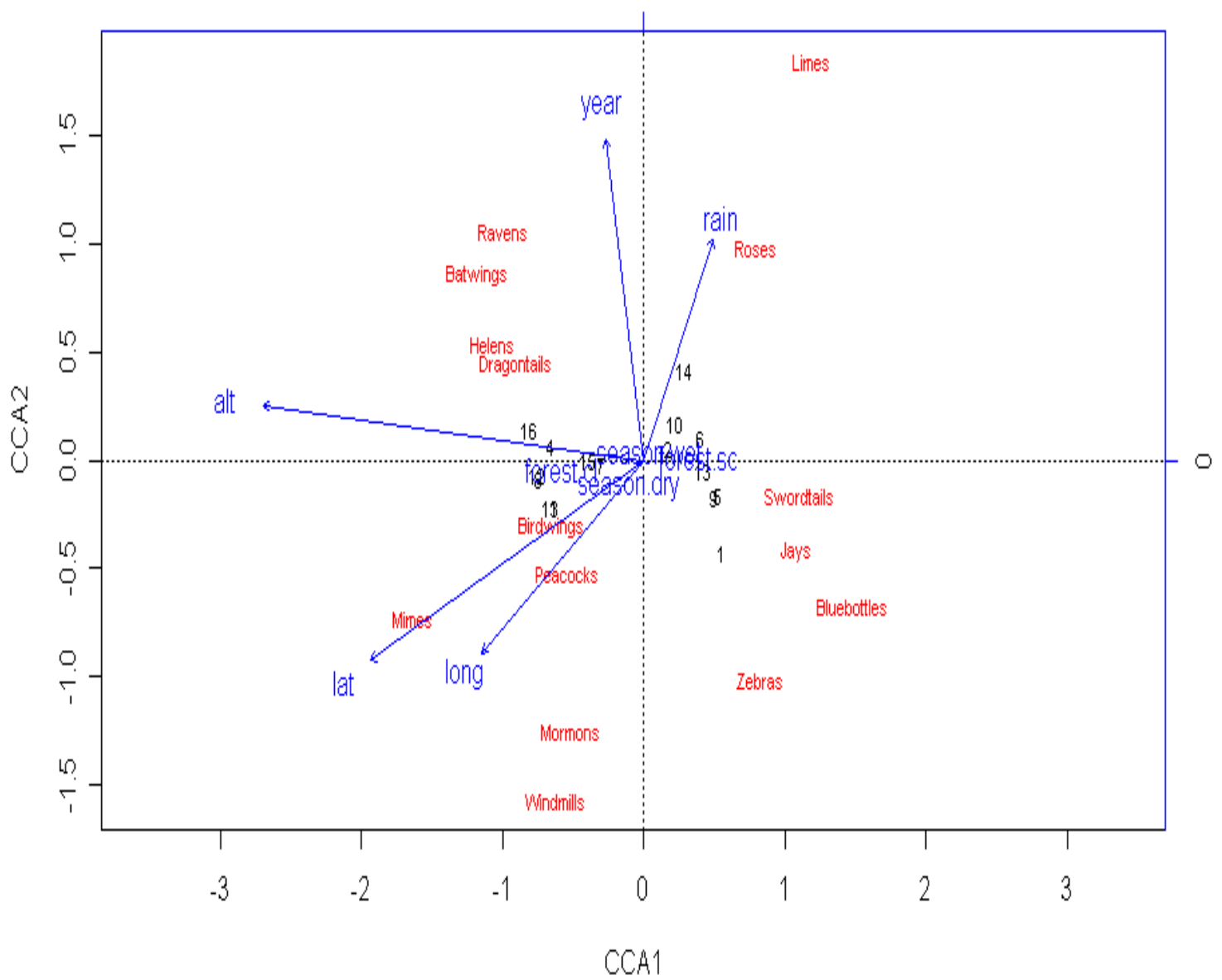

Figure 5.23: CCA ordination of swallowtail butterfly abundance (Group assemblages, genus-wise) of Rani range (S4 \& S5). Blue arrows indicate the direction of influence of continuous variables while season (season dry and season wet) and forest type shown as forest CL (Closed forest) and forest SC (Scattered forest) in blue are the centroids of categorical variables or ordered factors. Butterflies by group assemblages (common names) are labeled in red and the site scores or transects are in numbers (black). The independent variables in blue arrows are abbreviated as : lat $=$ latitude, long $=$ longitude, alt $=$ altitude, rain $=$ total rainfall during sampling season, year $=2$ years of study $(2003 \& 2004)$

\subsubsection{Ordination of the species assemblages}

The ordination results indicated that the species far from origin were rare and less important to analysis (Ramos, 2000). Species near the centre of the ordination diagram may reach an optimum abundance in that area of ordination space while species found away 
from the centre of the diagram but not near the edges are most likely to display clear relationships with the ordination axes (McCune \& Grace, 2002). Forest -dependant species like Golden Birdwing (Troides aeacus), Common Birdwing (Troides helena), Common Peacock (Papilio polycter), Krishna Peacock (Papilio krishna), Yellow Helen (Papilio nephelus), Lesser Batwing (Atrophaneura aidoneus), Crimson rose (Pachliopta hector), Green Dragontail (Lamproptera meges), Common Windmill (Atrophaneura polyeuctes), Great Mormon (Papilio memnon), and scattered or open forest dependant species like the Bluebottles (Graphium sarpedon), Common Jay (Graphium doson), Five-Bar Swordtail (Pathysa antipathes), Chain Swordtail (Pathysa aristeus), Lesser Zebra (Pathysa macareus) were found to be more abundant species and therefore could be classified as common species. Red Helen (Papilio helenus), Common Raven (Papilio castor), Common Batwing (Atrophaneura varuna) characteristic of the closed forests and Tailed Jay (Graphium agammemnon), Common Rose (Pachliopta aristolochiae), Great Zebra (Pathysa xenocles) and Common Mormon (Papilio polytes) from the open forests were fairly abundant. Closed forest species like Great Windmill (Atrophaneura dasarada) and Limes (Papilio demoleus) from the open forests could be classified as rare based on their locations in the ordination diagram (see Fig. 5.24). 


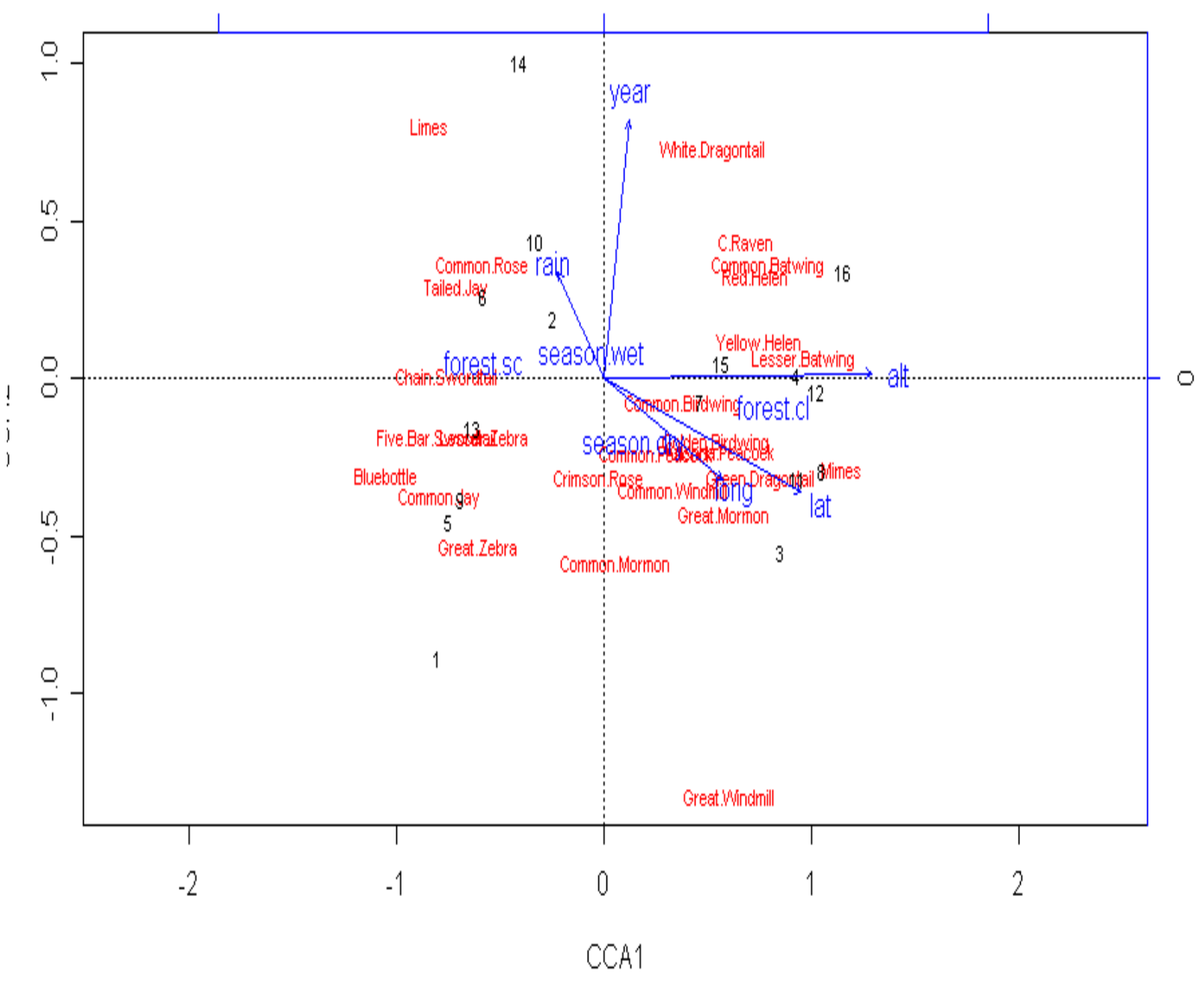

Figure 5.24: Ordination plot of CCA of swallowtail butterfly species matrix on sampling locations (pooled data of 8 fixed transects) of Rani range (S4 \& S5) during the wet and dry seasons of 2003-2004. The common names of the sampled butterfly species assemblage are in red and the site scores are in black numbers. Transects 1-4 (Dry season) are repeated for the wet season (5-8) for year 1 and again for year 2 (9-12 for dry season and 13-16 for wet season). The independent variables in blue arrows are abbreviated as : lat $=$ latitude, long $=$ longitude, alt $=$ altitude, rain $=$ total rainfall during sampling season, year $=2$ years of study (2003 \& 2004)

However taking into account the effect of rainfall as a variable on the species abundances it could be inferred that the abundance of Limes (Papilio demoleus) was significantly affected by rainfall and therefore higher the amount of rain higher the 
abundances of Limes (Papilio demoleus) and vice versa. Secondly this species was mostly encountered only in the open/scattered forest transects while the counts from the closed forest transects were almost negligible. This explains the deviation of the Limes from the centre of the ordination plot. The separating effects of habitat or forest types on the species assemblages were clearly indicated in the ordination map (see Fig. 5.23). Species like the White Dragontail (Lamproptera curius) and Common Mormon (Papilio polytes) which were encountered in moderate abundances in both open and closed forest transects could be classified as 'intermediate species' while axis 2 clearly demarcated the habitat specificity of the species assemblages within the study sites. Forest -dependant species were located on the right side and open forest species on the left side of the ordination diagram (see Figs. $5.23,5.24 \& 5.25)$.

\subsubsection{Effect of Independent variables on species assemblages within Rani range}

The continuum of seasonal abundance of swallowtail butterflies in the study sites is significant as the direction of the arrow showing year as a variable is highly correlated with axis 2 (see Figs. $5.24 \& 5.25$ ). The abundances of species typical of closed forest such as Red Helen (Papilio helenus), Common Batwing (Atrophaneura varuna) and Common Raven (Papilio castor) and species typical of open forests such as Tailed Jay (Graphium agammemnon), Common Rose (Pachliopta aristolochiae) and Limes (Papilio demoleus), as well as of species like White Dragontail (Lamproptera curius) from the intermediate zones were higher during the wet season of year 2 (see Fig. 5.23). The length of the arrow showing year as a variable indicated a strong correlation between the sampling period and total abundances of the species assemblages- there was a large variation in the abundances of the butterfly species between the years of study.

The direction of the arrow showing rainfall as an independent variable was correlated with axis 2 and showed that the abundances of Limes (Papilio demoleus), Common Rose (Pachliopta aristolochiae), Tailed Jay (Graphium agammemnon), Common Raven (Papilio castor), Common Batwing (Atrophaneura varuna), Red Helen (Papilio helenus) and White Dragontail (Lamproptera curius) were strongly influenced by rainfall and variations in the total abundance of these species was correlated with the amount of rainfall. Therefore it could be stated that the wet season abundances of these species were significantly higher than the dry season abundance. However the length of the arrow 
showing rainfall as an independent variable did not indicate significantly large variations in the abundance levels of the species assemblages.

The direction of the arrow showing altitude as an independent variable was highly correlated with axis 1 and indicated that a change in altitudinal gradient had a significant effect on the distribution of the species assemblages within the study sites. The species typical of the open forest transects were found at lower elevations while forest-dependant species were found at higher elevations. Altitude showed a strong correlation with the butterfly distribution and variation in abundance as indicated by the length of the arrow although the elevational gradient within the study sites was not very large. This could be attributable to the resampling of the same fixed transects.

The direction of the arrows showing latitude and longitude as variables indicated that the geographical position of the transects or the study sites were not significantly correlated with either axis 1 or axis 2 as seen in the ordination plots (see Figs. 5.23, $5.24 \& 5.25$ ). The length of the vectors however indicated a large variation in the abundances of the species assemblages. However again such a weak or insignificant correlation could be attributed to the small size of the sampling area and the close location of the sampled transects as also observed in the ordination on the swallowtail butterfly assemblages in Garbhanga range (see Figs. 5.20, $5.21 \& 5.22$ ).

The ordination of the species assemblages by their scientific names are presented in Fig. 5.25 and shows the same results as described above for the effects of the independent and categorical variables on the habitat association and changing abundance patterns of the swallowtail butterfly community in the two study sites of Rani range across the study period. 


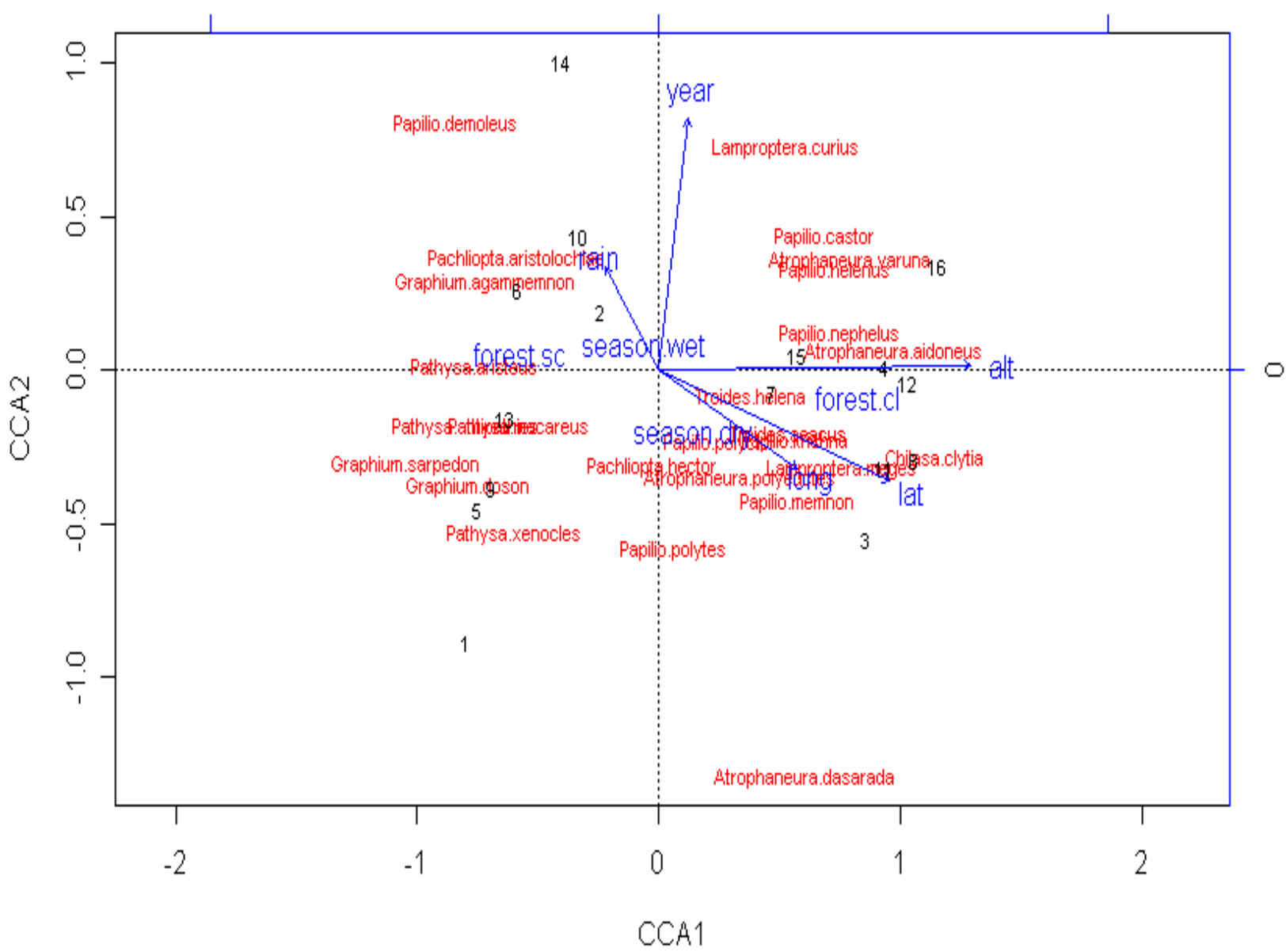

Figure 5.25 : Ordination plot of CCA of swallowtail butterfly species matrix on sampling locations (pooled data of 8 fixed transects) of Rani range (S4 \& S5) during the wet and dry seasons of 2003-2004. The scientific names of the sampled butterfly species assemblage are in red and the site scores are in black numbers. Transects 1-4 (Dry season) are repeated for the wet season (5-8) for year 1 and again for year 2 (9-12 for dry season and 13-16 for wet season). The independent variables in blue arrows are abbreviated as : lat $=$ latitude, long = longitude, alt $=$ altitude, rain $=$ total rainfall during sampling season, year $=2$ years of study (2003 \& 2004)

In Rani range ( 2 study sites and pooled data from 8 transects) it was seen that the CCA axes explained around 30\% variation by all the constraints in the abundance (genus wise), while $37 \%$ variation in the data were explained in total. The permutation tests for CCA under direct model (all constraints together) were significant $(\mathrm{p}<0.001)$. In species 
abundance, the CCA axes explained around 32\% variation out of the total $42 \%$ and the full model was significant $(\mathrm{p}<0.001)$ (see Permutation test in Appendix 5: 5.24.4).

\subsubsection{Partial conclusion on CCA on swallowtail butterfly assemblages within the study area}

The ordinations showed how the forest swallowtail butterfly community could be divided into two clear-cut strata (see Figs 5.20-5.25). There is a group of sun-loving open forest species, and a group of shade preferring closed forest species. The ordination results indicated that forest type, season, year and rainfall accounted for most variance in the distribution and abundance of the swallowtail butterflies within the forest reserve and their effect was highly significant. Altitude was found to have a significant effect on the distribution and abundance of the species assemblages within all the five study sites of Garbhanga and Rani ranges thereby indicating that some of the closed forest species were found to occur in higher abundances at higher elevations while some of the open forest dependant species were found to occur at higher abundances at lower elevations (see Figs. 5.20-5.25). The effect of altitude on species abundance and distribution was observed to be more pronounced in the study sites of Garbhanga than Rani range. However such a kind of significant correlation could have been related more to the sampling design where the closed forest transects were located at higher elevations while the open forest transects were located at lower elevations. Geographical position (latitude and longitude) did not account for an overall strong significant effect on the total variance of the swallowtail butterfly species abundance and distribution pattern in the study area although statistically a significant correlation could atleast be seen in the group-wise (Genus) and species ordination for the study sites of Garbhanga range (see Figs. 5.20, $5.21 \& 5.22$ ).

Based on our results from the CCA ordination on the seasonal abundance and habitat association pattern of the swallowtail butterfly species assemblages and the pre-defined geographic ranges of the Papilionidae (Spitzer et.al., 1993) the following tentative conclusions could be made:

- Species with narrow geographic ranges $(1=$ Eastern Himalayas $\& 2=$ Indo-China $)$ were found to be confined to the closed forest (Atrophaneura dasarada, Atrophaneura varuna, Troides aeacus, Papilio castor, Papilio nephelus, Papilio krishna) whereas species with wider ranges were characteristic of the open forests 
(Graphium sp., Papilio demoleus, Pachliopta aristolochiae, Papilio polytes).The geographic ranges of the species assemblages are defined according to Spitzer et al. (1993) in Appendix 5: 5.10. Our findings have conformity with the records of Spitzer et al. (1997).

- Amongst the 16 characteristic climax forest species, six species had restricted distribution (geographic range 1 \& 2) while another nine species had range 3 (IndoMalayan) and only one species (Papilio helenus) had the widest geographic range score 4 (See Appendix 5: 5.10). A total of nine species were found to be associated with scattered or open forest out of which only two species had restricted range score 1 (Pathysa aristeus and Pathysa xenocles) and another two species had range score 3 (Pathysa antiphates and Pachliopta aristolochiae) while five species (Graphium sp., Papilio demoleus and Pathysa macareus) had the widest range score 4 (See Appendix 5: 5.10). The species distribution trend with respect to association by forest type (closed and open /scattered forest) was similar for the study sites of both Garbhanga and Rani ranges (see Figs. 5.20-5.25).

There is a difficulty in interpreting the data on species seasonality as they come from relatively short periods of different years and the dynamics on species seasonality are dependant on variations in patterns of rainfall (Owen, 1971; Wolda, 1978). With respect to the effect of climate or season on the butterfly abundance and distribution, we considered all the climatic parameters relating to mean maximum temperature, mean humidity and total rainfall during the sampling seasons. However as is typical of tropical monsoon climate where there is very little variation in the annual mean maximum and minimum temperature and humidity, only the effect of rainfall was significant and was displayed in the ordinations for examining the effect of season on butterfly abundance and distribution pattern. 


\subsection{Impact of season and forest type on species diversity}

\subsubsection{Study sites of Garbhanga range}

There was no overall difference in diversity between dry and wet seasons of both years (One-way ANOVA by season; $\mathrm{p}>0.2$ for H', D, 1/D and alpha diversity). However all the indices were significantly higher in the closed forest transects for both years as compared to open forest transects (One-way ANOVA by habitat type; H', $\mathrm{F}_{1,10}=17.1$, $\mathrm{P}<0.05 ; \mathrm{D}, \mathrm{F}_{1,10}=15.5, \mathrm{P}<0.05 ; 1 / \mathrm{D}, \mathrm{F}_{1,10}=9.9, \mathrm{P}<0.05 ; \alpha$ diversity, $\mathrm{F}_{1,10}=7.1, \mathrm{P}<0.05$, see Table 5.5).

Table 5.5: Diversity indices of swallowtail butterfly species assemblages in the open and closed forest habitats of Garbhanga range (pooled data of 12 fixed transects) during dry and wet seasons of 2003-2004. The butterfly species diversity, richness, evenness and rarefaction estimates were defined by forest type and season.

Species wise diversity indices in Garbhanga range by forest type \& season

\begin{tabular}{|l|rrrr|rrrr|}
\hline \multirow{2}{*}{ Diversity indices } & \multicolumn{4}{|c|}{ Forest } & \multicolumn{4}{c|}{ Season } \\
\cline { 2 - 9 } & \multicolumn{3}{|c|}{ Year 1 } & \multicolumn{2}{c|}{ Year 2 } & \multicolumn{2}{c|}{ Year 1 } & \multicolumn{2}{c|}{ Year 2 } \\
\cline { 2 - 9 } & \multicolumn{1}{|c|}{ Closed } & Scattered & Closed & Scattered & Dry & Wet & Dry & Wet \\
\hline \hline H' (Shannon's index) & 2.8933 & 2.2641 & 2.7715 & 2.0913 & 2.5768 & 2.5453 & 2.2659 & 2.4898 \\
D (Simpson's index) & 0.9304 & 0.8308 & 0.9160 & 0.7826 & 0.8797 & 0.8728 & 0.8032 & 0.8606 \\
1/D (Inverse Simpson) & 14.3702 & 5.9095 & 11.9054 & 4.5989 & 8.3091 & 7.8636 & 5.0826 & 7.1754 \\
R (Rarefaction) & 1.9310 & 1.8309 & 1.9166 & 1.7827 & 1.8800 & 1.8730 & 1.8036 & 1.8608 \\
(a) Alpha diversity & 4.8743 & 3.6459 & 4.9246 & 3.8025 & 4.4717 & 3.8928 & 4.3873 & 3.9334 \\
S (Species richness) & 28 & 27 & 28 & 28 & 28 & 28 & 28 & 28 \\
J (Pielou's evenness) & 0.8683 & 0.6869 & 0.8317 & 0.6276 & 0.7733 & 0.7638 & 0.6800 & 0.7472 \\
\hline \hline
\end{tabular}

There was no significant difference in species richness between habitats or forest types and season (One-way ANOVA, by forest type: $F_{1,10}=2.3, p>0.2$; by season: $F_{1,10}$ $=3.6, \mathrm{p}>0.2$, see Table 5.5). The Evenness and rarefaction of species were significantly higher in the closed forests during both years as compared to open forest (One-way ANOVA, by forest type: Evenness: $\mathrm{F}_{1,10}=13.5, \mathrm{P}<0.05$; Rarefaction; $\mathrm{F}_{1,10}=15.2, \mathrm{P}<0.05$, see Table 5.5). However there were no significant differences in the evenness and rarefaction of species between seasons (One-way ANOVA, by season: $p>0.2$ for Evenness and Rarefaction ). 


\subsubsection{Study sites of Rani range}

Shannon's diversity ( $\left.\mathrm{H}^{\prime}\right)$ showed a significant difference between seasons of both years (One-way ANOVA, by season: $\mathrm{F}_{1,6}=6.0840, \mathrm{P}<0.05$, see Table 5.6), but there was no significant difference in diversity (H') between habitats or forest types (One-way ANOVA by forest type; $F_{1,6}=.82842, \mathrm{p}>0.2$ ). There was no overall difference in Simpson's, Inverse Simpson's and alpha diversity indices between seasons ( $\mathrm{p}>0.3$, for $\mathrm{D}, 1 / \mathrm{D} \& \alpha$ diversity) but the indices showed significant differences between habitats (One-way ANOVA, by forest type: $\left.\mathrm{D}, \mathrm{F}_{1,6}=14.826, \mathrm{P}<0.05 ; 1 / \mathrm{D}, \mathrm{F}_{1,6}=17.874, \mathrm{P}<0.05 ; \alpha-\mathrm{D}, \mathrm{F}_{1,6}=7.3362, \mathrm{P}<0.05\right)$. Scattered/open forests were more diverse than the closed forest habitats as indicated by Simpson's and Inverse Simpson's indices but $\alpha$ - diversity was again found to be higher in the closed forests (see Table 5.6).

Table 5.6: Species-wise diversity indices of swallowtail butterflies in the open and closed forest habitats of Rani range (pooled data of 8 fixed transects) during dry and wet seasons of 2003-2004. The butterfly species diversity, richness, evenness and rarefaction estimates were defined by forest type and season.

Species wise diversity indices in Rani range by forest type \& season

\begin{tabular}{|l|rrrr|rrrr|}
\hline \multirow{2}{*}{ Diversity indices } & \multicolumn{4}{c|}{ Forest type } & \multicolumn{4}{c|}{ Season } \\
\cline { 2 - 9 } & \multicolumn{3}{c|}{ Year 1 } & \multicolumn{2}{c|}{ Year 2 } & \multicolumn{3}{c|}{ Year 1 } \\
\cline { 2 - 9 } & \multicolumn{1}{|c|}{ Closed } & Scattered & Closed & Scattered & \multicolumn{1}{|l}{ Dry } & Wet & Dry & Wet \\
\hline \hline H' (Shannon's index) & 2.7961 & 2.8529 & 2.6562 & 2.7850 & 2.9361 & 2.9550 & 2.8766 & 2.8967 \\
D (Simpson's index) & 0.9140 & 0.9284 & 0.8922 & 0.9228 & 0.9350 & 0.9374 & 0.9282 & 0.9257 \\
1/D (Inverse Simpson) & 11.6244 & 13.9687 & 9.2754 & 12.9557 & 15.3882 & 15.9778 & 13.9305 & 13.4518 \\
R $^{2}$ (Rarefaction) & 1.9152 & 1.9293 & 1.8936 & 1.9238 & 1.9366 & 1.9381 & 1.9303 & 1.9265 \\
(a) Alpha diversity & 5.1909 & 4.7703 & 5.1593 & 4.9546 & 5.5841 & 4.6076 & 5.7608 & 4.7273 \\
S (Species richness) & 26 & 26 & 25 & 26 & 26 & 26 & 25 & 26 \\
J (Pielou's evenness) & 0.8582 & 0.8756 & 0.8252 & 0.8548 & 0.9012 & 0.9070 & 0.8937 & 0.8768 \\
& & & & & & & & \\
\hline \hline
\end{tabular}

There were no significant differences in species richness between habitats or forest types and seasons $(\mathrm{p}>0.05)$. The Evenness and Rarefaction of species assemblages were significantly higher in the scattered/open forest habitats (One-way ANOVA, by habitat: J, $\mathrm{F}_{1,6}=17.198, \mathrm{p}<0.05 ;$ Rarefaction, $\left.\mathrm{F}_{1,6}=31.078, \mathrm{p}<0.05\right)$. However there was no overall difference in evenness and rarefaction estimates between seasons $(p>0.05)$.

An overall opposite trend in the diversity parameters of the swallowtail butterfly species assemblages between the study sites of Garbhanga and Rani ranges were observed 
with respect to forest type- in the study sites of Garbhanga range the closed forests were more diverse than the open/scattered forests while in the study sites of Rani range the open forests were more diverse. A similar trend was also observed with the evenness and rarefaction estimates for the study sites of both the ranges With respect to season, there were no significant differences in the diversity parameters between the dry and wet seasons of the study period in the study sites of Garbhanga range while for the study sites of Rani range only Shannon diversity ( $\left.\mathrm{H}^{\prime}\right)$ was found to be higher during the wet seasons of the study period. 


\subsection{Indicator values and characteristic species}

\subsubsection{Indicator values and characteristic species in the study sites of Garbhanga range}

The swallowtail butterfly assemblages were analysed for detection of characteristic genera/species for the fixed transects within the two forest types (scattered and closed) of study sites S1, S2 and S3 in Garbhanga range during the sampling period (wet and dry seasons of 2003-2004) and, the observed Indicator values (IV \%) for the sampled species are presented in Tables 5.7 and 5.8 below.

Table 5.7: Indicator values (\%IndVals) of swallowtail butterflies (Genus-wise) in the 12 sampling transects of the three study sites (S1, S2 and S3) in Garbhanga range. Sampling data from the 12 transects during the study period (2003-2004) were pooled together to analyse and identify the characteristic genera for each forest type (transects $1 \& 2$ for scattered forest and transects $3 \& 4$ for closed forest). The species which scored significant IndVals are indicated in bold and red font pattern. The analysis was done by using the vegan subroutine in the program ' $R$ '.

\section{Garbhanga Line Transect}

\begin{tabular}{|c|c|c|c|c|}
\hline Genus & Transect & $\begin{array}{l}\text { Indval } \\
\%\end{array}$ & $\mathbf{p}^{*}$ & * \\
\hline 1 Bluebottles (Graphium sp.) & 1 & 61.22 & 0.01 & ** \\
\hline 2 Roses (Pachliopta sp.) & 1 & 52.17 & 0.03 & * \\
\hline 3 Swordtails (Pathysa sp.) & 1 & 50.66 & 0.05 & * \\
\hline 4. Mimes (Chilasa clytia) & 1 & 39.68 & 0.16 & -- \\
\hline 5 Dragontails (Lamproptera sp.) & 1 & 38.24 & 0.31 & -- \\
\hline 6 Helens (Papilio sp.) & 1 & 27.97 & 0.84 & -- \\
\hline 7 Jays (Graphium sp.) & 2 & 67.50 & 0.01 & ** \\
\hline 8 Zebras (Pathysa sp.) & 2 & 52.63 & 0.02 & * \\
\hline 9 Lime (Papilio demoleus) & 2 & 49.02 & 0.04 & * \\
\hline 10 Mormons (Papilio sp.) & 2 & 37.36 & 0.16 & -- \\
\hline 11 Common Raven (Papilio castor ) & 3 & 41.16 & 0.05 & * \\
\hline 12 Peacocks (Papilio sp.) & 4 & 32.08 & 0.08 & -- \\
\hline 13 Windmills (Atrophaneura sp.) & 4 & 59.54 & 0.12 & -- \\
\hline 14 Batwings (Atrophaneura sp.) & 4 & 45.79 & 0.17 & -- \\
\hline 15 Birdwings (Troides sp.) & 4 & 41.65 & 0.18 & -- \\
\hline
\end{tabular}


In the transects of the scattered/open forests, Graphium sp. (Jays and Bluebottles) scored IndVals $>60 \%(\mathrm{p}<0.05)$ while Pathysa sp. (Swordtails and Zebras), Pachliopta sp. (Roses), Papilio demoleus (Limes) scored IndVals $>45 \%(\mathrm{p} \leq 0.05)$. In the transects of the closed forest Papilio castor (Common Raven) scored an IndVal $<45 \%$ but was significant at $\mathrm{p} \leq 0.05$ while Atrophaneura sp. (Windmills) scored an IndVal $>55 \%$ but were not statistically significant at $p>0.05$. The groups or butterfly assemblages (genuswise) were defined by values of transects in an attempt to detect any characteristic genera or groups for the fixed transects in the two forest-types (see Table 5.7).

Table 5.8: Indicator values (\%IndVals) of swallowtail butterflies (Species-wise) in the 12 sampling transects of the 3 study sites (S1, S2, S3) under Garbhanga range. Sampling data from the 12 transects were pooled together to analyse the characteristic species for each forest type (transects $1 \& 2$ for scattered forest and transects $3 \& 4$ for closed forest).

\begin{tabular}{|c|c|c|c|c|}
\hline Species & Transect & IndVal (\%) & $\mathbf{p}^{*}$ & * \\
\hline 1 Bluebottles (Graphium sarpedon) & 1 & 61.22 & 0.01 & ** \\
\hline 2 Common Rose (Pachliopta aristolochiae) & 1 & 55.07 & 0.03 & * \\
\hline 3 Chain Swordtail (Pathysa aristeus) & 1 & 52.38 & 0.06 & -- \\
\hline 4 Five Bar Swordtail (Pathysa antipathies) & 1 & 48.95 & 0.07 & -- \\
\hline 5 Common Mormon (Papilio polytes) & 1 & 41.29 & 0.09 & -- \\
\hline 6 Green Dragontail (Lamproptera meges) & 1 & 45.45 & 0.10 & -- \\
\hline 7 Common Mime (Chilasa clytia ) & 1 & 39.68 & 0.16 & -- \\
\hline 8 Tailed Jay (Graphium agammemnon) & 2 & 63.74 & 0.00 & ** \\
\hline 9 Great Zebra (Pathysa xenocles) & 2 & 54.11 & 0.01 & $*$ \\
\hline 10 Common Jay (Graphium doson) & 2 & 66.88 & 0.02 & $*$ \\
\hline 11 Lime (Papilio demoleus) & 2 & 49.02 & 0.04 & $*$ \\
\hline 12 Lesser Zebra (Pathysa macareus) & 2 & 49.69 & 0.07 & -- \\
\hline 13 Great Mormon (Papilio memnon ) & 2 & 38.01 & 0.07 & -- \\
\hline 14 Paris Peacock (Papilio paris) & 2 & 31.48 & 0.70 & -- \\
\hline 15 Crimson Rose (Pachliopta hector) & 2 & 25.00 & 0.93 & -- \\
\hline 16 White Dragontail (Lamproptera) & 2 & 16.67 & 0.97 & -- \\
\hline 17 Yellow Helen (Papilio nephelus) & 2 & 26.21 & 0.97 & -- \\
\hline 18 Common Raven (Papilio castor) & 3 & 41.16 & 0.04 & $*$ \\
\hline 19 Krishna Peacock (Papilio krishna) & 3 & 36.36 & 0.38 & -- \\
\hline 20 Common Batwing (Atrophaneura varuna) & 3 & 34.29 & 0.48 & -- \\
\hline 21 Red Helen (Papilio helenus helenus) & 3 & 30.10 & 0.71 & -- \\
\hline 22 Common Peacock (Papilio polycter ) & 4 & 39.62 & 0.00 & $* *$ \\
\hline 23 White Headed Batwing (Atrophaneura sycorax) & 4 & 46.67 & 0.07 & -- \\
\hline 24 Common Windmill (Atrophaneura polyeuctes) & 4 & 63.10 & 0.09 & -- \\
\hline 25 Common Birdwing (Troides helena) & 4 & 41.76 & 0.14 & -- \\
\hline 26 Great Windmill (Atrophaneura dasarada) & 4 & 52.68 & 0.14 & -- \\
\hline 27 Lesser Batwing (Atrophaneura aidoneus) & 4 & 49.15 & 0.15 & -- \\
\hline 28 Golden Birdwing (Troides aeacus) & 4 & 41.56 & 0.42 & -- \\
\hline
\end{tabular}


In the scattered/open-forest transects, Graphium sarpedon (Bluebottles), G. agamemmnon (Tailed Jay), G. doson (Common Jay), Pathysa xenocles (Great Zebra), and Pachliopta aristolochiae (Common Rose) scored IndVals $>50 \%(p<0.05)$ and could be detected as indicator species for this forest type. Although the Limes (Papilio demoleus) scored an IndVal $<50 \%$ still they were statistically significant $(\mathrm{p}<0.05)$ and could be considered as an indicator species. In the transects of the closed forests, Papilo castor (Common Raven) and Papilio polyctor (Common Peacock) scored low IndVals $(<45 \%)$ but were statistically significant at $\mathrm{p}<0.05$ (see Table 5.8). Amongst the red-bodied Papilionidae, Atrophaneura polyeuctes (Common Windmill) scored an IndVal $>60 \%$ but was not statistically significant $(\mathrm{p}>0.05)$. Such species could be considered as accidental or anecdotal as they have their maximum indicator value for the given cluster level group (Dufrene \& Legendre, 1997).

However a re-analysis of the same data set where the taxonomic groups or species assemblages were defined by values of season and statistically tested for observed maximum indicator values for each species, showed that the forest dependant red-bodied assemblage - Atrophaneura polyeuctes (Common Windmill), Atrophaneura dasarada (Great Windmill), Atrophaneura varuna (Common Batwing) and Troides aeacus (Golden Birdwing) scored IndVals $>80 \%(\mathrm{p}<0.005)$. The black-bodied Papilio helenus (Red Helen) scored an IndVal $<70 \%$ but was significant at $\mathrm{p}<0.005$ (see Table 5.9). 
Table 5.9: Indicator values for 28 species of swallowtail butterflies sampled season-wise in the study sites of Garbhanga range during 2003-2004. The indicator values for the species assemblages were defined by values of mean seasonal abundances. Pooled data from 12 transects in three study sites (S1, S2, S3) were analysed using the program PC-ORD, 4.01.

\begin{tabular}{|c|c|c|c|c|}
\hline Species & $\begin{array}{l}\text { Indicator } \\
\text { Il (IV \%) }\end{array}$ & Mean & $\begin{array}{l}\text { Standard } \\
\text { Deviation }\end{array}$ & $\mathbf{p}^{*}$ \\
\hline 1 Common Windmill (Atrophaneura dasarada) & 88.8 & 61.6 & 11.62 & $0.0010 *$ \\
\hline 2Great Windmill (Atrophaneura polyeuctes) & 87.0 & 63.0 & 8.48 & $0.0010^{*}$ \\
\hline 3White-Headed Batwing (Atrophaneura sycorax) & 54.2 & 34.5 & 10.48 & 0.0500 \\
\hline 4Lesser.Batwing (Atrophaneura aidoneus) & 83.1 & 62.6 & 8.72 & 0.0160 \\
\hline 5Common Batwing (Atrophaneura varuna) & 88.6 & 47.1 & 10.53 & $0.0040 *$ \\
\hline 6 Golden Birdwing (Troides aeacus) & 83.8 & 61.4 & 8.35 & $0.0030 *$ \\
\hline 7 Common Birdwing (Troides helena) & 67.4 & 57.6 & 5.89 & 0.0770 \\
\hline 8 Common Rose (Pachliopta aristolochiae) & 68.1 & 61.0 & 7.92 & 0.2010 \\
\hline 9 Crimson Rose (Pachliopta hector) & 58.3 & 48.4 & 8.76 & 0.1600 \\
\hline 10 Green Dragontail (Lamproptera meges) & 47.7 & 47.9 & 8.60 & 0.4650 \\
\hline 11 White Dragontail (Lamproptera curius) & 41.7 & 36.8 & 10.67 & 0.3590 \\
\hline 12 Chain Swordtail (Pathysa aristeus) & 49.6 & 46.8 & 10.30 & 0.3440 \\
\hline 13 Five-Bar Swordtail (Pathysa antipathies & 48.6 & 46.8 & 10.22 & 0.3660 \\
\hline 14 Great Zebra (Pathysa xenocles) & 45.1 & 49.7 & 9.64 & 0.6150 \\
\hline 15 Lesser Zebra (Pathysa macareus) & 45.3 & 46.6 & 10.04 & 0.4700 \\
\hline 16 Common Mime (Chilasa clytia) & 70.9 & 57.6 & 5.84 & 0.0260 \\
\hline 17 Common Jay (Graphium doson) & 76.4 & 64.0 & 10.02 & 0.1530 \\
\hline 18 Tailed Jay (Graphium agammemnon) & 66.4 & 62.2 & 9.06 & 0.2880 \\
\hline 19 Common Peacock (Papilio polyctor) & 57.1 & 52.8 & 2.66 & 0.0480 \\
\hline 20 Paris Peacock (Papilio paris) & 72.2 & 54.4 & 8.31 & 0.0440 \\
\hline 21 Krishna Peacock (Papilio krishna) & 40.9 & 47.9 & 8.23 & 0.8230 \\
\hline 22 Common Mormon (Papilio polytes) & 61.6 & 57.2 & 5.63 & 0.2100 \\
\hline 23 Great Mormon (Papilio memnon) & 66.1 & 55.9 & 4.62 & 0.0240 \\
\hline 24 Red Helen (Papilio helenus) & 69.2 & 55.0 & 4.19 & $0.0010 *$ \\
\hline 25 Yellow Helen (Papilio nephelus) & 56.5 & 53.8 & 3.24 & 0.1880 \\
\hline 26 Common Raven (Papilio castor) & 61.6 & 56.1 & 4.62 & 0.1450 \\
\hline 27 Bluebottle (Graphium sarpedon) & 62.0 & 61.6 & 8.78 & 0.4030 \\
\hline 28 Lime Butterfly (Papilio demoleus) & 57.1 & 56.6 & 7.79 & 0.3960 \\
\hline
\end{tabular}

The detection of indicator taxa by 'forest type' and 'season' gave different results as observed from the Indicator values (\%IndVals) of the group and species assemblages (see Tables 5.7, $5.8 \& 5.9$ ). When the indicator values were defined by values of the mean transect abundance in the two forest types, statistically the results were more significant for some of the open/scattered forest species, particularly from the Graphium group comprising of the Jays and Bluebottles (see Table $5.7 \& 5.8$ ). However, when the same data set was defined by values of mean seasonal abundance, some of the closed forest restricted species 
from the genera Atrophaneura and Troides scored statistically significant IndVals (see Table 5.9).

\subsubsection{Indicator values and characteristic species in the study sites of Rani range}

The observed IndVals of three genera - Pathysa sp. (Zebras), Graphium sarpedon

(Bluebottles) and Papilio demoleus (Limes) characteristic of the scattered forests were $>45 \%$ and significant at $\mathrm{p}<0.05$. In the transects of the closed forests, all genera scored IndVals $<45 \%(\mathrm{p}>0.05)$ and no indicator taxa could be detected. Chilasa clytia (Mimes) scored IndVal $>45 \%$ but was not significant at $\mathrm{p}>0.05$ (see Table 5.10).

Table 5.10: Indicator values (\%IndVals) of swallowtail butterfly group assemblages (Genus-wise) in the 8 fixed transects of the two study sites (S4 \& S5) in Rani range. Sampling data from the 8 transects during the study period (2003-2004) were pooled together to analyse and identify the characteristic genera for each forest type (transects $1 \&$ 2 for scattered forest and transects $3 \& 4$ for closed forest). Groups were defined by values of the pooled transects in the vegan subroutine of program ' $R$ '.

\section{Rani Line transect}

\begin{tabular}{|c|c|c|c|c|}
\hline Genus & Transect & $\begin{array}{l}\text { IndVal } \\
\text { (\%) }\end{array}$ & $\mathbf{p}^{*}$ & * \\
\hline 1 Zebras (Pathysa sp.) & 1 & 46.15 & 0.02 & * \\
\hline 2 Bluebottles (Graphium sarpedon) & 1 & 56.23 & 0.04 & * \\
\hline 3 Jays (Graphium sp.) & 1 & 47.49 & 0.09 & -- \\
\hline 4 Swordtails (Pathysa sp.) & 1 & 44.68 & 0.21 & -- \\
\hline 5 Limes (Papilio demoleus) & 2 & 55.03 & 0.03 & * \\
\hline 6 Roses (Pachliopta sp.) & 2 & 40.39 & 0.38 & -- \\
\hline 7 Mimes (Chilasa clytia) & 3 & 47.25 & 0.09 & -- \\
\hline 8 Mormons (Papilio sp.) & 3 & 32.08 & 0.21 & -- \\
\hline 9 Dragontails (Lamproptera sp.) & 3 & 37.84 & 0.28 & -- \\
\hline 10 Peacocks (Papilio sp.) & 3 & 28.99 & 0.79 & -- \\
\hline 11 Batwings (Atrophaneura sp.) & 4 & 39.76 & 0.25 & -- \\
\hline 12 Helens (Papilio sp.) & 4 & 33.15 & 0.43 & -- \\
\hline 13 Birdwings (Troides sp.) & 4 & 29.95 & 0.53 & -- \\
\hline 14 Common Raven (Papilio castor) & 4 & 32.10 & 0.57 & -- \\
\hline 15 Windmills (Atrophaneura sp.) & 4 & 29.85 & 0.67 & -- \\
\hline
\end{tabular}

When the indicator values were defined for the species assemblages, two species characteristic of the open forests, Pathysa xenocles (Great Zebra) and Graphium doson (Common Jay) scored IndVals $>45 \%(\mathrm{p}<0.05)$. In the transects of the closed forests, all 
species scored low IndVals $(<40 \%, \mathrm{p}>0.05)$ and therefore no indicator species could be detected (see Fig. 5.11).

Table 5.11: Indicator values (\%IndVals) of swallowtail butterflies (Species-wise) in the fixed transects of the two study sites (S4 \& S5) in Rani range. Sampling data from the 8 transects during the study period (2003-2004) were pooled together to analyse the characteristic species for each forest type (transects $1 \& 2$ for scattered forest and transects 3 \& 4 for closed forest) and the species assemblages were defined by values of mean abundance in transects.

\begin{tabular}{|c|c|c|c|c|}
\hline Species & Transect & IndVal (\%) & $\mathbf{p}^{*}$ & * \\
\hline 1 Bluebottles (Graphium sarpedon) & 1 & 56.23 & 0.04 & * \\
\hline 2 Great Zebra (Pathysa xenocles) & 1 & 47.86 & 0.01 & $*$ \\
\hline 3 Common Jay (Graphium doson) & 1 & 51.67 & 0.03 & * \\
\hline 4 Lesser Zebra (Pathysa macareus) & 1 & 43.96 & 0.07 & -- \\
\hline 5 Five Bar Swordtail (Pathysa antipathies) & 1 & 44.90 & 0.17 & -- \\
\hline 6 Common Mormon (Papilio polytes) & 1 & 35.46 & 0.17 & -- \\
\hline 7 Chain Swordtail (Pathysa aristeus) & 1 & 44.53 & 0.27 & -- \\
\hline 8 Common Windmill (Atrophaneura polyeuctes) & 1 & 27.27 & 0.98 & -- \\
\hline 9 Limes (Papilio demoleus) & 2 & 55.03 & 0.03 & * \\
\hline 10 Tailed Jay (Graphium agammemnon) & 2 & 44.30 & 0.14 & -- \\
\hline 11 White Dragontail (Lamproptera curius) & 2 & 41.03 & 0.21 & -- \\
\hline 12 Common Rose (Pachliopta aristolochiae) & 2 & 40.82 & 0.42 & -- \\
\hline 13 Crimson Rose (Pachliopta hector) & 2 & 14.29 & 1.00 & -- \\
\hline 14 Great Mormon (Papilio memnon) & 3 & 37.95 & 0.06 & -- \\
\hline 15 Common Mime (Chilasa clytia) & 3 & 47.25 & 0.09 & -- \\
\hline 16 Green Dragontail (Lamproptera meges) & 3 & 40.00 & 0.29 & -- \\
\hline 17 Yellow Helen (Papilio nephelus) & 3 & 34.11 & 0.36 & -- \\
\hline 18 Common Peacock Papilio polyctor) & 3 & 26.19 & 0.98 & \\
\hline 19 Lesser Batwing (Atrophaneura aidoneus) & 4 & 37.50 & 0.28 & -- \\
\hline 20 Common Batwing (Atrophaneura varuna) & 4 & 36.21 & 0.31 & -- \\
\hline 21 Red Helen (Papilio helenus) & 4 & 34.42 & 0.37 & -- \\
\hline 22 Golden Birdwing (Troides aeacus) & 4 & 33.77 & 0.38 & -- \\
\hline 23 Krishna Peacock (Papilio krishna) & 4 & 33.33 & 0.56 & -- \\
\hline 24 Common Raven (Papilio castor) & 4 & 32.10 & 0.57 & -- \\
\hline 25 Great Windmill (Atrophaneura dasarada) & 4 & 26.09 & 0.65 & -- \\
\hline 26 Common Birdwing (Troides helena) & 4 & 27.27 & 0.99 & -- \\
\hline
\end{tabular}

A re-analysis of the same data set for statistically testing the significance of observed maximum values for the taxonomic groups defined by values of season showed IndVals $>65 \%(\mathrm{p} \leq 0.005)$ for the red-bodied species Atrophaneura varuna (Common Batwing), Troides aeacus (Golden Birdwing), Troides helena (Common Birdwing), 
Pachliopta aristolochiae (Common Rose) and the black-bodied species Papilio castor (Common Raven). Papilio nephelus (Yellow Helen) scored an IndVal $>65 \%$ but was not statistically significant at $\mathrm{p}>0.005$. With the exception of Pachliopta aristolochiae (Common Rose) which was the only gap species, all the other indicator species that were detected as characteristic indicator taxa were forest restricted (see Table 5.12).

Table 5.12: Indicator values for 26 species of swallowtail butterflies sampled season-wise in the 8 transects of study sites S4 and S5 within Rani range during 2003-2004. Pooled data from the fixed transects in the two study sites were analysed using the program PC-ORD, 4.01 .

\begin{tabular}{|c|c|c|}
\hline Species & $\begin{array}{l}\text { IndVal } \\
\text { (IV\%) }\end{array}$ & $\mathbf{p}^{*}$ \\
\hline 1 Common Windmill (Atrophaneura dasarada) & 63.6 & 0.0400 \\
\hline 2 Great Windmill (Atrophaneura polyeuctes) & 48.9 & 0.2850 \\
\hline 3 Lesser.Batwing (Atrophaneura aidoneus) & 56.2 & 0.1210 \\
\hline 4 Common Batwing (Atrophaneura varuna) & 79.3 & $0.0050 *$ \\
\hline 5 Golden Birdwing (Troides aeacus) & 67.5 & $0.0050 *$ \\
\hline 6 Common Birdwing (Troides helena) & 67.3 & $0.0040 *$ \\
\hline 7 Common Rose (Pachliopta aristolochiae) & 85.7 & $0.0030 *$ \\
\hline 8 Crimson Rose (Pachliopta hector) & 26.8 & 0.5070 \\
\hline 9 Green Dragontail (Lamproptera meges) & 47.1 & 0.4400 \\
\hline 10 White Dragontail (Lamproptera curius) & 51.6 & 0.4500 \\
\hline 11 Chain Swordtail (Pathysa aristeus) & 55.8 & 0.4370 \\
\hline 12 Five-Bar Swordtail (Pathysa antipathies) & 52.8 & 0.4060 \\
\hline 13 Great Zebra (Pathysa xenocles) & 61.5 & 0.2570 \\
\hline 14 Lesser Zebra (Pathysa macareus) & 60.4 & 0.2690 \\
\hline 15 Common Jay (Graphium doson) & 67.6 & 0.0700 \\
\hline 16 Tailed Jay (Graphium agammemnon) & 57.9 & 0.1520 \\
\hline 17 Common Peacock (Papilio polycter) & 66.7 & 0.0780 \\
\hline 18 Krishna Peacock (Papilio krishna) & 66.7 & 0.0300 \\
\hline 19 Common Mormon (Papilio polytes) & 62.5 & 0.0580 \\
\hline 20 Great Mormon (Papilio memnon) & 63.6 & 0.0300 \\
\hline 21 Red Helen (Papilio helenus) & 67.5 & 0.0280 \\
\hline 22 Yellow Helen (Papilio nephelus) & 70.6 & 0.0080 \\
\hline 23Bluebottle (Graphium sarpedon) & 58.5 & 0.1280 \\
\hline 24 Lime Butterfly (Papilio demoleus) & 54.6 & 0.1550 \\
\hline 25 Common Mime (Chilasa clytia) & 57.7 & 0.2550 \\
\hline 26 Common Raven (Papilio castor) & 71.6 & $0.0040 *$ \\
\hline
\end{tabular}
'* ' - Statistically significant $\mathrm{p}<0.005$ 
The analysed results showed that when groups (genus-wise) and species assemblages were defined by values of mean transect abundances; some of the characteristic gap species particularly from the genera Graphium and Pathysa scored significant IndVals $(>50 \%)$ while none of the forest-restricted species could be detected as indicator species (see Tables 5.7, 5.8, 5.10\& 5.11). However when the same groups and species assemblages were defined by values of mean seasonal abundances, with the exception of one gap species (Pachliopta aristolochiae), all the other selected indicator species with significant high IndVals $(>70 \%)$ were forest-restricted (see Tables $5.9 \& 5.12)$. When comparing between the results of the characteristic indicator taxa of the study sites of Garbhanga and Rani ranges, a similar trend with respect to the selection of more gap species as indicator taxa when defined by values of only transect abundances and detection of more forest-restricted species as indicator taxa when defined by values of seasonal abundances were observed for both the two ranges (see Tables $5.7-5.12$ ). Statistically the results were more significant when the species assemblages were tested season-wise although the analytical results on the characteristic species of the assemblages detected transect-wise were also meaningful. 


\section{PART III}

DISCUSSION AND RECOMMENDATIONS FOR CONSERVATION

CHAPTER 6 : DISCUSSION

CHAPTER 7 : RECOMMENDATIONS FOR CONSERVATION 


\section{CHAPTER 6 : DISCUSSION}

\section{1: Climate, Vegetation and butterfly abundance}

\subsubsection{Climate and butterfly abundance}

Butterflies are sensitive to environmental variation (Scoble, 1992). Positive relations have been found between butterfly diversity and environmental variables such as climate (Pollard \& Yates, 1993; Parmesan, 1996), topographic and moisture gradients (Kremen, 1992), landscape structure (Wood \& Samways, 1992), habitat complexity (Molina \& Palma, 1996), and plant diversity (Erhardt, 1985; Thomas \& Malorie, 1985; Leps \& Spitzer, 1990; Spitzer et al., 1997). Our investigations on the climate conditions during the study period and the butterfly sampling data showed that when comparing between the total annual rainfall and the annual abundance of butterflies, butterfly abundances were higher in the first year of study (2003) and the total annual rainfall of 2003 was also higher than that recorded in 2004. Differences in the seasonal abundances of swallowtail butterflies during the study period showed higher butterfly abundance during dry season of 2004 and wet season of 2003. Higher butterfly abundance in the first year (2003) was probably due to higher rainfall, which could have promoted the vegetation growth that is again known to directly influence both the larval and adult stages of the butterflies as food resources (Dover et al., 2000). This however contradicts the recent hypothesis of Hill et al. (2003) where higher rainfall was actually known to cause a decline in the butterfly abundance by adversely affecting larval and pupal survival. However when only comparing between the dry and wet seasons of both years it was seen that butterfly abundances were higher during the wet seasons of both years. Several studies have provided evidence that tropical insects undergo seasonal changes in abundance, atleast for those parts of the tropics where wet and dry seasons alternate (Davis, 1945; Dobzhansky \& Pavan, 1950; Owen, 1969; Emmel \& Leck, 1970; Gibbs \& Leston, 1970; Robinson \& Robinson, 1970; Fogden, 1972; Owen \& Changer, 1972; Wolda, 1977a; 1978). In areas with pronounced dry season the abundance of most insects in the dry season is relatively low. In areas with a very mild dry season, 
insects decrease in abundance during the drier season and increase during the wetter season (Fogden, 1972). Lepidopteron species with biogeographical affinities to the seasonal 'East Himalayan' region have been known to show relatively higher seasonality in the montane tropical rainforests of Vietnam where the most characteristic seasonal patterns in abundance fluctuations were closely related with the monsoon climate (Spitzer et al., 1993). Butterflies have been shown to be sensitive to environmental gradients in tropical regions (Kremen, 1992) particularly in those parts of the tropics with well-defined wet and dry seasons (Braby, 1995; Owen, 1971; Spitzer et al., 1993). Our results showed a similar trend with the findings of Spitzer et al. (1993) where the seasonal abundances of the swallowtail species were found to be positively correlated with higher 'monsoon precipitation' during the wet season for both years.

\subsubsection{Vegetation and butterfly abundance}

In tropical regions with distinct wet and dry seasons, many insect species attain maximum adult abundance during the wet season, probably in response to changes in plant physiology and growth (Didham \& Springate, 2003; Wolda, 1989), in particular the abundance of new foliage (Fensham, 1994; Novotny \& Basset, 1998; Shapiro, 1975). In tropical deciduous forests, the abundance of plants is positively correlated with the patterns of monsoon rainfall (Wolda, 1978). The onset of monsoon rain triggers the sprouting of tender young leaves which the larvae prefer to feed on. The availability of adequate larval and adult nectar sources influences the abundances of the adult population. Although our data on vegetation does not take into account the seasonal abundances of vegetation in the sampled sites, however the sampling information on the availability of adult and larval host plants within the sampled area determines the suitability of the habitat in supporting butterfly populations in general and the Papilionids in particular.

Although vegetation sampling was not done in all the five study sites, a comparison of the floral profile with respect to trees, herb/shrubs and climber species diversity, richness and evenness estimates between the two sampled sites (partially disturbed site S1 and disturbed site S4) showed an almost near similarity in the vegetation structure. The overall high diversity of trees and shrubs in study site S1 and comparatively higher climber diversity in study site S4 as indicated by the Shannon's and Simpson's diversity values suggests the presence of a relatively constant environment, particularly in case of trees and herb/shrubs (Spitzer et al., 1987). Moreover the presence of climbers particularly on tall 
trees as also observed in our study sites is an important structural component of the ecosystem and the presence of Aristolochiae vines is crucial for some of the swallowtail butterflies like the Troides sp. (Birdwings), Atrophaneura sp.(Windmills and Batwings) and the Roses or the Pachliopta sp. (Spitzer et al., 1987). The dominant tree species were represented by the families Rutaceae, Moraceae, Euphorbiaceae, Lauraceae, Magnoliaceae and Verbenaceae. There was a good diversity of undergrowth vegetation as indicated by the presence of 63 species of herbs and shrubs represented by some of the dominant families Verbenaceae, Solanaceae, Malvaceae, Euphorbiaceae and Caesalpiniaceae. The 34 species of climbers were dominantly represented by the family Fabaceae ( 9 species). The floristic composition showed the presence of some evergreen species like Lauraceae, Magnoliaceae and Rutaceae, which mostly represented the larval food plants. The family Rutaceae was dominated by such tree species belonging to the genera Citrus and Zanthoxylum and understorey species like Murrya paniculata and Glycosmis pentaphylla which are some of the primary larval food plants of the black-bodied swallowtails belonging to the genus Papilio). The high abundances of the Papilionid genus Papilio could be positively correlated with the dominant presence of Rutaceae in the study area. Similarly the high abundances of the genus Graphium (Jays and Bluebottles) with relatively small differences between the dry and wet seasons in both years could be attributed to the availability of the evergreen host-plant families Lauraceae and Magnoliaceae in the forest reserve. Therefore the most frequently observed species with relatively small differences in abundance during the dry and wet periods like Common Mormon (Papilio polytes ), Limes (P. demoleus), Bluebottles (Graphium sarpedon) were associated with evergreen food plants such as Rutaceae, Lauraceae and Magnoliaceae. Our observations are in conformity with the findings of Spitzer (1983). Most of the citrus-feeders have expanded their seasonal abundances by switching from their wild Rutaceous food plants onto cultivated varieties of Citrus which unlike the wild plants maintain their leaves throughout the dry season and this is in conformity with the observations of Owen (1971). A similar condition was also observed for the cultivated Citrus sp., Aegel marmelos, Polyalthia longifolia (Annonaceae) and Cinnamomum tamala (Lauraceae), which are the primary larval resources of Graphium and Papilio species.

The abundances of the red-bodied Papilionidae genera Atrophaneura (Windmills and Batwings), Pachliopta (Roses) and Troides (Birdwings) decreased during the dry season but they could safely survive the dry season in relatively humid patches of trees with 
Aristolochiaceae near the streams and our observations are in conformity with the findings of Spitzer (1983).

Although the larval stages were observed to be host-specific, as adults the papilionids were found to utilise a wide variety of nectar plants. The sun-loving species belonging to the genera Graphium (Jays and Bluebottles), Papilio (Mormons and Peacocks), Pathysa (Zebras and Swordtails) and Pachliopta (Roses) were frequently found nectaring at the flowers of an exotic species Lantana camara in the study area. Such exotic nectar plant species could have simply provided additional resources for the adult butterflies as otherwise if the gravid females did not find suitable larval host plants and critical habitats in the vicinity then it could affect the abundances of adult papilionids (Simonson et al., 2001). Exotic nectar plants could represent a threat to the native plant and butterfly diversity although in our study area such a trend was not observed as an immediate threat. Lantana camara is listed among the world's worst invasive alien species as recognised by the Invasive Species Specialist Group (IUCN, 2001) and is known to grow under a wide range of climatic conditions particularly in disturbed areas and is mostly found in the edges of tropical and sub-tropical forests (Thakur et al., 1992; Day et al., 2003). In secondary forests where gaps have been created by logging, such disturbance normally allows Lantana to encroach upon the forests as this species cannot survive under dense and intact canopies (Day et al., 2003). Therefore as the density of Lantana in the forests increases, species richness decreases (Fensham et al., 1994). In the study site S4 of Rani range where levels of disturbance although not measured was observed to be comparatively higher than in S1 (Garbhanga range) abundances of Lantana camara were found to be higher. In disturbed areas with high cattle grazing, Lantana is known to benefit from such destructive foraging activities. Other kinds of human disturbances in the form of cultivation, road construction and changes in fire regimes are also known to enhance Lantana propagation (Fensham et al., 1994). Therefore the potential role of Lantana as one of the preferred adult nectar sources of butterflies as well as its invasive threat upon natural ecosystems has to be further investigated upon. One of the best management options suggested against spread of Lantana invasion has been the strategy of shading by intact canopies (Duggin \& Gentle, 1998), commercial exploitation of its wide-spectrum biocidal potential and biogas production (Sharma et al., 2003).

Patterns in the study area support the conclusions of researchers who have identified Aristolochiaceae as the most important host plant family in South-East Asia, followed by Rutaceae and Lauraceae (Fiedler, 1998). However the species richness of the Papilionids 
(28 species) when compared with the total plant species richness in the forest reserve (197 species) clearly indicates that regions with a rich flora need not be rich in terms of butterfly species as already pointed out by Vane-Wright (1978) and Cottrell (1985). Moreover within the Papilionidae higher species diversity in tropical regions is not correlated with higher host plant diversity. Therefore local abundance and phenology of nectar and host-plant resources may be more important in determining the abundances and species diversity of the papilionid butterflies.

\subsection{Geographic Range and butterfly abundance :}

There has been much speculation over the relationship between species' abundance in communities and the species geographical range size (Spitzer et al., 1993). The generalist species should be simultaneously locally abundant and widely distributed as a consequence of their ability to exploit a wide range of resources on both local and regional scales (Brown, 1984). In our study we had observed the differences in the correlation between mean abundances and geographic range size of the Papilionidae between the study sites of Garbhanga and Rani ranges. Our correlation results for the study sites in Garbhanga range were corresponding with these findings where it was seen that the size of the geographic range correlated positively with the mean abundances of the species assemblages although the correlation was not strong but still significant. The most opportunistic species with wide geographic ranges recorded the highest abundances and this could be associated with the correlation between their characteristic seasonal patterns in abundance fluctuations, habitat preferences and capability to utilise a wide range of resources. However butterfly biogeography and fauna history evolution are known to be the most important under-lying factors determining the seasonality phenomena (Spitzer et al., 1993). The wide-ranging species especially the Graphium sp. were also observed to record low differences between the dry and wet season abundances and this could be primarily associated with the plant phenology, wide ranging resources and movements (Ehrlich, 1986). The species with the most restricted range 1 ( 1 = Eastern Himalayas) recorded almost equal abundances as those with range 3 ( 3 = Indo-Malayan) and this could be considered as a significant result as conservation priorities are represented first of all by species with small geographic range (Spitzer et al., 1997). Moreover our results on the higher abundances of the most range restricted species within the study sites of Garbhanga range were supported by the hypothesis of Gaston and Lawton (1990) who suggested that in rare and distinct habitats 
largely different from 'average' environmental conditions prevailing in the area, specialists with small geographic range are more efficient, which permits them to attain higher population sizes than generalists. Although none of these restricted range species were specialists, still such results could be treated as important issues concerning the conservation implications of butterflies.

However the outcome of the correlation between mean abundance and geographic range size of the Papilionidae in the study sites of Rani range was observed to be weak and not significant, although the correlation was positive. The mean abundances of the species with the widest geographic range $4(4=$ Indo-Australian $)$ did not show significantly high and wide variations in abundance levels as in case of the study sites of Garbhanga range. They also recorded lower abundance than species with range 3. This could have been attributed to the differences in the landscape structure between Garbhanga and Rani ranges. Both the study sites S4 and S5 in Rani range had higher levels of disturbance with teak plantation, household plantation, village settlements and cropland as observed both visually and from the satellite imageries on the land-use patterns in the study area. Moreover the distinction between the open and closed forest habitats in these two study sites of Rani range were not so widely different as compared to the study sites of Garbhanga range based on our visual observation. Another factor was the sampling intensity, where the number of sampling days was not equal for both the ranges and this could have also resulted in the differences in the mean abundances of the different genera for both the ranges, thereby also affecting the correlation results.

\subsection{Feeding guild and abundance:}

Although the host-plant databases for the tropical Southeast Asian realm is much less documented and are based on a single rearing or collection in the wild, substantial progress has been made in recent years on the database for the oriental Papilionidae (Igarashi \& Fukuda, 1997). Life-history information on the Southeast Asian Papilionidae has also improved significantly. In South-East Asia, the Papilionids were known to utilise eight plant families and Aristolochiaceae was the most important host plant family, followed by Rutaceae and Lauraceae (Scriber et al., 1995; Fiedler, 1998). Our results were corresponding with these findings as our investigations on the larval host-plant database for the Papilionidae within the study area showed a good representation. It was seen that seven species from the red-bodied genera Atrophaneura (Windmills and Batwings) and 
Pachliopta (Roses) and two species from Troides (Birdwings) fed exclusively on Aristolochiaceae $(2 \mathrm{sp}$.) where chemicals such as aristolochic acids have been identified as key mediators in regulating oviposition and feeding behaviour of the Papilionids and their larvae (Rosenthal \& Berenbaum, 1992) as well as assisting in the avoidance of predators (Dyer, 1995) and parasitoids (Gauld \& Gaston, 1992). Another black-bodied species Common Mime (Chilasa clytia) was monophagous on Lauraceae (2 sp.). The black-bodied Papilio (Mormons, Peacocks and Helens) and Graphium species (Jays and Bluebottles) were found to utilise six plant families out of which Rutaceae, Lauraceae and Magnoliaceae were the dominant ones. The Papilio sp. (8) were oligophagous on the family Rutaceae that was represented by both wild and cultivated varieties of Citrus in the study area while the polyphagous Graphium sp. (3) were found to feed on the families Lauraceae and Magnoliaceae. The year- long occurrence of Graphium and Papilio species with small differences in the dry and wet season abundances could be attributable to their polyphagous and oligophagous nature and their association with some of the evergreen food-plant families like Magnoliaceae and Lauraceae (Spitzer, 1983). Moreover the most abundant species collected during the study period (Graphium and Papilio sp.) were characterised by a wide host range that included some common plant species (Citrus sp., Cinnamomum sp.) which are normally abundant in rural landscapes (Boriani et al., 2005). The Dragontails or Lamproptera sp. (2) were the only monophagous specialists recorded in our study. As highly host-specific butterflies are more dependant on the survival of any one of their hostplants, they are more likely to be vulnerable to localized fragmentation of resources (Koh et.al., 2004) and similar conditions in the study area could have also contributed to the decreasing or low abundances of the Lamproptera sp. within the forest reserve. Therefore our findings showed the dominance of generalist feeders although with respect to the latitudinal gradient in food plant specialisation, the feeding habits of Papilionidae are known to be more specialized in the tropical regions (Scriber, 1973). The weak but significant and positive correlation between the mean abundances and diet breadth of the different species assemblages also showed the dominance of generalist species and polyphagy over specialist species and monophagy in our study area. This could be again correlated with seasonality of the species and plant phenology (Spitzer et al., 1993; Fiedler, 1998). Although in our study we did not quantitatively analyse the correlation between the host-plant diversity and butterfly diversity, however it is known from previous studies that within the Papilionidae, higher species diversity in tropical regions is not correlated with higher host-plant diversity (Fiedler, 1998). Therefore our investigation and findings on the host-plant database for the 
swallowtail butterflies within the study area could be considered to be the preliminary stage for more detailed analytical studies in the future.

We could consider our results on the feeding guild of the Papilionidae to be interpreted in context with their geographic range distribution where it was seen that amongst the 10 monophagous generalist species, nine species belonged to the red-bodied 'Aristolochiae' feeding category and amongst them three species were having restricted geographic range (1 and 2) and one of them, Great Windmill (Atrophaneura dasarada) was an endemic species with range 1. Again amongst the eight species belonging to the polyphagous feeding guild, six species from the genera Papilio, Pathysa and Graphium (Limes, Swordtails, Jays and Bluebottles) were having a wide distribution range $(3=$ IndoMalayan and 4 = Indo-Australian), while two species, Chain Swordtail (Pathysa aristeus) and Great Zebra (Pathysa xenocles) were endemics with a restricted range 1. Amongst the eight species belonging to the oligophagous feeding guild, only three species had narrow geographic range (1 and 2), and one of them, Common Raven (Papilio castor) was an Eastern Himalaya endemic with range 1. The only two monophagous specialist feeders recorded in the study area had a wide range 3 (Indo-Malayan). Therefore it was seen that amongst all the feeding guilds, the number of species with a wider geographic range was higher and a significant correlation between the species mean abundance and their feeding guilds with increasing abundance from 'Specialist' to 'Generalist' and 'Monophagy' to 'Polyphagy' could hold meaningful implications for future conservation purpose. Our results on the dominance of generalists with wide distribution was important with respect to their typical characteristics like broad tolerance limits, exploitation of more food types, flexible habitat requirements and strong dispersal and colonizing abilities (Kitahara \& Fujii, 1994).

Although the adult resources of the swallowtail butterflies were examined only with respect to the identification of some of the important plant families, the study area was found to have a good representation of plant species as good nectar sources for the butterflies. However the adults are as species less specific and more opportunistic in feeding than their larval stages (Gilbert \& Singer, 1975). As supported by previous studies, availability of both floral and larval resources and the effect of climate on plant phenology could be effective in determining butterfly diversity and abundance. Moreover the local abundance and phenology of nectar and host-plant resources may be more important than their presence (Erhardt, 1985; Simonson et al., 2001). In our study area, the phenology of 
the typical moist deciduous vegetation which is influenced by the seasonal monsoon climate could have had an influence on butterfly abundance and diversity as food availability being one of the primary biological factors within a local habitat structure determines the local butterfly assemblage (Ramos, 2000).

\subsection{Effects of environmental variables on swallowtail butterfly abundance and distribution pattern by using the method of multivariate analysis}

\subsubsection{Swallowtail butterfly species composition and habitat association by forest type}

Multivariate analysis has proven to be an important tool when investigating the relationships between species assemblages and environmental variables (Leps \& Spitzer, 1990; Kremen, 1992; Ramos, 1992; Spitzer et al., 1987; Spitzer et al., 1993; Spitzer et al., 1997). Corresponding to the findings of Spitzer et al., 1987, 1990 \& 1993 on the multivariate analysis of the differences among species composition of butterfly communities in particular habitat or forest types, the results of the CCA ordination in our present study showed that the swallowtail butterfly assemblages were homogenous with respect to species composition but heterogenous with respect to abundances and distribution in different forest types within the study area. In all the five study sites within the forest reserve, the species assemblages could be divided into two groups - open forest and closed forest preferring species. The red-bodied swallowtail group comprising of the genera Atrophaneura (5 sp.) commonly called the Windmills and Batwings, Troides (2 sp.) commonly called the Birdwings and Pachliopta hector (Crimson Rose) and the black-bodied genera Papilio (7 sp.) given by common names as Great Mormon, Common Raven, Red Helen, Yellow Helen, Common Peacock, Paris Peacock, Krishna Peacock and Chilasa (1 sp.) commonly called the Mimes were found to prefer the closed forests. The open forests preferring species were specifically confined to the genera Pathysa (4 sp.) commonly called the Swordtails and Zebras, Graphium (3 sp.) commonly called the Jays and Bluebottles, red-bodied Pachliopta aristolochiae (Common Rose) and the black-bodied Papilio demoleus (Limes). There was also a third group of species assemblage comprising of the genera Lamproptera (2 sp.) commonly called the Dragontails and Papilio (1 sp.) commonly Common Mormon which could be termed as intermediate species as they were not specifically confined to the open or closed forests but were encountered in the intermediate zones. The choice of forest 
type might be influenced by several biological factors for the adults - availability of suitable oviposition sites by the gravid females depending on greater abundance of host-plant availability, floral phenology, predators and mimics (Ramos, 2000). Ecological factors like suitable mud-puddling sites and more sheltered conditions as well as structural variables like size of the area, topography, temperature, humidity, light, gaps and ground pattern could account for the preference shown by the butterflies for different habitats or forest types (Ramos, 2000; Boriani et al, 2005). Our field observations are supported by the findings of the researchers. Although butterfly-host plant relationships are not always meaningful predictors of abundances of butterfly species (Sharp et al, 1974; Courtney \& Chew, 1987; Singer \& Ehrlich, 1991), for the monophagous red-bodied Atrophaneura and Troides sp., preferences or higher abundances in the closed forests could be attributed to the availability of Aristolochiaceae in association with tall trees in damp, shady habitats alongside forest streams and preferences for mud-puddling on wet soil along the stream banks. Troides aeacus (Golden Birdwing) and some of the Atrophaneura sp. (Windmills) are known to occur in forest gaps and along riparian corridors in tropical forests where there is an abundance of Aristolochia vines (Pinratana, 1992). In our study T. aeacus (Golden Birdwing) and A. dasarada (Great Windmill) recorded higher abundances in the closed forest transects but sightings were also made in the open forest gaps. This could be attributed to the fact that the increased canopy openness and light penetration caused by disturbance increases the abundance of herbaceous growth and vines and favours species frequenting tree fall gaps and streams for mud-puddling and sun basking (Ghazoul, 2002). The nine oligophagous black-bodied species that were associated with the host family Rutaceae might have preferred the closed forests due to the influence of structural variables like temperature, light, humidity although the correlation between these factors and butterfly abundances were not analysed individually but rather the overall effect of rainfall as an independent variable which included the combined effects of rainfall, maximum temperature and humidity and season as a categorical variable on the seasonal abundances of the Papilionidae were estimated. The family Rutaceae was represented by both wild and cultivated varieties of Citrus sp. and the host plant preferences of these Papilio sp. for the wild varieties could have accounted for their preferences for the closed forests. The geographically wide-ranging Papilio sp. are also migratory species flying over forested areas, thereby giving them an opportunity for visiting flowers in both open habitats and forest canopy while some species like Papilio paris (Paris Peacock)and P. helenus (Red Helen) are specifically canopy species and hence their habitat specificity (Spitzer et 
al.,1993). The genera Graphium (3 sp.), Pathysa (4 sp.), Pachliopta (1 sp.) and Papilio (2 sp.) had preferences for the scattered open forests, which were observed to be mostly the forest edges and gaps created by human disturbances. Such habitats or sampled transects with open vegetation formations were mostly located near to human settlements. These sunloving species were also observed to frequently mud-puddle on wet soil in open sunny patches near to human habitations, excreta of domestic animals and were also seen frequently nectaring at such floral resources like Ixora coccinea, Hibiscus rosa sinensis, Lantana camara, Vitex nugundo that occurred in higher abundances in areas of human settlements. Exotic invasive species like Lantana camara has been recorded to be an important nectar source for several species of Indian butterflies including some of the Papilionidae species (Borkar et al., 2004). This herbaceous plant was frequently observed growing along the edges of the transects in the open forests. The preference for the flowers of $L$. camara by butterflies is mainly because of its colour, aroma, nectar and proximity to the ground (Feltwell, 2001). The availability of preferred nectar sources like Hibiscus rosa sinensis and Lantana camara, which have a yearlong flowering period could also be considered to be a favourable biological factor determining the choice of such habitats by these species. The host-plants of these sun-loving species belonged to the families Lauraceae, Annonaceae, Magnoliaceae, Solanaceae and Aristolochiaceae. With the exception of Aristolochiaceae, the host-plant occurrences of all these swallowtail species were found to be higher in the areas of human habitation as cultivated species (Litsea sp., Magnolia pterocarpa, Cinnamomum sp.). The Graphium sp. (Jays and Bluebottles) have been reported to expand their ranges to Cinnamomum tree plantations throughout Southeast Asia (Haribal, 1994). Monoculture of Polyalthia longifolia, an important host-plant of Graphium sp. in human settlements close to the forest edges and gaps could also be attributed to the high abundances of Graphium sp. (Jays and Bluebottles) in such habitats although monoculture-like conditions in ecosystems and especially plantations of economic trees are normally known to cause a decline in floral diversity and hence a decrease in the diversity of butterflies (Borkar et al., 2004; Kunte et al., 2005). Species like Graphium sarpedon (Bluebottle), Papilio demoleus (Limes) are migratory and are able to fly over canopy of large forests and establish themselves in small open places in the forest. They are forest canopy visitors during some migrations only and are temporarily attracted by canopy flowers. These are the opportunist species with wide geographic distribution and as migrants are associated with disturbed and open habitats while some of these typical gap species are also characteristic canopy flyers - they are able to fly over canopy of large forests (Spitzer 
et al., 1993). Our studies also showed similar results where higher abundances of Graphium sp.(Jays and Bluebottles), Papilio demoleus (Limes), Papilio polytes (Common Mormon) were recorded in the disturbed habitats of study sites S4 and S5 as they were found flying in the gaps or small open areas within the study area. The habitat preferences of the Dragontails (Lamproptera sp.) were intermediate although they were observed to have stronger preferences for the open forests in the study area. White Dragontail (Lamproptera curius) is a typical gap species (Spitzer et al., 1993) and it showed the lowest abundances amongst all the 28 species recorded in the study area. The status of Dragontails (Lamproptera sp.) is 'Vulnerable' and there is lack of sufficient information on the host plant availability of the Dragontails (Lamproptera sp.) in Assam. It was the only monophagous specialist recorded in the forest reserve. The larval host-plant specificity and adult habitat specialization could be the reasons attributed to its low abundance as also its nearly restricted geographical range 3 could be correlated to its narrow ecological niches and less adaptability to rapidly changing environmental conditions such as those associated with habitat loss and degradation (Hamer et al., 1997; Hill et al., 1995; McKinney 1997; Purvis et al., 2000).

Corresponding to the findings of Spitzer et al., (1987, 1993), Leps \& Spitzer (1990) and Ramos (2000) and also as predicted in our hypothesis, the results of the CCA ordination showed that the swallowtail butterfly community in the forest reserve had a significant correlation with the categorical variable 'forest type' and a distinctly heterogenous species assemblage with respect to preference for open and closed forest types were found and thereby suggests the use of this categorical factor - 'forest type' as an appropriate indicator of habitat heterogeneity over this spatial scale.

The suitability of a habitat to sustain both immature and adult stages of butterflies is dependant on the availability of oviposition (larval) food plants and adult nectar plants which are available throughout the year so as to be able to sustain the minimum viable population even during periods of environmental stress. In our study it was observed that the forest-independent species like the Jays and Bluebottles (Graphium sp.), Limes (Papilio demoleus), Swordtails and Zebras (Pathysa sp.), Common Rose (Pachliopta aristolochiae) recorded in the open transects are probably better able to persist in the disturbed landscape (e.g. human settlement areas as in study sites S4 and S5 of Rani range) as they are more adaptable and better able to exploit a wide range of ecological niches (Jones et.al., 2001, Harcourt et al., 2002) including a wide range of host-plants and this could also be related to their wide geographical distributions (Jablonski, 1991; Spitzer et al., 1993). In contrast the 
forest-restricted butterflies were nearly found only in the forests and not only had restricted geographical ranges but the status of some species were 'vulnerable' and this could be attributed to the fact that they are highly sensitive to even very small local damage along the transects (Spitzer et al., 1997). An overview of the earlier records of Papilionidae species in Assam (Evans, 1932), which have not been recorded since many years, also indicates narrow geographical ranges for most of the species and hence a higher sensitivity to loss of forest covers and host plants (Spitzer et al., 1997; Koh et al., 2004).

\subsubsection{Seasonality of the Papilionidae}

The ordination diagrams showed the continuum of seasonal abundance of butterflies in the sampled transects of the open and closed forest types taking the effect of year and it was observed that the relative abundance of the Papilionids was species specific and under a significant influence of seasons. In all the five study sites of Garbhanga and Rani ranges the mean abundances of swallowtail butterflies were significantly higher during the wet season of both years while the relative position of the sites/transects (5-8 for wet season of year 1 and 13-16 for wet season of year 2) in the ordination plots showed the generalised seasonal variations in the abundances of the butterflies. In Garbhanga range transects 3 and 4 representing closed forest during dry season of year 1 (2003) could be compared to show the variations in abundances where transect 3 had higher abundances than transect 4 . In year 2 (2004) the same transects were again sampled as 11 and 12, showing higher abundances in transect 11 than 12. Similarly transects 8 and 16 representing closed forest during wet season of years 1 (2003) and 2 (2004) could be compared to show higher abundances in site 8 during wet season of year 1 (2003). In the study sites of Garbhanga range Common Jay (Graphium doson) and Tailed Jay (G. agammemnon) showed a predictable perennial abundance, reaching a peak during the wet season (summer months). They were encountered in the transects of the open forests in significantly high abundances while their overall total abundance was strongly influenced by rainfall and therefore again their wet season abundances were significantly higher. Hence their position in the constrained ordination matrix is skewed towards the edge of the diagram. The red-bodied group comprising of Windmills and Batwings (Atrophaneura sp.), Roses (Pachliopta sp.) and Birdwings (Troides sp.) normally have their peak flight period during the cooler months first part of the dry season (Borkar et al., 2004) but in the study sites of Garbhanga range it was seen that Golden Birdwing (Troides aeacus) had a peak abundance during the wet 
season of year 2 while Common Birdwing (T. helena) did not show significant differences in abundances between the dry and wet seasons of both years. Moreover the overall abundances of the Birdwings (Troides sp.) was not strongly influenced by rainfall and they could safely survive the dry season in riparian zones of the study area where Aristolochia vines were found to grow gregariously. Similar observations were also reported on abundances of Troides sp. with respect to the influence of monsoon seasonal climate and favourable environmental conditions relating to occurrence of humid groves of gallery forests with Aristolochiaceae vines near streams in Southeast Vietnam and a decline in their abundance during the dry season (Spitzer, 1983).

In the study sites of Rani range the effect of year on seasonal abundance of the butterfly assemblages (genus-wise) was significant and highly correlated with axis 2 . Jays and Bluebottles (Graphium sp.) recorded higher abundances during dry season of year 1 while Common Raven (Papilio castor) showed higher abundances during wet season of year 2 (2004). Limes (Papilio demoleus) had higher abundances during year 2 and the wet season of year 2 showed higher abundances than year 1 (2003). Moreover the overall total abundance of Limes was strongly influenced by the amount of rainfall and as a typical representative species of the open forests, individuals were not encountered in the closed forest transects and also dry season abundance was significantly low. That is why in the constrained ordination maps, their position is skewed towards the edge of the diagram. However the continuum of seasonal abundance on species assemblages showed that amongst the red-bodied group in the closed forest, the Birdwings (Troides sp.) recorded the highest abundances with no significant differences between the 2 years and season and this is in conformity with the findings of Spitzer, 1983. In the open forests, seasonal differences in abundance (dry and wet) were found in Common Rose (Pachliopta aristolochiae) but there were no significant differences in abundances between the wet seasons of the 2 years as indicated by the length of the arrow showing year as an independent variable on the butterfly species assemblages within the sampled transects (see Fig. 5.23). Moreover the effect of rainfall on the wet season abundances of Common Rose (Pachliopta aristolochiae), including that of Tailed Jay (Graphium agammemnon) and Limes (Papilio demoleus) was strongly significant.

The site scores could not be considered as strong meaningful predictors of butterfly seasonality because such predictions are normally dependant on sampling effort and the data on species seasonality is difficult to interpret if it is from a relatively short period because the seasonality of forest butterflies seems to be determined not only by plant phenology and 
climate but butterfly biogeography and fauna history evolution are also involved in the seasonality phenomena (Spitzer et al., 1993). In our study it was seen that the most characteristic patterns in abundance fluctuations were closely associated with the seasonal monsoon climate with significant differences seen in the dry and wet season abundances in all the study sites and this is in conformity with the findings of Spitzer et al., (1993) and Leps \& Spitzer (1990) on the seasonality of the East-Himalayan, Yunnan and Northern Indochina butterfly fauna.. Our results were also found to closely correspond with our hypothesis on the seasonality of the Papilionidae fauna of the study area.

\subsubsection{Effect of rainfall as an independent variable on the swallowtail butterfly species assemblages}

While examining the seasonality of the butterfly species assemblages, we tried to study the association between the combined effects of temperature, rainfall and humidity as climatic parameters and butterfly abundances during the sampling period. The effect of rain as an independent variable on the species abundance in the ordinations therefore included the combined data on rain, temperature and humidity from the sampling period. In tropical monsoon type of climate the variations in the temperature fluctuations between the dry and wet seasons is very little whereas changes in rainfall is very high and this is the most important factor affecting the seasonality of tropical insects (Hill et al., 2003; Wolda, 1989). Although the constrained ordinations showed a significantly strong correlation between rainfall and butterfly abundance, thereby predicting the influence of the monsoon climate on butterfly seasonality, significantly large variations in abundance levels of species with rainfall was not found. Species like the Limes (Papilio demoleus), Jays (Graphium sp.), Common Rose (Pachliopta aristolochiae) showed strong positive correlations with rainfall and were abundant all throughout the monsoons. Other species like Golden Birdwing (Troides aeacus), Common Birdwing (Troides helena), Red Helen (Papilio helenus) and Windmills (Atrophaneura sp.) from the closed forest and Bluebottles (Graphium sarpedon sarpedon), Mormons (Papilio sp.) Swordtails and Zebras (Pathysa sp.) from the open forests showed moderate seasonal trends with rainfall. While the open forest species reached a peak in the summer months, the red-bodied Birdwings (Troides sp.) and Windmills and Batwings (Atrophaneura sp.) had their flight period peak in the last part of the wet season while Red Helen (Papilio helenus) had its flight period during the late monsoon and early part of dry season. Some species like the Crimson Rose (Pachliopta hector) and Common Raven (Papilio castor) were strictly seasonal and confined to the monsoons only. Such a 
type of seasonal trend could be attributed to a synchrony with the phenology of food plants and especially in case of perennially occurring species, availability of food plants round the year is implicated (Spitzer, 1983). Again the combined effects of temperature, rainfall and humidity on various other aspects of butterfly ecology such as mate-location, egg-laying, nectaring, egg-survival, host-plant growth and habitat structure could have also accounted for the seasonal variations in the species assemblages within the study period (Pollard, 1988; Dennis \& Shreeve, 1991). Microclimatic conditions created by temperature and moisture gradients, which are quite independent of habitat types, defined by vegetation can also help in determining the distribution and local abundance of butterflies on a small scale (Whittaker, 1952; Scott, 1986). In our study, such local microclimatic conditions could have also accounted for variations in species abundances. We could still consider our results to be corresponding with the findings of Spitzer et al. (1993) on the seasonality pattern of the Southeast Asian Papilionidae and the influence of the monsoon climate on the abundance fluctuations of the butterfly fauna in Vietnam. However for examining the complete seasonality of the East Himalayan Papilionidae, the study period was short and more intensive studies over a period of several seasons are required.

\subsubsection{Effect of altitude as an independent variable on the abundance and distribution pattern of the swallowtail butterfly species assemblage}

The effect of altitude on the abundance and distribution of swallowtail butterflies was significant $(\mathrm{p}<0.001)$ in the three study sites of Garbhanga range (see Chapter 5 : Figs. $5.20,5.21 \& 5.22$ ). A similar result was also found for the two study sites of Rani range (see Chapter 5 : Figs. 5.23, $5.24 \&$ 5.25). The forest dependant species had preferences for higher elevations while the open forest species preferred the gaps at lower elevations. Elevation can affect the distribution of butterflies across time and space because cloud cover, precipitation and wind speed increase and ambient temperature decreases at higher elevations (Fleishman et al., 1998). Although the altitudinal variations in the sampled transects of Garbhanga and Rani ranges were not large, differences in abundances between open and closed forest transects along a narrow elevational gradient were observed. Even narrow elevational gradients could sometimes influence some of the biological activities of the butterflies like fecundity and opportunities to lay eggs (Boggs \& Murphy, 1997). In the study area, the distribution of the swallowtail butterflies pertaining to their habitat specificity and abundances at different altitudes could also have been attributed to the fact that the sampled transects of the open and closed forests were located at different elevations 
- the gaps were located at lower elevations and the abundance of the gaps decreased with distance from the forest edge and villages and increasing elevation. Although environmental factors related to altitude and climate (temperature and precipitation) have been known to account for most variances in the interspecific differences in the distribution of butterflies and birds (Storch et al., 2003), in our study only climate relating to the typical dry and wet monsoon periods were known to strongly affect the abundances of butterflies as already discussed on the basis of our findings and predicted in our hypothesis. But contradictory to the findings of Storch et al. (2003), our results showed a less strong but still significant correlation between the narrow elevational gradients or altitude as an independent variable and butterfly abundances and distribution. But as again already mentioned in our partial conclusion on the multivariate ordination of the Papilionidae, the correlation could have been attributed more to the location of the open and closed forest transects at lower and higher elevation gradients respectively rather than other factors. However it is known from pervious studies that for butterflies minimum altitude is much more important than maximum altitude (Storch et al., 2003).

\subsubsection{Effect of geographical position (latitude and longitude) on the abundance and distribution pattern of the swallowtail butterfly species assemblage}

There has been no scientific work on butterfly composition and distribution of North-east India (Eastern Himalayas) in the recent years except in the Sikkim Himalayas (Haribal, 1992) and for Assam in particular the contemporary documentation on the Papilionidae was restricted to authorative inventory and checklists (Arora \& Mondal, 1981; Kunte et al., 2005). New species records are lacking due to insufficient taxonomic and survey-related work and one of the foremost strategies for this is the need for geographical mapping of different taxa. In our study the purpose for examining the effects of geographical position (latitude and longitude) on the Papilionidae composition and distribution within the protected reserve is the first effort towards butterfly mapping. Our study area is an ecotone and such regions as 'hybrid zones' are normally known to harbour a rich species diversity (Storch et al., 2003) and therefore the biogeography of the region is an important part of such studies. Latitude and longitude can cause differences in local species composition (Storch et al., 2003). Therefore even if on a relatively small scale it is necessary to consider these effects on distribution patterns. In our constrained ordinations it was seen that the species composition, abundance and distribution patterns were significantly related to habitat factors (forest types) but this we could consider to be a by- 
product of similar geographical structure of habitat and species data. This could also have been the underlying cause for the significant correlation of geographical position with species assemblages atleast for the study sites of Garbanga range (see Figs. 5.20, 5.21 \& 5.22) although the correlation was not significant for the study sites of Rani range (see Figs. $5.23,5.24 \& 5.23)$, and also the overall geographical size of the study area was not sufficiently large enough for such kind of study. As the transects sampled in the five study sites of both the ranges (Garbhanga and Rani) were geographically located close to each other, the variation effect of latitude and longitude can be safely negated as the transects were positioned mainly keeping in view the forest types and not the geographical positions. The GIS map on land-use cover of the protected Forest Reserve (see Chapter 4 : Fig. 4.2) showed the superimposed butterfly collection sites where the initial phase of research work pertaining to building up the reference collection was conducted and these sites could be identified as 'butterfly hotspots' within the reserve. However our ordination results as well as results from previous studies demonstrate that although remote sensing data can reveal some important associations between species distribution and habitats, they are not appropriate for revealing all the important ecological factors that can affect the distribution of species perceiving habitats on finer scales (Storch et al., 2003). Therefore as far as conservation is concerned, even for the invertebrate taxa, the studying of habitat requirements of the individual species in the field as well as their distribution mapping must be a combined effort. Contradictory to the findings of Storch et al. (2003) and also our hypothesis predicting the significant influence of geographical position as an independent variable on butterfly abundance and distribution, our ordination results did not show an overall significant correlation between geographical position and swallowtail butterfly abundance and distribution pattern.

\subsection{Effect of season and forest/habitat type on species diversity, richness, evenness and rarefaction estimates:}

\subsubsection{Species diversity in the study sites by forest type and season}

Measures of species diversity play a central role in ecology and conservation biology (Whittaker, 1960; Peet, 1974; Pielou, 1975; Magurran, 1988). Some of the most commonly employed diversity measures were also used in our studies. The overall species assemblage in the pooled transects of the five study sites showed a homogenous pattern. Conflicting 
patterns of butterfly diversity, richness, evenness and rarefaction produced by the different indices showed the complexity of discriminating among different habitats in a landscape. The objective of calculating the different indices was primarily to examine the varying effects of season and forest type on the homogenous species assemblage within the study area as shown by the different indices. While both Shannon (H') and Simpson's index (D) account for the abundance of species, $\mathrm{H}^{\prime}$ is sensitive to changes in abundance of rare or intermediate abundant species and hence to sample size. However as a dominance measure, Simpson's index (D) considers the abundance of the most common species and is less sensitive to species richness and sample size. The Inverse Simpson index (1/D), one of the most meaningful diversity indices, reflects the evenness of species abundance although it may be influenced by common species. Another diversity index, the Fisher's $\alpha$ which is very similar to Inverse Simpson, is not affected by size of sampling area and is less affected by an abundance of rare species than the other measures. It principally considers the total number of individuals and is not so sensitive to sample size. This is a result of its dependence on the numbers of species of intermediate abundance (Magurran, 1988). As the data from the 20 fixed transects within the five study sites were pooled for multivariate analysis and the total diversity in a pooled set of data can exceed or equal the average diversity within the community, therefore these measures of diversity with different sampling bias and variance were used to examine the varying effects of season and forest type on the species richness, evenness, rarefaction and diversity of the Papilionidae within the study area.

In Garbhanga range there was no seasonal variation in species diversity but in relation to habitat/forest type, species diversity was significantly higher in the closed forest in all cases. However in Rani range, only Shannon's index (H') differed significantly between seasons and was found to be higher during the wet seasons of both years while Simpson's (D), Inverse Simpson's (1/D) and $\alpha$-diversity were found to vary significantly between habitats - D and 1/D were higher in the open forests while $\alpha$-diversity was higher in the closed forests. Higher diversity in the closed forest habitats of Garbhanga range could be attributed to several favourable environmental conditions like good canopy cover which is necessary for the shade-preferring, forest-restricted canopy species especially the Windmills and Batwings (Atrophaneura sp.), Paris Peacock (Papilio paris), Red Helen (P. helenus) and Yellow Helen (P. nephelus). It was observed that sunlight could still penetrate the canopy thereby enhancing the flight and survival of these forest-dependant species. Suitable riparian zones maintaining muddy patches that are used by adult butterflies were frequently 
observed in the closed forest transects of this range. Although the results of the CCA ordination showed low to intermediate abundances of the forest-restricted species, higher diversity could be related to the mixed assemblage of rare, common and intermediate species with varying levels of abundance in the closed forest transects. A total of 16 species of Papilionids were confined within the closed forest habitats of Garbhanga range out of which six species (Atrophaneura dasarada, A. varuna, Troides aeacus, Papilio castor, Papilio nephelus, Papilio krishna) had restricted geographical ranges 1 (Eastern Himalayas) and 2 (Northeast India \& Indo-China) . Number of species with range 3 was the highest (9 sp.). Only one species (Papilio helenus) had the widest range 4 (Indo-Australian). The species with range 3 (Indo-Malayan) recorded the lowest abundance as individual butterflies and therefore were classified as rare in the ordination results. The six species with restricted range $\left(\begin{array}{lll}1 & \& & 2\end{array}\right)$ also recorded moderate abundances. However the intermediate species (neither open or closed forest restricted) like the Mormons (Papilio sp.), which were classified as fairly common in the ordination results and with geographic range 3 , recorded moderate to high abundances in the closed forest. Spearman's rank correlation between the species mean abundance and geographic range also indicated a similar trend. Again some of these species like the Mormons and Peacocks (Papilio sp.) are also known migrants and the potential mobility of the adult butterflies can affect the sample size. However as the diversity measures considered all range of species from rare to common as well as the mean species abundance from the pooled data set, therefore the results could be considered as meaningful.

Differences in the landscape structure of the study sites in Garbhanga and Rani ranges were also observed both visually during our field surveys and in the satellite imageries (see Chapter 4 : Figs. $4.1 \& 4.2$ ), which could have influenced the differences in the diversity of the species assemblages between the study sites of the two ranges. Differences in the landscape features could be related to differences in microhabitat features for adult butterflies like light, moisture, topography as well as microclimatic conditions (Scott, 1986). In the study sites of Rani range, amongst the 14 forest-restricted species, only three species with geographic distribution ranging from 2 (Indo-China) to 3 (Indo-Malayan) recorded high abundances and were classified as common while another six forest restricted species with geographic distribution ranging from 1 (Eastern Himalayas) to 4 (IndoAustralian) recorded moderate to low abundances and were classified as less common and rare. A high Shannon's diversity (H') during the wet season of both years in Rani range could be attributed to favourable microclimatic conditions that may have been ideal for the 
adult butterflies. Temperature and moisture gradients even at a small-localised scale are known to influence the distribution and local abundance of butterflies and many other terrestrial taxa (Whittaker, 1952). The study sites of Rani range were located in closer proximity to human settlements where disturbance in the form of small-wood collection, grazing and shifting agriculture were observed. The findings from previous research studies have shown that disturbance can sometimes favour species by enhancing herbaceous and vines growth and creating gaps suitable for sun-basking and mud-puddling (Ghazoul, 2002). A similar condition could have also resulted in a higher H' diversity of the butterflies in the disturbed study sites S4 and S5 of Rani range. As H' diversity is more sensitive to rare or common species and the abundances of the some of the common widespread species from the genera Graphium (Jays and Bluebottles) and Papilio (Limes, Common Raven, Red Helen) were found to be significantly higher during the wet season, this could have also contributed to the higher $H^{\prime}$ diversity during the wet seasons. Again the occurrence of household plantations was higher as there was an abundance of cultivated Citrus and Polyalthia longifolia plantations in the study sites of Rani range. However there were no significantly large differences in the vegetation structure between the two sampled study sites S1 and S4 of the two ranges with respect to trees and under-storey species composition which could represent the general vegetation profile of the entire reserve. Therefore microclimatic conditions could alone have accounted for a higher $\mathrm{H}^{\prime}$-diversity of butterflies in Rani range. Higher diversity in the scattered or open forest habitats of Rani range as indicated by Simpson's and Inverse Simpson's index could have resulted due to moderate to high abundances of common species with wider geographic ranges like the Graphium sp. (Jays and Bluebottles,). But $\alpha$-diversity was higher in the closed forest habitats and this could be again attributed to the higher abundances of shade - preferring forest-restricted species (see Figs. $5.25 \& 5.26$ ). This contradicts with the results of previous studies where $\alpha$-diversity of tropical butterflies was found to be higher in the forest edges, gaps and disturbed areas (Leps \& Spitzer, 1990; Spitzer et al., 1993; Spitzer et al., 1997; Ramos, 2000). This index is also less affected by the abundance of the rarest or the commonest species than either H' (Shannon's) or $\lambda / D$ (Simpson's) and depends more on the number of species of intermediate abundance (Magurran, 1988). Our ordination results on the group and species assemblages showed the varying levels of abundance of the Papilionidae across the dry and wet seasons of the 2 year study period in the study area and accordingly their categorisation into rare, common and intermediate species. The results on the swallowtail 
butterfly diversity indices within the study area by forest type and season could also be interpreted in the light of the ordination results on group and species abundances.

\subsubsection{Species richness, evenness and rarefaction in the study sites by forest type and season}

There were no significant differences in species richness by forest type or season in all the study sites of Garbhanga and Rani ranges as probably all the recorded species were encountered in almost all the transects in varying levels of abundance and secondly could also be related to the pooled data.. The evenness and rarefaction estimates were found to be higher in the closed forest habitats of Garbhanga range and in the open forest habitats of Rani range. Differences in landscape structure and microclimatic conditions could have had a combined effect on the variations in the evenness and rarefaction estimates of butterflies between the open and closed forest habitats. In most of the landscapes in India, two factors associated with human disturbance are known to influence the species diversity and richness of flora and fauna - grazing by cattle and fires (Kunte, 1997). This holds particularly true for butterflies where vegetation is primarily affected by such kinds of disturbance. Although the gradients of disturbance in the study sites of Garbhanga and Rani ranges were not measured, the levels of disturbance were higher in the study sites of Rani range and the landscape structure also differed between these study sites. Higher species evenness in the disturbed open forests of Rani range could be attributed to higher abundances of wide-ranging generalist species that were more commonly associated with the open transects near to human settlements where abundance of cultivated varieties of food plants were available. According to Novotny (1991), a high disturbance level favours generalists irrespective of habitat distinctiveness. However the conditions were different in the study sites of Garbhanga range where favourable microclimatic conditions associated with fewer disturbances could have contributed to higher species evenness in the closed forests habitats. But again it is to be noted here that one of the study sites (S3) was heavily disturbed by shifting cultivation (see Chapter 4 : Fig. 4.2) but there was an abundance of grasses and shrubs accompanied by vines in the areas of regeneration and this site could be said to represent a typical example of vegetation created by traditional agricultural activities as in Indo-China region. Most of the wide-ranging opportunist species are normally known to be associated with such kinds of habitats and some of these species are also known to be common migrants (Spitzer et al., 1993). Therefore an assemblage of diverse ecological conditions within the closed forest transects could have contributed to higher species 
evenness in the closed forests of Garbhanga range. However for a clear evaluation of the different diversity parameters of the Papilionidae fauna within the protected reserve, further data from an extended time period are required. Moreover in tropical environments diversity or species richness measures often increase with disturbance, concurrent with a decrease in conservation value (Basset et al., 1998). In our study although we did not quantify and analyse the levels of disturbance, such factors have to be considered in depth for future monitoring studies. In many butterfly assemblages, forest disturbance allows a group of mobile, widespread and generalist taxa to colonize and coexist with much of the existing fauna thereby enhancing the overall diversity (Hamer et al., 1997; Spitzer et al., 1993, 1997). Such migrants are typically species of low conservation concern and it is not always sensible to give them equal weighting as the restricted range habitat specialists in conservation assessments (Lewis \& Basset, 2007).

In our findings, the overall abundances of some of the typical wide ranging gap species associated with disturbances like the Graphium (Jays and Bluebottles) and Papilio sp. (Limes and Common Mormon) were found to be higher particularly during the wet season and this could have contributed to higher diversity in the open forest habitats of Rani range. However in Garbhanga range it was seen that the closed forests were more diverse and this could be attributed to higher wet season abundances of some of the endemics like Atrophaneura dasarada (Great Windmill) as well as non-endemic species like Papilio paris (Paris Peacock) and Atrophaneura polyeuctes (Common Windmill). Therefore depending upon the local microclimatic conditions prevailing in different but closely located habitats or landscapes, results can not only vary but can also be very contradictory. Sometimes it is also considered reasonable to restrict analysis to endemics (Lewis et al., 1998) or to weigh the conservation value of a species to reflect its geographic range or rarity in a similar way to indices that take into account the taxonomic similarity of species for conservation assessments (Vane-Wright et al., 1991; Williams et al., 1991). In our study one limitation was the low levels of sampling due to which sometimes even a widespread species could be recorded as locally rare although we did not find such a trend in our results. However our analysis was not restricted to endemic taxa and neither did we remove the rare species from the analysis. Even if the sampling effort was equal across all sites, species diversity becomes a questionable criterion when habitats with different productivity or disturbance levels are compared or when the number of rare species is large (Dufrene \& Legendre, 1997). Therefore taking into consideration all these factors, we could still consider our results to be statistically meaningful. Our results on the higher Papilionidae species diversity 
in the open forests were corresponding to the findings of Ramos (2000) although our results on higher Papilionidae diversity in the closed forests of Garbhanga were contradictory to the findings of Ramos (2000) but corresponding to our hypothesis on expected higher species diversity in the closed forest habitats of the study area. We also did not find any significant differences in species richness between the two forest types which is contradictory to our hypothesis on expected higher species richness in the closed forests. Also contradictory to our hypothesis, we did not find any significant differences in the Papilionidae species diversity between seasons, although only Shannon's diversity ( $\left.H^{\prime}\right)$ was found to be significantly higher during wet season of the study period only in the study sites of Rani range and this could have been attributed to higher disturbance levels in the study sites which is known to favour some of the wide-ranging generalist species as already predicted in some previous studies (Novotny, 1991).

\subsection{Butterfly assemblages and indicator taxa:}

\subsubsection{Indicator species defined by transect abundance of butterflies in open and closed forest}

Multivariate techniques are highly useful tools for identifying sets of indicator species for different habitats. The IndVal method is good for classification and identification of indicator species as this method reflects the local patterns of habitat heterogeneity indicating which assemblage could be considered as an appropriate indicator of these habitat types (Dufrene \& Legendre, 1997; Kremen, 1992). Moreover the IndVal can be calculated independently for each species, and the sampling sites (habitat/forest types) can be categorised subjectively or quantitatively (McGeoch \& Chown, 1998). This method is however dependant on the degree to which species maintain high and significant indicator values (IndVals) when tested in different locations and times. As IndVal reflects frequency of occurrence (abundance), abundance changes are likely to alter year-to-year indicator values. However, the IndVal method may accommodate such abundance changes because IndVal is calculated by comparing a species' frequency of occurrence between habitat types, i.e. relative differences in frequency of occurrence between habitat types, rather than absolute values (McGeoch et al., 2002). Therefore we analysed our data on species abundance in the fixed transects of the five study sites within the protected reserve both location or transect -wise by forest type and season-wise. In our study area, two main 
sets of butterfly assemblages were identified, which showed characteristic properties of indicator species. In total, thirteen Papilionidae species were identified as characteristic of the two different assemblages : Bluebottle (Graphium sarpedon), Tailed Jay (G. agammemnon), Common Jay (G. doson), Great Zebra (Pathysa xenocles), Great Windmill (Atrophaneura dasarada), Common Windmill (A. polyeuctes), Common Batwing (A. varuna), Golden Birdwing (Troides aeacus), Common Birdwing (Troides helena), Common Rose (Pachliopta aristolochiae), Lime (Papilio demoleus), Red Helen (Papilio helenus) and Common Raven (Papilio castor). One assemblage was characterised by the strong relative abundance of forest dependant Atrophaneura sp. (Windmills and Batwings), Troides sp. (Birdwings) and Papilio sp. (Red Helen and Common Raven) and the other assemblage was characterised by the high relative abundance of forest independent Graphium sp. (Jays and bluebottles), Pathysa xenocles (Great Zebra), Pachliopta aristolochiae (Common Rose) and Papilio demoleus (Limes). Tailed Jay (G. agammemnon), Bluebottles (G. sarpedon), Common Rose (P. aristolochiae) and Limes (Papilio demoleus) are known migrants (New \& Thornton, 1992) and characteristic canopy flyers visiting flowers in both ruderal habitats and forest canopy (Spitzer et al., 1993). Although the Limes (Papilio sp.) showed indicator properties, on an overall they did not score high IndVals in the study sites of the forest reserve when groups were defined by values of the average transect abundance. However when species assemblages were defined by values of season, Yellow Helen (Papilio nephelus) and Common Raven (Papilio castor) scored high IndVals in the study sites of Rani range while Red Helen (P. helenus) scored a high IndVal in the study sites of Garbhanga range. Therefore the identification of indicator species both location or transectwise by forest type and season-wise was significant because it produced different results but gave some insight into how different variables can influence the indicator properties of the butterfly assemblages.

In the study sites of Garbhanga range, when the species assemblages were defined by values of average abundance in transect space, Common Rose (P. aristolochiae), Common Jay (Graphium doson), Tailed Jay (G. agammemnon), Bluebottle (G. sarpedon), Great Zebra (Pathysa xenocles) and Limes (Papilio demoleus) scored high IndVals $(p<0.05)$ and could be identified as indicator species characteristic for the open forests or gaps with disturbance (see Table 5.8). The vegetation in the transects where high abundances of Jays and Bluebottles (Graphium sp.) were recorded was dominated by both wild and cultivated varieties of Cinnamomum sp., Litsea sp. which are the primary food plants of the Graphium sp. As vegetation is known to integrate many ecological factors that 
may determine the distribution and abundance of butterfly species and specifically in case of the host plants which represent the larval resources and have been known to show significant correlations with the butterfly species (Sawchik et al., 2003), our results on the correlation between the high abundances and indicator properties of Graphium sp. in the open forest transects of Garbhanga range could be related to the vegetation or the larval food-plant availability. Similarly the availability of other plants that may provide nectar sources for the adults as well as the conditions necessary for sun-basking or mating places could have been more favourable for all these species in the given habitat type. Again disturbance increases the abundance of herbaceous growth and vines and favours species normally frequenting tree fall gaps and streams (Ghazoul, 2002). The indicator properties of Jays and Bluebottles (Graphium sp.) and Common Rose (Pachliopta aristolochiae) as characteristic gap species could be correlated to moderate levels of disturbance in the open forest transects of Garbhanga range.

However in the open forest transects of study sites S4 and S5 in Rani range, where monoculture of Polyalthia longifolia was dominant and the levels of disturbance were also much higher, comparatively lower abundances of Jays and Bluebottles (Graphium sp.) were recorded. As butterfly distributions are expected to covary with the distribution of their host plants even at small scales within forest stands (DeVries, 1988; Beccaloni, 1997), changes in the type of forest vegetation including host plants may reflect differences in the composition and abundance of butterfly communities among sites (Beccaloni, 1997). Secondly disturbance-induced environmental changes are likely to affect the abundances of some species in an assemblage more than others (Erhardt \& Thomas, 1991). Higher levels of disturbance in the sampled transects of Rani range which were in closer proximity with the forest villages and edges could have resulted in environmental variations that did not favour some species and could have been the reason attributed to the non-detection of Tailed Jay (Graphium agammemnon) and Common Rose (Pachliopta aristolochiae) as indicator taxa in the study sites of Rani range. The four species which showed indicator properties in the disturbed open forest transects in the study sites of Rani range were Common Jay (Graphium doson), Bluebottle (G. sarpedon), Great Zebra (Pathysa xenocles) and Limes (Papilio demoleus).

It is important to argue here that the Rutaceae feeders (Papilio sp.- Mormons and Limes) had recorded high abundances in the open transects of all the study sites within the forest reserve which could be correlated to the high abundances of their host-plants (wild and cultivated varieties of Citrus sp.) within the study sites although this correlation was 
based on visual observation and we had quantitatively measured the larval food-plant abundances for only two study sites, S1 and S4 which could be considered to represent the overall food-plant profile of the study area. However only one species, Papilio demoleus (Limes) scored an IndVal $>45 \%(p<0.05)$ in the study sites of both the ranges and could be selected as an indicator species for open disturbed habitats. Papilio demoleus is normally associated with disturbed habitats and is a characteristic species for open transects (Lien \& Yuan, 2003) and our studies also showed similar results. The IndVal method which is known to be sensitive to species abundances could have obscured the identity of characteristic species as a result of interseasonal differences in abundances levels between the study sites of the two ranges (McGeoch et al., 2002). Another reason could be attributed to transect sampling error as this method has certain limitations. The species representation reflects not only its abundance, but also its activity and unless the activity differs considerably among habitats, the preferences are estimated correctly by all statistical methods used (Spitzer et al., 1997). Therefore the typical gap species which could be detected as characteristic indicator species for open ruderal transects within the forest reserve were Common Jay (Graphium doson), Bluebottle (G. sarpedon), Great Zebra (Pathysa xenocles) and Limes (Papilio demoleus). These were also opportunistic, generalist species with wider geographic distribution and according to Brown (1984), generalist species can be simultaneously locally abundant and widely distributed as a result of their ability to exploit a wide range of resources on both local and regional scales. Such species are associated with disturbed and open habitats (Spitzer et al., 1993). Our results on the characteristic indicator species for gaps with moderate to high disturbance also showed a similar trend. However another important factor to be considered while evaluating our results was that normally such gap species like particularly the Graphium (Jays and Bluebottles) are also canopy fliers and migrants, and the transect method is less efficient for canopy fliers.

\subsubsection{Indicator species defined by values of mean seasonal abundance of butterflies}

Although habitat-specificity is a comparatively inflexible species-specific trait (Southwood, 1977; Greenslade, 1983), the abundance of species in an assemblage may change over time with season and weather conditions (Wolda, 1988; Tauber et al., 1998). Although inter-annual differences in say for example weather patterns are likely to have only minor effects on the IndVal of a species if it is similarly affected by environmental variability across all habitats or sites where it is found, our studies showed different results 
when the average abundance of the species assemblage was defined by values of season. A total of eight species met the indicator species criteria (see Tables $5.9 \& 5.12$ ). The observed IVs (Indicator Value) of six species from the red-bodied group Windmills and Batwings (Atrophaneura sp.), Birdwings (Troides sp.) and Roses (Pachliopta sp.) were statistically significant at $\mathrm{p} \leq 0.005$. In Garbhanga range, the red-bodied species Great Windmill (Atrophaneura dasarada), Common Windmill (A. polyeuctes), Common Batwing (A. varuna) and Golden Birdwing (Troides aeacus) with significant IndVals of $>80 \%(\mathrm{p}<0.005)$ and the black-bodied canopy species Red Helen (Papilio helenus, IV >65\%, p<0.005) could be selected as potential indicator species. In Rani range, four species from the red-bodied group- Common Batwing (Atrophaneura varuna), Golden Birdwing (Troides aeacus), Common Birdwing (T. helena), Common Rose (Pachliopta aristolochiae) and one blackbodied species, Common Raven (Papilio castor) with significant IndVals $>65 \%(\mathrm{p} \leq 0.005)$ could be selected as indicator species. Again only one species, Common Rose ( $P$. aristolochiae) characteristic of gaps and open forests with disturbance scored a high observed IV $(>80 \%, \mathrm{p}<0.005)$ as compared to other species that scored lower IVs $(>65 \%)$.

Amongst the potential indicators identified in the forest reserve by values of seasonal abundances, with the exception of Common Rose (P. aristolochiae) and Red Helen (Papilio helenus), the other species had restricted geographic distribution. Again with the exception of Common Rose (Pachliopta aristolochiae), these seasonal indicator species were mostly forest-restricted and could be distinctly divided into two groups- the red-bodied monophagous Aristolochiaceae feeders (6 sp.) and the black-bodied oligophagus Rutaceae feeders $(2 \mathrm{sp}$.). The observed IVs of the potential indicator species were clearly influenced by the differences in the seasonal abundance. The two species which scored high IndVals in the study sites of both the ranges were Common Batwing (Atrophaneura varuna) and Golden Birdwing (Troides aeacus). While the former is a typical stenotopic closed canopy species, the latter is known to be a typical gap species associated with disturbed secondary forest habitats (Spitzer et al.,1997), although in our study sites Golden Birdwing (T. aeacus) was recorded in higher abundances in the closed forest transects during the wet seasons of both years. Moreover this species is known to safely survive dry seasons along riparian corridors where there are normally an abundance of Aristolochiaceae vines (Spitzer, 1982) and this is also the reason why this species, although a habitat specialist actually benefits from increased disturbance as increased canopy openness and light penetration favours vines and herbaceous growth. The forest-restricted Atrophaneura sp.(Windmills and Batwings) were on an overall observed in very low abundances in the disturbed open areas. 
Such species are highly sensitive to even very small local damage along the transects (Spitzer et al., 1997). They could therefore be considered as 'asymmetrical indicators': their seasonal presence could not be predicted as in all sites/transects of one habitat type, but still contributed to the habitat specificity (Dufrene \& Legendre, 1997).

Our results suggest that the set of seven species that could be possibly selected as indicators for the particular habitat types - Tailed Jay (Graphium agammemnon), Bluebottle (G. sarpedon), Great Zebra (Pathysa xenocles), Limes (Papilio demoleus), Common Rose (Pachliopta aristolochiae), Common Raven ((Papilio castor) and Golden Birdwing (Troides aeacus) may constitute a useful tool for conservation. The five indicator species for the open transects were opportunistic species with wide geographic distribution and such species are known to be very good colonists of extreme early successional habitats (Leps \& Spitzer, 1990). The two indicators for the closed forest transects had restricted distribution and these are mostly stenotopic species and such taxons seem to be of endemic distribution in Northern Indo-China or the East Himalaya (Leps \& Spitzer, 1990). All the sites/transects showed the presence of at least one of these species. They are easily recognisable and moderately sensitive to human disturbance. One particular advantage in the case of the Jays and Bluebottles (Graphium sp.), Limes (Papilio demoleus), Golden Birdwing (Troides aeacus) and Common Rose (Pachliopta aristolochiae) is the considerable knowledge about their life history and ecology (Spitzer, 1982; Spitzer et al., 1997). Therefore the identification of indicator species both by mean transect and seasonal abundances thereby determining their habitat specificity could be considered as an useful tool for conservation. Our results on the identification of a mixed assemblage of four common species with wider geographic ranges and associated with disturbed habitats or forest types corresponds with the findings of Ramos (2000) as well as our hypothesis on indicator species selection criteria. Similarly the indicator properties shown by the two endemic closed forest restricted species and one endemic gap species also corresponds with the higher conservation priorities of restricted range species as observed by Spitzer et.al., (1993), although we did not predict the selection of restricted range species as indicators in our hypothesis. But our findings on this mixed assemblage could be considered as significant because the gap species are generally mobile, opportunistic species with low conservation value (VaneWright et al., 1991) and are not always considered to be reliable indicators of habitat quality while at the same time they are also reported to have the lower risks of extinction because they are less likely to be isolated, demographically and genetically than less mobile species (Macdonald \& Johnson, 2001). 


\section{CHAPTER 7 : RECOMMENDATIONS FOR CONSERVATION}

\subsection{Study overview}

The study on the species richness and relative abundance of the Papilionidae was done for the first time in Rani-Garbhanga Forest Reserve, Assam, India. The results showed a still high number of Papilionidae species. The local extinction of several Papilionidae species was noted. The conservation value of a biological community is determined not only by its richness and diversity, but also by the rarity and endemicity of its constituent species and the ability of species to maintain viable populations in the face of disturbance pressure (Ghazoul, 2002). In our present study, we recorded 28 species of Papilionidae upto the species level, out of which four species were endemic to the Eastern Himalayas - Great Windmill (Atrophaneura dasarada), Common Raven (Papilio castor), Chain Swordtail (Pathysa aristeus), Great Zebra (Pathysa xenocles) and amongst them two species were forest-restricted (Atrophaneura dasarada and Papilio castor) while the other two species were associated with open/scattered forest habitats (Pathysa aristeus and Pathysa xenocles). In comparison to the 69 species of Papilionidae documented in Northeast India by Evans (1932) and Talbot (1939) out of which the distribution range of five species were described to be endemic to Assam, the status of three species were reported to be very rare and they are presently protected by law in India. All these three species are forest-restricted and have been rarely recorded in the Eastern Himalayas in the past years and also not recorded in our present study. Based on our results on the multivariate ordination on the Papilionidae assemblage within the study area, 16 species were found to be associated with the closed forests while another 12 species were associated with the open forests. Out of the 16 forest restricted species, two species were endemic to the Eastern Himalayas with restricted range score 1 and another four species were endemic to Northeast India and Indo-China with restricted range score 2. Nine species had 'Indo-Malayan' distribution with a range score 3 and only one species had 'Indo-Australian' distribution with the widest range score 4. Amongst the 12 gap species, only two species were endemic to the Eastern Himalayas with range score 1 while five species had an 'Indo-Malayan' distribution with range score 3 and another five species had an 'Indo-Australian' distribution with the widest range score 4. Our 
results on the multivariate ordination of the swallowtail butterfly assemblage and their categorization into two clear-cut strata with respect to habitat association lends support to the hypothesis that the most vulnerable species are also the species with restricted distribution and the loss of these species will lead to increasing regional homogeneity of the butterfly fauna (Thomas, 1991; Spitzer et al., 1993; Hill et al., 1995; Hamer et al., 1997). Such results could hold meaningful implications for future conservation strategies because our studies showed that amongst the 28 identified species, only eight species with restricted range scores 1 and 2 were endemic to the Eastern Himalayas and Indo-China and out of these, six species were associated with the closed forest and two species were associated with the open forest or gaps. While most of the ecologists consider the forest restricted endemic taxa to be the more endangered groups requiring conservation priority, endemics from the open and more disturbed habitats also cannot be ignored (Ramos, 2000).

Although we did not conduct an intensive vegetation sampling within our study area, based on actual field observations, vegetation sampling in two study sites and reference from literature, our identification and documentation of the host-plants will not only play an important role in the future conservation process but will also contribute towards a better understanding of the biology and ecology of these butterflies. In the present study, the hostplant identification helped in the categorization of the diet breadth of the Papilionidae. Our results on the correlation between the mean abundance and feeding guild of the Papilionidae indicated a weak but significant and positive correlation and an increasing mean abundance from 'Specialist' to 'Generalist' and 'Monophagy' to 'Polyphagy' could be considered to be an important aspect for future conservation and eco-restoration programs. Our results also suggest a that a more detailed investigation should be done on the larval food-plant diversity of the Papilionidae and the probable use of vegetation as a management variable for future butterfly monitoring activities is recommended.

The hypothesis that endemic species which are more sensitive to habitat disturbances are confined to the closed canopy habitat and also have higher conservation value whereas the more widely distributed opportunistic species which can better adapt to environmental changes probably due to their ability to utilize a wide range of resources are therefore more often found in the gaps and disturbed habitats was confirmed. Although the correlation results were not strongly significant, they were still positive for atleast three of the study sites in Garbhanga range. We could consider the variations in the mean abundance of the species assemblages with different distribution ranges as probable indications of changes in 
habitat conditions (Pollard, 1992) and incorporate this aspect of our study for future conservation programs.

The relative abundance of the Papilionidae assemblage was found to be dependant on season and this is in conformity with the studies on the seasonality of the butterflies in Southeast Asia (Vietnam) by Spitzer et. al., (1993) and also corresponds to our hypothesis on the prediction of an overall higher wet season abundance and the influence of the monsoon climate on the seasonality of the Papilionidae within the study area. While comparing the mean seasonal abundances, the wet season abundances were significantly higher than the dry season abundances for both the years in all the study sites of Rani and Garbhanga ranges. With respect to genus-wise mean abundances, Graphium (Jays and Bluebottles) and Papilio (Mormons, Peacocks, Helens, Ravens and Limes) recorded the highest values throughout the study period within the protected reserve.

More important for conservation is the assessment of the status of butterflies that are confined to certain forest habitats and of butterflies that have restricted-range distributions. If forest disturbance results in a loss of these species then both richness and heterogeneity of the regional butterfly community will diminish, even though diversity may increase at local scales (Spitzer et al., 1993, 1997; Hamer et al., 1997). Some of the major limitations in our study were that butterfly sampling was restricted to only a specified study area and time period covering two dry and two wet seasons and our sampling effort was not equal across all the five study sites of the study area. This could have affected our sample size and the results. Secondly although the entire study area was a disturbed secondary forest, the scales of disturbance were not measured and neither was a detailed vegetation sampling done. We only identified the host -plant resources of the Papilionidae within the study area although we did not make an in-depth analysis of the correlation between the host-plant abundances and the butterfly abundances. The probable extinction or endangered status of most of the described species from the previous records of Evans (1932) and Talbot (1939) suggests of a similar situation as was predicted for the Southeast Asian butterfly fauna of Singapore (Koh et al., 2004) where larval host-plant specificity and adult habitat specialization were the two important determinants of butterfly extinctions. We therefore need to incorporate intensive vegetation sampling in the future studies for assessing such probabilities of coextinction of butterflies and their host-plants.

Although statistical information is a useful guide for designing conservation and management strategies for disturbed and non-disturbed habitats, decisions about the conservation value of each species has to be made using other information also (Spitzer et 
al., 1997). Moreover the protection of high - diversity sites does not guarantee the effective conservation of rare or spatially restricted organisms (Prendergast et al., 1993). Hence representative diversity would be a more satisfactory criterion which implies a list of the typical species assemblages for habitats or forest types as in case of our study or even ecological factor combinations. Such species lists or scores for habitats would be very useful in evaluating the comparative richness of sites (Dufrene \& Legendre, 1997). That is why we selected the method of multivariate analysis for our studies. Based on our results from multivariate ordination by taking the separating effects of forest and season as categorical variables for testing the abundance and distribution pattern of the Papilionidae species assemblage as well as based on actual field observations, we could consider the redbodied group comprising of the Windmills and Batwings (Atrophaneura sp.), Birdwings (Troides sp.) and Roses (Pachliopta sp.) from the closed forests to be of high conservation value and priority based on their sole dependence on the specific host-plant Aristolochia sp. which is an important medicinal plant and the extinction of this host-plant will ultimately lead to the extinction of the red-bodied taxa. Moreover the closed forest restricted taxa with small geographic range are particularly sensitive to even small-scale disturbance (Spitzer et $a l ., 1997)$ and therefore our conservation strategy must be directed towards the protection of such specific habitats which can otherwise endanger the survival of these stenotopic closed forest taxa. As for the other closed forest and gap species from the genera Papilio, Graphium and Pathysa which are primarily dependant on the families Rutaceae, Lauraceae and Annonaceae for larval feeding, a serious threat to their survival is still not predicted in the near future as they are mostly opportunist and can easily adjust to disturbances and can also fly over canopy of large forests and establish themselves in open ruderal habitats (Spitzer et al., 1993). Our results showed a higher abundance of open-forest associated or gap species. Therefore monitoring such wide-ranging opportunist species can be practical so long as the disturbance levels do not become too intensive. For our future monitoring program design, we could also consider evaluating the impact of management practices as proposed in our conservation implications and thus weigh the species abundances in a site in order to account more for the typical rather than vagrant species. Then we could consider using CCA to match a species assemblage to environmental factors like specifically vegetation variables and thus select a subset of species as indicators for more intensive monitoring as suggested by Kremen, 1992. As for the effects of environmental variables on the Papilionidae species assemblages, we could consider our results on the effects of season, year and rainfall which accounted for most variance in the abundance and distribution of the 
Papilionidae assemblages as statistically significant. The abundance of some of the group assemblages like the Jays and Bluebottles (Graphium sp.), Zebras and Swordtails (Pathysa sp.), Ravens and Helens (Papilio sp.), Batwings (Atrophaneura sp.), Limes (Papilio demoleus), Common Rose (Pachliopta aristolochiae) and Birdwings (Troides sp.) were strongly influenced by rainfall. However the seasonality of the 'East-Himalayan' butterflies have to be much explored and our study is the first attempt of its kind to address such issues.

The effect of altitude on the butterfly abundance and distribution was on an overall also found to be significant, with some of the closed forest restricted species found in higher abundances at higher elevations and open forest dependant species found at higher abundance at lower elevations. However the narrow elevational gradient between the transects in the study sites and the sampling design could have influenced the ordination results. As for the effect of geographical position (latitude and longitude) on the species abundance and distribution, although the results were not strongly significant, we could understand that such a kind of study covering larger areas will be necessary and helpful in the future for the butterfly-monitoring program with emphasis on butterfly mapping within specific protected areas in the region.

When tested by the two variables forest type and season we found that the closed forests were more diverse in the study sites of Garbhanga range and the open forests were more diverse in the study sites of Rani range. Higher diversity in the closed forest sites of Garbhanga range indicated its high conservation value and also the identification of the closed forest restricted species was important for setting the conservation priorities. A similar trend was also observed for the evenness and rarefaction estimates for the species assemblages when tested by forest type and season. The evenness and rarefaction estimates were higher for the closed forest transects in the study sites of Garbhanga range and for the open/scattered forest transects in the study sites of Rani range. Season as a variable did not affect the species diversity of the Papilionidiae in the study sites of Garbhanga range, but a higher Shannon's diversity was found during the wet seasons of both the years in the study sites of Rani range. There were no significant differences in species richness by forest type and season across all the five study sites throughout the two-year study period. Measures of local diversity are widely used to characterize species assemblages, but they give no information on species composition or conservation value (Hill et al., 1995; Lewis, 2001). Moreover high diversity does not insure that a site has a high ecological value (Dunn, 1994).

There is clearly a need for identifying characteristic indicator species in the field of nature conservation for monitoring and management. Butterflies are good indicators 
of habitat quality as they respond rapidly to modification of vegetation (Dewenter \& Tscharntke, 1997) Identification of characteristic indicator taxa by transect and seasonal abundances also produced contradictory results where a mixed assemblage of both open and closed forest dependant species showed significantly high IndVals. The indicators of the forest habitat were mostly endemic species but one of the indicator species from the open habitat was also an endemic. We could consider our attempt to identify the indicator species by seasonal abundances to be a statistically more meaningful effort as the seasonality of the typical 'East-Himalayan' butterfly fauna seems to be correlated with rainfall and phenology of vegetation and such factors or elements can be suitably used for biomonitoring of the butterflies in general and the Papilionidae in particular. So finally a mixed assemblage of seven species from all the five study sites were selected as the indicator species out of which two indicator species were closed forest endemics and five were indicators from the open forest and amongst them one was an endemic species. These open forest indicators makes it evident that some of the canopy forest of Papilionidae can still survive in heavily disturbed fragmented forests because of their high mobility and larval food plant availability. All these seven indicators not only scored high IndVals but what was more important was that they are moderately sensitive to human disturbances, there is sufficient knowledge about their biology and their monitoring by taking into account the seasonality factor can be considered to be a more practical approach towards assessment of habitat quality.

\subsection{Implications for Conservation of Butterflies}

Butterfly conservation in Northeast India including Assam is now getting a major impetus due to the continued efforts of a group of conservation biologists who have always stressed on the need and importance of focusing conservation efforts towards the invertebrate taxa and particularly the insects as this region harbors as good an insect diversity as rich plant diversity. However these conservation efforts could become fruitful only if a scientific approach towards the problems and threats confronting the conservation issues are dealt with and fundamental information on the biology and ecology at species level is acquired. 


\subsubsection{Threats to butterfly habitats}

\subsubsection{Habitat Exploitation and Fragmentation}

The effects of anthropogenic pressures on tropical landscapes has been a major issue since the population in the tropical countries have almost trebled since 1950 and is projected to grow further by 2030 (Wright, 2005). In India while habitat encroachment around protected areas only has drawn a lot of attention in the past, continuous and illegal exploitation of forest resources even in non-protected areas eventually leading to forest degradation has been a continuous threat to the survival of wildlife. In Northeast India, deforestation has already reduced the forest cover and what remains now are mostly fragmented habitats and conservation efforts should be directed towards these landscapes of forest fragments. However the situation in case of butterflies is different because they exhibit high host specificity and their breeding habitats are defined by the spatial availability of host plants which may represent patches of suitable habitat in a sea of unsuitable foliage (Lewis \& Basset, 2007). Specialist feeders are hardly affected in such situations finally leading to their occurrence as patchy populations or metapopulations on fragmented resource patches. Therefore conservation efforts should cover not only the 'endemic generalist' and 'rare' species' but also the endemic specialists with small geographic ranges since they are more likely to be endangered by habitat disturbance. In Assam another major threat to the butterfly habitats has been the tea plantations. The use of pesticides and monoculture conditions prevailing in tea gardens has been a major threat to the indigenous vegetation. For Assam this is a detrimental situation as most of the protected reserves are surrounded by or have tea plantations in their proximity and more forested areas are being cleared for new tea plantations.

In case of Rani-Garbhanga landscape, serious anthropogenic pressures exist in the form of (1) an existing railway track and a highway connecting the capital city to the airport running along the northern boundary of the reserve; (2) a 900 acres organic tea plantation located to the north-west side of Rani range; (3) encroachment by illegal immigrant workers trying to find employment in the nearby urban areas; (4) illegal logging activities of timber smugglers due to sharing of common boundary with the Garo hills of Meghalaya; (5) earthcutting from the hills and establishment of brick-making factories; (6) Shifting cultivation in the southern part of the reserve; and (7) Elephant poaching.

Saw/timber mills have also been observed to be mushrooming at the northern bordering areas of the reserve. Another serious threat has been industrial development along 
the periphery of the reserve. Due to the steep terrain of the reserve on the Assam side it has always been difficult for the Assam forest personnel to monitor anti-forest activities. This has worked to the advantage of the timber smugglers and poachers from the Meghalaya side and both illegal logging and poaching have been reported to be more rampant in Rani Forest Reserve due to its sensitive common boundary with Meghalaya in the south. While some of the local nature conservation organizations have been protesting against these issues, recently an amusement park covering an area of 5.45 ha has come up on a large-scale in the north-western part of the reserve. So with such challenging problems the conservationists have to work towards the protection and management of the existing habitats and landscape.

\subsubsection{Illegal trade in butterflies}

Although the illegal trade in butterflies in Northeast India has never been an important part of the issue on the illegal trade in wildlife, however this activity has been going on since 1950s and there have been several reports of butterfly smugglers being arrested in Sikkim, Arunachal Pradesh and Meghalaya. There is no such information from Assam about trade in butterflies and yet this matter has to be given a serious look into in order to prevent such activities in the future. From our present study in Rani-Garbhanga Landscape, three of the identified Papilionidae species are listed in Appendix II of the Indian Wildlife (Protection) Act, 1972. However there are more of such vulnerable species from the other butterfly families. There must be a directive for the anti-poaching camp within the reserve for monitoring all kinds of illegal activities. An anti-poaching camp established by the Hoolock Gibbon Conservation Project (US Fish and Wildlife Service, 2006) is already functional within the reserve. However from the legal point of view what is most urgently needed is the implementation of CITES legislation in the entire Northeast region of India.

\subsubsection{The role of butterflies in conservation}

In the conservation and management plan for Rani-Garbhanga Landscape, butterflies and particularly the Papilionidae can be taken as tools for habitat protection. Butterflies have always played a useful role in ecological impact assessments and continued monitoring of ecological health (Pullin, 1995). Their potential value as ecological 'indicator taxa' is due to their varied ecological requirements throughout their life history where as adults they rely on nectar, fruits, dung and carrion for energy and on specific host plants for laying eggs. The 
presence of the host-plants in turn requires specific ecological conditions. Therefore as a taxon they are highly sensitive to microclimatic heterogeneity and disturbance (Kremen, 1994; Sparrow et al. 1994; Daily \& Ehrlich, 1996; Brown, 1997). The strong habitat specificity of the Papilionidae observed in our studies can be used for monitoring the health of the vegetation along varying gradients of disturbance within the forest reserve. The Papilionidae are known to respond strongly to even slight disturbance and previous studies have also established the co-extinctions of butterflies and their host plants (Koh et al., 2004). They can be therefore used for even studying the effects of forest management. The present study identified some important food plants of the swallowtail butterflies and a majority of these food plants were found to have medicinal and economic value. The traditional indigenous knowledge of the local ethnic tribes of Northeast India including Assam has always played a very important role in forest conservation and management practices. The local conservation agencies can play an important role by collaborating with the Forest Department and promoting the planting of medicinal plants under the Joint Forest Management (JFM) program. Creation of awareness of butterfly conservation amongst the local people has to be initiated. Butterfly-plant interactions highlighting the ecological role of butterflies as one of the potential plant pollinators and the dependence of the butterflies on plants for egg-laying, larval feeding and adult nectaring have to be elucidated.

In the oriental culture including the Hindu folklore, butterflies have been regarded as an auspicious symbol of nuptial rites and rebirth. Artistic descriptions of butterflies have always been very popular in many cultures. The cultural aspect could also be integrated into the conservation strategy. While the local people living in the fringe areas of non-protected and protected forests and reserves are the greater stakeholders in conservation, the other suitable target groups are the youth (school and under-graduate students) and the managers of ecotourism. Exhibitions and workshops popularizing the science of butterfly conservation amongst school students is suggested to be one of the most effective strategies. However the conservation strategy targeting the undergraduate students has to be taken up with a more scientific approach and has to involve the Forest department and the existing conservation agencies who are interested in promoting butterfly conservation. Several proposals were made for upgrading Rani-Garbhanga Landscape into a wildlife sanctuary by some of the local environmental bodies and for also declaring it a 'Butterfly Sanctuary' by the Department of Entomology and Environmental Biology of Gauhati University, Assam. This can be regarded as a positive progress towards promoting butterfly conservation in this protected reserve. 


\subsubsection{Recommendations for conservation of butterflies in Rani-Garbhanga Lansdscape}

The following directives are being suggested as part of a bio-monitoring program for butterflies in general and Papilionidae in particular in the protected forest reserve :

\subsubsection{In-situ conservation}

- Habitat restoration and management - assessment of habitat quality by frequently monitoring the disturbance levels and conducting vegetation sampling.

- Design research projects for establishing the monitoring of butterflies - intensive field-work to gather more base-line data on the Papilionidae diversity within the forest reserve and to check their population density at regular intervals. Identification of the threats to the butterfly habitats must be observed.

- Extensive scientific research on the biology of the species.

- Food-plant monitoring - estimation of the abundances and species diversity and richness of the host-plants and to test their correlation with the butterfly abundances.

- Check the presence of some of the probably or suspected to be extinct Papilionidae species in the nearby forest reserves (Jarasal and Kwasing Reserve forests) and study the causes of their probable extinction.

- To investigate the possibilities of a re-introduction program for some of the endangered species.

\subsubsection{Ex-situ conservation}

- Involvement of the local people in the ex-situ conservation of the food-plants of the Papilionidae as majority of the host-plant species are of medicinal and economic value. The target group should be rural women who are the greater stakeholders in such 'benefit-sharing' programs.

- Prepare brochures in a simple but the local language for spreading mass awareness about the role of butterflies in the ecosystem and their effective conservation through conservation of their food-plants.

- Establish a 'Butterfly Garden', where initially the breeding of some common species could be introduced to be followed by the captive breeding of some endangered species. The primary step should be the creation of a suitable 'butterfly habitat' through proper landscaping and introduction of some suitable host-plants and maintenance of optimum temperature $\left(25-29^{\circ} \mathrm{C}\right)$ and humidity 
$(60-80 \%)$ conditions as climatic preferences of butterflies is one of the important parameters for designing such a project. As we have already found in our studies, with respect to host preferences, polyphagy and monophagy aspects must be considered while designing the garden and particularly with the Papilionidae assemblage, viable populations of a good species assemblage can be sustained through selection of the appropriate host-plants as already identified from previous and our present studies. As part of the scientific research, regular monitoring of the seasonal population trends two times in a year- dry and wet seasons must be conducted. As part of the eco-tourism enterprise, along with 'butterfly exhibitory', rural upliftment programmes through ranching of the butterflies as 'dead-stock' and plantation activites could be incorporated into the 'conservation awareness' drive although at the initial stages the outcome could not be predicted to be very profitable.

Due to lack of scientific documentation and research studies on the Papilionidae of Assam in recent times, there have always been a lot of questions to be answered on issues relating to the precise species record from Assam. In-depth scientific studies on the dry and wet season forms and polymorphic female forms particularly amongst the genus Papilio that exhibit a classic example of batesian mimicry in South east Asia have to be addressed in the future. Recent studies in Southeast Asia have reported high butterfly species richness in forest reserves and have also assessed the effectiveness of forest reserves (protected old secondary and primary forests), fragments (scattered ruderal vegetation) and urban parks (artificially revegetated habitats) in conserving butterfly diversity in urbanized tropical landscape (Koh \& Sodhi, 2004). Our vision on the establishment of a 'butterfly garden' within Rani-Garbhanga Landscape will prove to be very effective in the eco-restoration of the local butterfly population because suitable locations near natural forests have been predicted to result in the re-colonization of more number of species as compared to locations near urban areas. (Mathew \& Anto, 2007). Our recommendation on upgrading this protected reserve into a 'Wildlife sanctuary' or even declaring it as a 'Butterfly Park' and also looking into the possiblities of establishing this 'Butterfly Garden' will fulfill atleast one of the conservation implications as suggested by Miller \& Hobbs (2002) that sometimes such disturbed, fragmented landscapes represent an extreme on the continuum of desirable environmental conditions which very often the conservation 
biologists overlook during ecosystem management. Ongoing deforestation and human disturbance have been some of the most important events affecting the present Papilionidae community within Rani-Garbhanga Reserve Forest. We can consider our present research findings on the species diversity, abundance and distribution pattern of the Papilionidae species assemblage within Rani-Garbhanga landscape in relation to some environmental variables as preliminary results but they still indicate the direction along which we have to formulate our future monitoring program. Such a program must not only consider the major environmental gradients like the monsoon seasonality factor, but butterfly density and patterns of diversity within a mosaic of landscape and vegetation types or variables must be intensively explored. The monitoring of selected species is also necessary for observing the seasonal population trends which can also help to provide evidence of the threats to the Papilionidae community within the protected Reserve. 
REFERENCES, APPENDICES, PHOTO SECTION

- REFERENCES

- APPENDICES

- PHOTO SECTION 
REFERENCES 


\section{REFERENCES:}

Arora, G.S. \& Mondal, D.K. 1981. On the Papilioninae (Papilionidae, Lep.) from Arunachal Pradesh and adjoining areas of Assam in North-Eastern India. Rec. Zool. Surv. India Occ. Paper, $29: 1-65$.

Barua, K.K., Kakati, D. \& Kalita, J. 2004a. Diversity of Butterfly Fauna of Garbhanga Reserve Forest, Assam. Journal of Ecobiology. 16(4) : 241-265.

Barua, K.K., Kakati, D. \& Kalita, J. 2004b. Present Status of Swallowtail Butterflies in Garbhanga Reserve Forest, Assam, India. Zoos' Print Journal 19(4): 1439-1441.

Basset, Y. 1991a. The seasonality of arboreal arthropods foraging within an Australian rainforest tree. Ecological Entomology, 16: 265-278.

Basset, Y. 1991b. Leaf production of an over storey rainforest tree and its effects on the temporal distribution of associated insect herbivores. Oecologia. 88: 211-219.

Basset, Y., Novotny, V., Miller, S.E. \& Springate, N.D. 1998. Assessing the impact of forest disturbance on tropical invertebrates: some comments. Journal of Applied Ecology 35: 461-466.

Beccaloni, G.W. 1997. Vertical stratification of the ithomiine butterfly (Nymphalidae:Ithomiinae) mimicry complexes: the relationship between adult flight height and larval host-plant height. Biological Journal of the Linnean Society 62: 313-341.

Braby, M.F. 1995. Reproductive seasonality in tropical satyrine butterflies: strategies for the dry season. Ecological Entomology 20: 5-17.

Bingham, C.T. 1907. Fauna of British India. Butterflies, Volume 2. London : Taylor and Francis; Calcutta and Simla, Thacker, Spink, \& Co.

Blau, W.S. 1980. The effect of environmental disturbance on a tropical butterfly population. Ecology 61: 1005-1012.

Blair, R.B. \& Launer, A.E. 1997. Butterfly diversity and human land-use: Species assemblages along an urban gradient. Biological Conservation 80: 113-125.

Breedlove, D.E, \& Ehrlich, P.R. 1968. Plant-herbivore coevolution: Lupines and lycaenids. Science $162: 671-672$.

Brown, J.H. 1984. On the relationship between abundance and distribution of species. Am. Nat. 124: 255-279.

Brown, K.S. Jr. 1991. Conservation of neotropical environments: insects as indicators. In: Collins, N.M. \& Thomas, J.A. (eds). The Conservation of Insects and their Habitats. Academic Press, London. Pp. 449-504. 
Brown, Jr; K.S. 1997. Diversity, disturbance, and sustainable use of Neotropical forests: insects as indicators for conservation monitoring. J. Insect Conserv. 1: 25-42.

Brues, C.T., 1920. The selection of food plants by insects, with special reference to lepidopterous larvae. Am. Nat. Pp. 127-141.

Boggs, C.L. \& Murphy, D.D. 1997. Community composition in mountain ecosystems: climatic determinants of montane butterfly distributions. Global Ecology and Biogeography Letters 6: 39-48.

Botkin, D.B., Estes, J.E., McDonald R.M. \& Wilson M.V. 1984. Studying the Earth's vegetation from space; Bioscience 34. 508.

Boriani, L., Burgio, G., Marini, M. \& Genghini, M. 2005. Faunistic study on butterflies collected in Northern Italy rural landscape. Bulletin of Insectology 58 (1): 49-56.

Borkar, M.R. \& Komarpant, N. 2004. Diversity, abundance and habitat associations of butterfly species in Bondla wildlife Sanctuary of Goa, India. Zoos' Print Journal 19 (10): 1648- 1653.

Borah, K., Thakuria, K., Baruah, K.K., Sarma, N.K. \& Deka, K. 2005. Man-Elephant conflict problem: A case study. Zoos' Print 7: 22-25.

Bowman, D.J.M.S., Woinarski, J.C.Z., Sands D.P.A., Wells A. \& McShane V.J. 1990. Slash-and-burn agriculture in the west coastal lowlands of Papua New Guinea: responses of birds, butterflies and reptiles. Journal of Biogeography 17: 227-239.

Butler, AG. 1879. On a collection of Lepidoptera from Cachar. Trans. Entomol. Soc. London. Pp. 1- 8.

Champion, H.G. \& Seth, S.K. 1968. The Forest Types of India, The Manager of Publications, Delhi.

Chew, F.S. 1980. Food plants preferences of Pieris caterpillars (Lepidoptera). Oecologia 46: 347-353.

Cleary, D.F. \& Genner, M.J. 2004. Changes in rain forest butterfly diversity following major ENSO-induced fires in Borneo. Global Ecology and Biogeography 13 (2) : 129-140.

Collins, N.M. \& Morris, M.G. 1985. Threatened Swallowtail Butterflies of the world. IUCN Red Data Book. IUCN, Gland \& Cambridge. Pp. 401.

Cottrell, C.B. 1984. A phytophagy in butterflies: its relationship to myrmecophily. Zoological Journal of the Linnean Society, 80: 1-57.

Courtney, S.P. \& Chew, F.S. 1987. Coexistence and host use by a large community of Pierid butterflies: habitat is the templet..Oecologia. 71. Pp. 210.

D’Abrera, B. 1982. Butterflies of the Oriental Region. Part 1. Hill House, Melbourne. Pp. 244. 
Davis, D.E. 1945. The annual cycle of plants, mosquitoes, birds and mammals in two Brazilian forests. Ecological Monographs. 15: 243-295.

Day, M., Wiley, C.J., Playford, J. \& Zalucki, M.P. 2003. Lantana: Current Management Status and Future Prospects. ACIAR, Canberra, ACT, Australia.

Daily, G.C. \& Ehrlich, P.R. 1996. Nocturnality and species survival. Ecology 93 (21): 11709-11712

Daniel, J.C. \& H.S. Datye. 1995. A Week with Elephants. Bombay Natural History Society, Bombay, India.

De Niceville, L. 1881, 1882, 1883 \& 1885. Notes on the Butterflies of Sikkim. Journal of Royal Asiatic Society of Bengal.

De Niceville, L. 1889. On new or little known Butterflies from the Indian Region. J.Asiat. Soc. Bengal (II) 57 (4) : 273-293, pl. 13-14.

De Niceville, L. \& Gammie, G.A. 1890. A List of the Butterflies of Sikkim. The Gazetteer of Sikkim.

Dennis, R.L.H. \& Shreeve, T.G. 1991. Climatic change and the British butterfly fauna: opportunities and constraints. Biological Conservation. 55: 1-16.

DeVries, P.J. 1988. Stratification of fruit-feeding nymphalid butterflies in a Costa-Rican rainforest. Journal of Research on the Lepidoptera 26: 98-108.

De Vries, P.J., Murray, D. \& Lande, R. 1997. Species diversity in vertical, horizontal and temporal dimensions of a fruit-feeding butterfly community in an Equadorian rainforest. Biological Journal of the Linnaean Society 62: 343-364.

DeVries, P. J. \& Walla, T.R. 2001. Species diversity and community structure in neotropical fruit-feeding butterflies. Biological Journal of the Linnean Society 74: 1-15.

Steffan-Dewenter, I., Tscharntke, T. 1997. Early succession of butterfly and plant communities $\begin{array}{lllll}\text { on } & \text { set-aside } & \text { fields. } & \text { Oecologia } & \text { 109: }\end{array}$

Dethier, V.G. 1954. Evolution of feeding preferences in phytophagous insects. Evolution 8 : 33-54.

Dethier, V.G. 1959. Food plant distribution and density and larval dispersal as factors affecting insect populations. Canadian Entomologist $91: 581-596$.

Dethier, V.G. \& Fuller, W.C. 1961. Variation in Plebejus icarioides (Lycaenidae). Foodplant specificity. J. Lepid. Soc. 15: 34-42.

Didham, R.K. \& Springate, N.D. 2003. Determinants of temporal variation in community structure (Pp. 28-39) in Basset, Y., Novotny, V., Miller, S.E., \& Kitching, R.I. Arthropods 
of tropical forests. Spatio-temporal dynamics and resource use in the canopy. Cambridge University Press, Cambridge.

Doherty, W. 1889. Notes on Assam Butterflies. J. AS-Soc. Bengal 58 : 18-34.

Dobzhansky, T. \& Pavan, C. 1950. Local and seasonal variations in relative frequencies of species of Drosophila in Brazil. Journal of Animal Ecology 19: 1-14.

Dover, J.W., Sparks, T.H. \& Greatorex-Davies, J.N. 1997. The importance of shelter for butterflies in open landscapes. Journal of Insect Conservation 1 : 89-97

Dufrene, M. \& Legendre, P. 1997. Species assemblages and indicator species : the need for a flexible asymmetrical approach. Ecol. Monogr., 67 : 345-366.

Duggin, J.A. \& Gentle, C.B. 1998. Experimental evidence on the importance of disturbance intensity for invasion of Lantana camara L. in dry rainforest -open forest ecotones in north-eastern NSW, Australia. For. Ecol. Manag. 109. Pp. 279-292.

Dunn, Ch. 1994. Gaps in GAP. Plant Science Bulletin 40: 120-121.

Dyer, L.A. 1995. Tasty generalists and nasty specialists? Antipredator mechanisms in tropical lepidopteran larvae. Ecology 76: 1483-1496.

Elwes, H.J. 1880. A Catalogue of the Lepidoptera of Sikkim. Proceedings of the Zoological Society of London.

Elwes, H.J. \& Moller, Otto. 1888. The Catalogue of the Butterflies of Sikkim. Transactions of Entomological Society of London. Pp. 269-464.

Elwes, H.J. 1891. On butterflies collected by Mr. W. Doherty in Nagh and Karen hills. Peack. Proc. Zool. Soc. London.

Ehrlich, P.R. 1958. The comparative morphology, phylogeny and higher classification of the butterflies. University of Kansas Science Bulletin 39: 305-370.

Ehrlich, P. \& Ehrlich, A. 1961. How to Know the Butterflies. Dubuque, Iowa: Wm. C. Brown Company Publishers.

Ehrlich, P.R. \& Gilbert, L.E. 1973. Population structure and dynamics of the tropical butterfly Heliconius ethilla. Biotropica 5: 69-82

Ehrlich, P.R. \& Raven, P.H. 1964. Butterflies and plants: a study in coevolution. Evolution 18: 586-608.

Ehrlich, P.R. \& Gilbert, L.E. 1973. Population structure and dynamics of the tropical butterfly, Heliconius ethilla. Biotropica 5 (2): 69-82.

Ehrlich, P.R., White, R.R., Singer, M.C., McKechnie, S.W. \& Gilbert, L.E. 1975. Checkerspot butterflies: A historical perspective. Science 188:221-228. 
Ehrlich, P. R. 1986. Ecological understanding is not free: The case for basic research. Amicus Journal 7: 7-8.

Evans, W.H. 1932. The Identification of Indian Butterflies. ( $2^{\text {nd }}$ Ed. Revised), Bombay Natural History Society, Mumbai, India. Pp. 454.

Erhardt, A. 1985. Diurnal Lepidoptera: sensitive indicators of cultivated and abandoned grassland. Journal of Applied Ecology. 22: 849-861.

Erhardt, A. \& Thomas, J.A. 1991. Lepidoptera as indicators of change in semi-natural grasslands of lowland and upland Europe. In: N.M. Collins and J.A. Thomas, Editors, The Conservation of Insects and Their Habitats, Academic Press, San Diego, CA. Pp. 213-234.

Ellenberg, H., Weber, H.E., Dull, R. 1992. Indicator values of plants in Central Europe. Scripta Geobotanica. Goltze Verlag, Gottingen.

Eliot, J.N. 1992. The Butterflies of the Malay Peninsula ( $4^{\text {th }}$ edn.) Malayan Nature Society, Kuala Lumpur, Malaysia.

Emmel, Th. C. \& Leck, Ch. F. 1970. Seasonal changes in the organization of tropical rain forest butterfly populations in Panama. Journal of Research on the Lepidoptera 8: 133-152.

Endo, S. \& Nihira, I. 1990. Larval food of Japanese butterflies. Group 'TAMAMUSHI', Tokyo (In Japanese).

Fensham, R.J., Fairfax, R.J. \& Cannell, R.J. 1994. The invasion of Lantana camara L. in Forty Mile Scrub National Park, North Queensland. Austr. J. Ecol. 19 : 297-305.

Fensham, R.J. 1994. Phytophagous insect -woody sprout interactions in tropical eucalypt forest. I. Insect herbivory. Australian Journal of Ecology 19: 178-188.

Feltwell, 2001. Field guide to the butterflies and other and other insects of Britain. Oxford University Press. Pp. 352.

Fleishman, E., Austin, G.T. \& Weiss, A.D. 1998. An empirical test of Rapoport's rule: Elevational gradients in montane butterfly communities. Ecology. 79 (7): 2482-2493.

Fleishman, E., Murphy, D.D. \& Brussard, P.F. 2000. A new method for selection of umbrella species for conservation planning. Ecol. Appl., 10 : 569-579.

Fimbel, R.A., Grajal, A. \& Robinson, J.G. 2001. The Cutting Edge: conserving wildlife in logged tropical forests. Columbia University Press, New York. Pp. 700.

Fiedler, K. 1998. Diet breadth and host plant diversity of tropical-vs. temperate-zone herbivores: South-East Asian and West Palaearctic butterflies as a case study. Ecological Entomology $23: 285-297$.

Fogden, M.P.L. 1972. The seasonality and population dynamics of equatorial forest birds in Sarawak. Ibis 114: 307-343. 
FAO/UNEP. 1981. Tropical forest resources assessment project. Technical report No. 3 . FAO, Rome.

FSI 1999. State of Forest Report -1999. Forest Survey of India (Ministry of Environment and Forests), Government of India. Dehradun.

FSI 2000. State of Forest Report 1999. Forest Survey of India (Ministry of Environment and Forests), Government of India. Dehradun. Pp.119.

FSI 2003. State of Forest Report 2001. Application of Satellite Based Remote Sensing for Monitoring and Mapping of India's Forest and Tree Cover

Gardner, S.M., Cabido, M.R., Valladares, G.R. \& Diaz, S. 1995. The influence of habitat structure on arthropod diversity in Argentines semi-arid Chaco forest. Journal of Vegetation Science 6: 349-356.

Gaston, K.J. \& Lawton, J.H. 1990. Effects of scale and habitat on the relationship between regional distribution and local abundance. Oikos 58 (3): 329-335.

Gauld, I.D. \& Gaston, K.J. 1992. Plant allelochemicals, tritrophite interactions and the anomalous diversity of tropical parasitoids: the 'nasty' host hypothesis. Oikos 65: 353-357.

Ghazoul, J. 2002. Impact of logging on the richness and diversity of forest butterflies in a tropical dry forest in Thailand. Biodiversity and Conservation $11: 521-541$.

Gentry, A.H. 1995. Seasonally Dry Tropical Forests (eds S.H., Bullock, Mooney, H.A. \& Medina, E.). Cambridge University Press, Cambridge. Pp. 146-194.

Gibbs, D.G. \& Leston, D. 1970. Insect phenology in a forest cocoa-farm locality in west Africa. Journal of Applied Ecology 7: 519-548.

Gilbert, L.E. 1971. The effect of resource distribution on population structure in the butterfly Euphrydryas editha: Jasper Ridege vs. Del Puerto Canyon colonies. PhD. Thesis. Stanford University Press, Princeton, N.J.

Gilbert, L. \& Singer, M.C. 1975. Butterfly ecology. Annu. Rev. Ecol. Syst. 6, 365-397.

Gilbert, L. E. 1980. Coevolution of animals and plants: a 1979 postscript. Coevolution of Animals and Plants. Austin, University of Texas Press. Revised, ed. Pp. 247-263.

Greenslade, P.J.M. 1983. Adversity selection and the habitat templet. American Naturalist 122 : 352-356.

Groombridge, B. \& Jenkins, M.D. 2000. Global biodiversity: earth's living resources in the $21^{\text {st }}$ century. World Conservation Press, Cambridge.

Gupta, I.J. \& Shukla, J.P.N. 1988. Records of the Zoological Survey of India. Occasional Paper No. 109. Calcutta. 
Hamer, K.C., Hill, J.K., Lace, L.A. \& Langhan, A.M. 1997. Ecological and biogeographical effects of forest disturbance on tropical butterflies of Sumba, Indonesia. Journal of Biogeography 24: 67-75.

Hamer, K.C., Hill, J.K., Benedick, S., Mustafa, N. Sherratt, T.N., Maryati, M. \& Chey, V.K. 2003. Ecology of butterflies in natural and selectively-logged forests of northern Borneo: the importance of habitat heterogeneity. Journal of Applied Ecology 40: 150-162.

Hamer, K.C., Hill, J.K., Mustaffa, N., Benedick, S., Sherratt, T.N., Chey, V.K. \& Maryati, M. 2005. Temporal variation in abundance and diversity of butterflies in Bornean rain forests: opposite impacts of logging recorded in different seasons. Journal of Tropical Ecology 21: 1-9.

Harcourt, A.H., Coppeto, S.A. \& Parks, S.A. 2002. Rarity specialization and extinction in primates. Journal of Biogeography 29: 445-456.

Haribal, M. 1992. The Butterflies of Sikkim Himalaya. Sikkim Nature Conservation Foundation (SNCF), Gangtok.

Haribal, M. 1994. Butterflies of Sikkim Himalaya and their Natural History. Sikkim Nature Conservation Foundation (SNCF), Gangtok.

Hill, J.K., Hamer, K.C., Dawood, M.M., Tangah, J. \& Chey, V.K. 2003. Rainfall but not selective logging affect changes in abundance of a tropical forest butterfly in Sabah, Borneo. Journal of Tropical Ecology 19: 35-42. Cambridge University Press.

Hooker, J.D. 1855. Notes of Naturalist in Bengal, The Sikkim and Nepal Himalayas, The Khasia Mountains, etc. Himalayan Journals Vol. 1. Reg \& Philip Remington, London. Pp. 143.

Hooker, J.D. 1872-1897. Flora of British India. Vols. 1-7. L. Reeve \& Co., Ashford, Kent, UK.

Holloway, J.D. 1987. Macrolepidoptera diversity in the indo-australian tropics: geographic, biotopic and taxonomic variations. Biological Journal of the Linnaean Society 30: 225-241.

Holloway, J.D., Kirg-Spriggs, A.H. \& Chey, V.K. 1992. The response of some rain forest insect groups to logging and conversion to plantation. Phil. Trans. R. soc. Lond. B, 335, $425-436$.

Holl, K.D. 1995. Nectar resources and their influence on butterfly communities on reclaimed coal surface mine. Restoration Ecol. 3, 76-85.

Hoft, R. \& Hoft, M. 1995. The differential effects of elephants on rain forest communities in the Shimba Hills, Kenya. Biological conservation 73: 67-79.

Houghton, R.A., Woodwell, G.M. 1981. Biotic contributions to global carbon cycle: the role of remote sensing In: Proceedings of Seventh International Symposium on Machine Processing of Remote Sensing Data, West Lafayette, Indiana. Pp. 593-602. 
Hill, J.K., Hamer, K.C., Lace, L.A. \& Banham, W.M.T. 1995. Effects of selective logging on tropical butterflies on Buru, Indonesia. Journal of Applied Ecology 32: 454-460.

Hill, J.K. \& Hamer, K.C. 2004. Determining impacts of habitat modification on diversity of tropical forest fauna: the importance of spatial scale. Journal of Applied Ecology 41: 744754.

Hurlbert S.H. 1971. The nonconcept of species diversity: a critique and alternative parameters. Ecology 52: 577-586.

Hynniewta, T.M. \& Baishya, A.K. 1992. Floristic wealth of North-East India. Proc. Zool. Soc., Assam (Spl. Ed.). Pp. 23-33.

IFFN (International Forest Fire News) 2002. Fire Situation in India. Int. Forest Fire News, 26: 23-27.

Igarashi, S. \& Fukuda, H. 1997. The Life Histories of Asian Butterflies, Vol. I. Tokai University Press, Tokyo, Japan.

Ishii, M. 1993. Transect counts of butterflies. In: Yata $\mathrm{O}$ and Ueda $\mathrm{K}$ (eds) Decline and Conservation of Butterflies in Japan II. The Lepidopterological Society of Japan \& the Nature Conservation Society of Japan, Osaka, Japan [in Japanese with English summary] Pp. 91-101.

IUCN 1991. The Conservation Atlas of Tropical Forests: Asia and the Pacific. London and Basingstoke: Macmillan Press Ltd.

Invasive Species Specialist Group, IUCN. 2001. 100 World's Worst Invasive Alien species. Available from URL: http://www.issg.org/booklet.pdf.

Islam, M.Z \& Rahmani, A.R. 2004. Important Bird Areas in India: priority sites for conservation. Indian Bird Conservation Network. Bombay Natural History Society and Birdlife International (U.K). Pp. XVIII+1133.

ICBP, 1992. Putting Biodiversity on the Map: Priority Areas for Global Conservation. ICBP, Cambridge.

Jablonski, D. 1991. Extinctions: a palaeontological perspective. Science 253. 754-757.

Janzen, D.H. 1986. Biodiversity (ed. Wilson, E.O.), National Academy Press, Washington. 130-137.

Johnstone, R.C.B. 1967. Elephant protection problems in Budongo tropical high forest. Uganda Forestry Department Paper presented at the $9^{\text {th }}$ Commonwealth Forestry Conference, New Delhi, 1968. (Manuscript in Oxford Forestry Institute Library).

Jones, M.J., Sullivan, M.S., Marsden, S.J. \& Linsley, M.D. 2001. Correlates of extinction risk of birds from two Indonesian islands. Biological Journal of the Linnaean Society 73: 65-79. 
Kanjilal, V.N., Kanjilal, P.C., Das, A., De, R.N. \& Bor, N.L. 1934-1940. Flora of Assam, 5 Vols. Government Press, Shillong India.

Kitahara, M. \& Fuji, K. 1994. Biodiversity and community structure of temperate butterfly species within a gradient of human disturbance: an analysis based on the concept of generalist vs. specialist strategies. Researches on Population Ecology 36: 187-199.

Koh, L.P. \& Sodhi, N.S. 2004. Importance of Reserves, fragments and Parks for butterfly conservation in a tropical urban landscape. Ecological Applications 14 (6): 1695-1708.

Koh, L.P., Sodhi, N.S. \& Brook, B.W. 2004. Ecological Correlates of Extinction Proneness in Tropical Butterflies. Conservation Biology 18(6): 1571-1578.

Koh, L.P., Sodhi, N.S. \& Brook, B.W. 2004. Co-extinctions of tropical butterflies and their hostplants. Biotropica 36(2): 272- 274.

Kremen, C. 1992. Assessing the indicator properties of species assemblages for natural areas monitoring. Ecological Applications 2: 203-217.

Kremen, C. 1994. Biological inventory using target taxa: a case study of butterflies of Madagascar. Ecological Applications 4: 407-422.

Kremen, C., Colwell, R.K., Erwin, T.L., Murphy, D.D., Noss, R.F. \& Sanjayan, M.A. 1993: Terrestrial Arthropod Assemblages: Their use in conservation planning. Conservation Biology 7: 796-808.

Kent, M. \& Coker, P. 1992. Vegetation description and analysis - a practical approach. John Wiley and Sons, New York.

Krebs, C. J. 1989. Ecological Methodology. Harper Collins Publishers Inc., New York, N.Y.

Kunte, K. 1997. Seasonal patterns in butterfly abundance and species diversity in four tropical habitats in northern western ghats. J. Biosci., 22 (5) : 593-603.

Kunte, K., Joglekar, A., Utkarsh, G. \& Pramod, P. 1999. Patterns of butterfly, bird and tree diversity in the Western Ghats. Current Science 77 (4): 577-586.

Kunte, K., Agashe, D. \& Date, P. 2005. Checklist of Butterflies of India. Digitized version of information from W.H.Evans's Identification of Indian butterflies $\left(1932,2^{\text {nd }}\right.$ ed.).

Laurance, W.F. 1999. Ecology and management of fragmented tropical landscapes introduction and synthesis. Biological Conservation 91: 101-107.

Laws, R.M., Parker, I.S.C. \& \& Johnstone, R.C.B. 1970. Elephants and their habitats in North Bunyoro, Uganda. East African Wildlife Journal 8: 163-180.

Laws, R.M., Parker, I.S.C. \& \& Johnstone, R.C.B. 1975. Elephants and their habitats: the ecology of elephants of North Bunyoro, Uganda. Clarendon Press, Oxford, UK. Pp. 376. 
Lawton, J.H., Bignell, D.E., Bolton, B., Bloemers, G.F., Eggleton, P., Hammond, P.M., Hodda, M., Holt, R.D., Larsen, T.B., Mawdsley, N.A., Strok, N.E., Shrivastava, D.S. \& Watt, A.D. 1988. Biodiversity inventories, indicator taxa and effects of habitat modification in tropical forest. Nature 391: 72-76.

Leather, S.R. 1990. The analysis of species-area relationships, with particular reference to macrolepidoptera on Rosaceae: how important is insect data-set quality? Entomologist, 109: $8-16$.

Leps, J. \& Spitzer, K. 1990. Ecological determinants of butterfly communities (Lepidoptera, Papilionoidea) in the Tam Dao Mountains, Vietnam. Acta Entomol. Bohemoslov 87: 182-194.

Lewis, O.T., Wilson, R.J. \& Harper, M.C. 1998. Endemic butterflies on Grande Comore: habitat preferences and conservation priorities. Biological conservation 85: 113-121.

Lewis, O.T. 2001. Effect of experimental selective logging on tropical butterflies. Conservation Biology 15: 389-400.

Lewis, O.T. \& Basset, Y. 2007. Insect Conservation in Tropical Forests. Insect Conservation Biology. The Royal Entomological Society.

Lien, V.V. \& Yuan, D. 2003. The differences of butterfly (Lepidoptera, Papilionoidea) communities in habitats with various degrees of disturbance and altitudes in tropical forests of Vietnam. Biodiversity and Conservation 12: 1099-1111.

Loertscher, M., Erhardt, A., Zettel, J. 1995. Microdistribution of butterflies in a mosaiclike habitat: the role of nectar sources. Ecography $18: 15-26$.

Macdonald, D.W. \& Johnson, D.D.P. 2001. Dispersal in theory and practice: consequences for conservation in biology (Pp. 358-372) in Clobert, J., Danchin, E., Dhondt, A.A. \& Nichols, J.D. Dispersal. Oxford University Press, Oxford, United Kingdom.

Mani, M.S. 1986. Butterflies of the Himalaya. Oxford and IBH Co. Pvt. Ltd., New Delhi.

Magurran, A. E. 1988. Ecological diversity and its measurement. Princeton University Press, Princeton, N. J.

Mathew, G. \& Anto, M. 2007. In situ conservation of butterflies through establishment of butterfly gardens: A case study at Peechi, Kerala, India. Current Science 93 (3): 337-347.

Medina, E. 1995. Seasonally Dry Tropical Forests (eds S.H., Bullock, Mooney, H.A. \& Medina, E.). Cambridge University Press, Cambridge. Pp. 221-242.

McGeoch, M.A. \& Chown, S.L. 1998. Scaling up the value of bioindicators. Trends in Evolution and Ecology 13 : 46-47.

McGeoch, M.A., Van Rensburg, B.J. \& Botes, A. 2002. The verification and application of bioindicators: a case study of dung beetles in a savannah ecosystem. J. Appl. Ecol., 39 : 661-672.

McCune, B. \& Mefford, M.J. 1999. PC-ORD 4.0 for Windows. Multivariate analysis of 
ecological data. MjM Software, Gleneden Beach, Oregon, USA.

McKinney, M.L. 1997. Extinction vulnerability and selectivity: combining ecological and palaeontological views. Annual Review of Ecology and Systematics 28: 495-516.

Miller, J.R. \& Hobbs, R.J. 2002. Conservation where people live and work. Conservation Biology 16 : 330-337.

Ministry of Law and Justice, India (1972). The Wildlife (Protection) Act, 1972 and Revised List of Schedules to the Wildlife Protection Act, 1972, coming into force from 210- 1980 .

Molina, J.M. \& Palma, J.M. 1996. Butterfly diversity and rarity within selected habitats of western Andalusia, Spain (Lepidoptera:Papilionoidea and Hesperioidea). Nota Lepidopterologica 78: 267-280.

Murphy, D.D. 1983. Nectar sources as constraints on the distribution of egg masses by the checkerspot butterfly. Euphydryas chalcedona (Lepidoptera:Nymphalidae).Environ. Entomol. 12, 463-466.

Myers, N. 1984. The primary source: Tropical forests and our future. W.W. Norton, New York.

Myers, N., Mittermeier, A.R., 'Mittermeier, C.G., da Fonseca, G.A.B. \& Kent, J. 2000. Biodiversity hotspots for conservation priorities. Nature, 403 :853-858.

New, T.R. 1991. Butterfly Conservation. Oxford University Press, South Melbourne, Australia.

New, T.R. \& Collins, N.M. 1991. Swallowtail butterflies- An Action Plan for their Conservation. IUCN, Gland, Switzerland.

New, T.R. \& Thornton, I.W.B. 1992. The butterflies of Anak Krakatau, Indonesia: faunal development in early succession. J. Lepid. Soc. 46: 83-96.

New, T.R., Pyle, R.M., Thomas, J.A., Thomas, C.D. \& Hammond, P.C. 1995. Butterfly Conservation Management. Annual Review of Entomology 40: 57-83.

Novotny, V. 1991. Effect of habitat persistence on the relationship between geographic distribution and local abundance. Oikos 61: 431-433.

Novotny, V. \& Basset, Y. 1998. Seasonality of sap-sucking insects (Auchenorrhyncaa, Hemiptera) feeding on Ficus (Moracea) in a lowland rainforest in New Guinea. Oecologia 115: 514-522.

Olson, D.M. \& Dinerstein, E. 1998. The Global 200: A Representation Approach to Conserving the Earth's Most Biologically Valuable Ecoregions. Conservation Biology 12 (3): $502-515$. 
Opler, P.A. \& Krizek, G.O. 1984. Butterflies East of the Great Plains. John Hopkins University Press, Baltimore, Maryland.

Owen, D.F. 1969. Species diversity and seasonal abundance in tropical Sphingidae (Lepidoptera). Proceedings of the Royal entomological society of London, (A) 44: 10-12.

Owen, D. 1971. Tropical butterflies: the ecology and behaviour of butterflies in the tropics with special reference to African species. Clarendon Press, Oxford. Pp. 228

Owen, D.F. \& Chamber, D.O. 1972. Species diversity and seasonal abundance in Charaxes butterflies (Nymphalidae). Journal of Entomology, (A) 46: 135-143.

Parsons, R.E. \& Cantlie, K. 1947. The butterflies of the Khasi and Jaintia hills. Assam. J. Bombay Natural History Soc. 47: 198-522.

Parmesan, C. 1996. Climate change and species' range. Nature, 382. 765-766.

Peet, R.K. 1974. The Measurement of Species Diversity. Annual Review of Ecology and Systematics 5: 285-307.

Pielou, E.C.1975. Ecological Diversity, Wiley, New York.

Pimm, S.L. 1998. Ecology - the forest fragment classic. Nature 393: 23-24.

Pinratana, A. 1992. Butterflies of Thailand (Vol.I). $3^{\text {rd }}$ Revised Edition. Papilionidae, Danaidae. Vikram Press, Bangkok, Thailand.

Pollard, E. 1977. A method for assessing changes in the abundance of butterflies. Biol. Conserve. 12: 116-134.

Pollard, E. 1979. Population ecology and change in range of the White Admiral butterfly Ladoga camilla L. in England. Ecological Entomology 4 : 61-74.

Pollard, E. 1988. Temperature, rainfall and butterfly numbers. Journal of Applied Ecology 25: $819-828$.

Pollard, E. 1992. Monitoring populations of a butterfly during a period of range-expansion. In: Biological Recording of Changes in British Wildlife, (Ed. P.T. Harding) Pp. 60-64. HMSO, London.

Pollard, E. \& Yates, T.J. 1993. Monitoring Butterflies for Ecology and Conservation. Chapman \& Hall, London. Pp. 274.

Porter, K. 1992. Eggs and egg-laying. In: Dennis, R.L.H. (Ed.), The Ecology of Butterflies in Britain. Oxford University Press, Oxford. Pp. 46-72.

Prendergast, J.R., Quinn, R.M., Lawton, J.H., Eversham, C. \& Gibbons, D.W. 1993. Rare species, the coincidence of diversity hotspots and conservation strategies. Nature 365: 335-337. 
Proctor, J., Haridasan, K., Smith, G.W. 1998. How far North does Lowland Tropical Evergreen Rainforest Go? Global Ecology and Biogeography Letters. 7 (2) : 141-146

Purvis, A., Agapow, P.M., Gittleman, J.L. \& Mace, G.M. 2000. Non-random extinction and the loss of evolutionary history. Science 288: 328-330.

Pullin, A.S. 1995. Ecology and Conservation of Butterflies. Chapman and Hall, London

Ramakrishnan, P.S. 1993. Shifting Cultivation and Sustainable Development (An interdisciplinary Study from North-Eastern India. Oxford University Press, New Delhi.

Ramakrishnan, P.S. 1999. Ecology in developing countries: The emerging paradigms. Proc. Indian National Science Acad.( 65) B: 51-82.

Ramos, F.A. 1996(2000). Nymphalid butterfly communities in an Amazonian forest fragment. Journal of Research on the Lepidoptera. 35: 29-41.

Ramos, F.A. 1992. Diversidade de borboletas (Rhopalocera) em uma area da amazonia oriental (Acailandia MA). Master thesis. Universidade de Brasilia, Brasilia, Brazil.

Ravenscroft, N.O.M. 1994. The ecology of the chequered skipper butterfly Carterocephalus palaemon in Scotland: food plant quality and population range. J. Appl. Ecol. 31, 623-630.

Rauscher, M.D. \& Feeny, P. 1980. Herbivory, plant density and plant reproductive success: the effect of Battus philenor on Aristolochia reticulata . Ecology 61: 905-917.

Rausher, M.D. \& Papaj, D.R. 1983. Demographic Consequences of Discrimination among Conspecific Host Plants by Battus philenor Butterflies. Ecology, Vol. 64 (6) : 1402-1410.

Robinson, M.H. \& Robinson, B. 1970. Prey caught by a sample population of the spider Argiope argentata (Araneae: Araneidae) in Panama: a year's census data. Zoological Journal Linnean Society 49: 345-357.

Rosenthal, G.A. \& Berenbaum, M.R. 1992. Herbivores: their interactions with Secondary Plant Metabolites, $2^{\text {nd }}$ edn. II. Ecological and Evolutionary Processes. Academic Press, San Diego, California.

Roy, P.S. 1996. Forest fire and degradation assessment using satellite remote sensing and geographic information system. Satellite Remote Sensing and GIS Applications in Agricultural Meteorology : 361-400.

Samways, M.J. 1994. Insect conservation Biology. Chapman \& Hall, London.

Sawchik, J., Dufrene, M., \& Lebrun, P. 2003. Estimation of habitat quality based on plant community, and effects of isolation in a network of butterfly habitat patches. Acta. Oecol 24: $25-33$ 
Scriber, J.M. 1973. Latitudinal gradients in larval feeding specialization of the world Papilionidae (Lepidoptera). Psyche 80 : 355-373.

Scriber, J.M., Lederhouse, R.C. \& Hagen, R.H. 1991. Food plants and evolution within Papilio glaucus and Papilio troilus species groups (Lepidoptera: Papilionidae), Pp. 341-371. In Price, P.W:, Lewinsohn, T.M., Fernandes, G.W. \& Benson, W.W. (Eds.), Plant-animal Interactions. Wiley-Interscience, New York.

Scriber, J.M., Tsubaki, Y. \& Lederhouse, R.C. (Eds.). 1995. Swallowtail Butterflies: their Ecology and Evolutionary Biology. Scientific Publishers, Gainesville, Florida.

Scoble, M.J. 1992. The Lepidoptera: Form, Function and Diversity. Oxford University Press, New York.

Scott, J.A. 1986. The Butterflies of North America. Stanford University Press, Stanford, California.

Shankar, U. 2001. A case of high tree diversity in a sal (Shorea robusta)- dominated lowland forest of Eastern Himalaya: Floristic composition, regeneration and conservation. Current Science. Vol. 81 (7) : 776-786.

Shapiro, A.M. 1975. The temporal component of butterfly species diversity. In: Cody M.L. and Diamond J.M. (eds.), Ecology and Evolution of Communities. Belknap Press of Harvard University Press, Cambridge, Masssachusetts, Pp. 181-195.

Sharp, M.A., Parks, D.R. \& Ehrlich, P.R. 1974. Plant resources and butterfly habitat selection. Ecology 55: 870-875.

Sharma, P.K., Ladha, J.K., Verma, T.S., Bhagat, R.M. \& Padre, A.T. 2003. Rice wheat productivity and nutrient status in a Lantana (Lantana sp.) amended soil. Biol. Fert. Soils 37 : $108-114$.

Sheil, D. 1996. The ecology of long term change in a Ugandan rain forest. $\mathrm{PhD}$ thesis, Department of Plant Sciences, University of Oxford, UK. Pp. 229.

Shreeve, T.G. 1992. Adult behaviour. In: Dennis, R.L.H. (Ed.), The Ecology of Butterflies in Britain. Oxford University Press, Oxford. Pp. 22-45.

Shreeve, T.G. \& Mason, C.F. 1980. The number of butterfly species in woodlands. Oecologia (Berl) $45: 414418$.

Skole, David \& Tucker, C. 1993. Tropical Deforestation and Habitat Fragmentation in the Amazon: Satellite Data from 1978 to 1988. Science 25 Vol. 260 (5116) : 1905-1910.

Singer, M.C., Ehrlich, P.R., Gilbert, L.E. 1971. Butterfly feeding on Lycopsid. Science 172: 1341-1342.

Singer, M.C. \& Ehrlich, P.R. 1991. Host specialization of satyrine butterflies, and their response to habitat fragmentation in Trinidad. J. Res. Lepidoptera 30: 248-256. 
Singer, M.C. 1971. Evolution of food plant preferences of the butterfly Euphydryas editha. Evolution 35 : 383-389.

Singh, J.S. \& Singh, S.P. 1987. Forest vegetation of the Himalaya. Botanical Review 53: 80-192.

Simonson, S.E., Opler, P.A., Stohlgren, T.J., \& Chong, G.W. 2001. Rapid assessment of butterfly diversity in a montane landscape. Biodiversity and Conservation 10: 1369-1386.

Slansky Jr., F. 1972. Latitudinal gradients in species diversity of the New world swallowtail butterflies. J. Res. Lepid. 11(4): 201-217.

Slansky F. 1993. Nutritional ecology: the fundamental quests for nutrients. Caterpillars Ecological and Evolutionary Constraints on Foraging (ed. by N.E. Stamp and T.E. Casey). Chapman \& Hall, New York. Pp. 29-91.

Southwood, T.R.E. 1977. Habitat, the templet for ecological strategies? J. Anim. Ecol. 46: 337365 .

South, R. 1913. A list of butterflies collected by Captain F.M. Bailey in western China, south-eastern Tibet and the Mishimi hills. J. Bombay Nat. Hist. Soc. 22 (3): 598-615

Sparrow, H.R., Sisk, T.D., Ehrlich, P.R. \& Murphy, D.D. 1994. Techniques and guidelines for monitoring Neotropical butterflies. Conservation Biology. 8: 800-809.

Spitzer, K. 1982. The bionomic strategy of a swallowtail (Troides aeacus Feld.) in South East Asia. Ziva 30 (2) : 66 (In Czech).

Spitzer, K. 1983. Seasonality of the Butterfly Fauna in Southeastern Vietnam (Papilionoidea). The Journal of Research on the Lepidoptera. 22(2): 126-130.

Spitzer, K., Leps, J. \& Soldan, T. 1987. Butterfly communities and habitat of seminatural savanna in southern Vietnam (Papilionoidea, Lepidoptera). Acta Entomol. Bohemoslov., 84: 200-208.

Spitzer, K., Novotny, V., Tonner, M. \& Leps, J. 1993. Habitat preferences, distribution and seasonality of the butterflies (Lepidoptera, Papilionoidea) in a mountain tropical rain forest, Vietnam. Journal of Biogeography 20: 109-121.

Spitzer, K., Jaros, J., Havelka, J. \& Leps, J. 1997. Effect of small-scale disturbance on butterfly communities of an Indochinese montane rainforest. Biological Conservation 80: 915 .

Stattersfield, A.J., Crosby, M.J., Long A.J. \& Wedge D.C. 1998. Endemic bird areas of the world: priorities for biodiversity conservation. Birdlife International.

StatSoft. 1995. STATISTICA for Windows. StatSoft Inc., Tulsa, OK.

Stork, N.E. 1988. Insect diversity: facts, fiction and speculation. Biological Journal of the Linnaean Society. 35: 321-337. 
Storch, D., Konvicka, M., Benes, J., Martinkova, J. \& Gaston, K.J. 2003. Distribution patterns in butterflies and birds of the Czech Republic: separating effects of habitat and geographical position. Journal of Biogeography 30: 1195-1205.

Strong, D.J. Jr., Lawton, J.H., Southwood, R. 1984. Insects on plants: Community patterns and mechanisms. Blackwell, London, England.

Stuhsaker, T.T., Lwanga, J.S. \& Kasenene, J.M. 1996. Elephants, selective logging and forest regeneration in the Kibale forest, Uganda. Journal of Tropical Ecology 12: 45-64.

Sutton, S.L. \& Collins, N.M. 1991. Insects and tropical forest conservation. Pp. 405-424 in Collins, N.M. \& Thomas, J.A. (eds.) The Conservation of insects and their habitats. Academic Press, London.

Swengel, A.B. 1996. Effects of fire and hay management on abundance of prairie butterflies. Biological conservation 85 (2): 73-85.

Swinhoe, C. 1893. A List of Lepidoptera of the Khasi hills. Trans.Cast. Soc. London. PT II. Pp. 396-432.

Talbot, G. 1939. The Fauna of British India, Including Ceylon and Burma. Butterflies Vol. I. (Papilionidae \& Pieridae) Taylor and Francis Ltd., London, reprint New Delhi 1975. Pp. 600.

Tauber, M. J., Tauber, C.A., Nyrop, J.P. \& Villani, M.G. 1998. (Forum Article). Moisture, a vital but neglected factor in the seasonal ecology of insects: hypotheses \& tests of mechanisms. Environ. Entomol. 27: 523-530.

Terborgh, J. 1999. Requiem for Nature. Island Press, Washington.

Ter Braak, C.J.F. 1986. Canonical correspondence analysis: a new eigenvector technique for multivariate direct gradient analysis. Ecology 67: 1167-1179.

Thakur, M.L., Ahmad, M. \& Thakur, R.K. 1992. Lantana weed (Lantana camara var. aculeata Linn) and its possible management through natural insect pests in India. Ind. For. $118: 466-488$.

Thomas, J.A. 1983. A quick method for estimating butterfly numbers during surveys. Biological Conservation 27: 195-211.

Thomas, C.D. 1991. Habitat use and geographic ranges of butterflies from the wet lowlands of Costa Rica. Biol. Cons. 55 : 269-281.

Thomas, C.D. \& Malorie, H.C. 1985. Rarity, species richness and conservation: Butterflies of the atlas mountains in Morocco. Biological Conservation 33: 95-117.

Thompson, J.N. 1994. The Coevolutionary Process. University of Chicago Press, Chicago. 
Turner, J.R.G., Gatehouse, C.M. \& Corey, C.A. 1987. Does solar energy control organic diversity? Butterflies, moths and the British climate. Oikos, 48 :195-205.

Tytler, H. 1915. Notes on Some New and Interesting Butterflies from Manipur and the Naga Hills.Part.2. J. Bombay Nat. Hist. Soc. 23: 502-515.

Tyler, H.A., Brown, K.S. Jr. \& Wilson, K.H. 1994. Swallowtail Butterflies of the Americas : a Study in Biological Dynamics, Ecological Diversity, Biosystematics and Conservation Scientific Publishers, Gainesville, Florida.

Varshney, R.K. \& Chanda, S.K. 1971. Butterflies of Northeast India. Indian Museum Bul. Vol. 1.

Vane-Wright, R.I. 1972. Pre-courtship activity and a new scent organ in butterflies. Nature $239: 338-340$.

Vane-Wright, R.I. 1978. Ecological and behavioural origins of diversity in butterflies. The Diversity of Insect Faunas (ed. by L.A. Mound and N. Waloff). Blackwell Scientific Publishers, Oxford, U.K. Pp. 56-70.

Vane-Wright, R.I., Humphries, C.J. \& Williams, P.H. 1991. What to protect? Systematics and the agony of choice. Biological Conservation 55: 235-254.

von Euw, J., Reichstein, T. \& Rothschild, M. 1968. Aristolochic acid in the swallowtail butterfly Pachlioptera aristolochiae. Isr. J. Chem. 6: 659-670.

Vu, V.L. \& Dang, T.D. 2002. Species composition, habitat preferences and abundance of butterflies (Lepidoptera, Rhopalocera) of Cuc Phuong National Park. Proceedings of the $4^{\text {th }}$ Vietnam National Conference on Entomology. Agriculture Publishing House, Hanoi, Vietnam. Pp. 285-297.

Walpole, M.J. \& Sheldon, I.R. 1999. Sampling butterflies in tropical rainforest: an evaluation of a transact walk method. Biological Conservation 87: 85.91.

Warren, M.S., Pollard, E. \& Bibby, T.J. 1986. Annual and long-term changes in a population of the wood white butterfly Leptidea sinapis. J. Anim. Ecol. 55:707-719

Wells, S.M., Pyle, R.M. \& Collins, N.M. 1983. The IUCN Invertebrate Red Data Book. IUCN, Gland and Cambridge. Pp. 632.

Whittaker, R.H. 1952. A study of summer foliage insect communities in the Great Smoky Mountains. Ecological Monographs 22: 1-44.

Whittaker, R.H. 1960. Vegetation of the Siskiyou Mountains, Oregon and California. Ecological Monographs 30: 279-338

Whitmore, T.C. \& Sayer, J.A. 1992. Tropical Deforestation and Species Extinction. Chapman \& Hall. 176 pp. 
Wiklund, C. 1975. The evolutionary relationship between adult oviposition preferences and larval host plant range in Papilio machaon L. Oecologia 18: 185-197.

Wiklund, C. 1981. Generalist vs. specialist oviposition behaviour in Papilio machaon (Lepidoptera) and functional aspects of the hierarchy of oviposition preferences. Oikos 36: 163-170.

William, P.H., Humphries, C.J. \& Vane-Wright, R.I. 1991. Measuring biodiversity: taxonomic relatedness for conservation priorities. Australian Journal of Systematics and Botany. Pp. 665-679.

Williams, A.C. \& Johnsingh , A.J.T. 1996. Status survey of elephants and their habitats in Garo hills, North-east India. GAZAH 16: 43-60.

Williams, A.C. Johnsingh , A.J.T. 1996. Threatened elephant corridors in Garo hills, north-east India. GAZAH 16: 61-68.

Williams, A.C. \& Johnsingh , A.J.T. 1996. Elephant capture in Meghalaya, north-east India - The past and the future. GAZAH 17: 1-7.

Wilson, E.O. 1987. The little things that run the world. (The importance and conservation of invertebrates). Conservation Biology. 14: 1055-1065.

Wing, I.D. \& Buss, I.O. 1970. Elephants and forests. Wildlife Monographs 19 : 92.

Wood, B. \& Gillman, M.P. 1998. The effects of disturbance on forest butterflies using two methods of sampling in Trinidad. Biodiversity and Conservation 7: 597-616.

Wood, P.A. \& Samways, M.J. 1992. Landscape element pattern and continuity of butterfly flight paths in an ecologically landscaped botanic garden, Natal, South Africa. Biological Conservation 58: 149-166.

Wolda, H. 1977a. Fluctuations in abundance of some Homoptera in a neotropical forest. Proceedings of the third Symposium of Tropical Ecology, (Lubumbashi).

Wolda, H. 1978b. Seasonal fluctuations in rainfall, food and abundance of tropical insects. American Naturalist 112: Pp. 1017- 1045.

Wolda, H. 1988. Insect seasonality: why? Annual Review of Ecology and Systematics 19: $1-18$.

Wolda, H. 1989. Seasonal cues in tropical organisms. Rainfall? Not necessarily! Oecologia $80: 437-442$.

Wright, R.T. 2005. Environmental Science. Pearson Prentice Hall, New Jersey.

Wynter-Blyth, M.A. 1957. Butterflies of the Indian Region, Bombay Natural History Society, Mumbai, India. Pp. 523+72pls. 
WWF/IUCN. 1995. Centres of plant diversity: A guide and strategy for their conservation. Vol. 2. Asia, Australasia and the Pacific. World Conservation Union Publications Unit, Cambridge, UK.

WWF -India. 2002. Joint Forest Management. Policy practice and prospects. WWF India and IIED, London.

Yamamoto, M. 1988. On the research method for butterfly assemblages. Special Bulletin of the Lepidopterological Society of Japan 6: 191-210 [in Japanese with English abstract] 
APPENDICES 


\section{Appendix: 3}

3.1 Rainfall, Maximum temperature and Relative humidity (Monthly mean) for the years 1996 - 2000 in the study area

\begin{tabular}{lllc}
\hline Months & Rainfall $(\mathrm{mm})$ & Temperature $\left({ }^{\circ} \mathrm{C}\right)$ Humidity $(\%)$ \\
\hline January & 5.82 & 23.4 & 69.0 \\
February & 17.26 & 27.2 & 55.2 \\
March & 64.24 & 26.4 & 49.4 \\
April & 121.16 & 32.0 & 59.6 \\
May & 301.36 & 32.9 & 70.8 \\
June & 250.48 & 32.08 & 78.0 \\
July & 257.26 & 29.9 & 85.2 \\
August & 287.56 & 31.5 & 82.4 \\
September & 190.36 & 31.9 & 83.0 \\
October & 107.08 & 30.96 & 76.8 \\
November & 10.94 & 28.2 & 81.4 \\
December & 6.04 & 25.84 & 75.6 \\
\hline
\end{tabular}

3.2 Rainfall, Maximum temperature and relative humidity (Monthly mean) for the years 2001-2005 in the study area

\begin{tabular}{llll}
\hline Months & Rainfall $(\mathrm{mm})$ & Temperature $\left({ }^{\circ} \mathrm{C}\right)$ & Humidity $(\%)$ \\
\hline January & 27.1 & 23.04 & 72.8 \\
February & 29.0 & 25.56 & 61.2 \\
March & 63.8 & 29.02 & 52.2 \\
April & 125.1 & 30.68 & 59.2 \\
May & 287.94 & 30.56 & 72.6 \\
June & 382.92 & 31.38 & 80.0 \\
July & 341.5 & 32.42 & 80.0 \\
August & 357.42 & 32.58 & 81.6 \\
September & 201.22 & 31.68 & 82.0 \\
October & 114.9 & 30.6 & 78.4 \\
November & 10.32 & 27.78 & 77.6 \\
December & 6.38 & 24.14 & 75.4
\end{tabular}




\section{Appendix 4 :}

4.1. Monthly total rainfall, mean relative humidity and mean maximum temperature during the butterfly-sampling period (2003-2004). Data used in multivariate analysis for examining the effects of season (dry and wet) as categorical variable and amount of rainfall as independent environmental variable on butterfly abundance and distribution.

\begin{tabular}{|c|c|c|c|}
\hline Month \& Year & $\begin{array}{l}\text { Monthly total rainfall for } \\
2003-2004(\mathrm{~mm})\end{array}$ & $\begin{array}{l}\text { Monthly mean } \\
\text { relative humidity } \\
(\%)\end{array}$ & $\begin{array}{l}\text { Monthly mean } \\
\text { maximum } \\
\text { temperature }\left({ }^{\circ} \mathrm{C}\right)\end{array}$ \\
\hline January 2003 & 76.10 & 80 & 21.0 \\
\hline February 2003 & 61.30 & 70 & 24.5 \\
\hline March 2003 & 83.30 & 56 & 28.0 \\
\hline April 2003 & 102.50 & 61 & 30.0 \\
\hline May 2003 & 319.80 & 76 & 32.2 \\
\hline June 2003 & 487.60 & 80 & 30.5 \\
\hline July 2003 & 343.70 & 82 & 32.3 \\
\hline August 2003 & 378.70 & 86 & 32.1 \\
\hline September 2003 & 242.80 & 83 & 31.0 \\
\hline October 2003 & 24.80 & 77 & 30.7 \\
\hline November 2003 & 0.00 & 75 & 28.5 \\
\hline December 2003 & 0.00 & 70 & 23.5 \\
\hline January 2004 & 19.40 & 68 & 24.9 \\
\hline February 2004 & 30.00 & 56 & 25.3 \\
\hline March 2004 & 120.80 & 56 & 28.3 \\
\hline April 2004 & 156.40 & 63 & 30.6 \\
\hline May 2004 & 170.90 & 68 & 32.4 \\
\hline June 2004 & 349.80 & 85 & 31.9 \\
\hline July 2004 & 199.80 & 76 & 33.6 \\
\hline August 2004 & 315.80 & 82 & 33.3 \\
\hline September 2004 & 28.20 & 80 & 33.4 \\
\hline October 2004 & 149.10 & 77 & 30.1 \\
\hline November 2004 & 6.70 & 77 & 27.5 \\
\hline December 2004 & 0.00 & 74 & 24.9 \\
\hline
\end{tabular}

Total annual rainfall in $2003=2061 \mathrm{~mm}$

Total annual rainfall in $2004=1547 \mathrm{~mm}$ 


\section{Appendix 4 (continued):}

4.2 : The butterfly abundance data from the 20 transects of the five study sites in Garbhanga and Rani ranges were pooled by season, year and forest type for multivariate analysis.

\begin{tabular}{lllll}
\hline Sites & Season & Year & Transect & Forest type \\
\hline 1 & Dry & 1 & T1 & SCF \\
2 & Dry & 1 & T2 & SCF \\
3 & Dry & 1 & T3 & CF \\
4 & Dry & 1 & T4 & CF \\
5 & Wet & 1 & T1 & SCF \\
6 & Wet & 1 & T2 & SCF \\
7 & Wet & 1 & T3 & CF \\
8 & Wet & 1 & T4 & CF \\
9 & Dry & 2 & T1 & SCF \\
10 & Dry & 2 & T2 & SCF \\
11 & Dry & 2 & T3 & CF \\
12 & Dry & 2 & T4 & CF \\
13 & Wet & 2 & T1 & SCF \\
14 & Wet & 2 & T2 & SCF \\
15 & Wet & 2 & T3 & CF \\
16 & Wet & 2 & T4 & CF \\
\hline
\end{tabular}

$\mathrm{SCF}=$ Scattered or open forest

$\mathrm{CF}=$ Closed forest

$\mathrm{T} 1$ and $\mathrm{T} 2=$ Transects in scattered or open forest

$\mathrm{T} 3$ and $\mathrm{T} 4=$ Transects in closed forest

Categorical variables : Forest type (Scattered /Open forest and Closed forest)

Season (Dry season - January to March)

(Wet season - August to October)

Continuous independent variables : Year (Year $1=2003$, Year $2=2004$ ) 


\section{Appendix 4 (continued):}

4.3 : Environmental variables for ordination of swallowtail butterfly species assemblages showing their abundance and distribution in Garbhanga range.

\begin{tabular}{rrrrlllr}
\hline Site & Latitude & Longitude & $\begin{array}{l}\text { Average } \\
\text { Altitude } \\
(\mathrm{m}) \mathrm{MSL}\end{array}$ & $\begin{array}{l}\text { Total } \\
\text { Rainfall } \\
(\mathrm{mm})\end{array}$ & Forest & Season & Year \\
\hline 1 & 26.05261 & 91.46426 & 102 & 0 & SCF & Dry & 1 \\
2 & 26.05116 & 91.46289 & 88 & 16 & SCF & Dry & 1 \\
3 & 26.04507 & 91.46087 & 170 & 61 & CF & Dry & 1 \\
4 & 26.04384 & 91.46011 & 183 & 83 & CF & Dry & 1 \\
5 & 26.05261 & 91.46426 & 102 & 344 & SCF & Wet & 1 \\
6 & 26.05116 & 91.46289 & 88379 & SCF & Wet & 1 \\
7 & 26.04507 & 91.46087 & 170 & 243 & CF & Wet & 1 \\
8 & 26.04384 & 91.46011 & 183 & 25 & CF & Wet & 1 \\
9 & 26.05261 & 91.46426 & 102 & 0 & SCF & Dry & 2 \\
10 & 26.05116 & 91.46289 & 88 & 19 & SCF & Dry & 2 \\
11 & 26.04507 & 91.46087 & 170 & 30 & CF & Dry & 2 \\
12 & 26.04384 & 91.46011 & 183 & 121 & CF & Dry & 2 \\
13 & 26.05261 & 91.46426 & 102 & 200 & SCF & Wet & 2 \\
14 & 26.05116 & 91.46289 & 88 & 316 & SCF & Wet & 2 \\
15 & 26.04507 & 91.46087 & 170 & 28 & CF & Wet & 2 \\
16 & 26.04384 & 91.46011 & 183 & 149 & CF & Wet & 2 \\
\hline
\end{tabular}

4.4 : Environmental variables for ordination of swallowtail butterfly species assemblages showing their abundance and distribution in Rani range.

\begin{tabular}{|c|c|c|c|c|c|c|c|}
\hline Site & Latitude & Longitude & $\begin{array}{l}\text { Average } \\
\text { Altitude } \\
\text { (m) MSL }\end{array}$ & $\begin{array}{l}\text { Total } \\
\text { Rainfall } \\
(\mathrm{mm}) \\
\end{array}$ & Forest & Season & Year \\
\hline 1 & 26.01433 & 91.3551 & 100 & 0 & SCF & Dry & 1 \\
\hline 2 & 26.01425 & 91.35513 & 100 & 16 & SCF & Dry & 1 \\
\hline 3 & 26.04506 & 91.36109 & 100 & 61 & $\mathrm{CF}$ & Dry & 1 \\
\hline 4 & 26.01519 & 91.35363 & 60 & 83 & CF & Dry & 1 \\
\hline 5 & 26.01433 & 91.3551 & 100 & 344 & SCF & Wet & 1 \\
\hline 6 & 26.01425 & 91.35513 & 100 & 379 & SCF & Wet & 1 \\
\hline 7 & 26.04506 & 91.36109 & 100 & 243 & $\mathrm{CF}$ & Wet & 1 \\
\hline 8 & 26.01519 & 91.35363 & 60 & 25 & CF & Wet & 1 \\
\hline 9 & 26.01433 & 91.3551 & 100 & 0 & SCF & Dry & 2 \\
\hline 10 & 26.01425 & 91.35513 & 100 & 19 & SCF & Dry & 2 \\
\hline 11 & 26.04506 & 91.36109 & 100 & 30 & CF & Dry & 2 \\
\hline 12 & 26.01519 & 91.35363 & 60 & 121 & $\mathrm{CF}$ & Dry & 2 \\
\hline 13 & 26.01433 & 91.3551 & 100 & 200 & SCF & Wet & 2 \\
\hline 14 & 26.01425 & 91.35513 & 100 & 316 & SCF & Wet & 2 \\
\hline 15 & 26.04506 & 91.36109 & 100 & 28 & CF & Wet & 2 \\
\hline 16 & 26.01519 & 91.35363 & 60 & 149 & CF & Wet & 2 \\
\hline
\end{tabular}




\section{Appendix 5 :}

5.1 : Total number of individuals of each plant type sampled in the study sites S1 (Garbhanga) and S4 (Rani) during

\begin{tabular}{|l|l|l|l|l|l|l|}
\hline Study sites & \multicolumn{2}{|l|}{ S1 (Garbhanga) } & \multicolumn{2}{l|}{ S2 (Rani) } \\
\hline Plant category & Trees & Herb/Shrubs & Climbers & Trees & Herb/Shrubs & Climbers \\
\hline Number of species & 74 & 63 & 32 & 72 & 62 & 33 \\
\hline $\begin{array}{l}\text { Total number of } \\
\text { individuals }\end{array}$ & 1079 & 1137 & 481 & 1009 & 1155 & 475 \\
\hline
\end{tabular}




\section{Appendix 5 (Continued) :}

5.2: Rarefaction method (Hulbert, 1971) of species richness estimation for trees, herbs/shrubs and climbers sampled as total number of individuals in study site S1 (Garbhanga range).

\begin{tabular}{rrrr}
\hline $\begin{array}{c}\text { NO. OF } \\
\text { INDIVIDUALS }\end{array}$ & $\begin{array}{r}\text { EXPECTED NO. } \\
\text { OF SPECIES } \\
(\mathrm{Eq} .10 .1)\end{array}$ & $\begin{array}{c}\text { VARIANCE } \\
(\mathrm{Eq} .10 .2)\end{array}$ & $\begin{array}{l}\text { STANDARD } \\
\text { DEVIATION }\end{array}$ \\
\hline & & & \\
2800 & 169.0000 & .0000 & .0000 \\
2500 & 168.8987 & .0958 & .3095 \\
2200 & 168.6105 & .3491 & .5908 \\
1900 & 168.0789 & .7897 & .8887 \\
1600 & 167.1232 & 1.5387 & 1.2404 \\
1300 & 165.3742 & 2.8243 & 1.6806 \\
1000 & 162.0260 & 5.0688 & 2.2514 \\
700 & 154.9935 & 9.0656 & 3.0109 \\
400 & 137.0824 & 15.8924 & 3.9865 \\
100 & 69.3470 & 12.7228 & 3.5669 \\
\hline
\end{tabular}

5.3: Rarefaction method (Hulbert, 1971) of species richness estimation for trees, herbs/shrubs and climbers sampled as total number of individuals in study site S4 (Rani range).

\begin{tabular}{lccc}
\hline $\begin{array}{l}\text { NO. OF } \\
\text { INDIVIDUALS }\end{array}$ & $\begin{array}{l}\text { EXPECTED NO. } \\
\text { OF SPECIES } \\
(\text { Eq. 10.1) }\end{array}$ & $\begin{array}{l}\text { VARIANCE } \\
(\mathrm{Eq} .10 .2)\end{array}$ & $\begin{array}{l}\text { STANDARD } \\
\text { DEVIATION }\end{array}$ \\
\hline & & & .0000 \\
2800 & 167.0000 & .0000 & .2891 \\
2500 & 166.9134 & .4486 & .6695 \\
2200 & 166.4997 & 1.0473 & 1.0234 \\
1900 & 165.7641 & 2.0154 & 1.4196 \\
1600 & 164.4933 & 3.5737 & 1.8904 \\
1300 & 162.2825 & 6.0746 & 2.4647 \\
1000 & 158.3093 & 10.0983 & 3.1778 \\
700 & 150.5644 & 16.3343 & 4.0416 \\
400 & 132.3509 & 12.8837 & 3.5894 \\
100 & 67.7431 & & \\
\hline
\end{tabular}




\section{Appendix 5 (Continued):}

5.4: Tree families, genera and species sampled as total number of individuals in study sites S1 and S4 in Rani-Garbhanga Reserve Forest, Assam.

\begin{tabular}{|c|c|c|c|c|c|}
\hline Species & Family & Status & $\begin{array}{l}\text { Economic } \\
\text { value }\end{array}$ & S1 & S4 \\
\hline Shorea robusta Gaertn. & Dipterocarpaceae & & Timber & 21 & 38 \\
\hline Shorea assamica Dyers. & Dipterocarpaceae & & Timber & 35 & 16 \\
\hline Bauhinia variegata L. & Caesalpiniaceae & Adult nectar plant & & 29 & 5 \\
\hline Bauhinia purpurea L. & Caesalpiniaceae & & Medicinal & 22 & 12 \\
\hline Gmelina arborea L. & Verbenaceae & & Medicinal & 8 & 26 \\
\hline Sharaka indica L. & Caesalpiniaceae & $\begin{array}{l}\text { Larval food plant } \& \\
\text { adult nectar plant }\end{array}$ & Medicinal & 13 & 2 \\
\hline Aegel marmelos L. & Rutaceae & Larval food plant & Medicinal & 17 & 11 \\
\hline Litsea sebifera Pers. & Lauraceae & Larval food plant & Medicinal & 20 & 0 \\
\hline Litsea chinensis Sonn. & Lauraceae & Larval food plant & Medicinal & 0 & 8 \\
\hline Magnolia pterocarpa Roxb. & Magnoliaceae & Larval food plant & Medicinal & 8 & 0 \\
\hline Magnolia grandiflora L. & Magnoliaceae & Larval food plant & & 0 & 6 \\
\hline Michelia champaca L. & Magnoliaceae & Larval food plant & Essential oil & 6 & 9 \\
\hline Murrya koeningii L. & Rutaceae & Larval food plant & $\begin{array}{l}\text { Aromatic } \\
\text { food } \\
\text { flavouring }\end{array}$ & 16 & 13 \\
\hline Cinnamomum zylenicum L. & Lauraceae & $\begin{array}{l}\text { Larval food plant \& } \\
\text { adult nectar plant }\end{array}$ & $\begin{array}{l}\text { Essential oil } \\
\text { Medicinal }\end{array}$ & 12 & 0 \\
\hline Cinnamomum tamala Fr. & Lauraceae & Larval food plant & Medicinal & 9 & 0 \\
\hline $\begin{array}{l}\text { Cinnamomum camphora } \\
\text { F.Nees. }\end{array}$ & Lauraceae & $\begin{array}{l}\text { Larval food plant \& } \\
\text { adult nectar plant }\end{array}$ & Medicinal & 0 & 8 \\
\hline Polyalthia longifolia Sonn. & Annonaceae & Larval food plant & $\begin{array}{l}\text { Urban } \\
\text { plantations }\end{array}$ & 0 & 46 \\
\hline Citrus aurantifolia Swingle & Rutaceae & Larval food plant & Medicinal & 20 & 37 \\
\hline Citrus orientalis L. & Rutaceae & Larval food plant & Medicinal & 13 & 40 \\
\hline Citrus grandis L. & Rutaceae & Larval food plant & & 25 & 27 \\
\hline Zanthoxylum budrunga Roxb. & Rutaceae & $\begin{array}{l}\text { Larval food plant \& } \\
\text { adult nectar plant }\end{array}$ & Medicinal & 12 & 25 \\
\hline$Z$ rhetsa Roxb. & Rutaceae & Larval food plant & Medicinal & 5 & 30 \\
\hline Z hamiltonianum Roxb. & Rutaceae & Larval food plant & & 26 & 20 \\
\hline Z oxyphyllum Roxb. & Rutaceae & Larval food plant & Edible seed & 14 & 0 \\
\hline Vitex peduncularis Wall. & Verbenaceae & & & 0 & 21 \\
\hline Vitex pubescens Vahl & Verbenaceae & & & 15 & 0 \\
\hline Ficus religiosa L. & Moraceae & & Holy tree & 23 & 12 \\
\hline Ficus bengalensis L. & Moraceae & & Medicinal & 10 & 4 \\
\hline Ficus hispida L. & Moraceae & & Medicinal & 0 & 5 \\
\hline Ficus Roxburghii Wall. & Moraceae & & Fodder & 0 & 1 \\
\hline Ficus elastica Roxb. & Moraceae & & Rubber & 0 & 11 \\
\hline $\begin{array}{l}\text { Lagerstoemia parviflora } \\
\text { Roxb. }\end{array}$ & Myrtaceae & Adult nectar plant & & 5 & 10 \\
\hline Mangifera indica L. & Anacardiaceae & & & 18 & 45 \\
\hline Emblica officinalis Gaertn. & Euphorbiaceae & Adult nectar plant & Medicinal & 12 & 40 \\
\hline
\end{tabular}


Appendix 5 (Continued)

\begin{tabular}{|c|c|c|c|c|c|}
\hline Species & Family & Status & $\begin{array}{l}\text { Economic } \\
\text { value }\end{array}$ & S1 & S4 \\
\hline Spondias pinnata L. & Sapindaceae & & & 4 & 7 \\
\hline Garcinia speciosa Wall & Clusiaceae & & Medicinal & 2 & 2 \\
\hline G. pedunculata Roxb. & Clusiaceae & & Medicinal & 0 & 4 \\
\hline G. xanthochymus Hook. & Clusiaceae & Adult nectar plant & & 9 & 0 \\
\hline Salix tetrasperma Roxb. & Salicaceae & & Medicinal & 16 & 21 \\
\hline Tetrameles nudiflora R.Br. & Tetramelaceae & & & 20 & 5 \\
\hline Trewia nudiflora L. & Euphorbiaceae & Adult nectar plant & & 7 & 13 \\
\hline Terminalia chebula Retz. & Combretaceae & Adult nectar plant & Medicinal & 12 & 0 \\
\hline $\begin{array}{l}\text { Terminalia arjuna (Roxb.) W. } \\
\text { \& A. }\end{array}$ & Combretaceae & Adult nectar plant & Medicinal & 0 & 10 \\
\hline Tectona grandis L. & Verbenaceae & Adult nectar plant & Timber & 31 & 20 \\
\hline Cassia fistula L. & Caesalpinaceae & Adult nectar plant & Medicinal & 0 & 18 \\
\hline Albizzia lebbeck (L.) Benth. & Leguminoceae & & Medicinal & 10 & 0 \\
\hline $\begin{array}{l}\text { Albizzia chinensis (Osbeck) } \\
\text { Merr. }\end{array}$ & Leguminoceae & & Medicinal & 0 & 4 \\
\hline Schima walichii (DC.) Korth. & Theaceae & Adult nectar plant & Timber & 14 & 9 \\
\hline Cordia grandis Roxb. & Cordiaceae & & Medicinal & 4 & 6 \\
\hline $\begin{array}{l}\text { Echinocarpus assamicus } \\
\text { Benth. }\end{array}$ & Elaeocarpaceae & & & 15 & 0 \\
\hline Macaranga indica Wight & Euphorbiaceae & Adult nectar plant & & 17 & 0 \\
\hline $\begin{array}{l}\text { Macaranga dendiculata } \\
\text { Muell. Arg. }\end{array}$ & Euphorbiaceae & & & 0 & 3 \\
\hline Semecarpius anacardium L.f. & Anacardiaceae & & Medicinal & 16 & 11 \\
\hline Grewia elastica Royle & Malvaceae & & & 20 & 4 \\
\hline Cordia dichotoma G.Forst. & Cordiaceae & & & 22 & 0 \\
\hline Artocarpus lakoocha Roxb. & Moraceae & Adult nectar plant & & 16 & 0 \\
\hline $\begin{array}{l}\text { Artocarpus heterophyllus } \\
\text { Lam. }\end{array}$ & Moraceae & & & 21 & 15 \\
\hline $\begin{array}{l}\text { Holarrhena antidysentrica } \\
\text { Wall. }\end{array}$ & Apocynaceae & Adult nectar plant & Medicinal & 16 & 41 \\
\hline Evodia meliaefolia Benth. & Rutaceae & Larval food plant & & 7 & 11 \\
\hline Bischofia javanica Bl. & Euphorbiaceae & & Timber & 2 & 0 \\
\hline $\begin{array}{l}\text { Lannea grandis (Dennst.) } \\
\text { Engl. }\end{array}$ & Anacardiaceae & & & 13 & 0 \\
\hline $\begin{array}{l}\text { Lannea coromandelica } \\
\text { (Houtt.) Merr. }\end{array}$ & Anacardiaceae & & & 9 & 13 \\
\hline Calicarpa arborea Roxb. & Verbenaceae & & & 14 & 5 \\
\hline $\begin{array}{l}\text { Lithocarpus spicatus (Sm.) } \\
\text { Rehder \& Wils. }\end{array}$ & Fagaceae & & & 0 & 14 \\
\hline Sapium baccatum Roxb. & Euphorbiaceae & & & 10 & 4 \\
\hline Trema orientalis B1. & Ulmaceae & & & 5 & 16 \\
\hline $\begin{array}{l}\text { Butea monosperma Lam. } \\
\text { Taub. }\end{array}$ & Fabaceae & & & 11 & 0 \\
\hline
\end{tabular}




\begin{tabular}{|c|c|c|c|c|c|}
\hline \multicolumn{6}{|l|}{ Appendix 5 (Continued) } \\
\hline Species & Family & Status & $\begin{array}{l}\text { Economic } \\
\text { value }\end{array}$ & S1 & S4 \\
\hline Elaeocarpus aristatus Roxb. & Elaeocarpaceae & & & 4 & 0 \\
\hline Erythrina variegata L. & Fabaceae & & $\begin{array}{l}\text { Pulp for } \\
\text { paper }\end{array}$ & 16 & 0 \\
\hline $\begin{array}{l}\text { Protium serratum Wall. ex } \\
\text { Colebr.) Engl. }\end{array}$ & Busseraceae & & & 5 & 0 \\
\hline Sterculia villosa Roxb. & Sterculiaceae & & $\begin{array}{l}\text { Pulp for } \\
\text { paper }\end{array}$ & 12 & 0 \\
\hline Callicarpa macrophylla Vahl. & Verbenaceae & & & 4 & 0 \\
\hline Zizyphus mauritiana Lam. & Rhamnaceae & Adult nectar plant & Medicinal & 3 & 15 \\
\hline Moringa oleifera Lam. & Moringaceae & Adult nectar plant & Medicinal & 30 & 18 \\
\hline Alstonia scholaris L. R.Br. & Apocynaceae & Adult nectar plant & Medicinal & 19 & 6 \\
\hline Annona squamosa L. & Annonaceae & $\begin{array}{l}\text { Larval food plant \& } \\
\text { adult nectar plant }\end{array}$ & Medicinal & 21 & 12 \\
\hline $\begin{array}{l}\text { Dryptes/Camelia assamica (J. } \\
\text { W. Mast.) Kitam }\end{array}$ & Theaceae & & & 0 & 7 \\
\hline Sapindus mukorosii Gaertner & Sapindaceae & & Medicinal & 6 & 0 \\
\hline Mesua ferrea L. & Clusiaceae & & Medicinal & 7 & 0 \\
\hline Meliosma simplicifolia Roxb. & Meliosmaceae & & & 0 & 4 \\
\hline Aesculus assamica Griff. & Hyppocastanaceae & Adult nectar plant & & 18 & 11 \\
\hline Myristica angustifolia Lam. & Myristicaceae & & & 0 & 5 \\
\hline $\begin{array}{l}\text { Flacourtia jangomas (Lour.) } \\
\text { Raeusch }\end{array}$ & Flacourtiaceae & & & 0 & 3 \\
\hline $\begin{array}{l}\text { Paramichelia baillonii } \\
\text { (Pierre) } \mathrm{Hu}\end{array}$ & Magnoliaceae & & & 0 & 2 \\
\hline $\begin{array}{l}\text { Castanopsis indica (Roxb. ex } \\
\text { Lindl.) }\end{array}$ & Fagaceae & & & 14 & 0 \\
\hline $\begin{array}{l}\text { Dipterocarpus macrocarpus } \\
\text { Veque }\end{array}$ & Dipterocarpaceae & & & 10 & 37 \\
\hline $\begin{array}{l}\text { Tricalysia singularis } \mathrm{K} . \\
\text { Schum. }\end{array}$ & Rubiaceae & & & 0 & 14 \\
\hline Oroxylum idicum Vent. & Bignoniaceae & & Medicinal & 0 & 3 \\
\hline Streblus asper Lour. & Moraceae & & & 11 & 2 \\
\hline Careya arborea Roxb. & Myrtaceae & & & 0 & 4 \\
\hline $\begin{array}{l}\text { Dendrocalamus hamiltonii } \\
\text { Nees \& Arn. ex Munro }\end{array}$ & Poaceae & & $\begin{array}{l}\text { Pulp for } \\
\text { paper }\end{array}$ & 86 & 61 \\
\hline $\begin{array}{l}\text { Sterospermum chelonoides } \\
\text { DC. }\end{array}$ & Bignoniaceae & & Timber & 0 & 5 \\
\hline Syzygium cuminii L. & Myrtaceae & Adult nectar plant & Medicinal & 6 & 4 \\
\hline Diospyros variegata Kruz. & Ebenaceae & & Medicinal & 1 & 3 \\
\hline Bridelia retusa Spreng. & Euphorbiaceae & & & 0 & 4 \\
\hline Machilus bombycina King. & Lauraceae & & $\begin{array}{l}\text { Muga worm } \\
\text { foodplant }\end{array}$ & 0 & 5 \\
\hline Crataeva nurvula Buch Ham. & Capparidaceae & Adult nectar plant & Medicinal & 16 & 0 \\
\hline Gynocordia odorata R-Br. & Flacourtiaceae & Adult nectar plant & Medicinal & 25 & 0 \\
\hline
\end{tabular}




\section{Appendix 5 (Continued):}

5.5: Herb/Shrub families, genera and species sampled as total number of individuals in study sites S1 and S4 in Rani-Garbhanga Reserve Forest, Assam.

\begin{tabular}{|c|c|c|c|c|c|}
\hline Species & Family & Status & $\begin{array}{l}\text { Economic } \\
\text { Value }\end{array}$ & S1 & S4 \\
\hline Calotropis gigantia $\mathrm{Br}$. & Aselepiadaceae & Adult nectar plant & Medicinal & 23 & 14 \\
\hline Rauvolfia serpentina Benth. & Apocynaceae & & Medicinal & 16 & 5 \\
\hline Cannabis sativa $\mathrm{L}$. & Papaveraceae & Adult nectar plant & Narcotic & 22 & 17 \\
\hline Solanum indicum L. & Solanaceae & & Medicinal & 17 & 26 \\
\hline Solanum nigrum L. & Solanaceae & $\begin{array}{l}\text { Larval food plant \& } \\
\text { adult nectar plant }\end{array}$ & Medicinal & 12 & 32 \\
\hline Solanum khasianum Clarke & Solanaceae & & Medicinal & 9 & 2 \\
\hline Solanum verbascifolium $\mathrm{L}$ & Solanaceae & & Medicinal & 11 & 3 \\
\hline Nerium indicum Mill. & Apocynaceae & Adult nectar plant & & 15 & 7 \\
\hline Punica granatum L. & Punicaceae & Adult nectar plant & Medicinal & 28 & 17 \\
\hline $\begin{array}{l}\text { Glycosmis pentaphylla (Retz.) } \\
\text { DC }\end{array}$ & Rutaceae & Larval food plant & & 44 & 31 \\
\hline Murrya paniculata (L.) Jack & Rutaceae & Adult nectar plant & & 29 & 16 \\
\hline $\begin{array}{l}\text { Stephania hernandifolia } \\
\text { Walp. }\end{array}$ & Mensipermaceae & Adult nectar plant & Medicinal & 12 & 10 \\
\hline $\begin{array}{l}\text { Costus speciosus (J. König) } \\
\text { Smith }\end{array}$ & Zingiberaceae & Adult nectar plant & Medicinal & 29 & 15 \\
\hline Cassia occidentalis L. & Caesalpinaceae & & & 27 & 16 \\
\hline Cassia tora L. & Caesalpinaceae & & & 22 & 19 \\
\hline Cassia sophera L. & Caesalpinaceae & Adult nectar plant & & 19 & 25 \\
\hline Canna orientalis Rose & Caesalpinaceae & Adult nectar plant & & 26 & 10 \\
\hline Datura stramonium L. & Solanaceae & Adult nectar plant & & 15 & 13 \\
\hline Grewia hirsuta Vahl. & Tillaceae & & Medicinal & 8 & 6 \\
\hline Grewia sapida Roxb. ex DC., & Tillaceae & & & 5 & 9 \\
\hline Lantana camara L. & Verbenaceae & Adult nectar plant & Invasive sp. & 47 & 62 \\
\hline Sida acuta Burm. f. & Malvaceae & & & 4 & 19 \\
\hline Sida cordifolia L. & Malvaceae & Adult nectar plant & Medicinal & 23 & 12 \\
\hline $\begin{array}{l}\text { Clerodendron indicum (Linn.) } \\
\text { Kuntze }\end{array}$ & Verbenaceae & & Medicinal & 36 & 37 \\
\hline $\begin{array}{l}\text { Clerodendron infortunatum } \\
\text { Gaertn. }\end{array}$ & Verbenaceae & Adult nectar plant & Medicinal & 32 & 20 \\
\hline Adhatoda vasica Nees. & Acanthaceae & Adult nectar plant & Medicinal & 21 & 48 \\
\hline Ricinus communis L. & Euphorbiaceae & & $\begin{array}{l}\text { Foodplant of } \\
\text { silkworm }\end{array}$ & 19 & 2 \\
\hline $\begin{array}{l}\text { Eupatorium odoratum L. Siam } \\
\text { weed }\end{array}$ & Compositae & & $\begin{array}{l}\text { Medicinal Invasive } \\
\text { species }\end{array}$ & 41 & 50 \\
\hline Ficus heterophylla L. & Moraceae & & & 3 & 7 \\
\hline Coffea bengalensis Roxb. & Rubiaceae & & Coffee & 17 & 9 \\
\hline Curcuma aromatica Salisb. & Zingiberaceae & & Medicinal & 13 & 2 \\
\hline Mimosa himalayana Gamble & Leguminosae & & & 3 & 18 \\
\hline Musa sanguinea Hook. f. & Musaceae & & Medicinal & 9 & 5 \\
\hline
\end{tabular}


Appendix 5 (Continued)

\begin{tabular}{|c|c|c|c|c|c|}
\hline Species (Herb/Shrubs) & Family & Status & $\begin{array}{l}\text { Economic } \\
\text { Value }\end{array}$ & S1 & S4 \\
\hline Bauhinia acuminata L. & Fabaceae & & & 37 & 15 \\
\hline Abroma augusta L. & Sterculiaceae & & Medicinal & 2 & 8 \\
\hline Antidesma diandrum Roth. & Euphorbiaceae & & & 8 & 12 \\
\hline Maesa indica Wall. & Myrsinaceae & & Medicinal & 9 & 0 \\
\hline $\begin{array}{l}\text { Rhamnus nepalensis (Wall.) } \\
\text { Lawson }\end{array}$ & Rhamnaceae & & Medicinal & 6 & 15 \\
\hline Gardenia campanulata Roxb. & Rubiaceae & & & 17 & 21 \\
\hline $\begin{array}{l}\text { Desmodium pulchellum } \\
\text { Benth. }\end{array}$ & Leguminosae & & & 26 & 12 \\
\hline Desmodium latifolium DC. & Fabaceae & & & 19 & 26 \\
\hline Ardesia paniculata Roxb. & Myrsinaceae & & & 5 & 17 \\
\hline Litsaea salicifolia Roxb. & Lauraceae & & & 32 & 39 \\
\hline Homonoia riparia Lour. & Euphorbiaceae & & & 41 & 20 \\
\hline $\begin{array}{l}\text { Acanthopanax trifoliatum (L.) } \\
\text { Merr. }\end{array}$ & Araliaceae & & & 21 & 12 \\
\hline Aeschynomene indica L. & Papilionaceae & Adult nectar plant & & 10 & 17 \\
\hline Xanthium strumarium L. & Compositae & & Medicinal & 8 & 15 \\
\hline Vitex negundo L. & Verbenaceae & Adult nectar plant & Medicinal & 31 & 16 \\
\hline Ixora coccinea $\mathrm{L}$. & Rubiaceae & Adult nectar plant & & 22 & 49 \\
\hline Hibiscus rosa sinensis L. & Malvaceae & Adult nectar plant & & 47 & 32 \\
\hline Croton caudatus Geisel. & Euphorbiaceae & & Medicinal & 2 & 8 \\
\hline $\begin{array}{l}\text { Pandanus floribandus Merrill } \\
\text { \& L. M. Perry }\end{array}$ & Pandanaceae & & & 6 & 12 \\
\hline Elephantopus scaber L. & Asteraceae & & Medicinal & 3 & 8 \\
\hline Achyranthes aspera L. & Amranthaceae & & Medicinal & 4 & 13 \\
\hline Curculigo orchioides Gaetrn. & Hypoxidaceae & & Medicinal & 5 & 12 \\
\hline Duranta repens L. & Verbenaceae & Adult nectar plant & & 20 & 31 \\
\hline $\begin{array}{l}\text { Flemingia strobilifera (L.) } \\
\text { Aiton f. }\end{array}$ & Fabaceae & Adult nectar plant & & 5 & 16 \\
\hline Hemidesmus indicus R.Br. & Asclepiadaceae & & Medicinal & 9 & 1 \\
\hline Abutilon indicum L. & Malvaceae & Adult nectar plant & Medicinal & 29 & 10 \\
\hline Urena lobata L. & Malvaceae & Adult nectar plant & & 2 & 17 \\
\hline Plumbago zeylanica L. & Plumbaginaceae & Adult nectar plant & Medicinal & 18 & 27 \\
\hline Mussaenda roxburghii Hook. f. & Rubiaceae & & & 17 & 22 \\
\hline Holmskioldia sanguinea Retz. & Verbenceae & & & 19 & 28 \\
\hline GRASSES (excluded in analysis) & & & & & \\
\hline $\begin{array}{l}\text { Imperata cylindrica L. (Cogon } \\
\text { grass) }\end{array}$ & Poaceae & & & & \\
\hline $\begin{array}{l}\text { Microstegium ciliatum (Trin.) } \\
\text { A. Camus (Sau grass) }\end{array}$ & Poaceae & & & & \\
\hline Phyllanthus simplex Retz. & Euphorbiaceae & & & & \\
\hline
\end{tabular}




\section{Appendix 5 (Continued)}

5.6: Climber families, genera and species sampled as total number of individuals in study sites S1 and S4 in Rani-Garbhanga Reserve Forest, Assam.

\begin{tabular}{|c|c|c|c|c|}
\hline Species (Climbers) & Family & $\begin{array}{l}\text { Economic } \\
\text { value }\end{array}$ & S1 & $\mathbf{S 4}$ \\
\hline Mucuna prurita (L.)Hook. & Fabaceae & Medicinal & 10 & 7 \\
\hline Embelia ribes Burm. & Myrsinaceae & & 5 & 16 \\
\hline $\begin{array}{l}\text { Embelia nagushia } \\
\text { Don.Prodr.E. }\end{array}$ & Myrsinaceae & & 4 & 0 \\
\hline $\begin{array}{l}\text { Clematis cadmia Buch.- } \\
\text { Ham. ex Wall. }\end{array}$ & Ranunculaceae & & 13 & 18 \\
\hline $\begin{array}{l}\text { Dalbergia } \\
\text { tamarindifolia Roxb. }\end{array}$ & Fabaceae & Medicinal & 14 & 5 \\
\hline Dalbergia albiflora L. & Fabaceae & & 6 & 5 \\
\hline Bauhinia anguinea L. & Caesalpiniaceae & & 10 & 29 \\
\hline Bauhinia vahlii W. et. A. & Caesalpiniaceae & & 12 & 8 \\
\hline $\begin{array}{l}\text { Megistostigma } \\
\text { burmanica Kurz. }\end{array}$ & Euphorbiaceae & & 16 & 10 \\
\hline Butea parviflora Roxb. & Fabaceae & Medicinal & 15 & 19 \\
\hline $\begin{array}{l}\text { Jasminum scandens } \\
\text { Vahl. }\end{array}$ & Oleaceae & & 5 & 11 \\
\hline $\begin{array}{l}\text { Jasminum coarctatum } \\
\text { Roxb. }\end{array}$ & Oleaceae & & 0 & 19 \\
\hline $\begin{array}{l}\text { Merremia umbellata L. } \\
\text { Hallier f. }\end{array}$ & Convolvulaceae & & 40 & 12 \\
\hline $\begin{array}{l}\text { Acacia rugata (Lam.) } \\
\text { Voigt }\end{array}$ & Fabaceae & & 6 & 0 \\
\hline Acacia pinnata & Fabaceae & & 18 & 4 \\
\hline $\begin{array}{l}\text { Thunbergia grandiflora } \\
\text { Roxb. }\end{array}$ & Acanthaceae & & 12 & 18 \\
\hline Caesalpinia crista L. & Fabaceae & Medicinal & 15 & 21 \\
\hline Ficus scandens Roxb. & Moraceae & & 25 & 14 \\
\hline $\begin{array}{l}\text { Millettia auriculata } \\
\text { Baker ex. Brand. }\end{array}$ & Papilionaceae & & 9 & 6 \\
\hline Smilax zeylanica L. & Liliaceae & Medicinal & 11 & 4 \\
\hline $\begin{array}{l}\text { Smilax macrophylla } \\
\text { Roxb. }\end{array}$ & Liliaceae & & 0 & 10 \\
\hline $\begin{array}{l}\text { Combretum decandrum } \\
\text { Roxb. }\end{array}$ & Combretaceae & & 5 & 18 \\
\hline Delima sarmentosa (L.) & Dilleniaceae & & 18 & 27 \\
\hline $\begin{array}{l}\text { Vitis repanda (Vahl) } \\
\text { Wight \& Arn. }\end{array}$ & Vitaceae & & 9 & 6 \\
\hline Hibiscus fragrans & Malvaceae & & 8 & 3 \\
\hline Mussaenda glabra Vahl. & Rubiaceae & & 6 & 14 \\
\hline $\begin{array}{l}\text { Dioscorea kamoonensis } \\
\text { Kunth. }\end{array}$ & Dioscoreaceae & & 14 & 6 \\
\hline Entada scandens L. & Fabaceae & & 0 & 14 \\
\hline
\end{tabular}




\section{Appendix 5 (Continued)}

\begin{tabular}{|c|c|c|c|c|c|}
\hline Species (Climbers) & Family & Status & $\begin{array}{l}\text { Economic } \\
\text { value }\end{array}$ & S1 & S4 \\
\hline Paederia tomentosa $\mathrm{Bl}$. & Rubiaceae & & & 5 & 8 \\
\hline Derris elliptica Benth. & Fabaceae & & & 26 & 18 \\
\hline Aristolochia tagala Cham. & Aristolochiaceae & Larval food plant & Medicinal & 50 & 36 \\
\hline Aristolochia indica L. & Aristolochiaceae & Larval food plant & Medicinal & 41 & 30 \\
\hline $\begin{array}{l}\text { Stenochlaena palustris } \\
\text { (Burm.) Bedd }\end{array}$ & Blechnaceae & & & 18 & 21 \\
\hline Quisqualis indica L. & Combretaceae & Adult nectar plant & Medicinal & 25 & 16 \\
\hline Naravelia zeylanica L. & Ranunculaceae & & & 10 & 22 \\
\hline
\end{tabular}

Note : The information source on the economic and medicinal value of the listed plant species is from Hynniewta \& Baishya (1992). 
5.7 : Number of plant families and number of trees, herb/shrub and climber species per family sampled in study sites S1 (Garbhanga) and S4 (Rani) within the study area.

\begin{tabular}{|c|c|c|c|c|}
\hline Plant family & $\begin{array}{l}\text { Tree } \\
\text { species }\end{array}$ & $\begin{array}{l}\text { Herb/Shrub } \\
\text { species }\end{array}$ & $\begin{array}{l}\text { Climber } \\
\text { species }\end{array}$ & $\begin{array}{l}\text { Total } \\
\text { number of } \\
\text { species }\end{array}$ \\
\hline Fabaceae & 2 & 3 & 9 & 14 \\
\hline Rutaceae & 10 & 2 & 0 & 12 \\
\hline Verbenaceae & 6 & 6 & 0 & 12 \\
\hline Euphorbiaceae & 7 & 4 & 1 & 12 \\
\hline Caesalpiniaceae & 3 & 4 & 3 & 10 \\
\hline Moraceae & 8 & 1 & 1 & 10 \\
\hline Rubiaceae & 1 & 4 & 2 & 7 \\
\hline Malvaceae & 1 & 5 & 1 & 7 \\
\hline Lauraceae & 6 & 0 & 0 & 6 \\
\hline Solanaceae & 0 & 5 & 0 & 5 \\
\hline Magnoliaceae & 4 & 0 & 0 & 4 \\
\hline Apocynaceae & 2 & 2 & 0 & 4 \\
\hline Clusiaceae & 4 & 0 & 0 & 4 \\
\hline Anacardiaceae & 4 & 0 & 0 & 4 \\
\hline Leguminoceae & 2 & 2 & 0 & 4 \\
\hline Myrsinaceae & 0 & 2 & 2 & 4 \\
\hline Combretaceae & 2 & 0 & 2 & 4 \\
\hline Myrtaceae & 3 & 0 & 0 & 3 \\
\hline Dipterocarpaceae & 2 & 0 & 0 & 2 \\
\hline Poaceae & 1 & 2 & 0 & 3 \\
\hline Annonaceae & 2 & 0 & 0 & 2 \\
\hline Aristolochiaceae & 0 & 0 & 2 & 2 \\
\hline Papilionaceae & 0 & 1 & 1 & 2 \\
\hline Zingiberaceae & 0 & 2 & 0 & 2 \\
\hline Flacourtiaceae & 2 & 0 & 0 & 2 \\
\hline Rhamnaceae & 1 & 1 & 0 & 2 \\
\hline Ascelepiadaceae & 0 & 2 & 0 & 2 \\
\hline Theaceae & 2 & 0 & 0 & 2 \\
\hline Sapindaceae & 2 & 0 & 0 & 2 \\
\hline Cordiaceae & 2 & 0 & 0 & 2 \\
\hline Elaeocarpaceae & 2 & 0 & 0 & 2 \\
\hline Fagaceae & 2 & 0 & 0 & 2 \\
\hline Dilleniaceae & 1 & 0 & 1 & 2 \\
\hline Sterculiaceae & 1 & 1 & 0 & 2 \\
\hline Tillaceae & 2 & 0 & 0 & 2 \\
\hline Ranunculaceae & 0 & 0 & 3 & 3 \\
\hline Oleaceae & 0 & 0 & 2 & 2 \\
\hline Liliaceae & 0 & 0 & 2 & 2 \\
\hline Bignoniaceae & 2 & 0 & 0 & 2 \\
\hline Compositae & 0 & 2 & 0 & 2 \\
\hline Moringaceae & 1 & 0 & 0 & 1 \\
\hline Capparidaceae & 1 & 0 & 0 & 1 \\
\hline Mensispermaceae & 0 & 1 & 0 & 1 \\
\hline
\end{tabular}




\section{Appendix 5 (Continued)}

5.7 : (Continued)

\begin{tabular}{lrrrr} 
Plant family & $\begin{array}{r}\text { Tree } \\
\text { species }\end{array}$ & $\begin{array}{r}\text { Herb/Shrub } \\
\text { species }\end{array}$ & $\begin{array}{r}\text { Climber } \\
\text { species }\end{array}$ & $\begin{array}{r}\text { Total } \\
\text { number of } \\
\text { species }\end{array}$ \\
\hline Hyppocastanaceae & 1 & 0 & 0 & 1 \\
Plumbagenaceae & 0 & 1 & 0 & 1 \\
Punicaceae & 0 & 1 & 0 & 1 \\
Acanthaceae & 0 & 1 & 0 & 1 \\
Salicaceae & 1 & 0 & 0 & 1 \\
Tetramelaceae & 1 & 0 & 0 & 1 \\
Ulmaceae & 1 & 0 & 0 & 1 \\
Burseraceae & 1 & 0 & 0 & 1 \\
Meliosmaceae & 1 & 0 & 0 & 1 \\
Myristicaceae & 1 & 0 & 0 & 1 \\
Ebenaceae & 1 & 0 & 0 & 1 \\
Musaceae & 0 & 1 & 0 & 1 \\
Araliaceae & 0 & 1 & 0 & 1 \\
Pandanaceae & 0 & 1 & 0 & 1 \\
Asteraceae & 0 & 1 & 0 & 1 \\
Amranthaceae & 0 & 1 & 0 & 1 \\
Hypoxidaceae & 0 & 1 & 0 & 1 \\
Convolvulaceae & 0 & 0 & 1 & 1 \\
Vitaceae & 0 & 0 & 1 & 1 \\
Dioscoreaceae & 0 & 0 & 1 & 1 \\
Blechnaceae & 0 & 0 & 1 & 1 \\
Papaveraceae & 0 & 1 & 0 & 1 \\
& & & & 197 \\
\hline & 99 & 63 & 35 & \\
\hline & & & & 1 \\
\hline
\end{tabular}


5.8 : The important host-plant families for Papilionidae in South-East Asia (Fukuda et al., 1992; Igarashi \& Fukuda, 1997) and the important larval food-plants of the swallowtail butterflies identified in Rani-Garbhanga Reserve Forest, Assam. The host-plant records were reliably examined from literature (Haribal, 1992; Ackery, 1991; Igarashi \& Fukuda, 1997).

\begin{tabular}{|c|c|}
\hline $\begin{array}{l}\text { Plant family } \\
\text { species }\end{array}$ & Number of associated larval food-plant \\
\hline \multirow[t]{2}{*}{ Aristolochiaceae } & Aristolochia tagala \\
\hline & Aristolochia indica \\
\hline \multirow[t]{11}{*}{ Rutaceae } & Zanthoxyllum oxyphyllum \\
\hline & Zathoxyllum hamiltonianum \\
\hline & Zanthoxyllum rhetsa \\
\hline & Zanthoxyllum budrunga \\
\hline & Citrus aurantifolia \\
\hline & Citrus orientalis \\
\hline & Citrus grandis \\
\hline & Murrya koeningii \\
\hline & Glycosmis pentaphylla \\
\hline & Aegle marmelos \\
\hline & Evodia meliaefolia \\
\hline \multirow[t]{5}{*}{ Lauraceae } & Litsea sebifera \\
\hline & Litsea chinensis \\
\hline & Cinnamomum zeylanicum \\
\hline & Cinnamomum tamala \\
\hline & Cinnamomum camphora \\
\hline \multirow[t]{3}{*}{ Magnoliaceae } & Magnolia grandiflora \\
\hline & Magnolia pterocarpa \\
\hline & Michelia champaca \\
\hline \multirow[t]{2}{*}{ Annonaceae } & Polyalthia longifolia \\
\hline & Annona squamosa \\
\hline Solanaceae & Solanum nigrum \\
\hline Fabaceae & Saraca indica \\
\hline
\end{tabular}




\section{Appendix 5 (Continued)}

5.9 : Plant families and number of species representing the larval and adult food-plant sources of the Papilionidae within study sites S1 and S4 of Rani-Garbhanga Reserve Forest.

\begin{tabular}{|c|c|c|}
\hline \multirow[b]{2}{*}{ Family } & \multicolumn{2}{|c|}{ Larval host-plants and adult nectaring plants } \\
\hline & $\begin{array}{l}\text { Number of larval food } \\
\text { plant species }\end{array}$ & $\begin{array}{l}\text { Number of Adult } \\
\text { nectaring species }\end{array}$ \\
\hline Rutaceae & 11 & 2 \\
\hline Lauraceae & 5 & 2 \\
\hline Annonaceae & 2 & 1 \\
\hline Magnoliaceae & 3 & 0 \\
\hline Aristolochiaceae & 2 & 0 \\
\hline Caesalpiniaceae & 1 & 5 \\
\hline Verbenaceae & 0 & 5 \\
\hline Euphorbiaceae & 0 & 4 \\
\hline Combretaceae & 0 & 3 \\
\hline Apocynaceae & 0 & 3 \\
\hline Malvaceae & 0 & 3 \\
\hline Solanaceae & 1 & 2 \\
\hline Myrtaceae & 0 & 2 \\
\hline Rubiaceae & 0 & 1 \\
\hline Fabaceae & 0 & 1 \\
\hline Papilionaceae & 0 & 1 \\
\hline Moringaceae & 0 & 1 \\
\hline Papaveraceae & 0 & 1 \\
\hline Capparidaceae & 0 & 1 \\
\hline Zingiberaceae & 0 & 1 \\
\hline Flacourtiaceae & 0 & 1 \\
\hline Mensispermaceae & 0 & 1 \\
\hline Clusiaceae & 0 & 1 \\
\hline Hyppocastanaceae & 0 & 1 \\
\hline Plumbagenaceae & 0 & 1 \\
\hline Ramnaceae & 0 & 1 \\
\hline Punicaceae & 0 & 1 \\
\hline Ascelepiadaceae & 0 & 1 \\
\hline Moraceae & 0 & 1 \\
\hline Theaceae & 0 & 1 \\
\hline Acanthaceae & 0 & 1 \\
\hline Total number of spec & cies & 50 \\
\hline
\end{tabular}


5.10 : Systematic list of swallowtail butterflies of Rani-Garbhanga Reserve Forest, Assam, Northeast India. This is the checklist of the Papilionidae species identified in the Forest Reserve during the two year survey from 2001-2002. The species are arranged by the order of their respective genera. The geographic range classification for each follows Spitzer et al., 1993. The following abbreviations are used:

\section{Conservation Status (IUCN, 2006)}

$$
\begin{aligned}
& \mathrm{NR}=\text { Not Rare } \\
& \mathrm{NT}=\text { Not Threatened } \\
& \mathrm{NC}=\text { Not Common } \\
& \mathrm{C}=\text { Common }, \mathrm{S}=\text { Secure } \\
& \mathrm{VC}=\text { Very Common } \\
& \mathrm{UC}=\text { Uncommon } \\
& \mathrm{V}=\text { Vulnerable }
\end{aligned}
$$

\begin{tabular}{|c|c|c|c|c|c|c|c|}
\hline $\begin{array}{l}\text { Common } \\
\text { Name }\end{array}$ & Scientific name & $\begin{array}{l}\text { Wing } \\
\text { span } \\
(\mathrm{mm})\end{array}$ & $\begin{array}{l}\text { Larval host } \\
\text { plants }\end{array}$ & Feeding guild & Status & $\begin{array}{l}\text { Geographic } \\
\text { range }\end{array}$ & $\begin{array}{l}\text { Habitat } \\
\text { association } \\
\text { by forest } \\
\text { type based } \\
\text { on CCA } \\
\text { results }\end{array}$ \\
\hline $\begin{array}{l}\text { Great } \\
\text { Windmill }\end{array}$ & $\begin{array}{l}\text { Atrophaneura } \\
\text { dasarada Moore, } \\
1857\end{array}$ & $100-140$ & $\begin{array}{l}\text { Aristolochia } \\
\text { tagala, } A . \\
\text { indica } \\
\end{array}$ & $\begin{array}{l}\text { Monophagous } \\
\text { generalist }\end{array}$ & NR/NT & 1 & $\begin{array}{l}\text { Closed } \\
\text { forest }\end{array}$ \\
\hline $\begin{array}{l}\text { Common } \\
\text { Windmill }\end{array}$ & $\begin{array}{l}\text { Atrophaneura } \\
\text { polyeuctes } \\
\text { Doubleday, } 1842\end{array}$ & $100-130$ & $\begin{array}{l}\text { Aristolochia } \\
\text { tagala , A } \\
\text {.indica }\end{array}$ & $\begin{array}{l}\text { Monophagous } \\
\text { generalist }\end{array}$ & NR & 3 & $\begin{array}{l}\text { Closed } \\
\text { forest }\end{array}$ \\
\hline $\begin{array}{l}\text { Common } \\
\text { Batwing }\end{array}$ & $\begin{array}{l}\text { Atrophaneura } \\
\text { varuna Westwood, } \\
1842\end{array}$ & $88-136$ & $\begin{array}{l}\text { Aristolochia } \\
\text { tagala, } A . \\
\text { indica }\end{array}$ & $\begin{array}{l}\text { Monophagous } \\
\text { generalist }\end{array}$ & NR & 2 & $\begin{array}{l}\text { Closed } \\
\text { forest }\end{array}$ \\
\hline $\begin{array}{l}\text { Lesser } \\
\text { Batwing }\end{array}$ & $\begin{array}{l}\text { Atrophaneura } \\
\text { aidoneus } \\
\text { Doubleday, } 1845\end{array}$ & $100-120$ & $\begin{array}{l}\text { Aristolochia } \\
\text { tagala, } A . \\
\text { indica }\end{array}$ & $\begin{array}{l}\text { Monophagous } \\
\text { generalist }\end{array}$ & $\begin{array}{l}\mathrm{NC} / \\
\mathrm{NT}\end{array}$ & 3 & $\begin{array}{l}\text { Closed } \\
\text { forest }\end{array}$ \\
\hline $\begin{array}{l}\text { White head } \\
\text { Batwing }\end{array}$ & $\begin{array}{l}\text { Atrophaneura } \\
\text { sycorax Grose- } \\
\text { Smith, } 1885 \\
\end{array}$ & $110-130$ & $\begin{array}{l}\text { Aristolochia } \\
\text { tagala, } A . \\
\text { indica }\end{array}$ & $\begin{array}{l}\text { Monophagous } \\
\text { generalist }\end{array}$ & & 3 & $\begin{array}{l}\text { Closed } \\
\text { forest }\end{array}$ \\
\hline $\begin{array}{l}\text { Golden } \\
\text { Birdwing }\end{array}$ & $\begin{array}{l}\text { Troides aeacus } \\
\text { C\&R Felder, } 1860\end{array}$ & $120-190$ & $\begin{array}{l}\text { Aristolochia } \\
\text { tagala, } A . \\
\text { indica }\end{array}$ & $\begin{array}{l}\text { Monophagous } \\
\text { generalist }\end{array}$ & $\mathrm{V} / \mathrm{NT}$ & 2 & $\begin{array}{l}\text { Closed } \\
\text { forest }\end{array}$ \\
\hline $\begin{array}{l}\text { Common } \\
\text { Birdwing }\end{array}$ & $\begin{array}{l}\text { Troides helena } \\
\text { C\&R Felder, } 1865\end{array}$ & $140-190$ & $\begin{array}{l}\text { Aristolochia } \\
\text { tagala }, A . \\
\text { indica }\end{array}$ & $\begin{array}{l}\text { Monophagous } \\
\text { generalist }\end{array}$ & V & 3 & $\begin{array}{l}\text { Closed } \\
\text { forest }\end{array}$ \\
\hline
\end{tabular}




\begin{tabular}{|c|c|c|c|c|c|c|c|}
\hline $\begin{array}{l}\text { Common } \\
\text { Rose }\end{array}$ & \begin{tabular}{|l} 
Pachliopta \\
aristolochiae \\
Fabricius, 1775 \\
\end{tabular} & $80-110$ & $\begin{array}{l}\text { Aristolochia } \\
\text { tagala , A indica }\end{array}$ & $\begin{array}{l}\text { Monophagous } \\
\text { generalist }\end{array}$ & $\mathrm{VC} / \mathrm{NT}$ & 3 & $\begin{array}{l}\text { Scattered/ } \\
\text { open forest }\end{array}$ \\
\hline $\begin{array}{l}\text { Crimson } \\
\text { Rose }\end{array}$ & $\begin{array}{l}\text { Pachliopta hector } \\
\text { Linnaeus, } 1758\end{array}$ & $90-100$ & $\begin{array}{l}\text { Aristolochia } \\
\text { tagala }, A . \\
\text { indica }\end{array}$ & $\begin{array}{l}\text { Monophagous } \\
\text { generalist }\end{array}$ & \begin{tabular}{|l|} 
NT \\
(Protect \\
ed)
\end{tabular} & 3 & $\begin{array}{l}\text { Closed } \\
\text { forest }\end{array}$ \\
\hline $\begin{array}{l}\text { Common } \\
\text { Mormon }\end{array}$ & $\begin{array}{l}\text { Papilio polytes } \\
\text { Cramer, } 1775\end{array}$ & $80-100$ & $\begin{array}{l}\text { Aegel marmelos, } \\
\text { Glycosmis } \\
\text { pentaphylla, } \\
\text { Murrya } \\
\text { koeningii, Citrus } \\
\text { sp., } \\
\text { Zanthoxylum sp. } \\
\text { Evodia } \\
\text { meliaefolia }\end{array}$ & $\begin{array}{l}\text { Oligophagous } \\
\text { generalist }\end{array}$ & $\mathrm{VC} / \mathrm{NT}$ & 3 & Intermediate \\
\hline $\begin{array}{l}\text { Great } \\
\text { Mormon }\end{array}$ & $\begin{array}{l}\text { Papilio memnon } \\
\text { Linnaeus, } 1758\end{array}$ & $120-150$ & $\begin{array}{l}\text { A. marmelos, } \\
\text { G pentaphylla, } \\
\text { M. koeningii, } \\
\text { Citrus and } \\
\text { Zanthoxylum sp. } \\
\text { Evodia } \\
\text { meliaefolia }\end{array}$ & $\begin{array}{l}\text { Oligophagous } \\
\text { generalist }\end{array}$ & $\mathrm{C} / \mathrm{NT}$ & 3 & $\begin{array}{l}\text { Closed } \\
\text { forest }\end{array}$ \\
\hline $\begin{array}{l}\text { Common } \\
\text { Raven }\end{array}$ & $\begin{array}{l}\text { Papilio castor Wd., } \\
1909\end{array}$ & $100-130$ & $\begin{array}{l}\text { A marmelos, } \\
\text { G. pentaphylla, } \\
\text { M koeningii, } \\
\text { Citrus and } \\
\text { Zanthoxylum sp. }\end{array}$ & $\begin{array}{l}\text { Oligophagous } \\
\text { generalist }\end{array}$ & $\mathrm{C} / \mathrm{NT}$ & 1 & $\begin{array}{l}\text { Closed } \\
\text { forest }\end{array}$ \\
\hline Red Helen & $\begin{array}{l}\text { Papilio helenus } \\
\text { Linnaeus, } 1758\end{array}$ & $100-120$ & $\begin{array}{l}\text { A. marmelos, } \\
\text { G. pentaphylla, } \\
\text { M. koeningii, } \\
\text { Citrus and } \\
\text { Zanthoxylum } \\
\text { rhetsa }\end{array}$ & $\begin{array}{l}\text { Oligophagous } \\
\text { generalist }\end{array}$ & $\mathrm{C} / \mathrm{NT}$ & 4 & $\begin{array}{l}\text { Closed } \\
\text { forest }\end{array}$ \\
\hline $\begin{array}{l}\text { Yellow } \\
\text { Helen }\end{array}$ & $\begin{array}{l}\text { Papilio nephelus } \\
\text { Westwood, } 1845\end{array}$ & $115-130$ & $\begin{array}{l}\text { A. marmelos, } \\
\text { G. pentaphylla, } \\
\text { M. koeningii, } \\
\text { Citrus and } \\
\text { Zanthoxylum sp. }\end{array}$ & $\begin{array}{l}\text { Oligophagous } \\
\text { generalist }\end{array}$ & $\mathrm{C} / \mathrm{NT}$ & 2 & $\begin{array}{l}\text { Closed } \\
\text { forest }\end{array}$ \\
\hline $\begin{array}{l}\text { Common } \\
\text { Peacock }\end{array}$ & $\begin{array}{l}\text { Papilio polyctor } \\
\text { Moore, } 1758\end{array}$ & $120-150$ & \begin{tabular}{|l} 
Citrus \\
aurantifolia, \\
Zanthoxylum \\
oxyphyllum, Z \\
hamiltonianum \\
\end{tabular} & $\begin{array}{l}\text { Oligophagous } \\
\text { generalist }\end{array}$ & $\mathrm{C} / \mathrm{NT}$ & 3 & $\begin{array}{l}\text { Closed } \\
\text { forest }\end{array}$ \\
\hline $\begin{array}{l}\text { Paris } \\
\text { Peacock }\end{array}$ & $\begin{array}{l}\text { Papilio paris, } \\
\text { Linnaeus } 1758\end{array}$ & $90-120$ & $\begin{array}{l}\text { Wild and } \\
\text { cultivated citrus } \\
\text { plants }\end{array}$ & $\begin{array}{l}\text { Oligophagous } \\
\text { generalist }\end{array}$ & $\mathrm{C}$ & 3 & $\begin{array}{l}\text { Closed } \\
\text { forest }\end{array}$ \\
\hline $\begin{array}{l}\text { Krishna } \\
\text { Peacock }\end{array}$ & $\begin{array}{l}\text { Papilio krishna } \\
\text { Moore, } 1857\end{array}$ & $120-130$ & $\begin{array}{l}\text { Wild and } \\
\text { cultivated Citrus } \\
\text { sp. }\end{array}$ & $\begin{array}{l}\text { Oligophagous } \\
\text { generalist }\end{array}$ & UC & 2 & $\begin{array}{l}\text { Closed } \\
\text { forest }\end{array}$ \\
\hline Lime & Papilio demoleus & $80-100$ & Solanum & Polyphagous & $\mathrm{VC}$ & 4 & Scattered/ \\
\hline
\end{tabular}




\begin{tabular}{|c|c|c|c|c|c|c|c|}
\hline butterfly & Linnaeus, 1758 & & $\begin{array}{l}\text { nigrum, Citrus } \\
\text { sp., G. } \\
\text { pentaphylla, } \\
\text { M..koeningii, A.. } \\
\text { marmelos }\end{array}$ & generalist & & & open forest \\
\hline $\begin{array}{l}\text { Common } \\
\text { Mime }\end{array}$ & $\begin{array}{l}\text { Chilasa clytia } \\
\text { Linnaeus, } 1758\end{array}$ & & \begin{tabular}{|l} 
Litsea sebifera \\
Cinnamomum \\
zeylanicum \\
\end{tabular} & $\begin{array}{l}\text { Monophagous } \\
\text { generalist }\end{array}$ & \begin{tabular}{|l|}
$\mathrm{C} / \mathrm{NT}$ \\
(Protect \\
ed)
\end{tabular} & 3 & $\begin{array}{l}\text { Closed } \\
\text { forest }\end{array}$ \\
\hline $\begin{array}{l}\text { Chain } \\
\text { Swordtail }\end{array}$ & $\begin{array}{l}\text { Pathysa aristeus } \\
\text { Doubleday, } 1846\end{array}$ & $85-90$ & $\begin{array}{l}\text { Annona } \\
\text { squamosa, } \\
\text { Michleia sp. }\end{array}$ & $\begin{array}{l}\text { Polyphagous } \\
\text { generalist }\end{array}$ & $\begin{array}{l}\text { Protecte } \\
\mathrm{d}\end{array}$ & 1 & $\begin{array}{l}\text { Scattered/ } \\
\text { Open forest }\end{array}$ \\
\hline $\begin{array}{l}\text { Five-Bar } \\
\text { swordtail }\end{array}$ & $\begin{array}{l}\text { Pathysa antipathies } \\
\text { Fabricius, } 1787\end{array}$ & $80-95$ & $\begin{array}{l}\text { Annona } \\
\text { squamosa,., } \\
\text { Michelia } \text { sp. }\end{array}$ & $\begin{array}{l}\text { Polyphagous } \\
\text { generalist }\end{array}$ & & 3 & $\begin{array}{l}\text { Scattered/ } \\
\text { Open forest }\end{array}$ \\
\hline $\begin{array}{l}\text { Great } \\
\text { Zebra }\end{array}$ & $\begin{array}{l}\text { Pathysa xenocles } \\
\text { De Niceville, } 1897\end{array}$ & $85-120$ & $\begin{array}{l}\text { Annona } \\
\text { squamosa, } \\
\text { Michelia } \mathrm{sp} . \\
\end{array}$ & $\begin{array}{l}\text { Polyphagous } \\
\text { generalist }\end{array}$ & $\mathrm{C} / \mathrm{NT}$ & 1 & $\begin{array}{l}\text { Scattered/ } \\
\text { Open forest }\end{array}$ \\
\hline $\begin{array}{l}\text { Lesser } \\
\text { Zebra }\end{array}$ & $\begin{array}{l}\text { Pathysa macareus } \\
\text { Fruhstorfer, } 1902\end{array}$ & $80-100$ & $\begin{array}{l}\text { Annona } \\
\text { squamosa, } \\
\text { Michelia sp. }\end{array}$ & $\begin{array}{l}\text { Polyphagous } \\
\text { generalist }\end{array}$ & $\mathrm{C} / \mathrm{NT}$ & 4 & $\begin{array}{l}\text { Scattered/ } \\
\text { Open forest }\end{array}$ \\
\hline $\begin{array}{l}\text { Common } \\
\text { Jay }\end{array}$ & $\begin{array}{l}\text { Graphium doson } \\
\text { C\&R Felder, } 1864\end{array}$ & $70-80$ & $\begin{array}{l}\text { Magnolia } \\
\text { grandiflora, } \\
\text { Polyalthia } \\
\text { longifolia, } M . \\
\text { champaca, } \\
\text { Cinnamomum } \\
\text { sp. }\end{array}$ & $\begin{array}{l}\text { Polyphagous } \\
\text { generalist }\end{array}$ & $\mathrm{S}$ & 4 & $\begin{array}{l}\text { Scattered/ } \\
\text { Open forest }\end{array}$ \\
\hline Tailed Jay & $\begin{array}{l}\text { Graphium } \\
\text { agammemnon } \\
\text { Linnaeus, } 1758\end{array}$ & $85-100$ & $\begin{array}{l}\text { A. squamosa, } P \\
\text { longifolia, } \\
\text { Michelia } \\
\text { champaca }\end{array}$ & $\begin{array}{l}\text { Polyphagous } \\
\text { generalist }\end{array}$ & $\begin{array}{l}\mathrm{C} / \mathrm{NT} \& \\
\mathrm{~S}\end{array}$ & 4 & $\begin{array}{l}\text { Scattered/ } \\
\text { Open forest }\end{array}$ \\
\hline $\begin{array}{l}\text { Blue } \\
\text { Triangle/ } \\
\text { Common } \\
\text { Bluebottle }\end{array}$ & $\begin{array}{l}\text { Graphium sarpedon } \\
\text { Linnaeus, } 1758\end{array}$ & $80-90$ & $\begin{array}{l}\text { Saraca indica, } \\
\text { Cinnamomum } \\
\text { zeylanicum, A. } \\
\text { squamosa, P } \\
\text { longifolia, } \\
\text { Litsea chinensis } \\
\end{array}$ & $\begin{array}{l}\text { Polyphagous } \\
\text { generalist }\end{array}$ & $\mathrm{S}$ & 4 & $\begin{array}{l}\text { Scattered/ } \\
\text { Open forest }\end{array}$ \\
\hline $\begin{array}{l}\text { Green } \\
\text { Dragontail }\end{array}$ & $\begin{array}{l}\begin{array}{l}\text { Lamproptera meges } \\
\text { Tytler }\end{array} \\
\end{array}$ & $40-50$ & Illigera cordata & $\begin{array}{l}\text { Monophagous } \\
\text { specialist }\end{array}$ & NT $/ \mathrm{V}$ & 3 & Intermediate \\
\hline $\begin{array}{l}\text { White } \\
\text { Dragontail }\end{array}$ & $\begin{array}{l}\text { Lamproptera curius } \\
\text { Fabricius, } 1787\end{array}$ & $40-50$ & Illigera cordata & $\begin{array}{l}\text { Monophagous } \\
\text { specialist }\end{array}$ & NT7V & 3 & Intermediate \\
\hline
\end{tabular}


5.11 : Systematic list of swallowtail butterflies from the Indian Himalayan region (excluding the Apollos, Parnassius species) and Peninsular India. (Evans, 1932; Talbot, 1939; Mani, 1986; Haribal, 1994). The species are arranged according to their geographic range distribution. The species identified and recorded in the present study in Rani-Garbhanga Reserve Forest, Assam, India are indicated in bold letters.

\begin{tabular}{|c|c|c|c|c|}
\hline Endemic Species & English name & $\begin{array}{l}\text { Distribution } \\
\text { range }\end{array}$ & $\begin{array}{l}\text { Status } \\
\text { (Evans, } \\
\text { 1932) }\end{array}$ & $\begin{array}{l}\text { Present status } \\
\text { (IUCN, 2006) }\end{array}$ \\
\hline $\begin{array}{l}\text { Atrophaneura coon cachariensis } \\
\text { Butler, } 1865\end{array}$ & Common Clubtail & Assam & VR & $\begin{array}{l}\text { Rarely } \\
\text { recorded }\end{array}$ \\
\hline $\begin{array}{l}\text { Papilio bootes bootes Westwood, } \\
1842\end{array}$ & Tailed Redbreast & Assam & $\mathrm{R}$ & $\begin{array}{l}\text { Protected by } \\
\text { law in India }\end{array}$ \\
\hline $\begin{array}{l}\text { Papilio elephenor elephenor } \\
\text { Doubleday, } 1845\end{array}$ & $\begin{array}{l}\text { Yellow-crested } \\
\text { Spangle }\end{array}$ & Assam & VR & $\begin{array}{l}\text { Protected by } \\
\text { law in India }\end{array}$ \\
\hline Pathysa macareus lioneli, Fruh.1902 & Lesser Zebra & Assam & NR & $\mathrm{C} / \mathrm{NT}$ \\
\hline $\begin{array}{l}\text { Pathysa xenocles xenocles, Db., } \\
1842\end{array}$ & Great Zebra & Assam & NR & $\mathrm{C} / \mathrm{NT}$ \\
\hline $\begin{array}{l}\text { Atrohaneura dasarada dasarada } \\
\text { Moore, } 1857\end{array}$ & Great Windmill & Sikkim-Assam & NR & $\mathrm{NR} / \mathrm{NT}$ \\
\hline Pathysa eurous sikkimica, Heron & Six-Bar Swordtail & Sikkim-Assam & NR & NT \\
\hline $\begin{array}{l}\text { Pathysa aristeus anticrates, Db. } \\
1846\end{array}$ & Chain Swordtail & Sikkim-Assam & $\mathrm{R}$ & Protected \\
\hline $\begin{array}{l}\text { Meandrusa gyas gyas, Westwood, } \\
1841\end{array}$ & Brown Gorgon & Sikkim-Assam & $\mathrm{R}$ & Protected \\
\hline $\begin{array}{l}\text { Meandrusa payeni evan Doubleday, } \\
1845\end{array}$ & Yellow Gorgon & Sikkim-Assam & NR & NT \\
\hline $\begin{array}{l}\text { Teinopalpus imperialis imperialis } \\
\text { Hope, } 1843\end{array}$ & Kaiser-I-Hind & Sikkim-Assam & $\mathrm{R}$ & $\begin{array}{l}\text { Appendix-II, } \\
\text { Protected by } \\
\text { law }\end{array}$ \\
\hline $\begin{array}{l}\text { Atrophaneura zaleucus Hewitson, } \\
1865\end{array}$ & Burmese Batwing & $\begin{array}{l}\text { Shan states, } \\
\text { S.Burma }\end{array}$ & NT & $\mathrm{NC}$ \\
\hline $\begin{array}{l}\text { Atrophaneura crassipes Oberthur, } \\
1879\end{array}$ & Black Windmill & $\begin{array}{l}\text { Manipur-Shan } \\
\text { states }\end{array}$ & VR & $\begin{array}{l}\text { Protected by } \\
\text { law in India }\end{array}$ \\
\hline $\begin{array}{l}\text { Atrophaneura alcinous pembertoni, } \\
\text { M. }\end{array}$ & $\begin{array}{l}\text { Pemberton's Chinese } \\
\text { Windmill }\end{array}$ & Sikkim-Bhutan & VR & Not known \\
\hline $\begin{array}{l}\text { Atrophaneura alcinous tytleri, } \\
\text { Evans. }\end{array}$ & $\begin{array}{l}\text { Tytler's Chinese } \\
\text { Windmill } \\
\end{array}$ & $\begin{array}{l}\text { Manipur-Chin } \\
\text { hills }\end{array}$ & $\mathrm{R}$ & Not known \\
\hline Papilio bootes mixta Tytler, 1915 & Tailed Redbreast & $\begin{array}{l}\text { Manipur, } \\
\text { Nagas, } \\
\text { N.Burma }\end{array}$ & $\mathrm{R}$ & Not known \\
\hline Papilio mahadeva Moore, 1878 & Burmese Raven & Shan-S. Burma & & $\mathrm{NC}$ \\
\hline Papilio castor polas, Jord. & Common Raven & Sikkim & NR & $\mathrm{C} / \mathrm{NT}$ \\
\hline $\begin{array}{l}\text { Papilio machaon sikkimensis, Moor, } \\
1884\end{array}$ & $\begin{array}{l}\text { Common Yellow } \\
\text { Swallowtail }\end{array}$ & Sikkim-Bhutan & & Not known \\
\hline
\end{tabular}




\begin{tabular}{|c|c|c|c|c|}
\hline $\begin{array}{l}\text { Pathysa macareus indicus, } \\
\text { Rothschild }\end{array}$ & Lesser Zebra & Sikkim & NR & $\mathrm{C} / \mathrm{NT}$ \\
\hline Pathysa xenocles phrontis, DeN. & Great Zebra & Sikkim & & NT \\
\hline $\begin{array}{l}\text { Bhutanitis lidderdalei Atkinson, } \\
1873\end{array}$ & Bhutan glory & $\begin{array}{l}\text { Bhutan, Naga } \\
\text { \& Chin hills }\end{array}$ & $\mathrm{R}$ & $\begin{array}{l}\text { Needs } \\
\text { monitoring }\end{array}$ \\
\hline $\begin{array}{l}\text { Atrophaneura latreillei kabrua } \\
\text { Tytler, } 1915\end{array}$ & Rose Windmill & $\begin{array}{l}\text { Assam- } \\
\text { N.Burma }\end{array}$ & $\mathrm{R}$ & $\begin{array}{l}\text { Protected by } \\
\text { law in India }\end{array}$ \\
\hline $\begin{array}{l}\text { Atrophaneura polla de Niceville, } \\
1897\end{array}$ & $\begin{array}{l}\text { De Niceville's } \\
\text { Windmill }\end{array}$ & $\begin{array}{l}\text { Assam- } \\
\text { N.Burma }\end{array}$ & VR & $\begin{array}{l}\text { Protected by } \\
\text { law in India }\end{array}$ \\
\hline $\begin{array}{l}\text { Atrophaneura nevilli Wood-Mason, } \\
1896\end{array}$ & Neville's Windmill & Assam-S.Shan & VR & $\begin{array}{l}\text { NT/Protected } \\
\text { by law in } \\
\text { India }\end{array}$ \\
\hline $\begin{array}{l}\text { Atrophaneura philoxenus } \\
\text { polyeuctus, Db. }\end{array}$ & Common Windmill & Sikkim -Burma & $\mathrm{C}$ & NR \\
\hline Chilasa agestor agestor Gray, 1832 & Tawny Mime & $\begin{array}{l}\text { Sikkim- } \\
\text { Dawnas }\end{array}$ & NR & NT \\
\hline $\begin{array}{l}\text { Chilasa epicydes epicydes, } \\
\text { Hewitson, } 1862\end{array}$ & Lesser Mime & $\begin{array}{l}\text { Sikkim- } \\
\text { N.Burma }\end{array}$ & & $\begin{array}{l}\text { NT/ Protected } \\
\text { by law in } \\
\text { India }\end{array}$ \\
\hline $\begin{array}{l}\text { Chilasa slateri slateri, Hewitson, } \\
1857\end{array}$ & Blue-Striped Mime & $\begin{array}{l}\text { Sikkim- } \\
\text { N.Burma }\end{array}$ & $\mathrm{R}$ & $\begin{array}{l}\mathrm{R} / \text { Protected } \\
\text { by law in } \\
\text { India }\end{array}$ \\
\hline $\begin{array}{l}\text { Chilasa paradoxa telearchus } \\
\text { Hewitson, } 1852\end{array}$ & Great Blue Mime & Assam-Burma & $\mathrm{R}$ & $\begin{array}{l}\mathrm{R} / \text { Protected } \\
\text { by law in } \\
\text { India }\end{array}$ \\
\hline Papilio memnon agenor, L. 1758 & Great Mormon & Sikkim-Burma & $\mathrm{C}$ & $\mathrm{C} / \mathrm{NT}$ \\
\hline $\begin{array}{l}\text { Papilio protenor euprotenor, Fruh. } \\
1908\end{array}$ & Spangle & $\begin{array}{l}\text { Sikkim- } \\
\text { N.Burma }\end{array}$ & NR & $\mathrm{C} / \mathrm{NT}$ \\
\hline Papilio polyctor ganesa, M. 1758 & Common Peacock & $\begin{array}{l}\text { Sikkim- } \\
\text { N.Burma }\end{array}$ & $\mathrm{C}$ & C/NT \\
\hline $\begin{array}{l}\text { Papilio arcturus arcturus } \\
\text { Westwood, } 1842\end{array}$ & Blue Peacock & Nepal-Dawnas & NR & NT \\
\hline Papilio krishna, M. 1857 & Krishna Peacock & Sikkim-Burma & NR & $\mathrm{NC} / \mathrm{NT}$ \\
\hline $\begin{array}{l}\text { Papilio castor castor Westwood, } \\
1842\end{array}$ & Common Raven & $\begin{array}{l}\text { Assam- } \\
\text { N.Burma }\end{array}$ & NR & $\mathrm{C} / \mathrm{NT}$ \\
\hline $\begin{array}{l}\text { Papilio machaon verityi } \\
\text { Fruhstorfer, } 1907\end{array}$ & $\begin{array}{l}\text { Common Yellow } \\
\text { Swallowtail }\end{array}$ & $\begin{array}{l}\text { Assam, } \\
\text { N.Burma }\end{array}$ & $\mathrm{R}$ & NR/ Protected \\
\hline Pathysa glycerion Gray, 1813 & Spectacle Swordtail & $\begin{array}{l}\text { Sikkim- } \\
\text { N.Burma }\end{array}$ & NR & $\mathrm{NC}$ \\
\hline $\begin{array}{l}\text { Pathysa agetes agetes, Westwood, } \\
1841\end{array}$ & Four-Bar Swordtail & $\begin{array}{l}\text { Sikkim- } \\
\text { N.Burma } \\
\end{array}$ & NR & $\mathrm{C} / \mathrm{NT}$ \\
\hline $\begin{array}{l}\text { Pathysa nomius swinhoei Moore } \\
1878\end{array}$ & Spot Swordtail & $\begin{array}{l}\text { Assam- } \\
\text { S.Burma }\end{array}$ & NR & NT \\
\hline $\begin{array}{l}\text { Pathysa antipathies pompilius, F. } \\
1787\end{array}$ & Five-Bar Swordtail & Sikkim-Burma & $\mathrm{C}$ & NT \\
\hline
\end{tabular}




\begin{tabular}{|c|c|c|c|c|}
\hline $\begin{array}{l}\text { Graphium evemon albociliatis, } \\
\text { Fruhstorfer, } 1901\end{array}$ & Lesser Jay & Assam-Tavoy & $\mathrm{R}$ & $\begin{array}{l}\text { NT } \\
\text { Protected }\end{array}$ \\
\hline $\begin{array}{l}\text { Graphium eurypylus cheronus, } \\
\text { Fruh., } 1903\end{array}$ & Great Jay & Sikkim-Burma & NR & NT \\
\hline $\begin{array}{l}\text { Graphium bathycles chiron Wallace, } \\
1865\end{array}$ & Veined Jay & Sikkim-Burma & NR & Not Known \\
\hline Graphium arycles Boisduval, 1836 & Spotted Jay & $\begin{array}{l}\text { Assam- } \\
\text { S.Burma }\end{array}$ & $\mathrm{R}$ & $\begin{array}{l}\text { Scarce, } \\
\text { Protected }\end{array}$ \\
\hline $\begin{array}{l}\text { Pathysa megarus megarus } \\
\text { Westwood, } 1841\end{array}$ & Spotted Zebra & $\begin{array}{l}\text { Assam- } \\
\text { N.Burma }\end{array}$ & $\mathrm{R}$ & $\begin{array}{l}\mathrm{C} / \mathrm{NT} / \\
\text { Protected }\end{array}$ \\
\hline $\begin{array}{l}\text { Lamproptera curius curius } \\
\text { Fabricius, } 1787\end{array}$ & White Dragontail & Assam-Burma & NR & NT \\
\hline Lamproptera meges, Tyt. & Green Dragontail & $\begin{array}{l}\text { Assam- } \\
\text { N.Burma }\end{array}$ & NR & NT \\
\hline $\begin{array}{l}\text { Troides helena cerberus } C \& R \\
\text { Felder, } 1865\end{array}$ & Common Birdwing & $\begin{array}{l}\text { Orissa, } \\
\text { Sikkim-Burma }\end{array}$ & NR & $\begin{array}{l}\mathrm{C} / \text { Widely } \\
\text { distributed }\end{array}$ \\
\hline Atrophaneura sycorax, Gr.S., 1885 & Whitehead Batwing & S.Shan, Burma & VR & NT \\
\hline Atrophaneura aidoneus, D. 1845 & Lesser Batwing & Garhwal-Shan & $\mathrm{R}$ & $\mathrm{NC} / \mathrm{NT}$ \\
\hline A.varuna astorion, Wd. 1842 & Common Batwing & $\begin{array}{l}\text { Kumaon- } \\
\text { Tavoy }\end{array}$ & NR & $\mathrm{NR} / \mathrm{NT}$ \\
\hline Troides aeacus aeacus Felder, 1860 & Golden Birdwing & $\begin{array}{l}\text { SW } \\
\text { Himalayas- } \\
\text { Burma, NW } \\
\text { China }\end{array}$ & $\mathrm{C}$ & $\mathrm{C} / \mathrm{NT}$ \\
\hline $\begin{array}{l}\text { Pachliopta aristolochiae } \\
\text { aristolochiae, Fabricius } 1775\end{array}$ & Common Rose & India & $\mathrm{VC}$ & $\mathrm{C} / \mathrm{NT}$ \\
\hline Pachliopta hector, L. 1758 & Crimson Rose & $\begin{array}{l}\text { SriLanka- } \\
\text { Assam }\end{array}$ & VR & $\begin{array}{l}\mathrm{C} / \mathrm{NT} / \text { Protect } \\
\text { ed }\end{array}$ \\
\hline $\begin{array}{l}\text { Atrophaneura latreillei latreillei } \\
\text { Donovan, } 1836\end{array}$ & \begin{tabular}{|l|} 
Rose \\
Windmill \\
\end{tabular} & $\begin{array}{l}\text { Garhwal- } \\
\text { Sikkim }\end{array}$ & $\mathrm{NR} / \mathrm{NT}$ & $\mathrm{NR} / \mathrm{NT}$ \\
\hline $\begin{array}{l}\text { Atrophaneura philoxenus philoxenus } \\
\text { Gray, } 1831\end{array}$ & Common Windmill & Kashmir-Nepal & NR & NR \\
\hline $\begin{array}{l}\text { Atrophaneura dasarada ravana } \\
\text { Moore, } 1857\end{array}$ & Great Windmill & $\begin{array}{l}\text { Kashmir- } \\
\text { Kumaon }\end{array}$ & & NR \\
\hline $\begin{array}{l}\text { Chilasa agestor govindra, Moore, } \\
1875\end{array}$ & Tawny Mime & $\begin{array}{l}\text { Kashmir- } \\
\text { Kumaon }\end{array}$ & & NT \\
\hline $\begin{array}{l}\text { Chilasa clytia clytia, L. } 1758 \\
\text { Chilasa clytia form dissimilis } \\
\text { Linnaeus, } 1758\end{array}$ & Common Mime & India & NR & $\begin{array}{l}\mathrm{C} / \mathrm{NT} / \text { Protect } \\
\text { ed }\end{array}$ \\
\hline Papilio bootes janaka Moore, 1857 & Tailed Redbreast & Garhwal-Abor & & NT \\
\hline Papilio rhetenor Westwood, 1841 & Redbreast & $\begin{array}{l}\text { Kumaon- } \\
\text { Burma }\end{array}$ & & $\mathrm{C} / \mathrm{NT}$ \\
\hline $\begin{array}{l}\text { Papilio protenor protenor Cramer, } \\
1775\end{array}$ & Spangle & $\begin{array}{l}\text { Kashmir- } \\
\text { Kumaon }\end{array}$ & & $\mathrm{C} / \mathrm{NT}$ \\
\hline
\end{tabular}




\begin{tabular}{|c|c|c|c|c|}
\hline $\begin{array}{l}\text { Papilio polyctor polyctor } \\
\text { Boisduval, } 1836\end{array}$ & Common Peacock & $\begin{array}{l}\text { Chitral- } \\
\text { Kumaon }\end{array}$ & & $\mathrm{C} / \mathrm{NT}$ \\
\hline Papilio paris paris, L. 1758 & Paris Peacock & $\begin{array}{l}\text { Orissa, } \\
\text { Kumaon- } \\
\text { Burma }\end{array}$ & $\mathrm{C}$ & $\mathrm{C} / \mathrm{NT}$ \\
\hline Papilio arcturus arius, Roth. & Blue Peacock & $\begin{array}{l}\text { Kashmir- } \\
\text { Kumaon }\end{array}$ & & NT \\
\hline Papilio crino Fabricius, 1792 & $\begin{array}{l}\text { Common Banded } \\
\text { Peacock }\end{array}$ & $\begin{array}{l}\text { SriLanka, } \\
\text { S.India-Bengal }\end{array}$ & & NT \\
\hline Papilio helenus helenus, L.1758 & Red Helen & $\begin{array}{l}\text { Mussourie- } \\
\text { Burma }\end{array}$ & & $\mathrm{C} / \mathrm{NT}$ \\
\hline $\begin{array}{l}\text { Papili nephelus chaon, Westwood, } \\
1844\end{array}$ & Yellow Helen & $\begin{array}{l}\text { Orissa, Nepal- } \\
\text { N.Burma }\end{array}$ & $\mathrm{C}$ & $\mathrm{C} / \mathrm{NT}$ \\
\hline $\begin{array}{l}\text { Papilio polytes romulus Cr. } 1775 \\
\text { Papilio polytes stichius }\end{array}$ & Common Mormon & $\begin{array}{l}\text { India, Burma, } \\
\text { Srilanka }\end{array}$ & $\mathrm{VC}$ & $\mathrm{C} / \mathrm{NT}$ \\
\hline Papilio demoleus demoleus, L 1758 & Lime butterfly & $\begin{array}{l}\text { India, } \\
\text { N.Burma, } \\
\text { Srilanka }\end{array}$ & $\mathrm{VC}$ & $\mathrm{VC}$ \\
\hline Papilio machon asiaticus, Ménétriés & \begin{tabular}{|l|} 
Common Yellow \\
Swallowtail \\
\end{tabular} & Chitral-Nepal & & $\mathrm{C} / \mathrm{NT}$ \\
\hline Pathysa eurous cashmirensis, Roth. & Six-Bar Swordtail & $\begin{array}{l}\text { Kashmir- } \\
\text { Kumaon }\end{array}$ & & $\mathrm{C} / \mathrm{NT}$ \\
\hline Pathysa nomius nomius Esper, 1798 & Spot Swordtail & $\begin{array}{l}\text { S.India- } \\
\text { Sikkim, } \\
\text { Srilanka }\end{array}$ & & $\mathrm{C} / \mathrm{NT}$ \\
\hline $\begin{array}{l}\text { Graphium cloanthus Westwood, } \\
1841\end{array}$ & Glassy bluebottle & $\begin{array}{l}\text { Kashmir- } \\
\text { Burma }\end{array}$ & NR & $\mathrm{C} / \mathrm{NT}$ \\
\hline $\begin{array}{l}\text { Graphium sarpedon sarpedon, Fd. } \\
1758\end{array}$ & Common Bluebottle & $\begin{array}{l}\text { Kashmir- } \\
\text { Burma }\end{array}$ & $\mathrm{C}$ & $\mathrm{VC} / \mathrm{NT}$ \\
\hline Graphium doson eleius, Fr. 1902 & Common Jay & $\begin{array}{l}\text { South India, } \\
\text { Bengal }\end{array}$ & $\mathrm{C}$ & $\mathrm{C}$ \\
\hline Graphium doson axion, Fd. 1864 & Common Jay & $\begin{array}{l}\text { Kumaon- } \\
\text { Burma }\end{array}$ & $\mathrm{C}$ & $\mathrm{C}$ \\
\hline $\begin{array}{l}\text { Graphium agammemnon } \\
\text { agammemnon, L. } 1758\end{array}$ & Tailed Jay & $\begin{array}{l}\text { Kumaon- } \\
\text { Burma }\end{array}$ & $\mathrm{C}$ & $\mathrm{C} / \mathrm{NT}$ \\
\hline Iphiclides podalirius Linnaeus 1758 & Scarce Swallowtail & Himalayas & & $\begin{array}{l}\text { More } \\
\text { monitoring } \\
\text { needed }\end{array}$ \\
\hline Troides helena minos Cramer, 1779 & Southern Birdwing & South India & & $\mathrm{C} / \mathrm{NT}$ \\
\hline $\begin{array}{l}\text { Pachliopta jophon pandiyana } \\
\text { Moore, } 1881\end{array}$ & Malabar Rose & South India & & $\mathrm{NC} / \mathrm{NT}$ \\
\hline $\begin{array}{l}\text { Papilio polymnestor polymnestor } \\
\text { Cramer, } 1775\end{array}$ & Blue Mormon & South India & & $\mathrm{C} / \mathrm{NT}$ \\
\hline Papilio paris tamilana Moore, 1881 & Tamil Peacock & South India & $\mathrm{C}$ & $\mathrm{C} / \mathrm{NT}$ \\
\hline Papilio buddha Westwood, 1872 & $\begin{array}{l}\text { Malabar Banded } \\
\text { Peacock }\end{array}$ & South India & & $\begin{array}{l}\text { NR/NT } \\
\text { Protected }\end{array}$ \\
\hline
\end{tabular}




\begin{tabular}{|l|l|l|l|l|}
\hline $\begin{array}{l}\text { Papilio dravidarum Wood-Mason, } \\
1880\end{array}$ & Malabar Raven & South India & & UC/NT \\
\hline Papilio helenus daksha, Moore & Red Helen & South India & & NR \\
\hline $\begin{array}{l}\text { Papilio demoleus liomedon Moore, } \\
1874\end{array}$ & $\begin{array}{l}\text { Malabar Banded } \\
\text { Swallowtail }\end{array}$ & South India & VC & VC \\
\hline $\begin{array}{l}\text { Pathysa antipathes naira, Moore, } \\
1881\end{array}$ & Five bar Swordtail & South India & & NT \\
\hline $\begin{array}{l}\text { Graphium sarpedon teredon } \\
\text { C \& R Felder, } 1864\end{array}$ & Common Bluebottle & $\begin{array}{l}\text { South India, } \\
\text { Srilanka }\end{array}$ & & VC \\
\hline $\begin{array}{l}\text { Graphium agammemnon menides } \\
\text { Fruhstorfer, 1904 }\end{array}$ & Tailed Jay & $\begin{array}{l}\text { South India, } \\
\text { Srilanka }\end{array}$ & C & C/NT \\
\hline
\end{tabular}

\section{NOTE:}

- Papilio sakontala Hewitson, 1864 described from Northern India eastwards to Assam and Naga hills by D'Abrera, 1982 is thought by some authors (Evans, 1932; Antram, 1924) to be a form of Papilio polytes rather than a good species (Collins \& Morris, 1985).

- In the Indian Himalayan region, the sub-family Parnassiinae (Apollos) are represented by 14 species, which have not been included in the Papilionidae checklist.

- The nominate sub-species are protected by law in India under the 'The Wildife (Protection) Act, 1972 .

- Species described from the Andamans and Nicobar Islands have not been included. 


\section{Appendix 5 (Continued):}

5.12 : Total number of swallowtail butterflies sampled as individuals in the study sites S1, S2, S3, S4 and S5 in Rani-Garbhanga Reserve Forest.

\begin{tabular}{lcc}
\hline Season & Year & $\begin{array}{c}\text { Total number } \\
\text { of individuals }\end{array}$ \\
\hline Dry season & 1 & 2921 \\
Wet season & 1 & 6469 \\
Dry season & 2 & 3025 \\
Wet season & 2 & 6004 \\
\hline - $\quad$ Year $1=2003$ & \\
- & \\
\hline
\end{tabular}

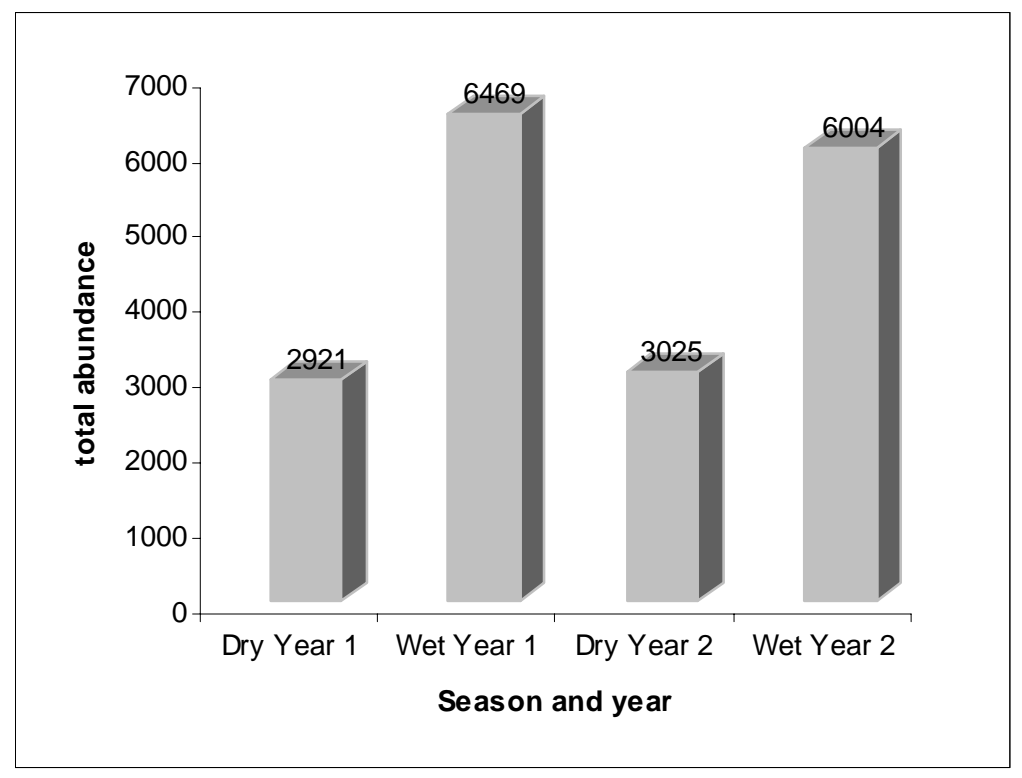

5.13 : Total number of swallowtail butterflies sampled as individuals during the dry and wet seasons of the 2-year study period from the 20 fixed transects of study sites S1, S2, S3, S4 and S5 of Rani-Garbhanga Reserve Forest, Assam, India. 


\section{Appendix 5 (Continued) :}

5.14 : Categorization of the larval feeding guild of the Papilionidae recorded in RaniGarbhanga Reserve Forest, Assam. The diet breath classification follows Endo \& Nihira (1990) and Kitahara \& Fuji (1994).

\begin{tabular}{ll}
\hline \multicolumn{1}{c}{ Larval Feeding Guild } & \multicolumn{1}{c}{ Range of host-plant use } \\
\hline Monophagous Specialist & Single species from one genus and family \\
Monophagous Generalist & Two or more species from one genus and \\
& family \\
Oligophagous Generalist & Several species from different genera, \\
& single family \\
Polyphagous Generalist & Several species from different genera and \\
& different families \\
\hline
\end{tabular}




\section{Appendix 5 (Continued):}

5.15 Total number of swallowtail butterfly individuals (Genus/Group-wise) recorded during Line transect sampling in the open/scattered and closed forest habitats of Garbhanga range during the dry and wet seasons of year 1 (2003).

\begin{tabular}{lrrrrrrrr}
\hline & \multicolumn{7}{c}{ YEAR 1 } & (2003) \\
& D-SC-T1 & D-SC-T2 & D-CL-T3 & D-CL-T4 & W-SC-T1 & W-SC-T2 & W-CL-T3 & W-CL-T4 \\
\hline Windmills(Atrophaneura sp.) & 13 & 2 & 16 & 26 & 45 & 51 & 72 & 216 \\
Batwings (Atrophaneura sp.) & 0 & 1 & 4 & 2 & 3 & 3 & 17 & 21 \\
Birdwings (Troides sp.) & 10 & 13 & 12 & 29 & 22 & 37 & 69 & 82 \\
Roses (Pachliopta sp.) & 21 & 11 & 9 & 3 & 43 & 34 & 8 & 6 \\
Dragontail (Lamproptera sp.) & 2 & 3 & 2 & 2 & 4 & 5 & 3 & 0 \\
Swordtails (Pathysa sp.) & 42 & 26 & 2 & 0 & 67 & 59 & 11 & 0 \\
Zebras (Pathysa sp.) & 43 & 67 & 4 & 0 & 57 & 81 & 12 & 0 \\
Jays (Graphium sp.) & 112 & 369 & 20 & 13 & 530 & 897 & 32 & 34 \\
Bluebottles (G. sarpedon) & 349 & 256 & 13 & 7 & 951 & 310 & 18 & 16 \\
Peacocks (Papilio sp.) & 32 & 19 & 28 & 40 & 37 & 35 & 49 & 52 \\
Mormons (Papilio sp.) & 41 & 65 & 30 & 11 & 116 & 102 & 37 & 22 \\
Helens (Papilio sp.) & 37 & 21 & 30 & 26 & 45 & 52 & 69 & 35 \\
Limes (Papilio demoleus) & 119 & 131 & 18 & 0 & 149 & 129 & 27 & 5 \\
C. Raven (Papilio castor) & 47 & 20 & 41 & 27 & 51 & 31 & 99 & 36 \\
Common Mime (Chilasa clytia) & 16 & 9 & 12 & 4 & 23 & 27 & 20 & 5 \\
\hline
\end{tabular}

5.16: Total number of swallowtail butterfly individuals (Genus/Group-wise) recorded during Line transect sampling in the open/scattered and closed forest habitats of Garbhanga range during the dry and wet seasons of year 2 (2004).

YEAR 2 (2004)

\begin{tabular}{lllllll} 
D-SC-T1 D-SC-T2 & D-CL-T3 & D-CL-T4 & W-SC-T1 & W-SC-T2 & W-CL-T3 W-CL-T4 \\
\hline
\end{tabular}

\begin{tabular}{|c|c|c|c|c|c|c|c|c|}
\hline Windmills(Atrophaneura sp.) & 5 & 4 & 22 & 32 & 37 & 63 & 90 & 344 \\
\hline Batwings(Atrophaneura sp.) & 1 & 0 & 3 & 3 & 16 & 2 & 8 & 23 \\
\hline Birdwings (Troides sp.) & 12 & 9 & 14 & 36 & 15 & 18 & 101 & 90 \\
\hline Roses (Pachliopta sp.) & 11 & 9 & 5 & 5 & 45 & 12 & 3 & 5 \\
\hline Dragontail (Lamproptera sp.) & 5 & 1 & 1 & 0 & 2 & 0 & 1 & 3 \\
\hline Swordtails (Pathysa sp.) & 29 & 31 & 1 & 0 & 54 & 50 & 7 & 0 \\
\hline Zebras (Pathysa sp.) & 31 & 41 & 3 & 0 & 65 & 61 & 10 & 0 \\
\hline Jays (Graphium sp.) & 177 & 342 & 15 & 9 & 237 & 949 & 30 & 22 \\
\hline Bluebottles (G. sarpedon) & 582 & 432 & 10 & 12 & 791 & 598 & 11 & 10 \\
\hline Peacocks (Papilio sp.) & 29 & 20 & 21 & 30 & 22 & 41 & 27 & 48 \\
\hline Mormons (Papilio sp.) & 52 & 59 & 22 & 15 & 87 & 74 & 46 & 24 \\
\hline Helens (Papilio sp.) & 29 & 16 & 19 & 22 & 42 & 36 & 31 & 37 \\
\hline Lime (Papilio demoleus) & 100 & 116 & 14 & 3 & 118 & 197 & 41 & 2 \\
\hline C. Raven (Papilio castor) & 26 & 29 & 33 & 16 & 32 & 40 & 83 & 11 \\
\hline Common Mime (Chilasa clytia) & 17 & 5 & 7 & 2 & 42 & 35 & 14 & 9 \\
\hline
\end{tabular}


5.17: Total number of swallowtail butterfly individuals (species assemblages) recorded during Line transect sampling in the open/scattered and closed forest habitats of Garbhanga range during the dry and wet seasons of year 1 (2003).

Dry and Wet seasons of Year 1 (2003)

\begin{tabular}{|c|c|c|c|c|c|c|c|c|}
\hline & D-SC-T1 & D-SC-T2 & D-CL-T3 & $\overline{\text { D-CL-T4 }}$ & $\overline{\text { W-SC-T1 }}$ & $\overline{\text { W-SC-T2 }}$ & $\overline{\text { W-CL-T3 }}$ & W-CL-T4 \\
\hline Common Windmill & 4 & 0 & 7 & 12 & 13 & 23 & 39 & 119 \\
\hline Great Windmill & 9 & 2 & 9 & 14 & 32 & 28 & 33 & 97 \\
\hline White Headed Batwing & 0 & 0 & 0 & 1 & 0 & 0 & 4 & 3 \\
\hline Lesser Batwing & 1 & 1 & 3 & 1 & 2 & 1 & 6 & 11 \\
\hline Common Batwing & 0 & 0 & 1 & 0 & 1 & 2 & 7 & 7 \\
\hline Golden Birdwing & 4 & 5 & 4 & 8 & 10 & 21 & 28 & 59 \\
\hline Common Birdwing & 6 & 8 & 8 & 21 & 12 & 16 & 41 & 23 \\
\hline Common Rose & 20 & 9 & 7 & 3 & 41 & 32 & 6 & 5 \\
\hline Crimson Rose & 1 & 2 & 2 & 0 & 2 & 2 & 2 & 4 \\
\hline Green Dragontail & 2 & 1 & 2 & 1 & 2 & 3 & 1 & 0 \\
\hline White Dragontail & 0 & 2 & 0 & 1 & 2 & 2 & 2 & 0 \\
\hline Chain Swordtail & 19 & 14 & 0 & 0 & 43 & 27 & 7 & 0 \\
\hline Five-Bar Swordtail & 23 & 12 & 2 & 0 & 24 & 32 & 4 & 0 \\
\hline Great Zebra & 31 & 43 & 3 & 0 & 37 & 56 & 8 & 0 \\
\hline Lesser Zebra & 12 & 24 & 1 & 0 & 20 & 25 & 4 & 0 \\
\hline Common Mime & 16 & 9 & 12 & 4 & 23 & 27 & 20 & 5 \\
\hline Common Jay & 72 & 197 & 13 & 8 & 389 & 594 & 26 & 19 \\
\hline Tailed Jay & 40 & 172 & 7 & 5 & 241 & 303 & 6 & 15 \\
\hline Common Peacock & 11 & 9 & 14 & 17 & 15 & 13 & 20 & 21 \\
\hline Paris Peacock & 3 & 2 & 1 & 6 & 4 & 8 & 8 & 2 \\
\hline Krishna Peacock & 18 & 8 & 13 & 27 & 18 & 14 & 21 & 30 \\
\hline Common Mormon & 30 & 47 & 19 & 7 & 83 & 64 & 22 & 13 \\
\hline Great Mormon & 11 & 18 & 11 & 4 & 33 & 38 & 15 & 9 \\
\hline Red Helen & 12 & 4 & 18 & 11 & 29 & 28 & 42 & 17 \\
\hline Yellow Helen & 25 & 17 & 12 & 15 & 16 & 24 & 27 & 18 \\
\hline Common Raven & 47 & 20 & 41 & 27 & 51 & 31 & 99 & 36 \\
\hline Common Bluebottle & 349 & 256 & 13 & 7 & 951 & 310 & 18 & 16 \\
\hline Lime Butterfly & 119 & 131 & 18 & 0 & 149 & 129 & 27 & 5 \\
\hline
\end{tabular}

\footnotetext{
$D=$ Dry season

W $=$ Wet season

$\mathrm{SC}=$ Scattered/Open forest

$\mathrm{CL}=$ Closed forest

T1 \& T2 = Transacts in open forest

T3 \& T4 = Transacts in closed forest
}

- The names of the swallowtail butterflies are given by their common names. 
5.18: Total number of swallowtail butterfly individuals (species assemblages) recorded during Line transect sampling in the open/scattered and closed forest habitats of Garbhanga range during the dry and wet seasons of year 2(2004).

Dry and Wet seasons of Year 2 (2004)

\begin{tabular}{|c|c|c|c|c|c|c|c|c|}
\hline & D-SC-T1 & D-SC-T2 & D-CL-T3 & D-CL-T4 & W-SC-T1 & W-SC-T2 & W-CL-T3 & W-CL-T4 \\
\hline Common Windmill & 2 & 1 & 10 & 11 & 16 & 13 & 27 & 123 \\
\hline Great Windmill & 3 & 3 & 12 & 21 & 21 & 50 & 63 & 163 \\
\hline White Headed Batwing & 0 & 0 & 0 & 1 & 2 & 0 & 2 & 2 \\
\hline Lesser Batwing & 1 & 1 & 1 & 1 & 8 & 1 & 4 & 16 \\
\hline Common Batwing & 0 & 0 & 2 & 1 & 6 & 1 & 2 & 5 \\
\hline Golden Birdwing & 6 & 3 & 7 & 13 & 8 & 12 & 72 & 48 \\
\hline Common Birdwing & 6 & 6 & 7 & 23 & 7 & 6 & 29 & 42 \\
\hline Common Rose & 11 & 8 & 5 & 3 & 42 & 11 & 3 & 1 \\
\hline Crimson Rose & 0 & 1 & 0 & 2 & 3 & 1 & 0 & 2 \\
\hline Green Dragontail & 4 & 1 & 1 & 0 & 2 & 0 & 0 & 2 \\
\hline White Dragontail & 1 & 0 & 0 & 0 & 0 & 0 & 1 & 1 \\
\hline Chain Swordtail & 13 & 17 & 1 & 0 & 24 & 19 & 5 & 0 \\
\hline Five-Bar Swordtail & 16 & 14 & 0 & 0 & 30 & 31 & 2 & 0 \\
\hline Great Zebra & 17 & 29 & 3 & 0 & 40 & 43 & 6 & 0 \\
\hline Lesser Zebra & 14 & 12 & 0 & 0 & 25 & 18 & 4 & 0 \\
\hline Common Mime & 17 & 5 & 7 & 2 & 42 & 35 & 14 & 9 \\
\hline Common Jay & 84 & 207 & 9 & 4 & 177 & 682 & 18 & 13 \\
\hline Tailed Jay & 93 & 135 & 6 & 5 & 60 & 267 & 12 & 9 \\
\hline Common Peacock & 15 & 8 & 10 & 12 & 18 & 18 & 9 & 14 \\
\hline Paris Peacock & 0 & 2 & 1 & 0 & 1 & 5 & 1 & 10 \\
\hline Krishna Peacock & 15 & 10 & 11 & 12 & 3 & 18 & 17 & 24 \\
\hline Common Mormon & 39 & 32 & 14 & 8 & 59 & 46 & 18 & 10 \\
\hline Great Mormon & 13 & 27 & 8 & 7 & 28 & 28 & 28 & 14 \\
\hline Red Helen & 18 & 7 & 12 & 10 & 31 & 21 & 18 & 21 \\
\hline Yellow Helen & 11 & 9 & 7 & 12 & 11 & 15 & 13 & 16 \\
\hline Common Raven & 26 & 29 & 33 & 16 & 32 & 40 & 83 & 11 \\
\hline Common Bluebottle & 582 & 432 & 10 & 12 & 791 & 598 & 11 & 10 \\
\hline Lime Butterfly & 100 & 116 & 14 & 3 & 118 & 197 & 41 & 2 \\
\hline
\end{tabular}

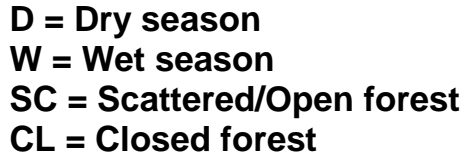

- $\quad$ The names of the swallowtail butterflies are given by their common names. 
5.19: Total number of swallowtail butterfly individuals (Genus/Group-wise) recorded during Line transect sampling in the open/scattered and closed forest habitats of Rani range during the dry and wet seasons of year 1 (2003).

YEAR 1 (2003)

\begin{tabular}{|c|c|c|c|c|c|c|c|c|}
\hline & D-SC-T1 & D-SC-T2 & D-CL-T3 & D-CL-T4 & W-SC-T1 & W-SC-T2 & W-CL-T3 & W-CL-T4 \\
\hline Windmills (Atrophaneura sp.) & 3 & 3 & 4 & 6 & 7 & 5 & 8 & 7 \\
\hline Batwings (Atrophaneura sp.) & 0 & 2 & 3 & 5 & 5 & 9 & 10 & 12 \\
\hline Birdwings (Troides sp.) & 7 & 5 & 8 & 12 & 14 & 15 & 13 & 21 \\
\hline Roses (Pachliopta sp.) & 9 & 4 & 3 & 5 & 36 & 40 & 11 & 8 \\
\hline Dragontails (Lamproptera sp.) & 0 & 4 & 5 & 8 & 0 & 10 & 11 & 6 \\
\hline Swordtails (Pathysa sp.) & 16 & 8 & 4 & 7 & 42 & 51 & 12 & 0 \\
\hline Zebras (Pathysa sp.) & 26 & 15 & 8 & 3 & 30 & 18 & 11 & 5 \\
\hline Jays (Graphium sp.) & 22 & 14 & 0 & 0 & 50 & 42 & 17 & 3 \\
\hline Bluebottles (G. sarpedon) & 21 & 16 & 0 & 0 & 72 & 46 & 12 & 0 \\
\hline Mimes (Chilasa clytia) & 5 & 3 & 6 & 4 & 2 & 5 & 10 & 14 \\
\hline Peacocks (Papilio sp.) & 0 & 4 & 2 & 2 & 10 & 8 & 9 & 3 \\
\hline Mormons (Papilio sp.) & 33 & 27 & 39 & 22 & 49 & 43 & 61 & 57 \\
\hline Helens (Papilio sp.) & 0 & 17 & 26 & 25 & 17 & 20 & 46 & 47 \\
\hline Limes (Papilio demoleus) & 15 & 28 & 0 & 0 & 29 & 52 & 19 & 0 \\
\hline Ravens (Papilio castor) & 0 & 18 & 21 & 30 & 23 & 32 & 41 & 40 \\
\hline
\end{tabular}

5.20 : Total number of swallowtail butterfly individuals (Species assemblages) recorded during Line transect sampling in the open/scattered and closed forest habitats of Rani range during the dry and wet seasons of year 2 (2004).

YEAR 2 (2004)

\begin{tabular}{|c|c|c|c|c|c|c|c|c|}
\hline & D-SC-T1 & D-SC-T2 & D-CL-T3 & D-CL-T4 & W-SC-T1 & W-SC-T2 & W-CL-T3 & W-CL-T4 \\
\hline Windmills (Atrophaneura sp.) & 5 & 0 & 2 & 1 & 4 & 2 & 4 & 6 \\
\hline Batwings (Atrophaneura sp.) & 0 & 1 & 6 & 2 & 3 & 7 & 4 & 14 \\
\hline Birdwings (Troides sp.) & 4 & 6 & 10 & 9 & 20 & 12 & 17 & 14 \\
\hline Roses (Pachliopta sp.) & 3 & 5 & 1 & 0 & 29 & 33 & 9 & 7 \\
\hline Dragontails (Lamproptera sp.) & 0 & 3 & 7 & 2 & 4 & 7 & 5 & 2 \\
\hline Swordtails (Pathysa sp.) & 10 & 14 & 3 & 2 & 37 & 22 & 7 & 0 \\
\hline Zebras (Pathysa sp.) & 13 & 10 & 4 & 2 & 27 & 25 & 8 & 3 \\
\hline Jays (Graphium sp.) & 10 & 8 & 5 & 0 & 41 & 27 & 20 & 0 \\
\hline Bluebottles (G.sarpedon) & 14 & 11 & 0 & 0 & 51 & 30 & 8 & 0 \\
\hline C. Mime (Chilasa clytia) & 0 & 0 & 10 & 3 & 0 & 1 & 17 & 11 \\
\hline Peacocks (Papilio sp.) & 0 & 1 & 4 & 6 & 7 & 1 & 5 & 7 \\
\hline Mormons (Papilio sp.) & 25 & 15 & 40 & 14 & 50 & 21 & 47 & 40 \\
\hline Helens (Papilio sp.) & 0 & 11 & 14 & 20 & 22 & 41 & 32 & 30 \\
\hline Limes (Papilio demoleus) & 21 & 17 & 0 & 0 & 40 & 67 & 10 & 0 \\
\hline Ravens (Papilio castor) & 7 & 19 & 25 & 11 & 26 & 47 & 54 & 67 \\
\hline
\end{tabular}


5.21: Total number of swallowtail butterfly individuals (species assemblages) recorded during Line transect sampling in the open/scattered and closed forest habitats of Rani range during the dry and wet seasons of year 1 (2003).

Dry and Wet seasons of Year 1 (2003)

\begin{tabular}{|c|c|c|c|c|c|c|c|c|}
\hline & D-SC-T1 & D-SC-T2 & D-CL-T3 & D-CL-T4 & W-SC-T1 & W-SC-T2 & W-CL-T3 & W-CL-T4 \\
\hline Common Windmill & 2 & 3 & 1 & 4 & 3 & 4 & 5 & 3 \\
\hline Great Windmill & 1 & 0 & 3 & 2 & 4 & 1 & 3 & 4 \\
\hline Lesser Batwing & 0 & 0 & 1 & 3 & 2 & 3 & 2 & 5 \\
\hline Common Batwing & 0 & 1 & 2 & 2 & 3 & 6 & 8 & 7 \\
\hline Golden Birdwing & 2 & 3 & 4 & 5 & 8 & 6 & 4 & 11 \\
\hline Common Birdwing & 5 & 2 & 4 & 7 & 6 & 9 & 9 & 10 \\
\hline Common Rose & 9 & 3 & 3 & 4 & 36 & 39 & 9 & 8 \\
\hline Crimson Rose & 0 & 1 & 0 & 1 & 0 & 1 & 2 & 0 \\
\hline Green Dragontail & 0 & 2 & 3 & 6 & 0 & 3 & 8 & 4 \\
\hline White Dragontail & 0 & 2 & 2 & 2 & 0 & 7 & 3 & 2 \\
\hline Chain Swordtail & 11 & 3 & 3 & 4 & 19 & 32 & 7 & 0 \\
\hline Five-Bar Swordtail & 5 & 5 & 1 & 3 & 23 & 19 & 5 & 0 \\
\hline Great Zebra & 14 & 10 & 3 & 2 & 17 & 12 & 8 & 3 \\
\hline Lesser Zebra & 12 & 5 & 5 & 1 & 13 & 6 & 3 & 2 \\
\hline Common Jay & 16 & 8 & 0 & 0 & 38 & 27 & 11 & 3 \\
\hline Tailed Jay & 6 & 6 & 0 & 0 & 12 & 15 & 6 & 0 \\
\hline Common Peacock & 0 & 3 & 2 & 1 & 7 & 5 & 4 & 1 \\
\hline Krishna Peacock & 0 & 1 & 0 & 1 & 3 & 3 & 5 & 2 \\
\hline Common Mormon & 16 & 10 & 20 & 10 & 27 & 25 & 14 & 23 \\
\hline Great Mormon & 17 & 17 & 19 & 12 & 22 & 18 & 47 & 34 \\
\hline Red Helen & 0 & 8 & 9 & 12 & 6 & 10 & 19 & 18 \\
\hline Yellow Helen & 0 & 9 & 17 & 13 & 11 & 10 & 27 & 29 \\
\hline Common Bluebottle & 21 & 16 & 0 & 0 & 72 & 46 & 12 & 0 \\
\hline Lime Butterfly & 15 & 28 & 0 & 0 & 29 & 52 & 19 & 0 \\
\hline Common Mime & 5 & 3 & 6 & 4 & 2 & 5 & 10 & 14 \\
\hline Common Raven & 0 & 18 & 21 & 30 & 23 & 32 & 41 & 40 \\
\hline
\end{tabular}

$D=$ Dry season

W $=$ Wet season

SC $=$ Scattered/Open forest

$\mathrm{CL}=$ Closed forest

T1 \& T2 = Transacts in open forest

T3 \& T4 = Transacts in closed forest

- The names of the swallowtail butterflies are given by their common names. 
5.22: Total number of swallowtail butterfly individuals (species assemblages) recorded during Line transects sampling in the open/scattered and closed forest habitats of Rani range during the dry and wet seasons of year 2 (2004).

\begin{tabular}{|c|c|c|c|c|c|c|c|c|}
\hline \multicolumn{9}{|c|}{ Dry and Wet seasons of Year 2 (2004) } \\
\hline & D-SC-T1 & D-SC-T2 & D-CL-T3 & D-CL-T4 & W-SC-T1 & W-SC-T2 & W-CL-T3 & W-CL-T4 \\
\hline Common Windmill & 3 & 0 & 2 & 1 & 4 & 2 & 3 & 4 \\
\hline Great Windmill & 2 & 0 & 0 & 0 & 0 & 0 & 1 & 2 \\
\hline Lesser Batwing & 0 & 0 & 2 & 0 & 0 & 2 & 0 & 4 \\
\hline Common Batwing & 0 & 1 & 4 & 2 & 3 & 5 & 4 & 10 \\
\hline Golden Birdwing & 3 & 1 & 3 & 4 & 4 & 5 & 8 & 6 \\
\hline Common Birdwing & 1 & 5 & 7 & 5 & 16 & 7 & 9 & 8 \\
\hline Common Rose & 3 & 5 & 1 & 0 & 27 & 33 & 9 & 7 \\
\hline Crimson Rose & 0 & 0 & 0 & 0 & 2 & 0 & 0 & 0 \\
\hline Green Dragontail & 0 & 1 & 1 & 0 & 3 & 2 & 2 & 0 \\
\hline White Dragontail & 0 & 2 & 6 & 2 & 1 & 5 & 3 & 2 \\
\hline Chain Swordtail & 4 & 6 & 2 & 2 & 27 & 14 & 3 & 0 \\
\hline Five-Bar Swordtail & 6 & 8 & 1 & 0 & 10 & 8 & 4 & 0 \\
\hline Great Zebra & 7 & 4 & 3 & 2 & 18 & 10 & 3 & 1 \\
\hline Lesser Zebra & 6 & 6 & 1 & 0 & 9 & 15 & 5 & 2 \\
\hline Common Jay & 8 & 5 & 4 & 0 & 31 & 16 & 13 & 0 \\
\hline Tailed Jay & 2 & 3 & 1 & 0 & 10 & 11 & 7 & 0 \\
\hline Common Peacock & 0 & 1 & 3 & 4 & 4 & 1 & 2 & 4 \\
\hline Krishna Peacock & 0 & 0 & 1 & 2 & 3 & 0 & 3 & 3 \\
\hline Common Mormon & 11 & 8 & 13 & 6 & 35 & 8 & 14 & 11 \\
\hline Great Mormon & 14 & 7 & 27 & 8 & 15 & 13 & 33 & 29 \\
\hline Red Helen & 0 & 5 & 7 & 9 & 8 & 19 & 10 & 14 \\
\hline Yellow Helen & 0 & 6 & 7 & 11 & 14 & 22 & 22 & 16 \\
\hline Common Bluebottle & 14 & 11 & 0 & 0 & 51 & 30 & 8 & 0 \\
\hline Lime Butterfly & 21 & 17 & 0 & 0 & 40 & 67 & 10 & 0 \\
\hline Common Mime & 0 & 0 & 10 & 3 & 0 & 1 & 17 & 11 \\
\hline Common Raven & 7 & 19 & 25 & 11 & 26 & 47 & 54 & 67 \\
\hline
\end{tabular}

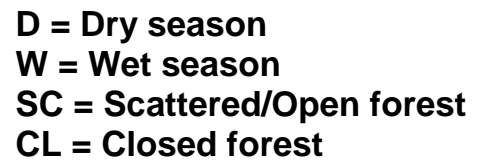

T1 \& T2 = Transacts in open forest T3 \& T4 = Transacts in closed forest

- The names of the swallowtail butterflies are given by their common names. 


\section{Appendix 5 (Continued):}

\section{Summary of multivariate analyses}

\subsection{3 : Garbhanga range:}

5.23.1 : CCA (formula $=\mathbf{k m} 2 \sim$ lat. + long. + alt. + forest + season + year + class + rain + relative humidity + temp $^{\mathrm{r}} \cdot$ data $=\mathbf{k m} 2 \mathrm{env}$ )

\begin{tabular}{lcl}
\hline \multicolumn{2}{c}{ Inertia } & Rank \\
\hline Total & 0.7119 & \\
Constrained & 0.6165 & 6 \\
Unconstrained & 0.0954 & 9 \\
\hline
\end{tabular}

Note: Inertia is mean squared contingency coefficient

Some constraints were aliased because they were collinear (redundant)

\subsection{2 : Eigenvalues for constrained axes:}

\begin{tabular}{llllll}
\hline CCA1 & CCA2 & CCA3 & CCA4 & CCA5 & CCA6 \\
\hline 0.444800 & 0.085232 & 0.063837 & 0.014316 & 0.005352 & 0.002960
\end{tabular}

\subsection{3 : Eigenvalues for unconstrained axes:}

\begin{tabular}{llllllll}
\hline CA1 & CA2 & CA3 & CA4 & CA5 & CA6 & CA7 & CA8 \\
\hline 0.0443515 & 0.0161758 & 0.0104091 & 0.0082800 & 0.0054979 & 0.0052432 & 0.0023398 & 0.0021577
\end{tabular}

CA 9

0.0009469

$>\mathrm{Km} 2 . p 12<-$ plot $(\mathrm{km} 2 . c c a$, scaling=TRUE)

$>$ Anova (km2.cca)

\subsection{4 : Permutation test for cca under direct model:}

Model: cca (formula $=\mathrm{km} 2 \sim$ lat + long + alt + forest + season + year + class + rain + relative humidity + temp $^{\text {r. }}$ data $=\mathrm{km} 2 \mathrm{env}$ )

\begin{tabular}{|c|c|c|c|c|c|c|}
\hline & Df & Chisq & $\mathbf{F}$ & N.Perm & $\operatorname{Pr}(>F)$ & \\
\hline Model & 6 & 0.6165 & 9.6932 & 200 & $<0.005$ & $* * *$ \\
\hline Residual & 9 & 0.0954 & & & & \\
\hline
\end{tabular}




\subsection{4: Rani range:}

5.24.1 : CCA (formula $=\mathbf{k m 8} \sim$ lat + long + alt + forest. + season. + year + class + rain + relative humidity + temp $^{\mathrm{r}} \cdot$ data $\left.=\mathbf{k m 8 e n v}\right)$

\begin{tabular}{lrl}
\hline & \multicolumn{1}{c}{ Inertia } & Rank \\
\hline Total & 0.42122 & \\
Constrained & 0.32978 & 6 \\
Unconstrained & 0.09144 & 9 \\
\hline
\end{tabular}

Inertia is mean squared contingency coefficient

Some constraints were aliased because they were collinear (redundant)

\subsection{2 : Eigenvalues for constrained axes:}

\begin{tabular}{cccccl}
\hline CCA1 & CCA2 & CCA3 & CCA4 & CCA5 & CCA6 \\
\hline 0.255326 & 0.036822 & 0.017222 & 0.008136 & 0.006708 & 0.005569 \\
\hline
\end{tabular}

\subsection{3 : Eigenvalues for unconstrained axes:}

\begin{tabular}{llllllll}
\hline CA1 & CA2 & CA3 & CA4 & CA5 & CA6 & CA7 & CA8 \\
\hline 0.019951 & 0.017955 & 0.012911 & 0.011875 & 0.010739 & 0.007223 & 0.004451 & 0.003432 \\
\hline CA9 & & & & & & & \\
\hline 0.002904 & & & & & & \\
\hline
\end{tabular}

$>$ Km8.pl2<-plot (km8.cca, scaling=TRUE)

$>$ Anova (km8.cca)

\subsection{4 : Permutation test for cca under direct model}

Model: cca (formula $=\mathrm{km} 8 \sim$ lat + long + alt + forest. + season. + year + class + rain + relative humidity + temp $^{\text {r. }}$ data $=\mathrm{km} 8 \mathrm{env}$ )

\begin{tabular}{lccccc}
\hline & Df & Chisq & F & N.Perm & $\operatorname{Pr}(>\mathbf{F})$ \\
\hline Model & 6 & 0.3298 & 5.4097 & 200 & $<0.005 * * *$ \\
Residual & 9 & 0.0914 & & & \\
\hline Significance codes: $0^{\text {'***' }} 0.001^{\text {'**' }} 0.01^{\text {'*' }} 0.05^{\text {'.' } 0.1^{\prime \prime} \text { ' } 1}$
\end{tabular}




\section{Appendix 5 (Continued):}

5.25: Diversity parameters analysed for the swallowtail butterfly species assemblages from the pooled abundance data of 12 transects of 3 study sites (S1, S2 \& S3) at Garbhanga range during dry and wet seasons of $2003 \& 2004$ using the program 'R'.

\begin{tabular}{|c|c|c|c|c|c|c|c|c|c|}
\hline Forest & Season & Year & $\begin{array}{l}\mathbf{H}^{\prime} \\
\text { (Shannon) }\end{array}$ & Simpson & Inv.Simpson & $\begin{array}{l}\mathbf{R}^{2} \\
\text { (Rarefaction) }\end{array}$ & $\begin{array}{c}\text { Fisher's } \\
\text { Alpha } \\
(\alpha) \\
\end{array}$ & $\mathbf{S}$ & $\begin{array}{c}\text { Pielou's } \\
\text { Evenness } \\
\mathbf{J}\end{array}$ \\
\hline $\mathrm{SC}$ & Dry & 1 & 2.766497 & 0.91961 & 12.4393 & 1.92182 & 5.536415 & 24 & 0.870501 \\
\hline $\mathrm{SC}$ & Dry & 1 & 2.1607 & 0.809174 & 5.240385 & 1.810469 & 4.950827 & 24 & 0.679882 \\
\hline $\mathrm{CL}$ & Dry & 1 & 2.79747 & 0.918866 & 12.32532 & 1.923263 & 6.984631 & 24 & 0.880246 \\
\hline $\mathrm{CL}$ & Dry & 1 & 2.731795 & 0.922763 & 12.94717 & 1.927569 & 5.996335 & 21 & 0.897282 \\
\hline $\mathrm{SC}$ & Wet & 1 & 2.29681 & 0.824332 & 5.692563 & 1.825054 & 4.514152 & 25 & 0.713544 \\
\hline $\mathrm{SC}$ & Wet & 1 & 2.112108 & 0.768853 & 4.326255 & 1.769397 & 4.523184 & 26 & 0.648264 \\
\hline $\mathrm{CL}$ & Wet & 1 & 2.832178 & 0.918445 & 12.26164 & 1.920293 & 6.120917 & 27 & 0.85932 \\
\hline $\mathrm{CL}$ & Wet & 1 & 2.488723 & 0.879519 & 8.300028 & 1.881236 & 4.406428 & 21 & 0.817443 \\
\hline $\mathrm{SC}$ & Dry & 2 & 2.540552 & 0.883759 & 8.60283 & 1.885884 & 4.948487 & 22 & 0.821908 \\
\hline $\mathrm{SC}$ & Dry & 2 & 2.126201 & 0.796058 & 4.903363 & 1.797465 & 5.080599 & 24 & 0.669026 \\
\hline $\mathrm{CL}$ & Dry & 2 & 2.766722 & 0.918348 & 12.24711 & 1.923914 & 6.800231 & 22 & 0.895077 \\
\hline CL & Dry & 2 & 2.637316 & 0.916886 & 12.03164 & 1.922311 & 5.481607 & 19 & 0.895694 \\
\hline $\mathrm{SC}$ & Wet & 2 & 2.684602 & 0.897216 & 9.729183 & 1.898507 & 5.072187 & 25 & 0.834019 \\
\hline $\mathrm{SC}$ & Wet & 2 & 1.898288 & 0.711689 & 3.46848 & 1.712205 & 4.126455 & 24 & 0.597312 \\
\hline $\mathrm{CL}$ & Wet & 2 & 2.635105 & 0.900399 & 10.04003 & 1.9024 & 5.704034 & 25 & 0.818641 \\
\hline $\mathrm{CL}$ & Wet & 2 & 2.337819 & 0.844023 & 6.411216 & 1.845544 & 4.839412 & 23 & 0.745598 \\
\hline
\end{tabular}

KEY :

Sites 1-4 - $\rightarrow$ Dry season of year 1 (2003)

Sites 5-8 $\rightarrow$ Wet season of year 1

Sites 9-12 $\rightarrow$ Dry season of year 2 (2004)

Sites13-16- $\rightarrow$ Wet season of year 2

- All the sites (1-8 for year 1 and 9-16 for year 2) represent the 12 pooled transects and each site or transect is sampled twice in a year - e.g. site 1 sampled during dry season of year 1 is resampled as site 5 during wet season of year 1 . 
5.26: Diversity parameters analysed for the swallowtail butterfly species assemblages from the pooled abundance data of 8 transects of 2 study sites (S4 \& S5) at Rani range during dry and wet seasons of $2003 \& 2004$ using the program 'R'.

\begin{tabular}{|c|c|c|c|c|c|c|c|c|c|}
\hline Forest & Season & Year & $\begin{array}{l}\text { H' }^{\prime} \\
\text { (Shannon) }\end{array}$ & Simpson & Inv.Simpson & $\begin{array}{l}\text { R2 } \\
\text { (Rarefaction) }\end{array}$ & $\begin{array}{l}\text { Fisher's } \\
\text { Alpha }(\alpha)\end{array}$ & \begin{tabular}{l}
\multicolumn{1}{c}{$\mathrm{S}$} \\
(Species \\
richness)
\end{tabular} & $\begin{array}{c}\text { Pielou's } \\
\text { Evenness } \\
\mathbf{J} \\
\end{array}$ \\
\hline $\mathrm{SC}$ & Dry & 1 & 2.344775 & 0.893133 & 9.357441 & 1.9009 & 3.754533 & 13 & 0.91416 \\
\hline $\mathrm{SC}$ & Dry & 1 & 2.715704 & 0.918877 & 12.32701 & 1.927975 & 7.438584 & 20 & 0.906524 \\
\hline CL & Dry & 1 & 2.433068 & 0.880046 & 8.336538 & 1.888759 & 6.342413 & 18 & 0.841784 \\
\hline CL & Dry & 1 & 2.688619 & 0.916565 & 11.98539 & 1.926316 & 7.731516 & 20 & 0.897483 \\
\hline $\mathrm{SC}$ & Wet & 1 & 2.643113 & 0.914231 & 11.65919 & 1.917761 & 4.717766 & 19 & 0.897663 \\
\hline $\mathrm{SC}$ & Wet & 1 & 2.748725 & 0.919893 & 12.48323 & 1.923431 & 6.080758 & 23 & 0.876648 \\
\hline CL & Wet & 1 & 2.722391 & 0.904192 & 10.43752 & 1.908539 & 6.59604 & 23 & 0.86825 \\
\hline CL & Wet & 1 & 2.440346 & 0.885123 & 8.704968 & 1.890392 & 5.098051 & 18 & 0.844302 \\
\hline $\mathrm{SC}$ & Dry & 2 & 2.344396 & 0.886939 & 8.844765 & 1.899793 & 4.7001 & 13 & 0.914013 \\
\hline $\mathrm{SC}$ & Dry & 2 & 2.66136 & 0.923667 & 13.10048 & 1.93632 & 6.909254 & 17 & 0.939343 \\
\hline CL & Dry & 2 & 2.490563 & 0.874349 & 7.958549 & 1.883553 & 7.686763 & 20 & 0.83137 \\
\hline CL & Dry & 2 & 2.366983 & 0.887634 & 8.899471 & 1.903206 & 5.862115 & 14 & 0.896905 \\
\hline $\mathrm{SC}$ & Wet & 2 & 2.664038 & 0.914909 & 11.75207 & 1.918674 & 5.506727 & 21 & 0.875027 \\
\hline $\mathrm{SC}$ & Wet & 2 & 2.66604 & 0.916692 & 12.00367 & 1.921345 & 5.177435 & 19 & 0.905449 \\
\hline CL & Wet & 2 & 2.638599 & 0.90306 & 10.3157 & 1.908812 & 6.499026 & 21 & 0.866671 \\
\hline CL & Wet & 2 & 2.441854 & 0.885716 & 8.750145 & 1.892976 & 5.34977 & 17 & 0.861867 \\
\hline
\end{tabular}

\section{KEY :}

Sites 1-4 - $\rightarrow$ Dry season of year $1(2003)$

Sites $5-8 \rightarrow$ Wet season of year 1

Sites 9-12 $\rightarrow$ Dry season of year 2 (2004)

Sites13-16- $\rightarrow$ Wet season of year 2

- All the sites (1-8 for year 1 and 9-16 for year 2) represent the 8 pooled transects and each site or transect is sampled twice in a year - e.g. site 1 sampled during dry season of year 1 is resampled as site 5 during wet season of year 1 .

- Sites $1 \& 2$ represent transects $\mathrm{T} 1 \& \mathrm{~T} 2$ in scattered forest and sites $3 \& 4$ represent transacts T3 \& T4 in closed forest during dry season of year 1 and the continuum. 


\section{PHOTO SECTION}
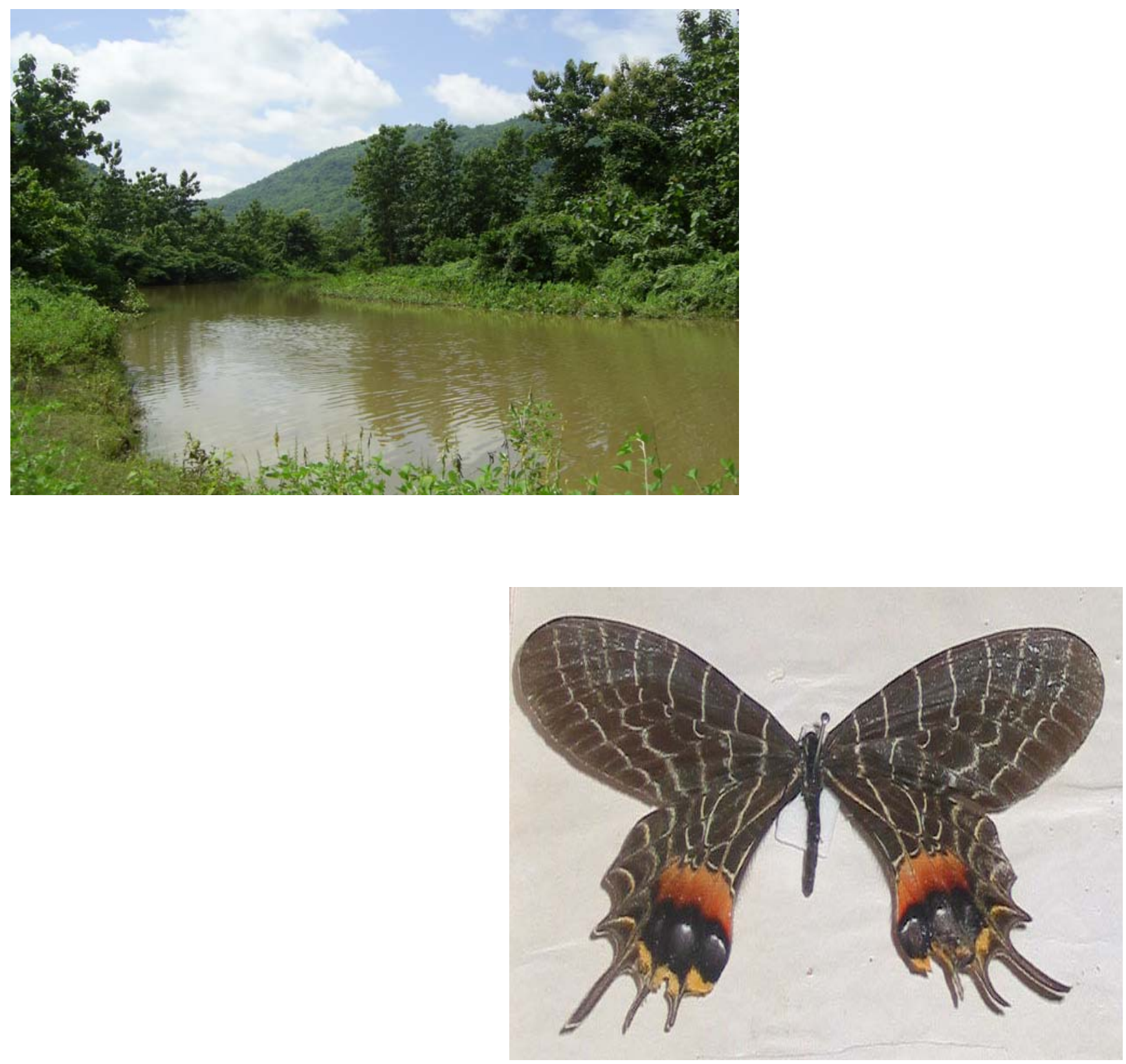


\section{PAPILIONIDAE PHOTO SECTION}

1. Photos of identified species of Papilionidae upto nominate sub-species level in Rani-Garbhanga Reserve Forest, Assam, India during the period of field survey from 2000-2002.

1.1 The red-bodied group - Windmills and Batwings (Atrophaneura sp.), Roses (Pachliopta sp.) and Birdwings (Troides sp.)

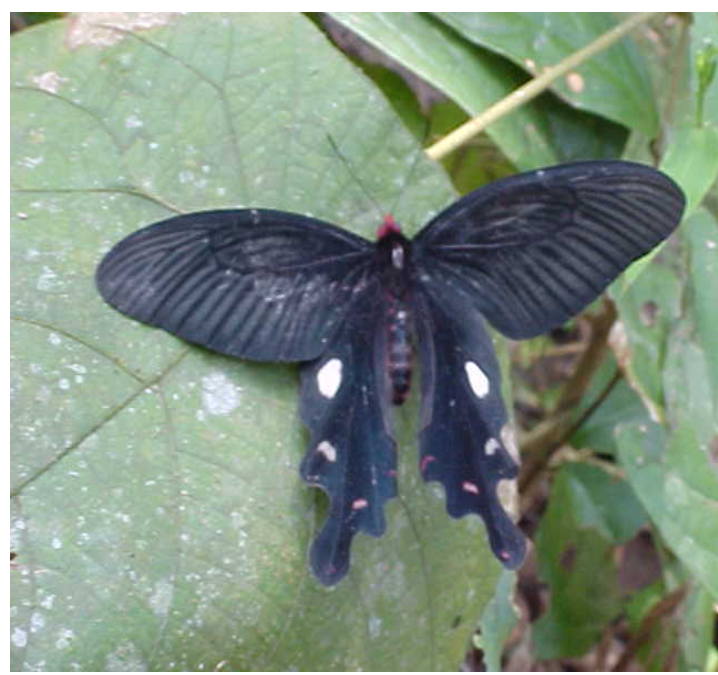

GREAT WINDMILL (Atrophaneura dasarada dasarada) (MALE)

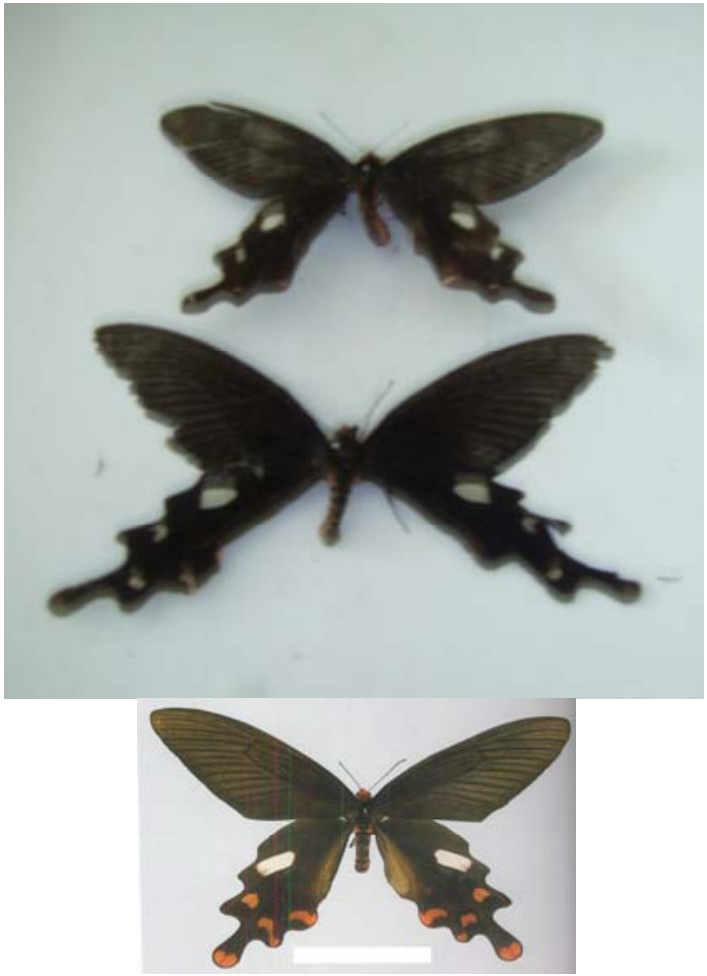

COMMON WINDMILL (Atrophaneura polyeuctes polyeuctes)

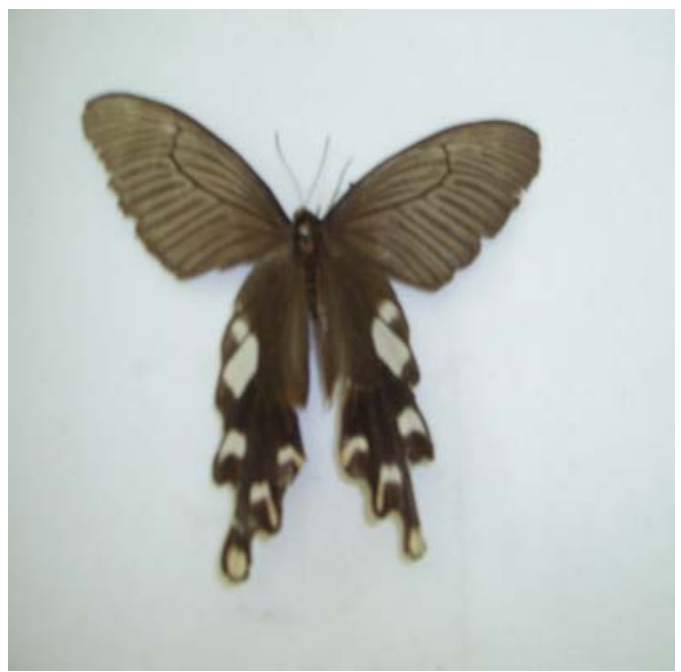

COMMON WINDMILL (Atrophaneura species)

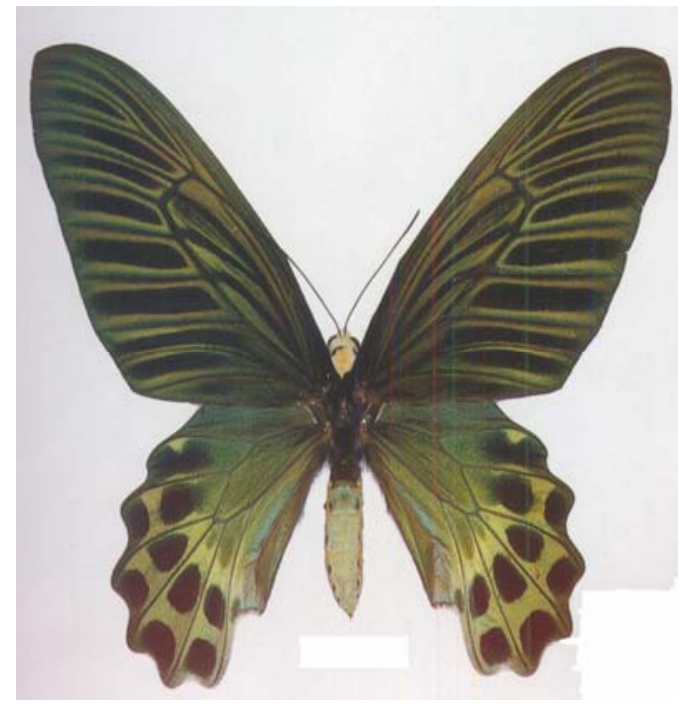

WHITE-HEAD BATWING (Atrophaneura sycorax) 


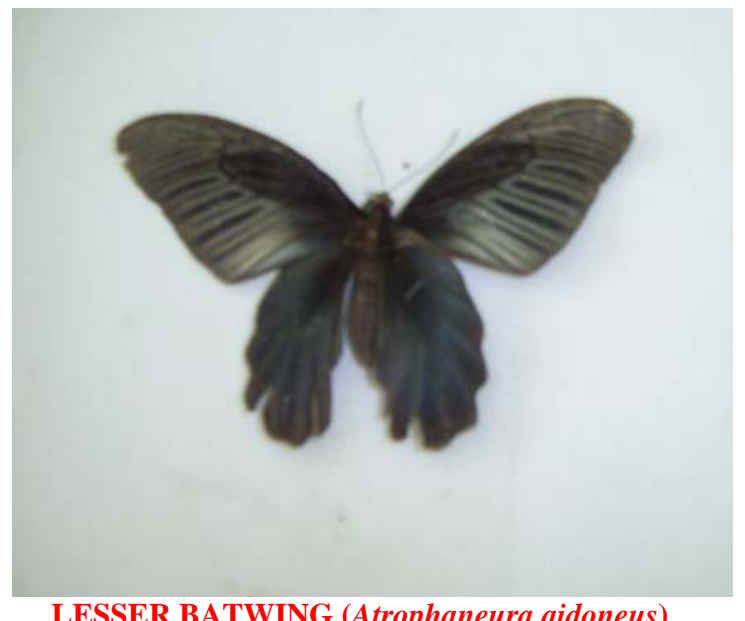

LESSER BATWING (Atrophaneura aidoneus)

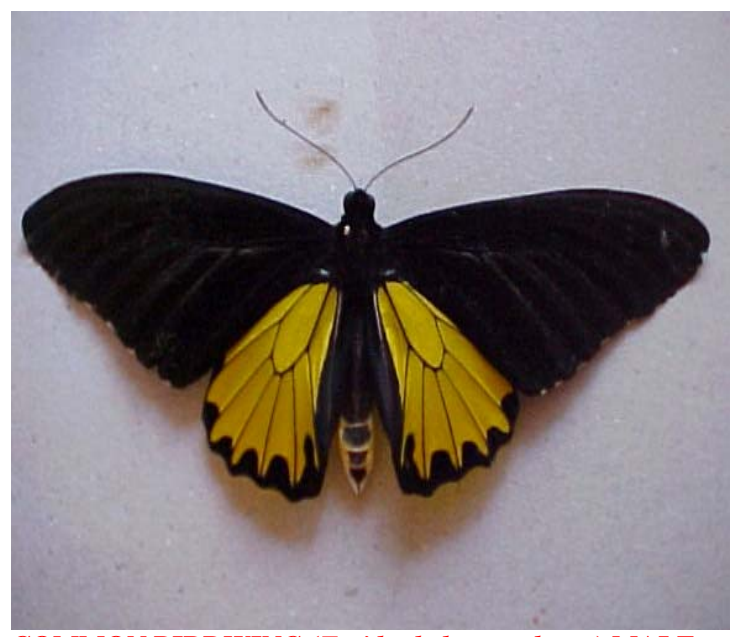

COMMON BIRDWING (Troides helena cerberus) MALE

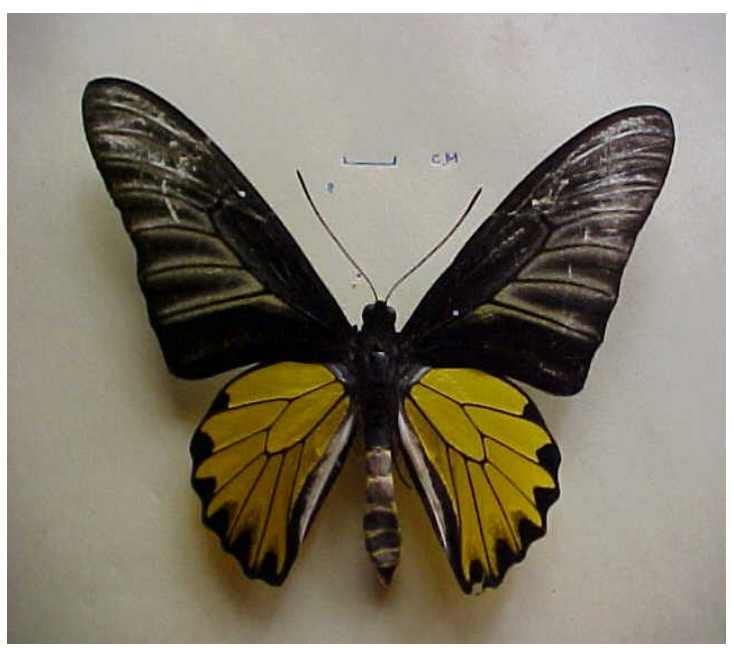

GOLDEN BIRDWING (Troides aeacus aeacus) MALE
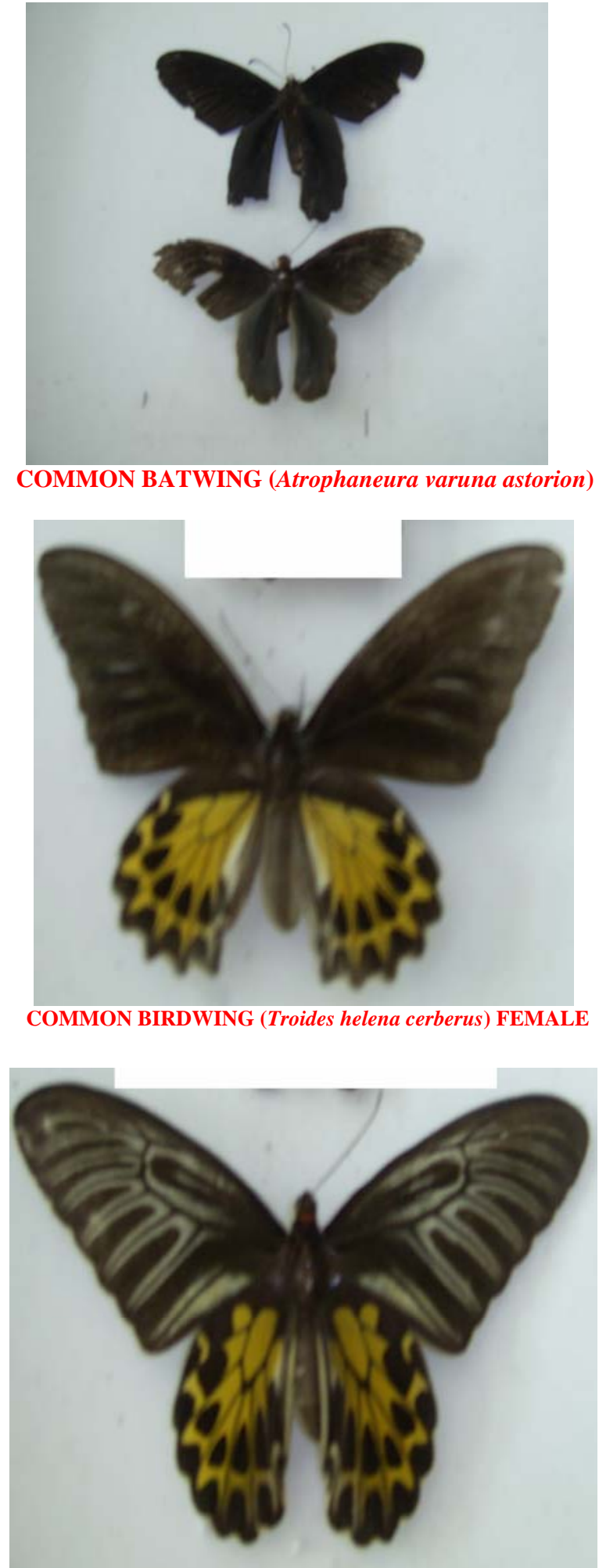

GOLDEN BIRDWING (Troides aeacus aeacus) FEMALE 

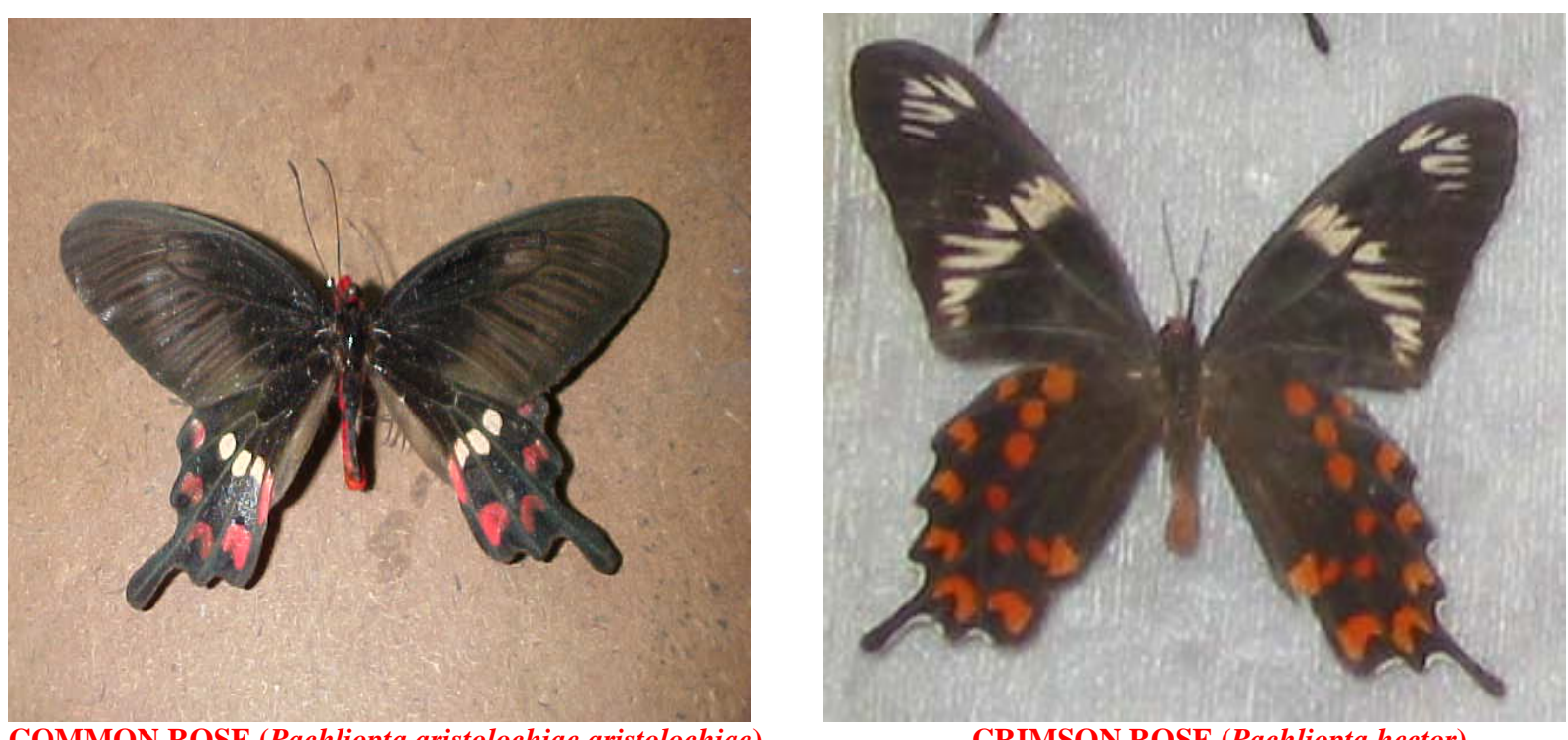

CRIMSON ROSE (Pachliopta hector)

1.2 Black-bodied group - Mormons, Helens, Peacocks, Limes (Papilio sp.) and Mimes (Chilasa sp.)

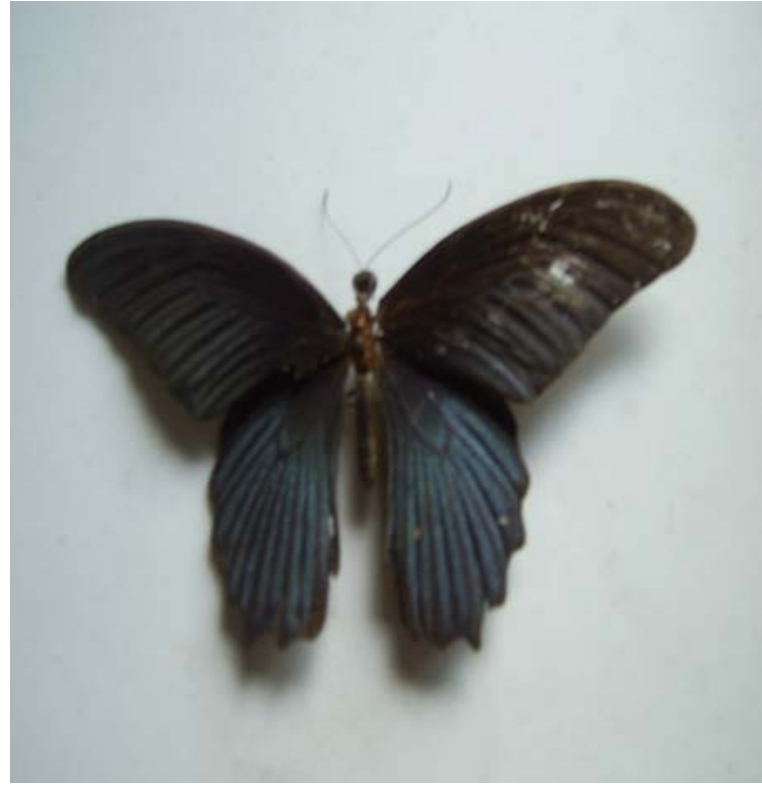

GREAT MORMON (Papilio memnon agenor) MALE

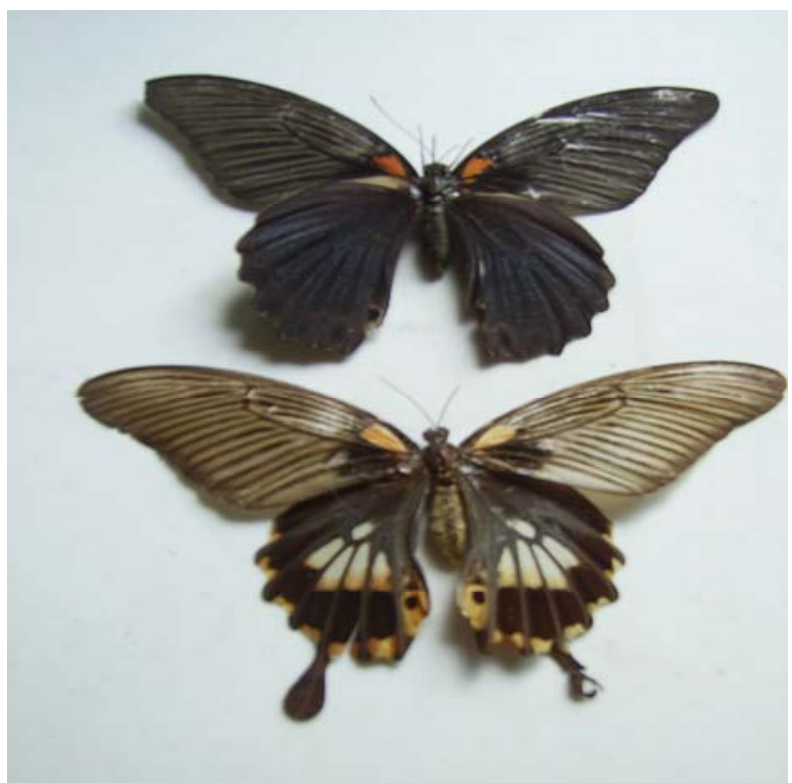

GREAT MORMON (Papilio memnon agenor) Polymorphic females 


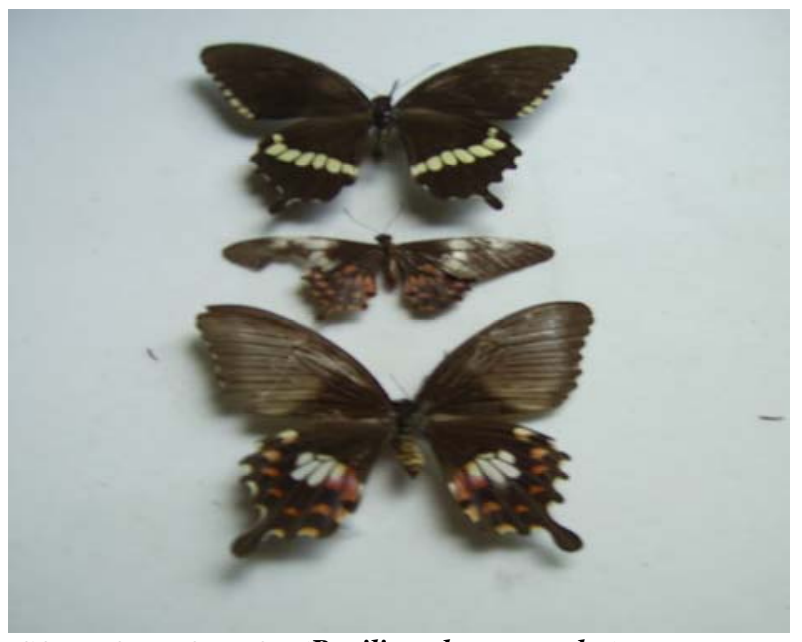

COMMON MORMON (Papilio polytes romulus) UPPER 1 - MALE, MIDDLE 2 \& LOWER 3 - POLYMORPHIC FEMALES

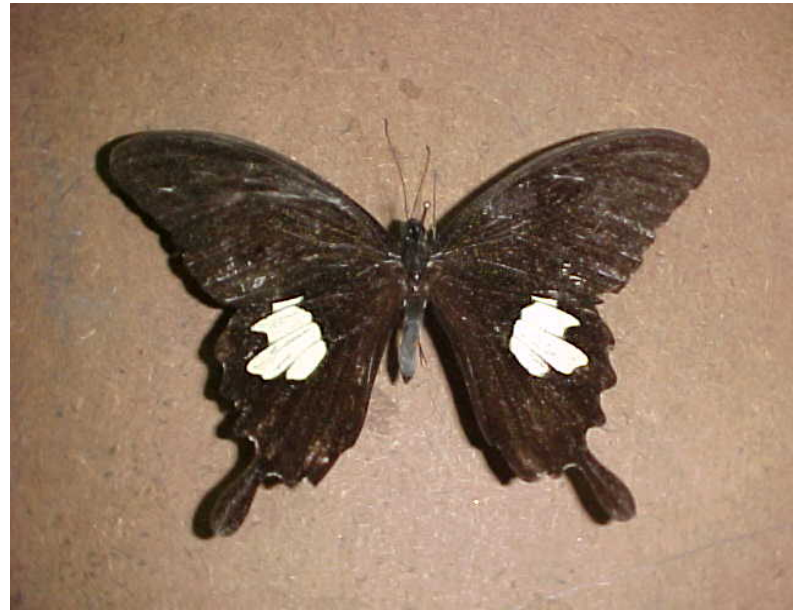

YELLOW HELEN (Papilio nephelus chaon)

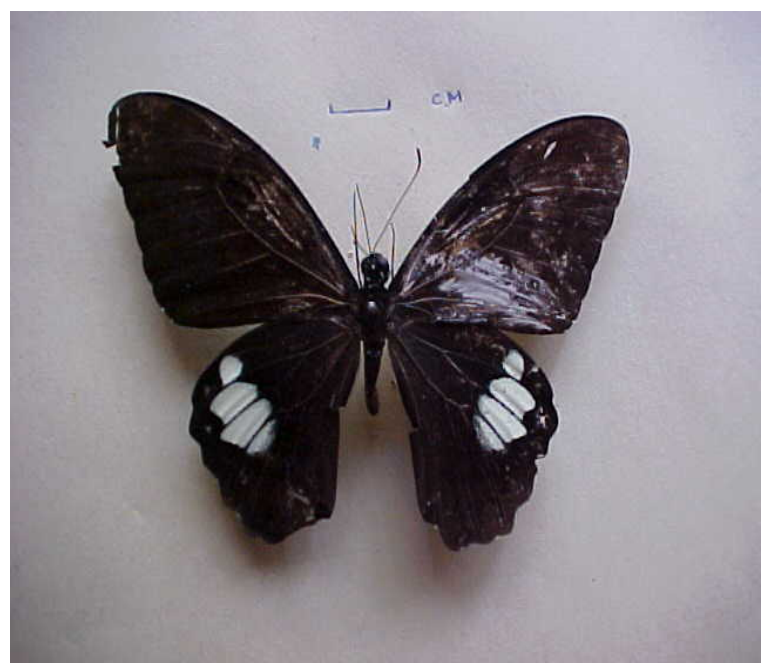

COMMON RAVEN (Papilio castor castor) MALE

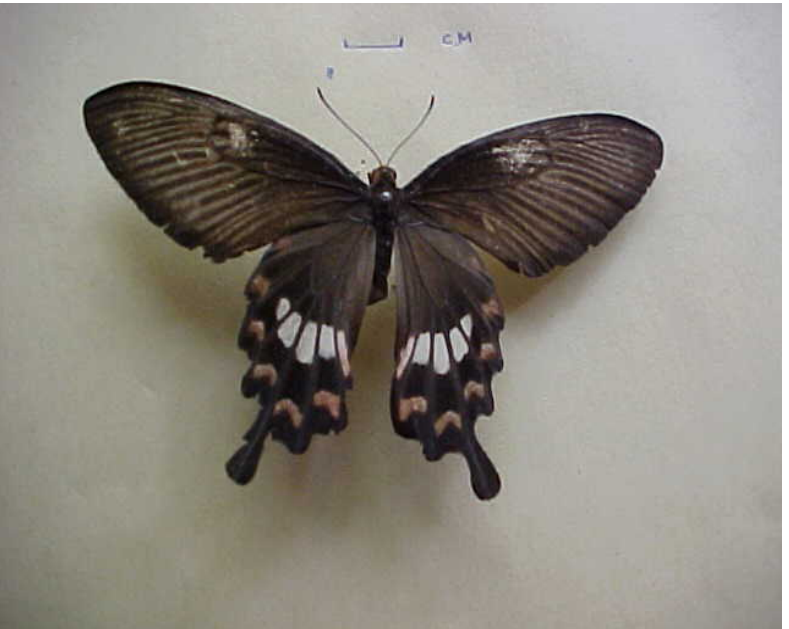

COMMON MORMON (Papilo polytes stichius) FEMALE
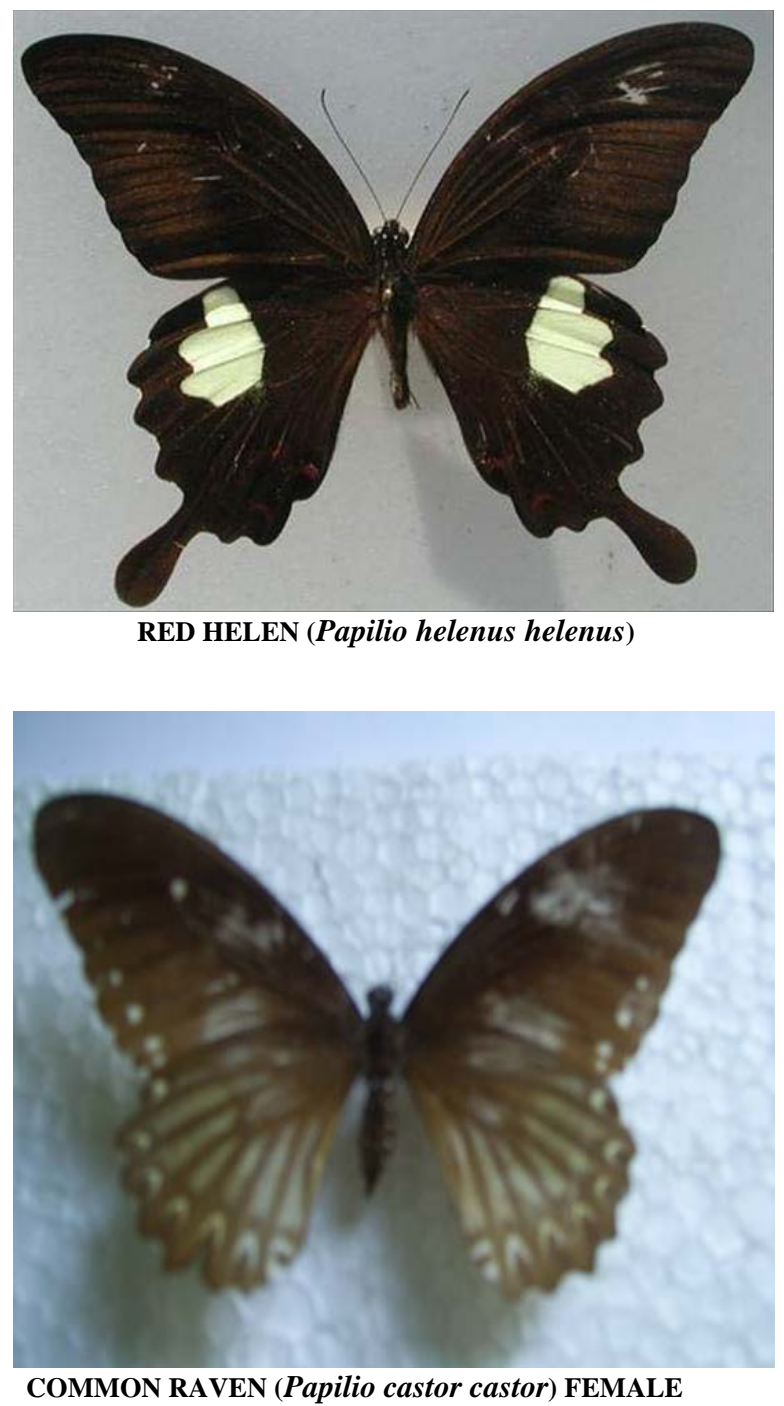


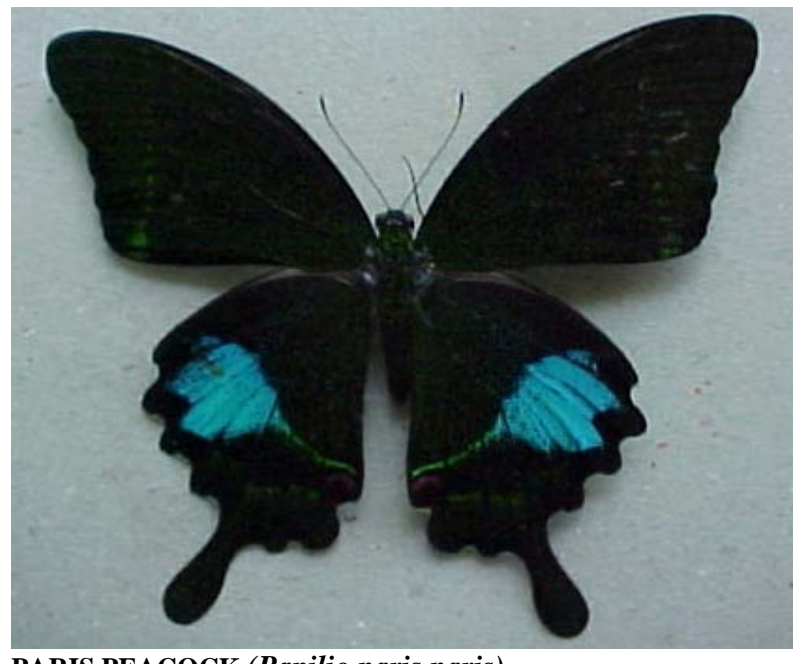

PARIS PEACOCK (Papilio paris paris)

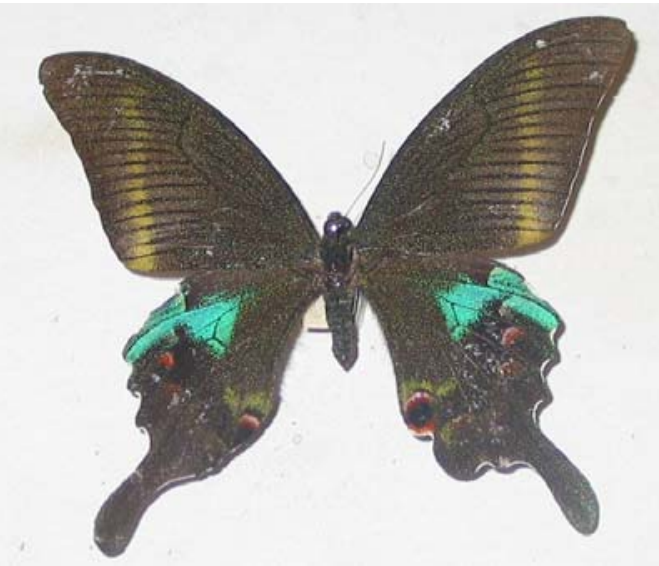

KRISHNA PEACOCK (Papilio krishna krishna)

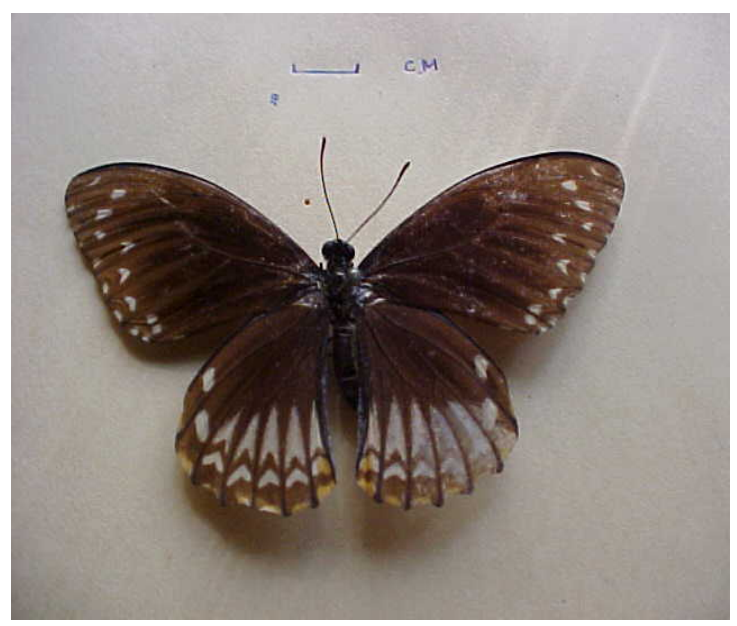

COMMON MIME (Chilasa clytia clytia)

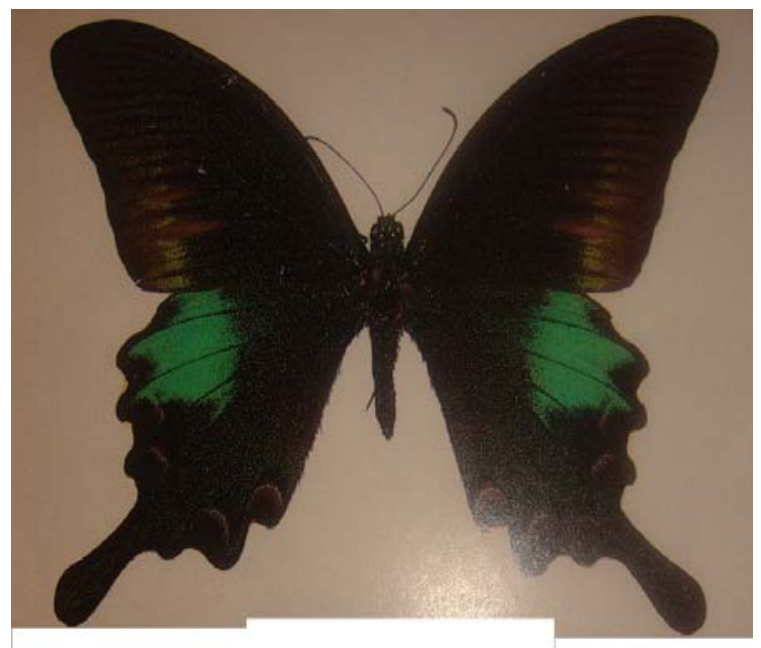

COMMON PEACOCK (Papilio polyctor ganesa)

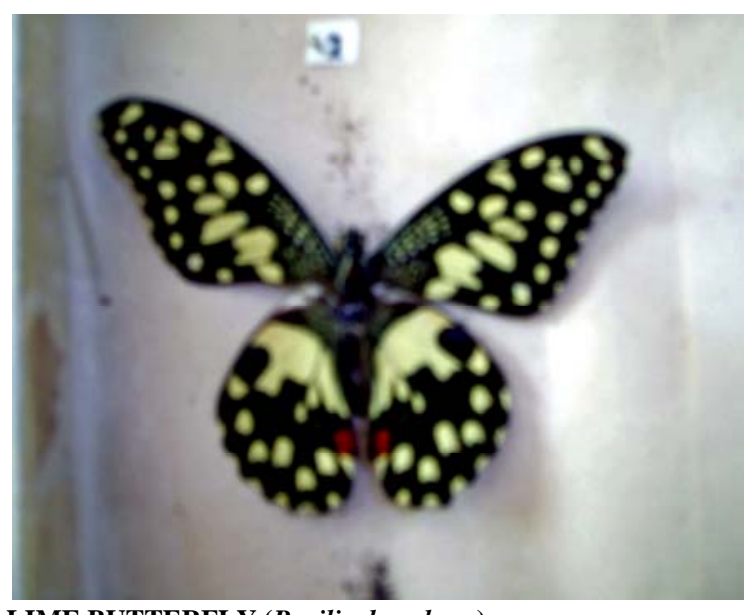

LIME BUTTERFLY (Papilio demoleus )

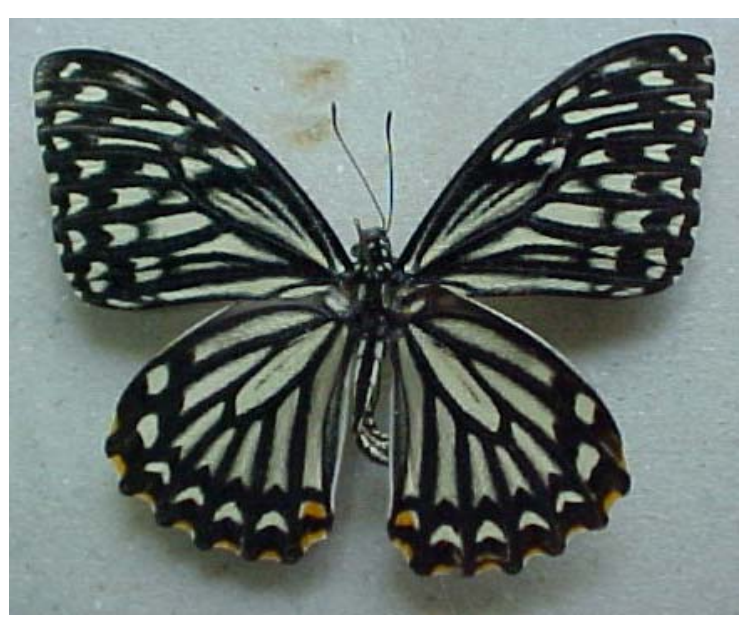

COMMON MIME (Chilasa clytia dissimilis) 
1.3 Swordtails and Zebras (Pathysa sp.)

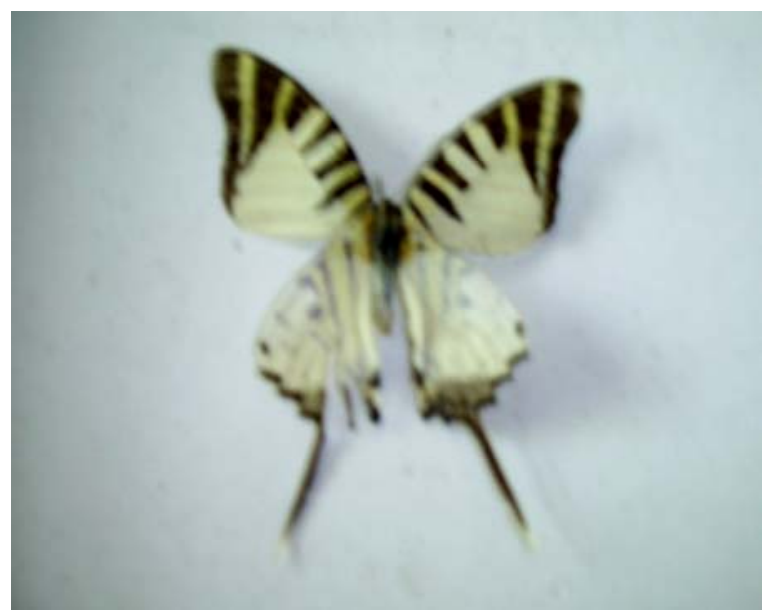

FIVE-BAR SWORDTAIL (Pathysa antiphates pompilius)

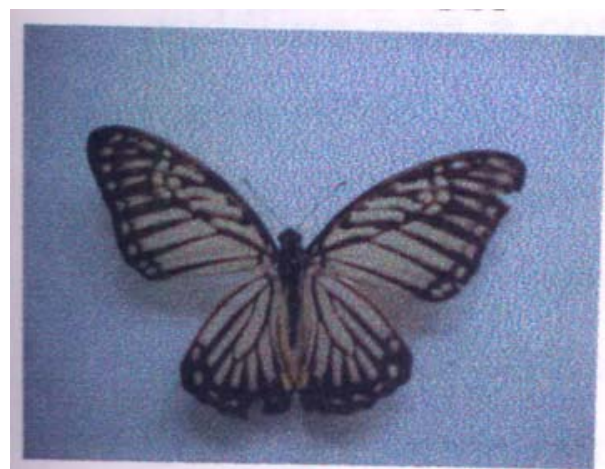

GREAT ZEBRA (Pathysa xenocles xenocles)

1.4 Dragontails (Lamproptera sp.)

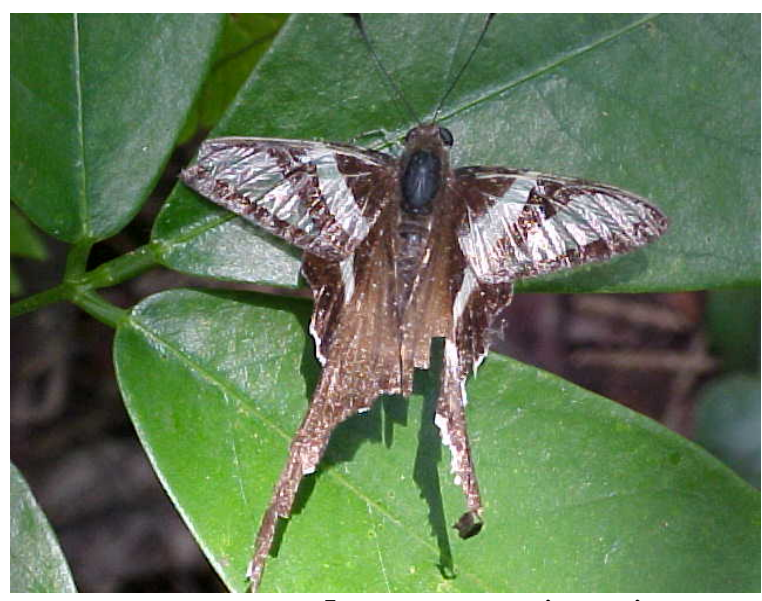

WHITE DRAGONTAIL (Lamproptera curius curius)

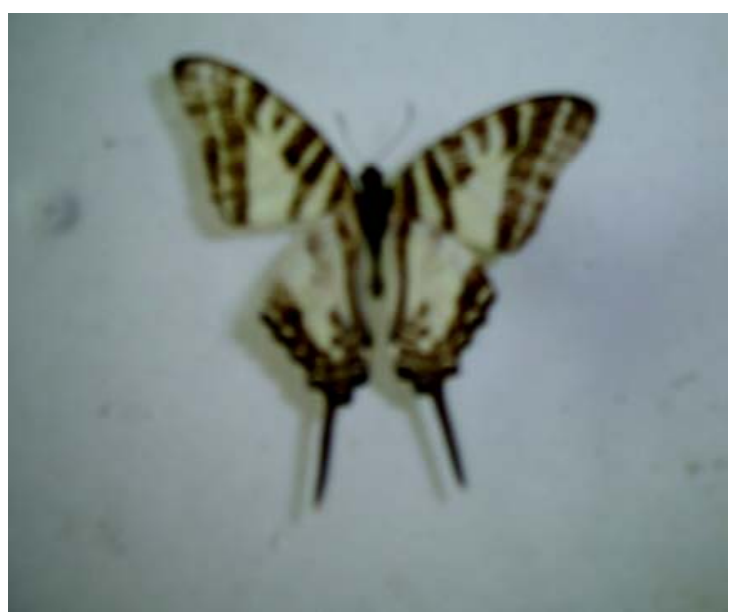

CHAIN SWORDTAIL (Pathysa aristeus anticrates)

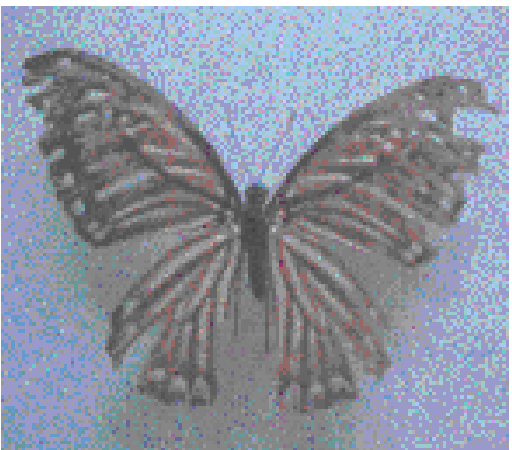

LESSER ZEBRA (Pathysa macareus lioneli)

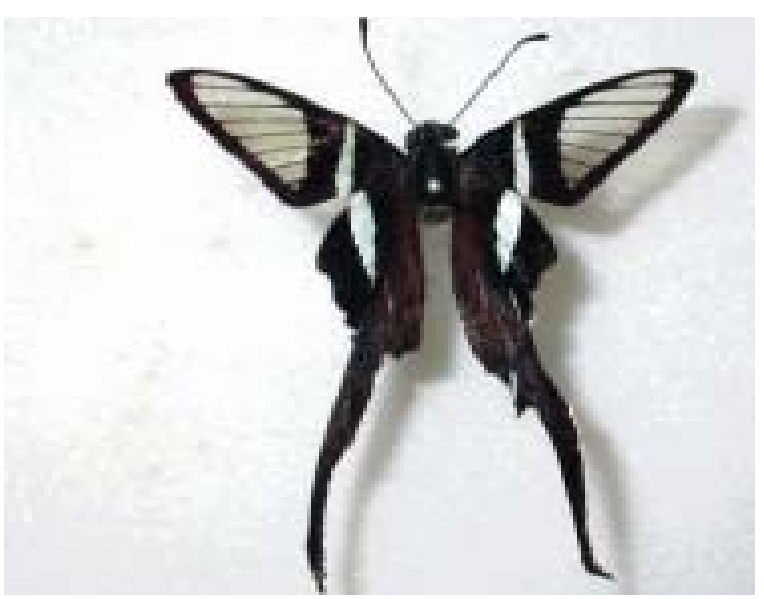

GREEN DRAGONTAIL (Lamproptera meges) 
1.5 Jays and Bluebottles (Graphium sp.)

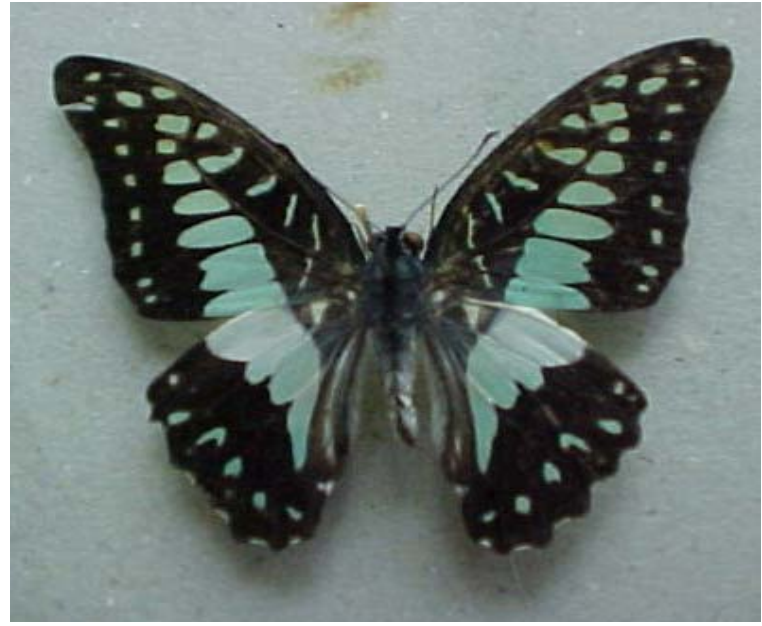

COMMON JAY (Graphium doson axion)

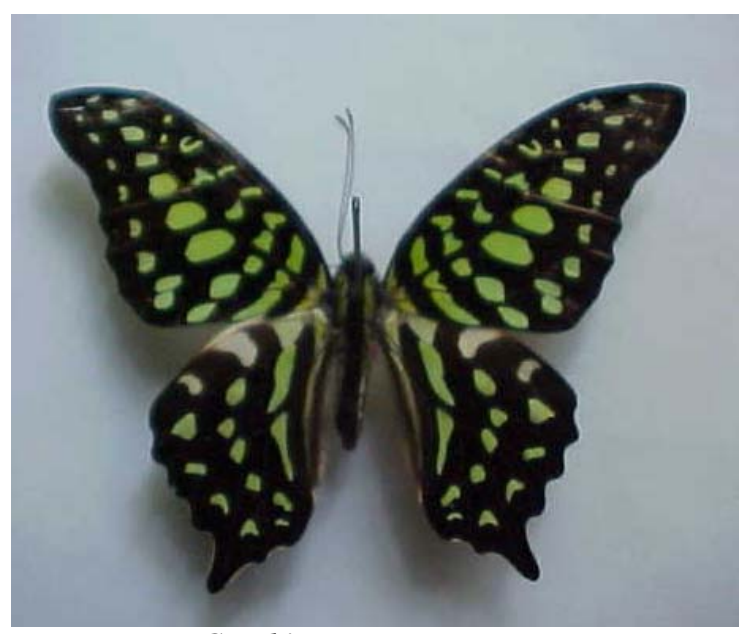

TAILED JAY (Graphium agammemnon agammemnon)

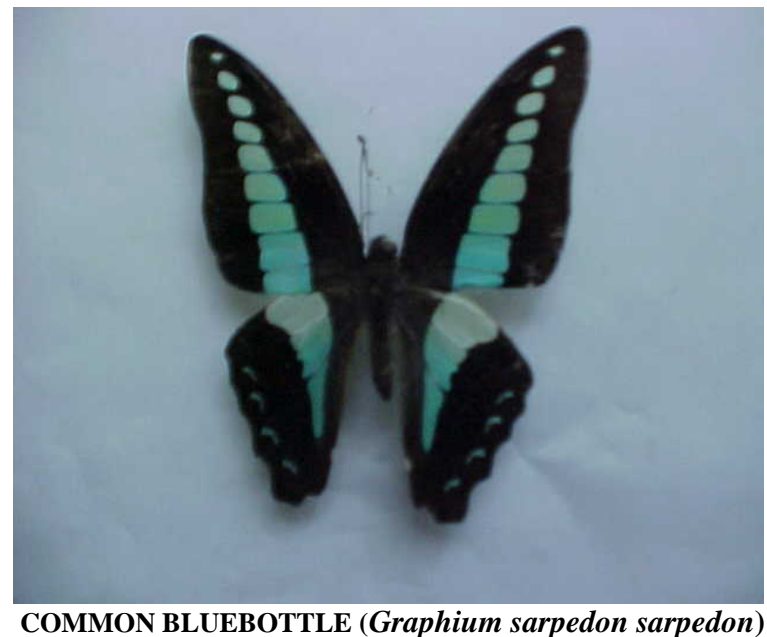




\section{Photos of Papilionidae larvae on their host-plants}

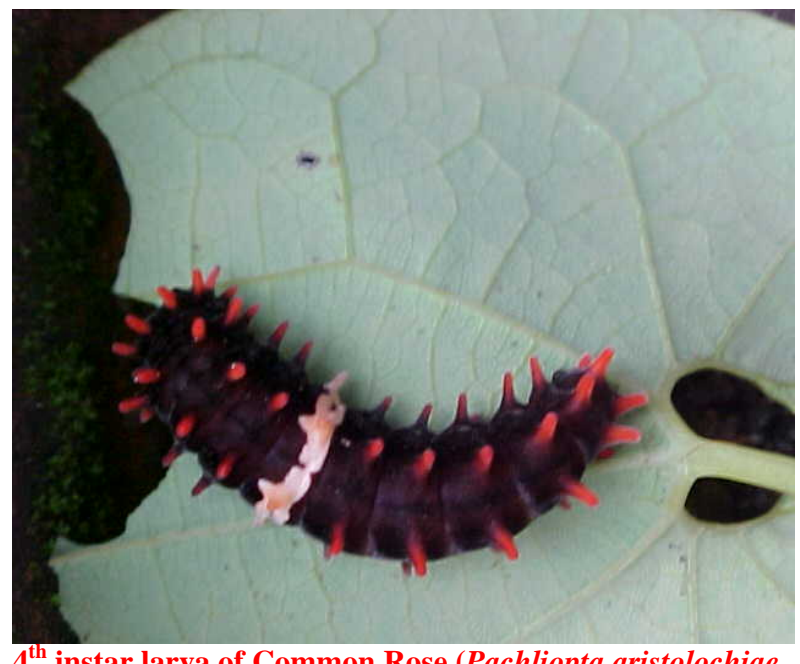

$4^{\text {th }}$ instar larva of Common Rose (Pachliopta aristolochiae aristolochiae) feeding on mature leaf of Aristolochiae tagala

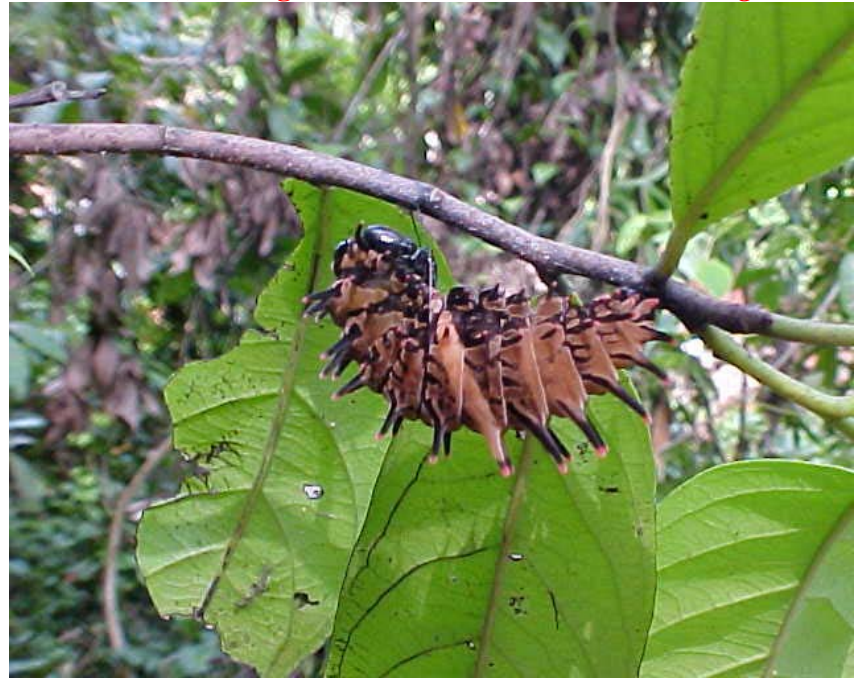

5th instar larva of Golden Birdwing (Troides aeacus aeacus) forms chimaster and begins pupation

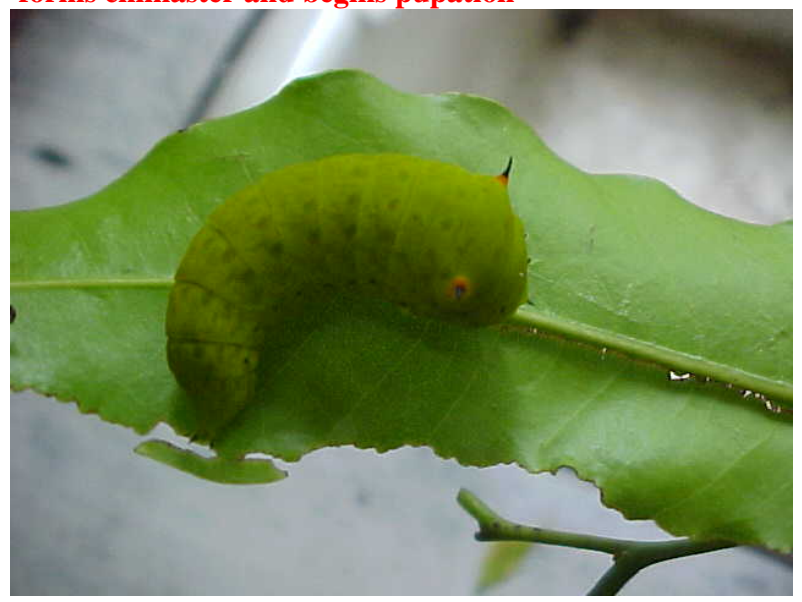

3rd instar larva of Tailed Jay (Graphium agammemnon agammemnon) feeding on the host plant Polyalthia longifolia

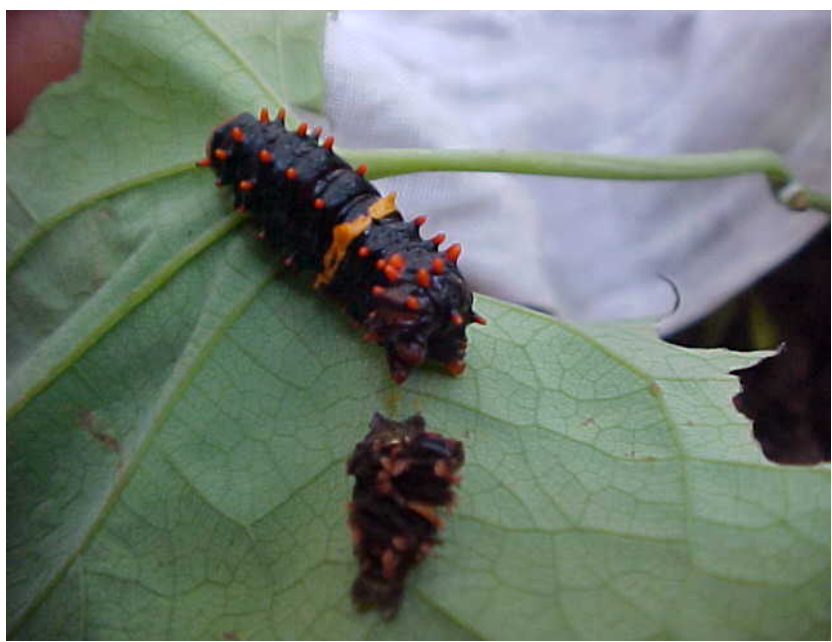

$4^{\text {th }}$ instar larva of Golden Birdwing (Troides aeacus aeacus) feeding on mature leaf of Indian Birthwort (Aristolochiae tagala

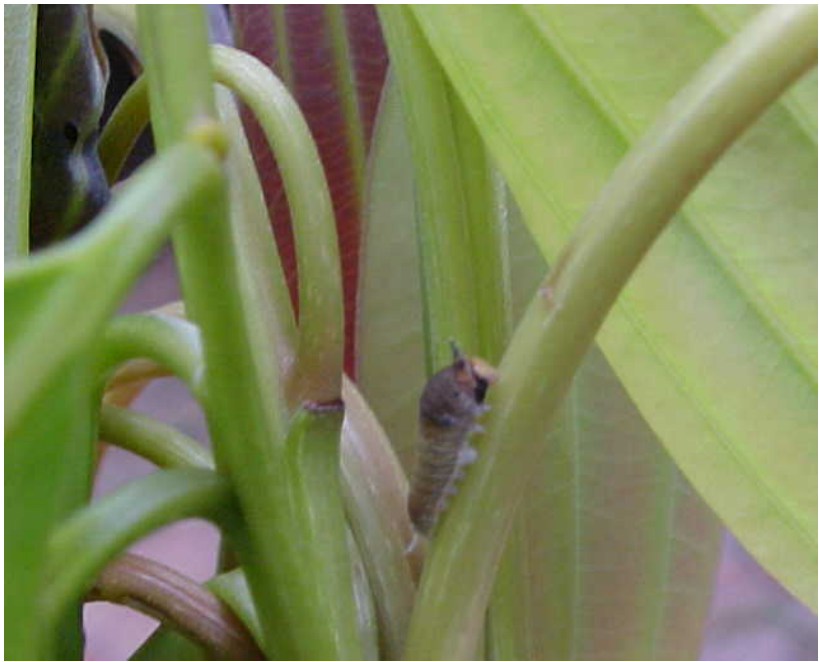

$2^{\text {nd }}$ instar larva of Common Bluebottle (Graphium sarpedon sarpedon) on the host-plant Cinnamomum tamala

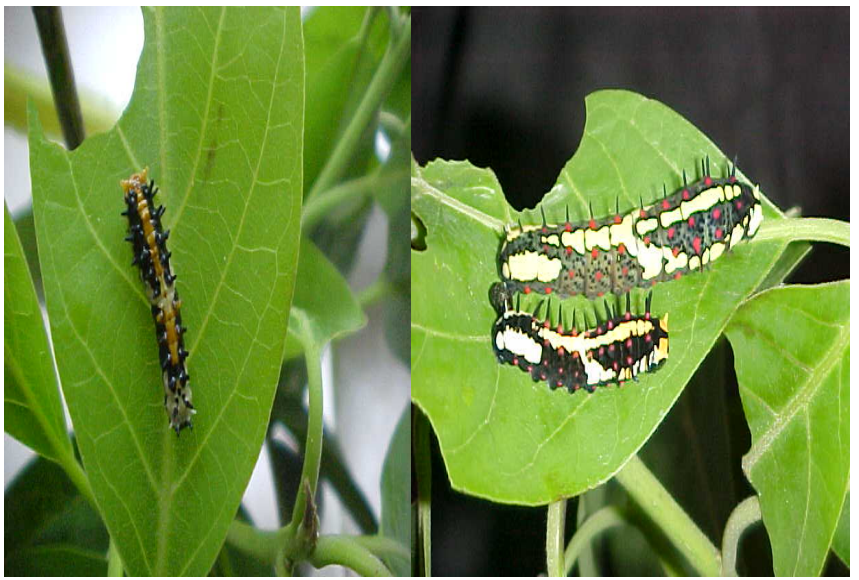

3rd and 4th instar larvae of Common Mime (Chilasa clytia) on the host plant Litsea sebifera 


\section{Swallowtail butterflies mud-puddling on wet soil and nectaring on flowers}

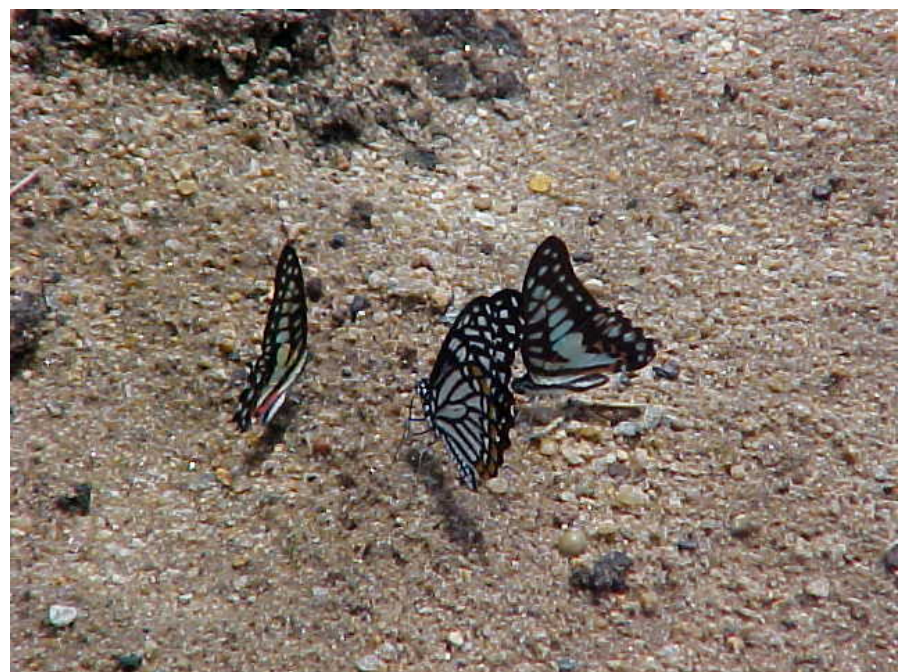

COMMON JAY (Graphium doson axion)

and COMMON MIME (Chilasa clytia)

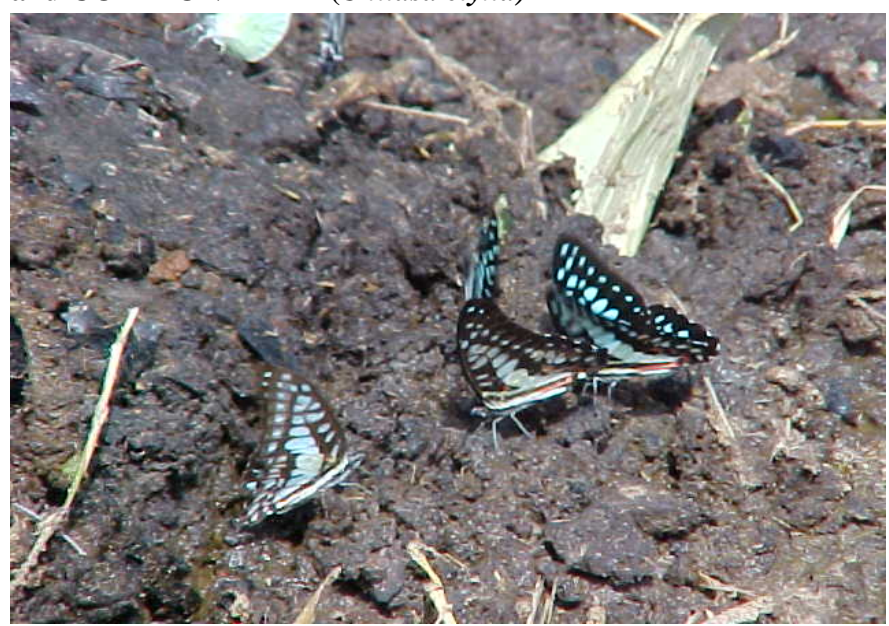

COMMON JAYS (Graphium doson axion)

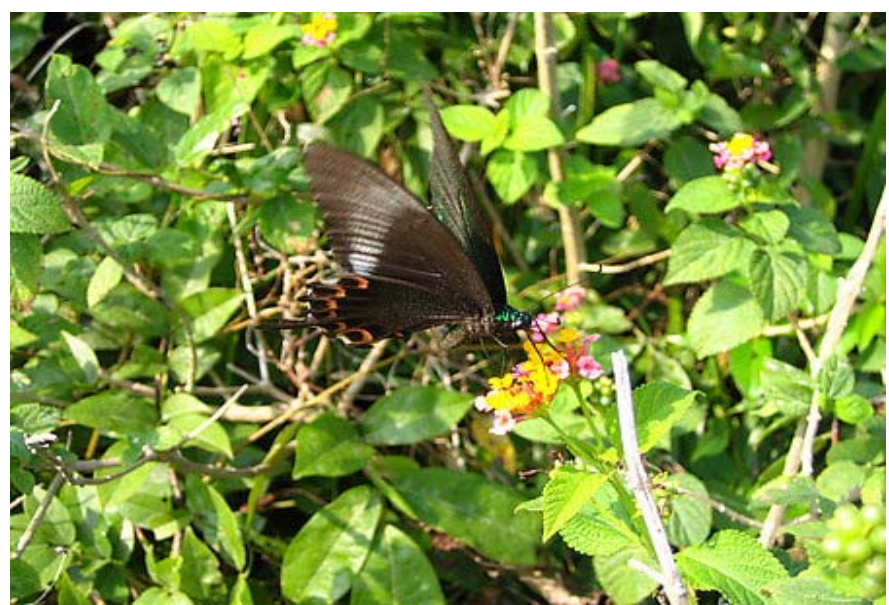

PARIS PEACOCK (Papilio paris paris) feeding on Lantana camara

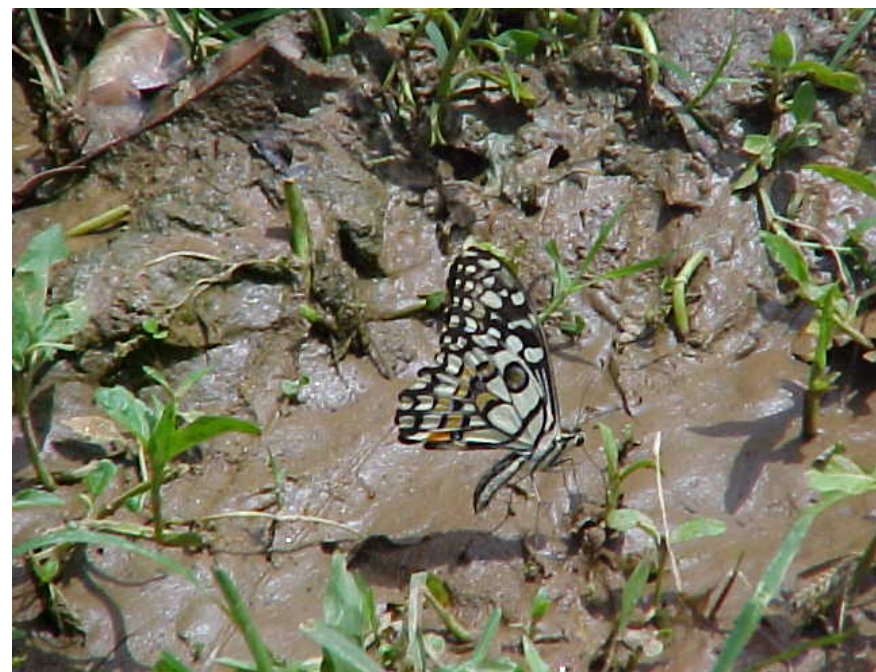

LIME BUTTERFLY (Papilio demoleus)

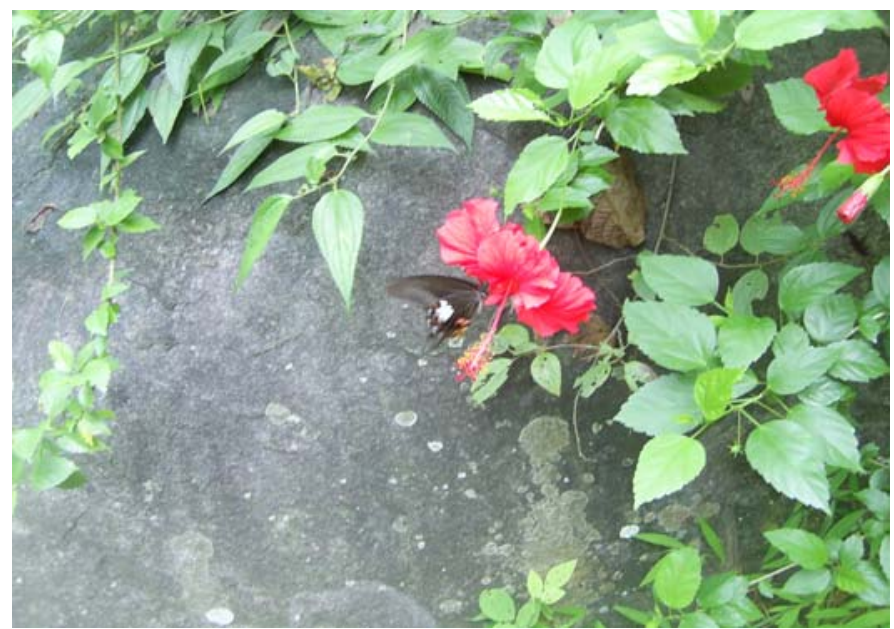

COMMON MORMON (Papilio polytes) nectaring on Ixora species

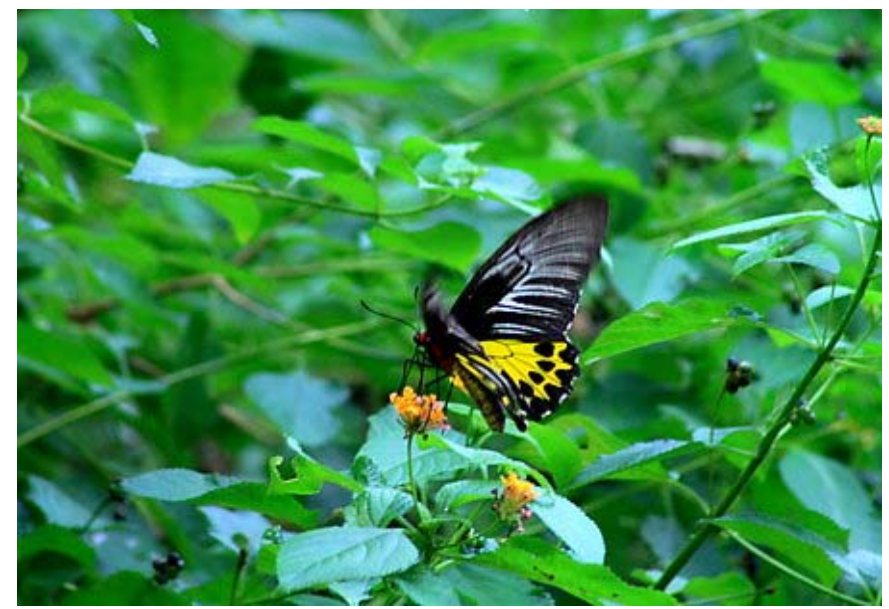

COMMON BIRDWING(Triodes helena cerberus )nectaring on

Lantana camara 
4. Egg and Chrysalis of swallowtail butterflies (Papilionidae)

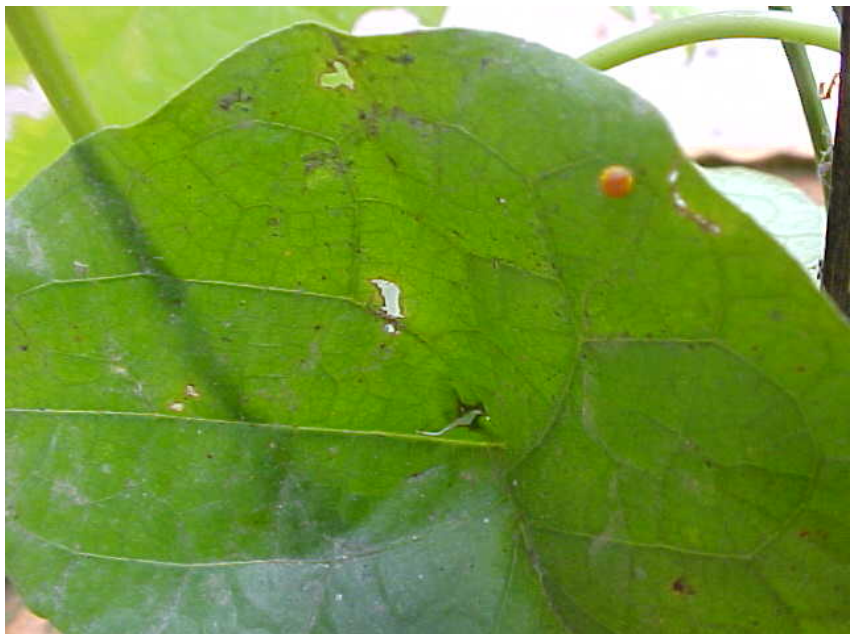

The egg of Common Rose (Pachliopta aristolochiae) on the host-plant Aristolochia tagala

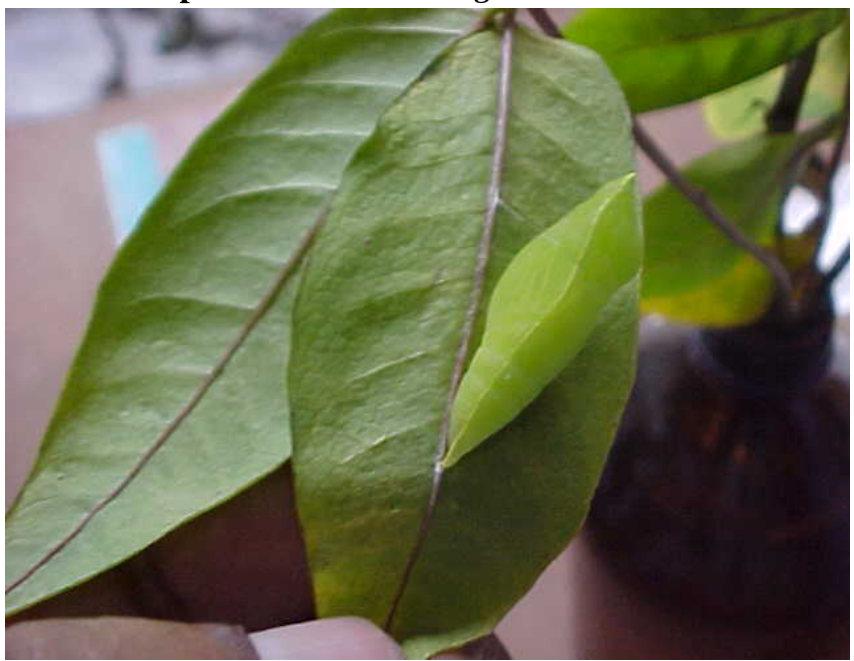

Pupa of Common Jay (Graphium doson axion)

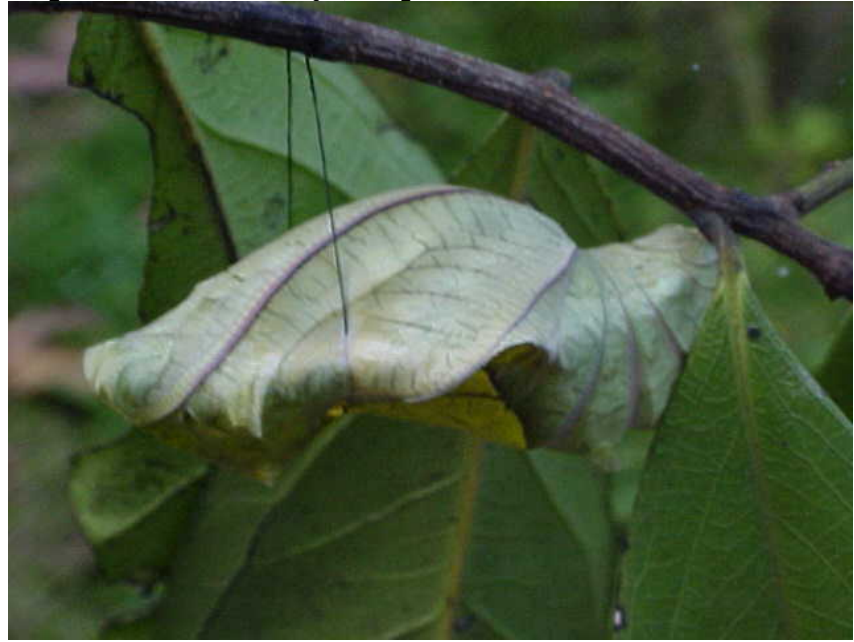

Chrysalis of Golden Birdwing (Troides aeacus)

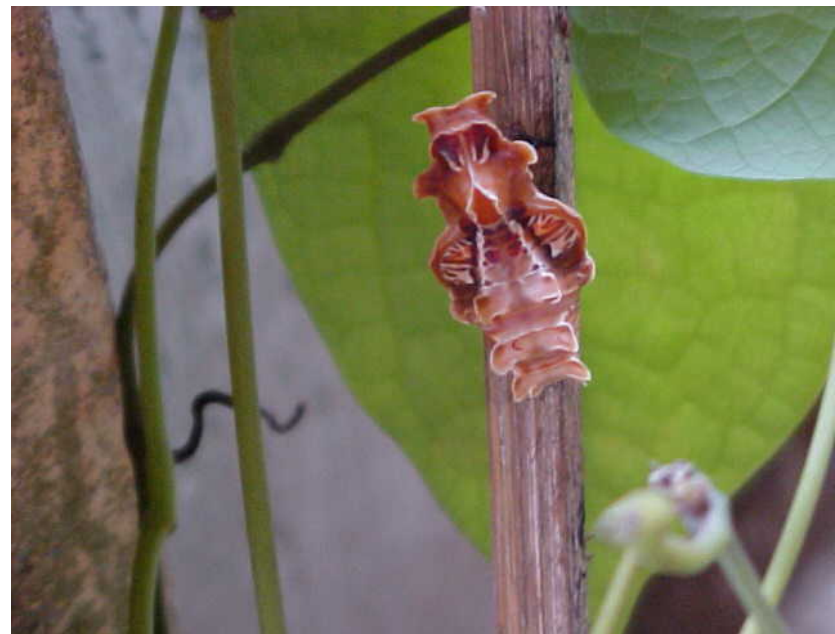

Chrysalis of Common Rose (Pachliopta aristolochiae)

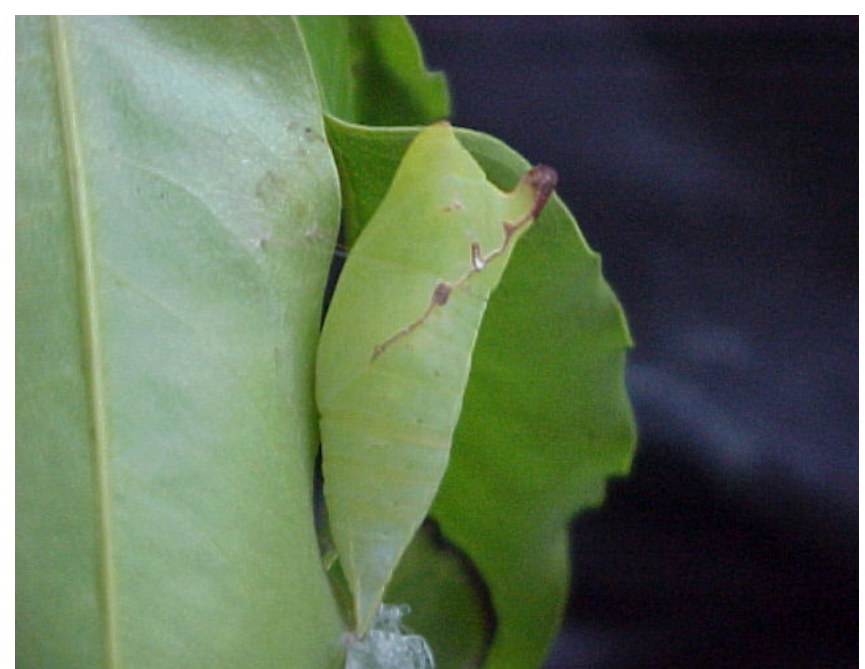

Pupa of Tailed Jay (Graphium agammemnon agammemnon)

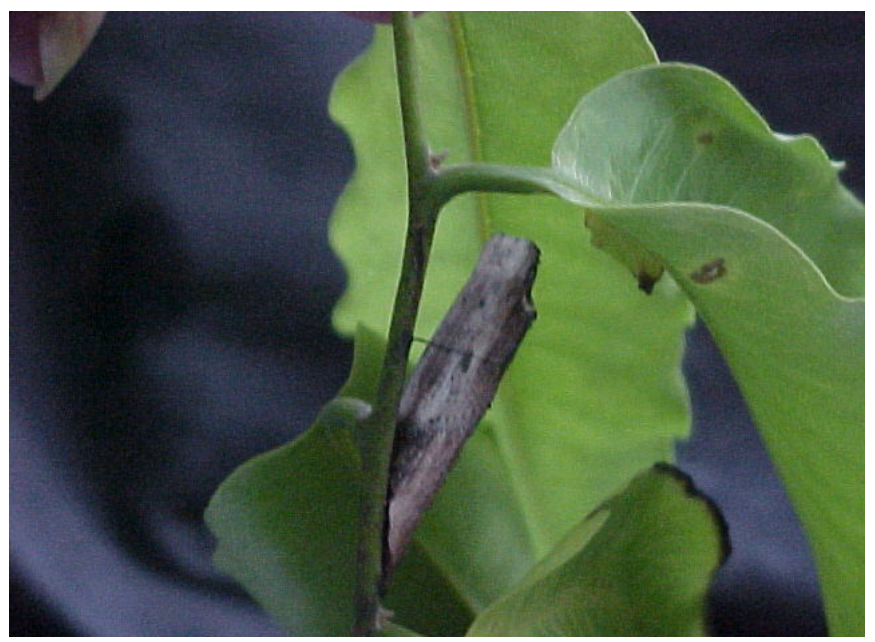

Chrysalis of Common Mime (Chilasa clytia) 


\section{Adult nectar sources and larval food-plants of Papilionidae}
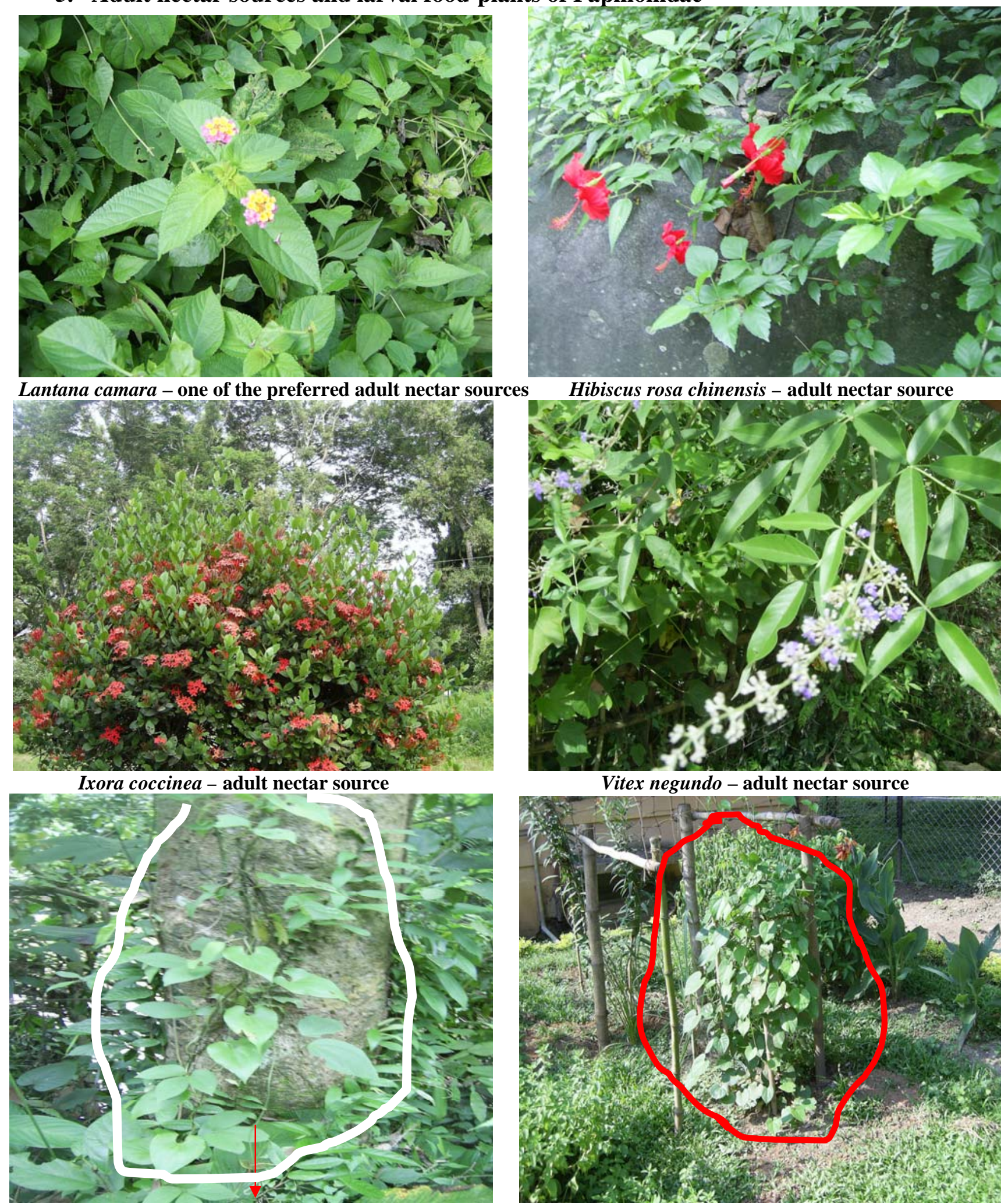

Indian Birthwort (Aristolochia tagala) - food-plant of the red-bodied Papilionidae in the study area

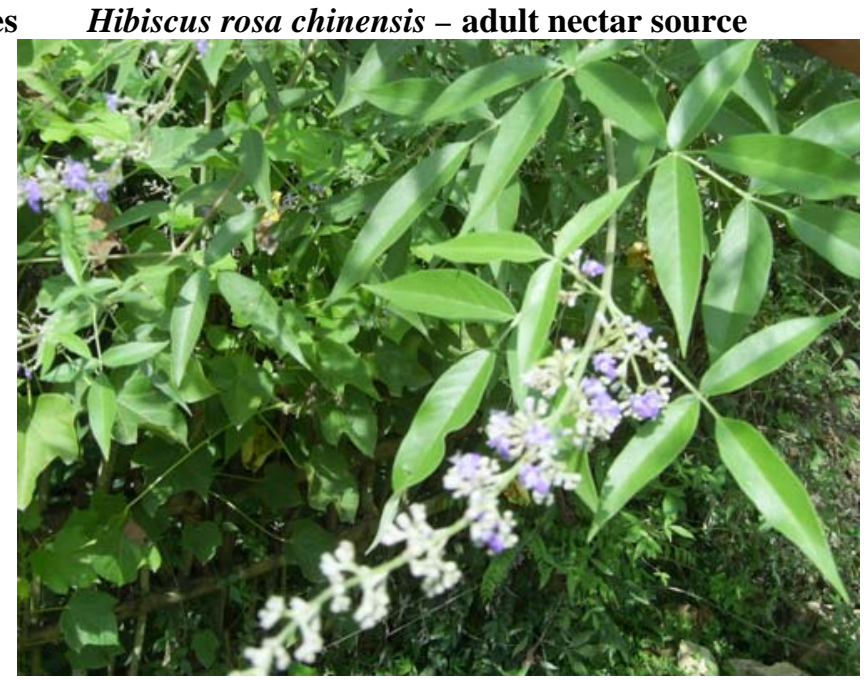

Vitex negundo - adult nectar source

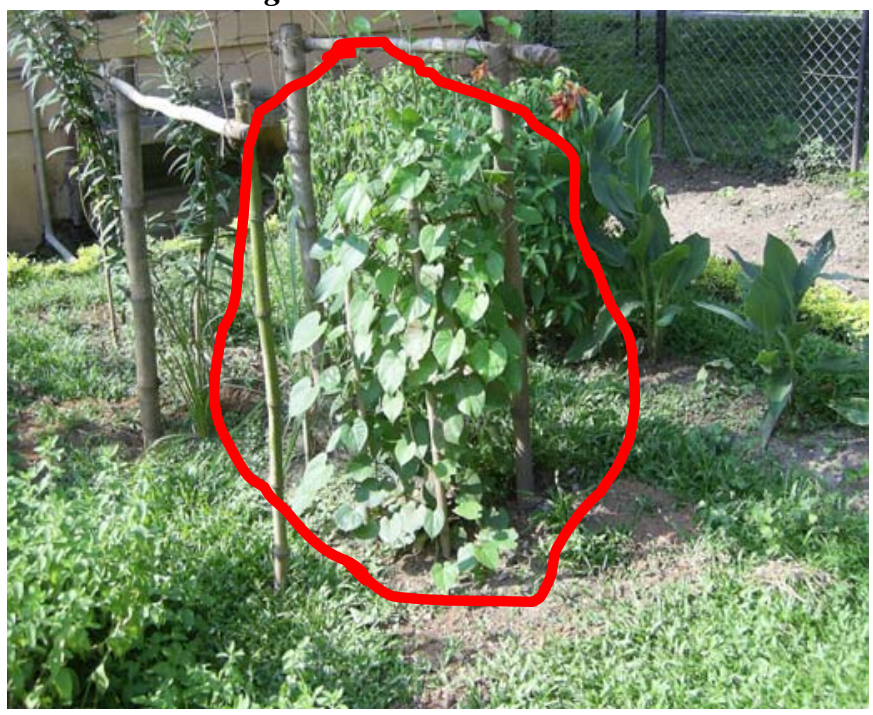

Aristolochia tagala cultivated in gardens for it's medicinal properties 


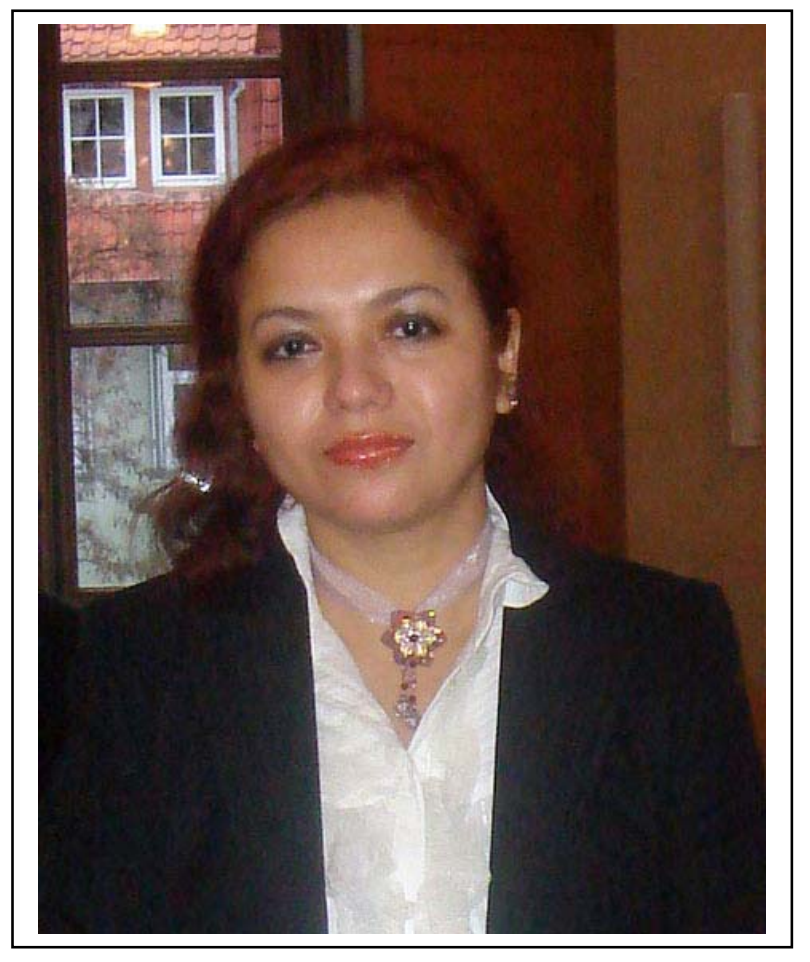

Dr. rer. nat. Kamini Kusum Barua, Ecology and Conservation Biology

Centre for Nature Conservation, Georg-August University, 37075 - Gottingen, Germany

kbarua@gwdg.de, kaminikusum@yahoo.com, kaminikusum@gmail.com

Phone: +49551 395639 (Institute) +49551399234 (FAX)

Research interests: Conservation Biology, Community based Wildlife Management, Biomonitoring and Protected Area Management

Career objectives: Focus on issues of nature conservation, address the problems of wildlife management and design biomonitoring strategies in protected areas for habitat quality assessment.

Career summary: My dual career accomplishment pertaining to teaching cum research has been the hallmark of my professional abilities as a Conservation Biologist and Ecologist.

As a lecturer of Zoology, I have had the opportunity to train Senior Secondary level students of Science in the General Biology curricula and at the Undergraduate level to teach Evolutionary Biology, Bioinformatics and Physiology.

My pursuit of a research career in biodiversity and nature conservation has enabled me to address the issues of nature conservation and the challenging problems of habitat degradation in Assam, which is located in the remote Northeastern corner of the Indian subcontinent but is 
ecologically significant as one of the biodiversity hotspots (Eastern Himalayas) in the IndoBurma region.

My experience as a PhD student in Georg-August University, Germany has given me the exposure to an international experience in nature conservation and application of statistical analytical methods in biodiversity conservation and management strategies. This expertise acquired in Germany coupled with my experience of field -work in the Eastern Himalyan region and interactions with the local community in my research study area will enable me to work confidently on the practical aspects of nature conservation.

\section{Research Experience:}

2002-2006 - Junior Research Fellow in a Ministry of Environment and Forests, Government of India funded Research Project on the "Diversity of Entomofauna in DibruSaikhowa Biosphere Reserve, Assam, India with special reference to butterflies and beneficial insects".

2001 - Junior Research Fellow in the 'All India Coordinated Project on Taxonomy', (AICOPTAX), Ministry of Environment and Forests, Government of India funded Research project on “Microlepidoptera Fauna in North -East India”.

\section{Publications:}

Kalita, Jatin \& Barua, Kamini K. (2002). A Preliminary Study on Diversity of Entomofauna in DibruSaikhowa Biosphere Reserve, Assam. J. Himalayan Biosphere Reserves, Vol. 4 (1 \& 2). 39 - 43.

Barua, K.K., Kakati, D. \& Kalita, J. (2003). Diversity of Butterfly fauna in Garbhanga Reserve Forest, Assam, India. J. EcoBiology. Vol. 15. 241-265.

Barua, K.K., Kakati, D. \& Kalita, J. (2004) Bio-Ecology of Leptosia nina nina Fabricius (Lepidoptera: Pieridae) on Cleome viscosa. J. Applied Zool. Res. Vol. 15 (1).

Barua, K.K., Kakati, D. \& Kalita, J. (2003) Study on Some Aspects of Ecology and Biology of Mottled Emigrant (Catopsilla pyranthae pyranthae, Lin. 1758 on Cassia occidentalis. J. Ecology, Environment \& Conservation 9 (4). $439-444$.

Barua, K.K., Kakati, D. \& Kalita, J. (2004). Present Status of Swallowtail Butterflies in Garbhanga Reserve forest, Assam, India. J. Zoos' Print Vol. 19 (4): 1439-1441

(6) Kakati, D., Barua, K.K. \& Kalita, J. (2004). Oviposition and Larval Stages of Great Mormon (Princeps memnon agenor Linn.) The Black-bodied Swallowtail butterfly. J. Nature Conservation 16 (1) 97-100.

\section{Publications reviewed and accepted:}

Barua, Kamini K. \& Slowik, Jolanta. (2007). Study on the Biology and Consumption Potential of Common Rose (Pachliopta aristolochiae aristolochiae F (Lepidoptera: Papilionidae) on Aristolochia tagala. Polish Journal of Entomology. Vol. 76.

Accepted: 30 December 2007 
Barua, K.K., Kakati, D. \& Kalita, J. Study on the Early Stages of Tailed Jay, Graphium agamemmnon agammemnon (Lepidoptera: Papilionidae) on Polyalthia longifolia. J. Environment and Ecology. Accepted: 14 February 2003

Kakati, D., Barua, K.K. \& Kalita, J. Role of Swallowtail Butterflies (Papilionidae) in the Propagation of Indigenous Medicinal Plant Resources in Kamrup district of Assam, India. J. Environment and Ecology. Accepted: 8 June 2003

\section{Seminars, Workshops and Training programs:}

2007, November 12-16. "Biodiversity and Nature Conservation in Assam (Eastern Himalayas), Northeast India". Socrates-Erasmus Exchange Program, Zoological Institute, Wroclaw University, Wroclaw, Poland.

2007, November 12-16. "Diversity, Abundance and Distribution of Papilionidae in a Protected Forest Reserve in Assam, Northeast India with special reference to their association with forest types, influence of environmental variables and identification of some indicator species". Polish Zoological Society meeting at the Zoological Institute, Wroclaw University, Wroclaw, Poland.

2007, July 15 -27. Summer School Program "Close-to-Nature Forestry", Georg-August Universitat, Gottingen, Germany.

2007, May 16. "Biodiversity and Nature Conservation in Assam, Northeast India". Research Centre for Agricultural and Forest Environment, Polish Academy of Sciences, Poznan, Poland.

2006, $2^{\text {nd }}$ February. "Significance of Butterflies as Natural Resource and their Role in Human Welfare". National Seminar on "Zoology For Human Welfare", Zoological Society of Assam, Department of Zoology, Gauhati University, Assam, India.

2005, July 23 - 24. "Bioindicator Insect fauna of Assam with special reference to Papilionidae". National Seminar on Biodiversity in Northeast India and its impact on Employment generation, Department of Geography, Guwahati College, Guwahati, Assam, India.

2003, March 17. Participated in the National Seminar on "Science Awareness and Popularization", Indian Science Congress Association and Institution of Engineers (India), Guwahati, Assam, India.

2003, October 14-21. "Impact of Habitat Stress on the Diversity of Butterfly fauna in Garbhanga Reserve Forest, Assam, India". International Conference on Eco- restoration, National Institute of Ecology, New Delhi, India.

2003, November 5-7. "Diversity of Swallowtail Butterflies in Manas Biosphere Reserve, Assam, India". National Symposium on Frontier Areas of Entomological Research, Indian Agricultural Research Institute, New Delhi, India.

2002, September 3. (a) "Butterflies - An important Natural Resource of Kamrup (Assam)". National Seminar on "Resource Appraisal and problems of development in the Brahmaputra valley with special emphasis on the undivided Kamrup district (Assam), Department of Geography, Pragjyotish College, Guwahati, Assam, India.

(b) Co-Author for the presentation on "Diversity of Swallowtail Butterflies and their role in the Propagation of Indigenous Medicinal Plant Resources of Kamrup, Assam".

2002, November 27 - 28. (a) "Diversity and Conservation of Nymphalid and Papilionid Butterflies in Assam, India", Regional Seminar on the "Role of Biodiversity and Environment strategies in Northeast India for sustainable development", Saint Mary's College, Shillong, Meghalaya, India. 
(b) Co-Author for the presentation on "Role of Swallowtail Butterflies (Papilionidae) in the propagation of indigenous medicinal plant resources in Kamrup district (Assam), India.

2001, June $13-15$. Participated in the training course on 'Collection, Preservation, and Identification techniques of Zoological specimens', Zoological Survey of India (Eastern Regional Station in Shillong), Ministry of Environment and Forests, Government of India.

2000, September 14. Poster presention on "Swallowtail butterfly diversity in the Eastern Himalayas". Regional Seminar on the "Recent trends in Zoology", Department of Zoology, Northeast Hill University, Shillong, Meghalaya, India.

1991. "Global warming - causes and effects". Seminar session of the Department of Zoology, Gauhati University, Guwahati, Assam, India.

\section{Academic Qualification:}

2008 - PhD (Doctor of Philosophyl Doctor rerum naturalium) in Ecology and Conservation Biology, Faculty of Mathematics and Natural Sciences, Georg-August University, Gottingen, Germany

1993 - MSc (Master of Science) in Ecology, Gauhati University, Guwahati, Assam, India.

1989 - BSc (Bachelor of Science) with Honours in Zoology, Cotton College, Guwahati, Assam, India

1986 - HSSLC (Higher Secondary School Leaving Certificate) examinations in Science, Vivekananda Vidyalaya, Digboi, Assam, India

1985 - ICSE (Indian Certificate of Secondary Education) with English, Science, Mathematics, Economics History, Civics and Geography from Carmel School, Digboi, Assam, India

\section{Honours:}

- Scored "Magna cum laude" grade for the doctoral dissertation and oral examinations (Rigorosum).

- Secured First class $4^{\text {th }}$ rank in Gauhati University for MSc (Ecology)

- Secured First class $3^{\text {rd }}$ rank in Gauhati University for BSc (Honours in Zoology)

- Awarded Assam State Merit Scholarship for Bachelor's and Masters Programs

- Secured First Class grades in Senior Secondary (HSSLC) and High School (ICSE) examinations

- Awarded International Research Scholarship (IRS) in 2004 for pursuing PhD program at the School of Biology, University of Newcastle, United Kingdom.

Skills:

- $\quad$ Language skills: International English Language Testing System (IELTS) score of 6.5

Fluent reading and writing skills in English with Catholic convent schooling background and currently pursuing a University course in German for International PhD students in Georg- August University, Gottingen, Germany.

- Diploma in Computer Applications: Excellent working knowledge of Windows environment, FoxPro, DOS, HTML, Internet applications and Statistical programs (Data formatting, analysis and interpretation in programs like R, Statistica, PC-Ord, SPSS and Estimate S). 
Professional Experience:

2002 - 2006: Junior Research Fellow, Department of Zoology, Gauhati University, Assam, India

Work profile: Extensive fieldwork in the Eastern Himalayas, Laboratory-based studies on the biology of selected Papilionidae, data collection with line-transect method in the in Rani-Garbhanga Reserve forest (research study area).

1999 - 2001: Lecturer in Zoology (Animal and Human Physiology), Handique Girls' College, Guwahati, Assam, India.

Work profile: Theory and practical lectures at Senior Secondary (Science) and UnderGraduate (General and Honours) levels in Evolutionary Biology, Bioinformatics, Animal and Human Physiology.

\section{1: Junior Research Fellow, All India Coordinated Project in Taxonomy, Department of Zoology, Handique Girls' College, Guwahati, Assam, India.}

Work profile: Extensive fieldwork in the Eastern Himalayas for data collection on Microlepidopteron fauna, basic training on identification keys for micro moths relating to morphology and systematics and micro dissection of genitalia of micro moths.

1995- 1998: Lecturer in Zoology, Ascent Academy Junior Science and Arts College, Guwahati, Assam.

Work profile: Theory and practical lectures at Senior Secondary level in General Biology, Systematics and Taxonomy, Genetics, Evolutionary Biology and Ecology

\section{Additional information:}

- Widely traveled in Europe, Asia (India, Thailand and Hong Kong). Professional study tours to Mongolia and South Africa are under preparation.

- Hobbies include traveling, wildlife photography, trekking, hiking and bicycle tours.

- Member of the Gottingen International Church and promotion of cross-cultural ideas and concepts through "International get-togethers - Brotherhood Beyond Borders". 